\title{
Occupational choice in the developing world
}

Citation for published version (APA):

Nagler, P. (2015). Occupational choice in the developing world. [Doctoral Thesis, Maastricht University]. Boekenplan. https://doi.org/10.26481/dis.20151009pn

Document status and date:

Published: 01/01/2015

DOI:

10.26481/dis.20151009pn

Document Version:

Publisher's PDF, also known as Version of record

\section{Please check the document version of this publication:}

- A submitted manuscript is the version of the article upon submission and before peer-review. There can be important differences between the submitted version and the official published version of record.

People interested in the research are advised to contact the author for the final version of the publication, or visit the DOI to the publisher's website.

- The final author version and the galley proof are versions of the publication after peer review.

- The final published version features the final layout of the paper including the volume, issue and page numbers.

Link to publication

\footnotetext{
General rights rights.

- You may freely distribute the URL identifying the publication in the public portal. please follow below link for the End User Agreement:

www.umlib.nl/taverne-license

Take down policy

If you believe that this document breaches copyright please contact us at:

repository@maastrichtuniversity.nl

providing details and we will investigate your claim.
}

Copyright and moral rights for the publications made accessible in the public portal are retained by the authors and/or other copyright owners and it is a condition of accessing publications that users recognise and abide by the legal requirements associated with these

- Users may download and print one copy of any publication from the public portal for the purpose of private study or research.

- You may not further distribute the material or use it for any profit-making activity or commercial gain

If the publication is distributed under the terms of Article $25 \mathrm{fa}$ of the Dutch Copyright Act, indicated by the "Taverne" license above, 


\section{Occupational Choice \\ In the Developing World}

Paula Nagler 
Copyright (c) Paula Nagler, 2015

ISBN 9789086663798

Cover Design: Fernanda Nagler

All rights reserved. No part of this publication may be reproduced, stored in a retrieval system, or transmitted in any form, or by any means, electronic, mechanical, photocopying, recording or otherwise, without the prior permission in writing, from the author.

Publisher: Boekenplan, Maastricht, the Netherlands 


\section{Occupational Choice \\ in the Developing World}

\section{DISSERTATION}

to obtain the degree of Doctor at Maastricht University, on the authority of the Rector Magnificus Prof. Dr. L.L.G. Soete, in accordance with the decision of the Board of Deans, to be defended in public on Friday, 9 October 2015 at 10 hrs.

by

Paula Nagler 


\section{Supervisors}

Prof. Dr. Pierre Mohnen

Prof. Dr. Wim Naudé

Prof. Dr. Milan Vodopivec

\section{Assessment Committee}

Prof. Dr. Adam Szirmai (Chair)

Prof. Dr. Andries de Grip

Prof. Dr. José Ernesto Amorós (Universidad del Desarrollo, Santiago de Chile)

Dr. Luc Christiaensen (The World Bank) 


\section{Acknowledgements}

The idea of writing a $\mathrm{PhD}$ thesis emerged while I was working on innovative social protection policies at the OECD Development Centre. There I realized, that during a $\mathrm{PhD}$ I would learn how to conduct research and prove my ability to do so, which in turn would give me access to work in a field that I enjoy. The job also provided the initial idea for this thesis, to conduct analysis about unemployment protection policies in Latin America and occupational choice in the developing world. After five years of hard work, of ups and downs, of struggles and frustration, but also of many moments of satisfaction and happiness, this thesis represents my research journey. Presenting not only the newly acquired knowledge and empirical findings on rural entrepreneurship and unemployment protection, but equally reflecting a much broader learning process - professionally, but also personally.

This thesis would not have been possible without the invaluable help and support of many people that accompanied my path over these past five years, and whom I would like to thank in this acknowledgement.

The central component of each $\mathrm{PhD}$ thesis is the supervisory team. Therefore my special words of gratitude go first of all to my supervisors - Pierre Mohnen, Wim Naudé and Milan Vodopivec - for their guidance, support and critical comments throughout the research process. Their time to listen to my ideas, to read and comment on my drafts and to read once more through the finalized papers, was invaluable and decisively contributed to the success of this thesis. I am also grateful for their flexibility when I suggested to add a second topic to the dissertation.

Pierre, thank you for your time, support and swift responses, and for asking critical questions in each of our meetings. Wim, I highly appreciate the opportunity to join the "Myths and Facts" project and would like to thank you for your constant and helpful feedback. Working with you on African entrepreneurship opened the door to a completely 
new field of research, and has been accompanied by lively and interesting discussions. Thank you Milan, for being a present supervisor far away from Maastricht, for taking your time to supervisor me via skype and for inviting me to your house in Ljubljana.

I am also thankful to the members of the reading committee - José Ernesto Amorós, Luc Christiaensen, Andries de Grip and Adam Szirmai - who helped with insightful comments to improve the thesis and contributed significantly to the final version of this dissertation.

I would also like to thank the PhD directors of this program, Mindel, Robin, and for a short while, Tatiana. Your guidance and advice throughout the $\mathrm{PhD}$ process were highly appreciated. Equally important was the constant support of Luc Soete and Bart Verspagen, the deans of UNU-MERIT, who found time beyond their busy schedules to team up for running events and for listening to the concerns and difficulties of the $\mathrm{PhD}$ fellows at the institute. A big thank you also goes to the administrative staff of UNUMERIT and the Maastricht Graduate School of Governance, who helped with sometimes strenuous bureaucratic procedures, computer problems and travel planning. Eveline, many thanks for your help and advice throughout the $\mathrm{PhD}$, especially during the final spurt.

The University of Chile also plays a special role in the completion of the thesis, where the Department of Economics hosted me during four months in 2012. I would like to especially thank Patricia Medrano, who made this stay possible, as well as many other colleagues of the department, who supported me with the data and gave useful feedback during discussions and meetings.

Further I would like to thank the Secretariat for Social Security of Chile for letting me use the database of the Social Protection Survey, as well as the LSMS-ISA team of the World Bank for the provision of the household surveys covering six countries in rural Sub-Saharan Africa. As a member of the World Bank project "Agriculture in Africa Telling Facts from Myths" I benefited tremendously from the teamwork, as well as from the many suggestions and comments during our meetings and events. I would like to especially mention Luc Christiaensen and Amparo Palacios-López who were helpful and supportive at any time and from any location, and facilitated this work with critical feedback, data assistance and events to disseminate the findings.

I also received support and help from many colleagues working in my field, and I would like to refer to those who had a particularly important role for the realization of my thesis: Richard Bluhm and Dennis de Crombrugghe, who were always helpful in giving 
advice on many of my econometric questions, Mira Bierbaum who joined any STATA challenge I came up with (and generally won), and my brother Markus who proofread and commented on many of my first drafts. I would also like to thank Omar Rodriguez, Andrés Mideros and Richard Bluhm for their comprehensive feedback on the papers I presented during the poverty research seminars. Numerous other colleagues, from UNUMERIT and the Maastricht Graduate School of Governance, as well as participants at conferences in Bonn, Brussels, Lima, Lusaka and Washington, provided helpful feedback which contributed decisively towards the improvement of my thesis.

These five years, however, were not only filled with work. They were equally filled with friends, social gatherings, travels and fun. Maastricht became a home for me and the many friends and lovely people I met during this time contributed enormously to my experience here. My $\mathrm{PhD}$ cohort, who were the first people I got to know in Maastricht and who helped with settling into this small city. My different office mates over these past years, who did not only help with econometric or citation questions, but who would always have some time for a little chat over non-work related topics and who made the long days of work also sweet and fun. The many countless friends that I have met during my time in Maastricht, at $\mathrm{PhD}$ Academy events, birthday parties and $\mathrm{PhD}$ defenses, Café Zondag bar evenings, bike trips, mensa lunches and movie nights. Maastricht would not be the same without you! Especially the international dinner group that contributed with tasty local dishes from Malaysia to Iran and Italy, and where "interesting" conversation topics were never missing. The all Bavarian office of the past two years, whose members (Ortrun and Mira) regularly imported bread from over the boarder. And the recently established WLC, who did not only provide healthy and varied food for the daily lunch, but also offered language classes, laughed over gossip and joined the guerrilla dishwashing.

I would like to mention some very special people. My neighbor Alejandro, el vecino, "fighting" over the washing machine, suffering from magic coloring (white turns into pink) and drinking mate, always up for a fun trip or a chat in the evening. I miss you! Cheng, you are simply an amazing friend and cook. Visiting you for dinner and drinking tea afterwards ended more than once in all night conversations until the early morning hours. I miss you, too! Eli and Ali - each GT night out with you is legendary! You are rocking paranymphs!

And there are many other friends, spread all over Europe and the world, who have made these past years so special - with phone and skype calls, postcards, letters, e-mails and messages, anytime and over many time zones. In moments of happiness, and also cheering me up when things were not going so well. And sometimes it was possible 
to also meet in person, in Berlin, Bonn, Buenos Aires, Deggendorf, Franca, Groningen, Lima, London, Madrid, Munich, Paris, Rome, São Paulo and Washington. The trips to Patagonia, Romania and Cuzco are unforgettable. Amanda, Analúcia, Aslihan, Bettina, Emma, Farshad, Friederike, Martin, Maya, Michelle, Milena, Monika, Philippe, Prisca, Saba, Sepideh, Tomas - thank you!

Another very special THANK YOU goes to my parents, who have supported me in everything that I have done with love, trust and relocation assistance. Words are not sufficient to express my gratitude. Without you, I would not be the person I am today.

There are more family members to whom I would also like to express my appreciation. My brother, an economist and $\mathrm{PhD}$ student himself, who cheered me up in moments when I lost my motivation, and has been helpful when I had questions. Many many thanks for your support, you are a star economist! My sister, who hosted me many times in Munich, particularly during the Oktoberfest, and has been a frequent visitor to Maastricht. You two are amazing siblings. My grandparents in Munich, who have been caring and supportive, and regularly sent delicious home made cookies baked by my grandmother. My grandparents in São Paulo, who were/are always close, even though an ocean separates us. I am blessed with a wonderful family.

Finally, I would like to thank a very special person. After receiving a vacuum cleaner (!) for my birthday last year, this year's birthday rewarded me with an amazing cadeautje Giacomo. Life is full of wonderful surprises. I am grateful of sharing this special moment with you.

Paula

Maastricht, October 2015 


\section{Contents}

Acknowledgements $\quad$ v

1 General Introduction 1

1.1 Purpose of the Thesis . . . . . . . . . . . . . . . . . 2

1.2 Key Concepts . . . . . . . . . . . . . . . . . . . 5

1.2.1 Occupational Choice . . . . . . . . . . . . 5

1.2.2 Non-Farm Entrepreneurship and Self-Employment . . . . . . . . . 7

1.2.3 Unemployment Insurance Savings Accounts . . . . . . . . . . . . 9

1.3 Contributions of the Thesis . . . . . . . . . . . . . 10

1.4 Outline . . . . . . . . . . . . . . . . . . 13

\section{Part I Non-Farm Entrepreneurship in Rural Africa}

2 Overview and Data $\quad 17$

2.1 Introduction . . . . . . . . . . . . . . . . . . . 18

2.2 Theory . . . . . . . . . . . . . . . . . . . . . . . 19

2.3 Literature Review . . . . . . . . . . . . . . . . . . . . 22

2.3.1 Prevalence and Importance . . . . . . . . . . . . . . . 22

2.3.2 Determinants of Enterprise Operation . . . . . . . . . . . 24

2.3.3 Determinants of Enterprise Productivity . . . . . . . . . . 26

2.3.4 Enterprise Productivity in Sub-Saharan Africa . . . . . . . . . . 27

2.4 The LSMS-ISA Database . . . . . . . . . . . . . . . . . . . . . . . 28

2.5 Summary and Concluding Remarks . . . . . . . . . . . . . . . . 30

3 Patterns and Determinants 33

3.1 Introduction . . . . . . . . . . . . . . . . . . . . . 34

3.2 Descriptive Statistics . . . . . . . . . . . . . . . . . . 35

3.2.1 Importance of Non-Farm Enterprises . . . . . . . . . . . . . . 35

3.2.2 Determinants of Enterprise Operation . . . . . . . . . . . . 37

3.2.3 Type of Business Activity . . . . . . . . . . . . . . 39 
3.3 Methodology . . . . . . . . . . . . . . . . . . . . 40

3.4 Results . . . . . . . . . . . . . . . . . . . . . . . . . 42

3.4.1 Probit Model . . . . . . . . . . . . . . . . . . . . . . . . . . 42

3.4.2 Multinomial Logit Model . . . . . . . . . . . . . . . . . . 48

3.5 Summary and Concluding Remarks . . . . . . . . . . . . . . . . 50

4 Productivity $\quad 55$

4.1 Introduction . . . . . . . . . . . . . . . . . 56

4.2 Descriptive Statistics . . . . . . . . . . . . . . . . . . . 57

4.3 Methodology . . . . . . . . . . . . . . . . . . . 60

4.4 Results . . . . . . . . . . . . . . . . . 63

4.4.1 Heckman Selection Model . . . . . . . . . . . . . . 63

4.4 .2 Panel Data Analysis . . . . . . . . . . . . . . . . . 66

4.5 Summary and Concluding Remarks . . . . . . . . . . . . . . . . 68

\section{Part II Unemployment Insurance Savings Accounts}

5 Overview and Data $\quad 73$

5.1 Introduction . . . . . . . . . . . . . . . . . . 74

5.2 Description of UISA . . . . . . . . . . . . . . . . . . 75

5.3 UISA in Latin America . . . . . . . . . . . . . . . . . . . . 76

5.4 UISA Assessment . . . . . . . . . . . . . . . . . . . . . . . . . . . 76

5.5 The Chilean UISA Scheme . . . . . . . . . . . . . . . . 80

5.5.1 Context . . . . . . . . . . . . . . . . 80

5.5 .2 Detailed Description . . . . . . . . . . . . . 81

5.6 The EPS Database . . . . . . . . . . . . . . . . . . . . . . . . . 83

5.7 Summary and Concluding Remarks . . . . . . . . . . . . . . . . . 84

6 Employment Duration $\quad 85$

6.1 Introduction . . . . . . . . . . . . . . . . . . . . . 86

6.2 Literature Review . . . . . . . . . . . . . . . . . . . . . . . . 87

6.3 Descriptive Statistics . . . . . . . . . . . . . . . . . . . . 89

6.4 Methodolody . . . . . . . . . . . . . . . . . . . . . 92

6.5 Results . . . . . . . . . . . . . . . . . . . . 95

6.5.1 Survival Model . . . . . . . . . . . . . . . . . . . . . 96

6.5.2 Competing-Risk Model . . . . . . . . . . . . . . . . . . . 103

6.5.3 Robustness . . . . . . . . . . . . . . . . . . . . . 108

6.6 Summary and Concluding Remarks . . . . . . . . . . . . . . . . 109 
7 Subsequent Employment Quality 113

7.1 Introduction . . . . . . . . . . . . . . . . . . . . . . . . 114

7.2 Literature Review . . . . . . . . . . . . . . . . . . 116

7.3 Descriptive Statistics . . . . . . . . . . . . . . . . . . . . 120

7.4 Methodology . . . . . . . . . . . . . . . . . . 123

7.5 Results . . . . . . . . . . . . . . . . . . . . 125

7.5.1 Graphical Analysis . . . . . . . . . . . . . . 126

7.5.2 Difference-in-Differences . . . . . . . . . . . . . . . . . . . . . 128

7.5.3 Robustness . . . . . . . . . . . . . . . . . . . . 132

7.6 Summary and Concluding Remarks . . . . . . . . . . . . . . . . . 134

8 Conclusion $\quad 137$

8.1 Introduction . . . . . . . . . . . . . . . . . . . . . . . 138

8.2 Summary . . . . . . . . . . . . . . . . . . . . . 138

8.2.1 Non-Farm Entrepreneurship in Rural Africa . . . . . . . . . . . . 138

8.2.2 Unemployment Insurance Savings Accounts . . . . . . . . . . . . 139

8.3 Policy Implications . . . . . . . . . . . . . . . . . . . . . . . 140

8.4 Avenues for Future Research . . . . . . . . . . . . . . . . . . . . 143

8.5 Concluding Remarks . . . . . . . . . . . . . . . . . . 144

A Non-Farm Entrepreneurship in Rural Africa $\quad 161$

B Unemployment Insurance Savings Accounts 181

$\begin{array}{ll}\text { Valorization } & 201\end{array}$

$\begin{array}{lr}\text { About the Author } & 207\end{array}$

$\begin{array}{ll}\text { MGSoG Dissertation Series } & 209\end{array}$ 


\section{List of Figures}

3.1 Contribution of Activity to Total Household Income . . . . . . . . . . . 37

3.2 Months in Operation . . . . . . . . . . . . . . . . . . 39

4.1 Productivity Dispersal - by Location . . . . . . . . . . . . . 58

4.2 Productivity Dispersal - by Region and Distance . . . . . . . . . . . . . 60

6.1 KM Survival Estimates . . . . . . . . . . . . . . . . . . . . . . . . 97

6.2 Hazard Functions . . . . . . . . . . . . . . . . . . . . . 103

6.3 KM Survival Estimates . . . . . . . . . . . . . . . . . . . . . . 104

6.4 Hazard Functions - by UISA Introduction . . . . . . . . . . . . 108

7.1 Wage and Contract Type Differences - Post-Employment . . . . . . . . . 127

7.2 Wage and Contract Type Differences - Post-Unemployment . . . . . . . . 127

A.1 Productivity Dispersal - by Gender . . . . . . . . . . . . . . . . . 171

A.2 Productivity Dispersal - by Ability to Read \& Write . . . . . . . . . . . . 172

A.3 Productivity Dispersal - by Shock Experience . . . . . . . . . . . . . 173

B.1 Permanent Contract . . . . . . . . . . . . . . . . . . . . . . . 182

B.2 Temporary Contract . . . . . . . . . . . . . . . . . . . . . . . . 182

B.3 Business Cycle Volatility . . . . . . . . . . . . . . . . . . . . . 198

B.4 Unemployment Rate . . . . . . . . . . . . . . . . . . . . 199 


\section{List of Tables}

3.1 Prevalence of Rural Non-Farm Enterprises . . . . . . . . . . . . . . 35

3.2 Type of Business Activity . . . . . . . . . . . . . . . . 40

3.3 Probit Regressions - Complete Sample . . . . . . . . . . . . . . . . . . . 43

3.4 Probit Regressions - Average Marginal Effects . . . . . . . . . . . . . . . 46

3.5 Multinomial Logit Model - Ethiopia . . . . . . . . . . . . . . . . . 49

3.6 Multinomial Logit Model - Malawi . . . . . . . . . . . . . . . 50

4.1 Heckman Selection Model . . . . . . . . . . . . . . . . . . 65

4.2 Panel Data Analysis . . . . . . . . . . . . . . . . . 67

5.1 Overview UISA in Latin America . . . . . . . . . . . . . . . . 77

5.2 Benefit Changes Before and After UISA Introduction . . . . . . . . . . 83

6.1 Change in Employment Duration - by UISA Introduction . . . . . . . . . 91

6.2 Regressions - Cox Model . . . . . . . . . . . . . . . . . . . . 99

6.3 Generalized Gamma Regressions . . . . . . . . . . . . . . . . . . . . . 102

6.4 Regressions - Cox Model . . . . . . . . . . . . . . . . . . . . . . 105

6.5 Generalized Gamma Regressions . . . . . . . . . . . . . . . . . . 107

7.1 Descriptive Statistics - Post-Employment . . . . . . . . . . . . . . 122

7.2 Descriptive Statistics - Post-Unemployment . . . . . . . . . . . . . . 123

7.3 Before-After Regression Analysis (Without Control Group) . . . . . . . . 130

7.4 Difference-in-Differences (With Control Group) . . . . . . . . . . . . . 131

A.1 Prevalence of Urban Non-Farm Enterprises . . . . . . . . . . . . . . . . 164

A.2 Months in Operation . . . . . . . . . . . . . . . . . . . 164

A.3 Summary Statistics - Probit Regressions (Rural) . . . . . . . . . . . 165

A.4 Summary Statistics - Probit Regressions (Urban) . . . . . . . . . . 166

A.5 Summary Statistics - Heckman Selection Model . . . . . . . . . . . . 168

A.6 Summary Statistics - Panel Data Analysis . . . . . . . . . . . . . . 170

A.7 Probit Regressions - Coefficients and Average Marginal Effects (Rural) . 174

A.8 Probit Regressions - Coefficients and Average Marginal Effects (Urban) . 176

A.9 Heckman Selection Model (Rural) . . . . . . . . . . . . . . 178 
A.10 Panel Data Analysis (Rural) . . . . . . . . . . . . . . . . . . 179

B.1 Summary Statistics . . . . . . . . . . . . . . . . . . 183

B.2 Summary Statistics - Post-Employment . . . . . . . . . . . . . 185

B.3 Summary Statistics - Post-Unemployment . . . . . . . . . . . . . 186

B.4 Test of Proportional Hazards Assumption - Multiple Cox Regression . . . 188

B.5 Test of Proportional Hazards Assumption - Competing-Risk . . . . . . . 189

B.6 Stratified Cox Model . . . . . . . . . . . . . . . . . . . 190

B.7 Stratified Cox Model - Competing Risk . . . . . . . . . . . . . . . . 191

B.8 Regression Table Cox Model - Extended Sample . . . . . . . . . . . . . . 193

B.9 Regression Table Cox Model - Control Group . . . . . . . . . . . . . . . 195

B.10 Marginal Effects . . . . . . . . . . . . . . . . . . . . 196

B.11 Basic Macroeconomic Indicators - Overview . . . . . . . . . . . . . . 197 


\section{Abbreviations}

\begin{tabular}{|c|c|}
\hline AFT & Accelerated Failure Time \\
\hline $\mathrm{AIC}$ & Akaike Information Criterion \\
\hline AME & Average Marginal Effects \\
\hline CARA & Constant Absolute Risk Aversion \\
\hline CLP & Chilean Peso \\
\hline EPS & Encuesta de Protección Social (Social Protection Survey) \\
\hline $\mathrm{FE}$ & Fixed Effects \\
\hline ILO & International Labour Organization \\
\hline IMACEC & Indicador Mensual de Actividad Económica \\
\hline & (Monthly Indicator of Economic Activity) \\
\hline IZA & Institute for the Study of Labor \\
\hline KM & Kaplan-Meier \\
\hline LSMS-ISA & Living Standards Measurement Study - Integrated Surveys on Agriculture \\
\hline MNLM & Multinomial Logit Model \\
\hline NFE & Non-Farm Enterprise \\
\hline OECD & Organisation of Economic Co-operation and Development \\
\hline OLS & Ordinary Least Squares \\
\hline PAYG & Pay-As-You-Go \\
\hline $\mathrm{PH}$ & Proportional Hazards \\
\hline RIGA & Rural Income Generating Activities \\
\hline $\mathrm{SF}$ & Solidarity Fund \\
\hline $\mathrm{UI}$ & Unemployment Insurance \\
\hline UISA & Unemployment Insurance Savings Accounts \\
\hline USD & United States Dollar \\
\hline VAT & Value-Added Tax \\
\hline
\end{tabular}



Chapter 1

\section{General Introduction}




\subsection{Purpose of the Thesis}

Labor provides the main source of household income around the world. The occupational choices household members make, for example the number of hours allocated to labor, the type of work performed or the choice of employment sector, largely determine their incomes, and thus their livelihoods. Within this context, two major avenues are possible to increase earnings: by moving from inactivity or low-return activities into more productive occupations, or by improving the prospects in the current employment. Occupational choices, however, are often restricted and people therefore limited in their options to act, preventing them from progressing into more favorable employment opportunities. The labor market framework, characterized by both formal and informal rules and regulations, decisively shapes the magnitude of these choices. This framework varies significantly between advanced economies and the developing world, and thus requires to take the surrounding conditions into consideration. Understanding the labor market in developing countries and understanding the effects of the introduction of new policies on labor market outcomes in such a context, have an important role in fostering effective policies for development. Household members that have the possibility to make meaningful occupational choices, for example by engaging in more productive activities, or by better securing or increasing their incomes, will be able to contribute to their well-being and that of their families (Cho et al., 2012).

The differences in the labor market framework between advanced economies and developing countries are considerable. Capital productivity is on average lower in developing countries due to static and dynamic inefficiencies in the allocation of resources. Labor is less productive due to lower education and other skills. Within the developing world differences are also extensive. Many middle-income countries are rapidly growing and undergoing a phase of fast structural change, whereby labor is allocated away from agriculture into more productive sectors, for example the industrial sector. However, this labor re-allocation is also accompanied by labor market frictions, since workers need to acquire new skills to participate in newly created jobs. If they do not manage to acquire them, growth and structural change can leave workers excluded from the labor market, increasing within country inequalities or decelerating the development process. Poorer countries, in contrast, generally display slow structural change. In these economies a large share of labor continues to work in agriculture, is self-employed in the informal sector, or works in small family businesses as non-renumerated household members due to insufficient wage-employment opportunities (Cho et al., 2012). At both levels of 
development, countries face challenges in the understanding and regulation of the labor market framework that defines a worker's possibility to engage in productive activities. For this thesis, two regions and countries are selected to study labor market frameworks in emerging and developing economies, as well as changes in the labor market due to a new policy introduction.

In Sub-Saharan Africa the majority of the population continues to live in rural areas and earns its living in agriculture. Structural change that enhances productivity growth requires the movement of workers out of farming to more productive forms of labor allocation, such as entrepreneurship or wage employment. It also requires that higher productivity is actually achieved in these areas of employment compared to farming activities. With regard to non-farm enterprises in rural Sub-Saharan Africa, the evidence of why households engage in this form of self-employment and how these enterprises perform continues to be scarce. Existing evidence is often based on one-country, singleperiod and incomplete data. Hence, a large gap remains in the understanding of a rural household's decision to engage in entrepreneurship, and the resulting outcomes of such a choice.

In Latin America, structural change and catch-up growth have been faster. In an urbanizing and emerging middle-income country such as Chile, obtaining further increases in labor productivity requires more sophisticated labor market policies. In this respect Chile has been innovative in introducing a new unemployment protection scheme, unemployment insurance savings accounts (UISA). The scheme is expected to relax labor market rigidities, allowing formal private sector workers to be more flexible in their occupational choices. The new scheme gives them the possibility to change jobs without losing all protection rights, and better securing unemployment protection in case of unemployment. Relaxing labor market rigidities and expanding unemployment protection can lead to changes in labor market outcomes with controversial consequences for the worker. Until now, however, knowledge has been limited on how the introduction of this new unemployment protection scheme affected different labor market outcomes. As a consequence, a lack of understanding remains if and how the introduction of the new unemployment protection scheme has changed the occupational outcomes of formal private sector workers.

This dissertation focuses on the labor market framework, new labor market policies and the resulting occupational choices in emerging and developing countries. ${ }^{1}$ Occupational

1 In this thesis I distinguish between developing countries and emerging economies due to a highly diverging labor market framework in Sub-Saharan Africa and Chile. The first part of the thesis 
choice is vital for productivity growth and for improving livelihoods at various stages of development, but substantial gaps remain in the literature. The thesis contributes to filling the identified knowledge gap by using two recent and unique data sets from Sub-Saharan Africa and Latin America to study labor markets frameworks, new labor market policies and occupational choices in emerging and developing economies.

In the first part, entrepreneurship in rural Sub-Saharan Africa, data from six countries in both West and East Africa is used. The occupational choices of the working age population in rural areas are restricted and often limited to farming or non-farm selfemployment. I study the decision of rural households to engage in entrepreneurship, their choice of business activity and the performance of these enterprises. Whether individuals and households operate enterprises due to choice, because they perceive a promising business opportunity, or due to necessity, because they need to cope with adverse events (ex-ante or ex-post), is still under-researched. However, the motivation is assumed to have an effect on the choice of business activity, the enterprise performance, the ability to grow and survive, and to offer employment to non-household workers.

In the second part, unemployment insurance saving accounts, data from the Chilean social protection survey is used. The changes in occupational choice result from the introduction of a new unemployment protection scheme in October 2002. I analyze this new scheme with regard to its effect on employment duration and subsequent employment quality. The previous unemployment protection arrangement, severance pay combined with minimal unemployment insurance, resulted in rigidities of the Chilean labor market without offering adequate protection in case of unemployment. Expanding the coverage of unemployment protection while simultaneously reducing opportunity costs in case of job change, offers workers a legal framework with more protection and enhanced occupational choices.

The remainder of the introduction is organized as follows. In Section 1.2 I define the concept of occupational choice and discuss the role of entrepreneurship and social protection in this context. I also present an overview of my two thesis topics: nonfarm entrepreneurship in rural Sub-Saharan Africa and unemployment insurance savings accounts in Chile. In Section 1.3 I illustrate the contributions of this thesis, before presenting the outline of the dissertation in the final section.

focuses on developing countries, the second part on an emerging economy. 


\subsection{Key Concepts}

\subsubsection{Occupational Choice}

The development process of a country affects the occupational choices of its labor force, since the demand and supply of different types of employment change, and consequently the potential returns to labor or the risk of engaging in a specific type of activity. Occupational choice is also influenced by the initial distribution of wealth, since occupations that require higher levels of investment (e.g. in education or for starting an enterprise) cannot be accessed by the poorer population (Banerjee and Newman, 1993). Taking this explanation as a baseline, I additionally describe occupational choice as the freedom of individuals to choose in which type of economic activity they want to engage, while simultaneously allowing them to secure their incomes and thus their livelihoods. This is particularly relevant in a developing country context with substantial capital market imperfections and a large informal labor market.

The occupational choice literature describes three avenues that potentially influence an individual's decision of employment: first, individual characteristics (e.g. preferences and abilities), with the socio-economic and cultural context as framing conditions in which the person chooses the occupation. Second, the external labor market framework, including government policies and labor market characteristics (e.g. wage structure and labor demand). And third, the social and cultural context, including the status of parents and other family members, and the resulting preconditions and expectations. Occupational choice is furthermore a process that unfolds over the life span of working age individuals, since people can choose to be active or drop out of the labor market at various stages of life, as well as to take different positions in different sectors and employment areas, or to become entrepreneurial (Blau et al., 1956).

In the economic literature the decision to choose entrepreneurship as occupation has often been described as an individual's choice between wage-employment and entrepreneurship (e.g. Lucas, 1978; Evans and Jovanovic, 1989; Murphy et al., 1991). In the rural African context, however, the choices of working age individuals differ decisively. Instead of wage-employment, individuals often face the decision between farming, caring activities, migration or self-employment. Wage-employment, in contrast, is of minor importance and often not an option in rural areas. The factors that influence the decision to become an entrepreneur depend on the individual's characteristics (e.g. entrepreneurial abilities), 
the expected rate of return in the business, capital constraints (e.g. access to credit) and start-up costs, and the opportunity costs of non-farm entrepreneurship (e.g. returns in agriculture). They can also depend on the necessity to diversify income ex-ante or the necessity to react to adverse events ex-post.

In the African context another aspect also plays a central role: the informality of most businesses. Many developing countries face this situation, which is described by Zenou (2008) as a dual economy, but where the duality is not found in the traditional versus the modern sector, but within the labor market itself. Entrepreneurs are commonly found in the informal economy, whereas wage-employment is more often located in the formal sector. Entrepreneurship accounts for 20 to 80 percent of non-agricultural work in African countries (Zenou, 2008). While businesses can be informal due to limited access to formal structures and remote locations, informal entrepreneurship can also be a conscious decision to evade taxes and regulations, or to engage in illegal trade (de Paula and Scheinkman, 2007). However, informal businesses tend to be less efficient, have less access to credit and are often dominated by entrepreneurs of lower abilities. Therefore, entrepreneurship is often a subsistence activity in a dual economy. This implies that higher growth might be obtained by supporting entrepreneurs with higher ability to move into the formal sector.

Social protection policies also affect occupational choices. Social protection covers a wide range of different schemes, such as pensions, unemployment insurance, cash transfers (conditional or unconditional) or social assistance. In developing countries social protection benefits are often attached to formal employment, leaving workers in the informal sector without or with limited benefits and protection. In the formal sector, the design of such policies influences the behavior of workers, since quitting or changing a job might leave them without or with less protection than before. Social protection schemes can be simultaneously restricting and beneficial in this context. On the one hand, social protection schemes can introduce rigidities to the labor market that hinder or slow down structural change by preventing the re-allocation of workers into more productive sectors. They may also create barriers for informal workers to enter formal employment due to more segmented labor markets. On the other hand, social protection does not always mean "politics against markets" as Estevez-Abe et al. (1999) explain, since social protection can also prevent market failures. Unemployment protection plays a special role in this regard, as it decisively influences the skill formation and risk-taking of workers. People have a lower likelihood to invest in specific skill formations if the risk of losing employment with these specific skills is high. Therefore firms that require 
specific skills in order to be competitive in international markets, need to provide some form of guarantee to potential workers to allow them to manage risks and to facilitate labor market transitions. Without social protection policies that can facilitate longerterm employment, wage stability and protection rights in case of unemployment, the formation of specific skills will be under-supplied. This is one reason why social protection as governmental policy could present a critical step in supporting structural change and economic development (Estevez-Abe et al., 1999).

Occupational choice therefore presents an essential aspect when analyzing labor markets, since the choice of labor activity is of fundamental importance in securing livelihoods in emerging and developing countries. Why individuals decide to be active, why they enter a certain sector or employment type, and how they plan their occupations throughout the life course, fundamentally depend on the labor market framework and policies they encounter. These decisions, in turn, affect their well-being and that of their families. Examining this framework, for non-farm entrepreneurship in rural Sub-Saharan Africa, as well as for formal private sector workers in Chile, provides scholars, policy makers and donors with a deeper insight of labor market mechanisms. It allows governments to better understand the impact of labor market conditions and helps them to design policies that have the potential to support the development of labor markets, and hence assist countries in the structural change of their economies. Eventually such policies have the potential to improve a country's economic performance and reduce poverty.

\subsubsection{Non-Farm Entrepreneurship and Self-Employment}

As low-income countries develop economically, labor is re-allocated from agriculture into more productive sectors. Wage-employment, however, is initially not an option for the bulk of the poorer population. Instead, non-farm entrepreneurship and self-employment are usually the first steps within this process and wage-employment only an option for the better educated population in urban areas. Wage-employment only increases its share with higher levels of economic development. Informal entrepreneurship ${ }^{2}$ is therefore widespread, with estimates suggesting that about half of all jobs can be found in this sector. The numbers, however, range significantly between countries, depending on a variety of factors, for example the level of economic development, institutions and government policies, as well as infrastructure and geographic location (Margolis, 2014).

2 Formal entrepreneurship can also be found in developing countries. However, its share is often negligible, especially in rural areas. 
In the context of structural change, entrepreneurship is considered to be a major engine for countries to advance economically at low levels of development (Anokhin et al., 2008). As explained by Wennekers and Thurik (1999) and Dejardin (2011) the formation of new enterprises plays a crucial role in facilitating competition, that in turn induces innovation and the creation of new business sectors (Quatraro and Vivarelli, 2013). As a consequence, these new enterprises have the potential to contribute to employment creation (see also Malchow-Møller et al., 2011). This finding translates into more support for non-farm self-employment, since more entrepreneurs would also mean more economic development (Holcombe, 1998; Dejardin, 2000). So far, however, most studies have focused on entrepreneurship in advanced economies or formal enterprises in developing countries, but research on informal entrepreneurship in developing countries continues to be scarce (Naudé, 2010). The role of entrepreneurship in the development process still lacks adequate insights and understanding, especially in data-poor regions such as Sub-Saharan Africa. Whether the role of entrepreneurship in the development process of low-income economies is similar to that in more advanced economies, continues to be unclear (Quatraro and Vivarelli, 2013).

One noticeable difference in developing economies is that non-farm self-employment is often driven by poverty and by the necessity to diversify sources of household income to survive, instead of perceived business opportunities (Yamada, 1996; Desai, 2009; Naudé, 2009, 2010). Individuals set up small informal businesses, for example as street vendors and personal service providers, but rarely provide wage-employment to externals. Instead, they rely on non-renumerated household members if additional laborers are needed (Quatraro and Vivarelli, 2013). Generally these enterprises remain informal, small and have a low productivity. Self-employment in developing countries therefore crucially differs from self-employment in more advanced economies. Amorós and Cristi (2011) confirm that the informal type of developing countries' entrepreneurship does not have the same potential to drive economic growth as it does in advanced economies. However, it still affects poverty rates and can improve inequality and wealth levels. Naudé et al. (2014) suggest to broaden the efficiency view of entrepreneurship and expand the measures to include non-material measures of well-being, especially with regard to individual and societal development (Quatraro and Vivarelli, 2013). Still, entrepreneurship in the developing world continues to be characterized by low productivity. Increasing enterprise performance and achieving higher levels of productivity can lead to faster economic growth, and consequently to decreasing poverty levels (Margolis, 2014).

A better understanding of entrepreneurship in developing countries therefore has the 
potential to help develop support programs and government policies that promote higher productive enterprises. Especially the availability of new data sources allows research in low-income countries to provide new insights.

\subsubsection{Unemployment Insurance Savings Accounts}

Over the past decade an increasing number of emerging and developing countries has indicated interest in social protection schemes. Governments show interest in shielding their vulnerable population from income shocks and unsustainable coping mechanisms. Apart from introducing new schemes, governments have also initiated reforms to adapt social protection to the socio-economic reality or to changes in society, often diverging from previously copied schemes of developed countries or former colonial powers.

Social protection, defined as public measures for individuals or households to secure their incomes, has a dual function. It smooths consumption when households fall into economic constraints, shielding people from falling into poverty, and enables laborers to increase their productivity by allowing them to engage in higher return activities (Holzmann and Jørgensen, 2001). Countries that introduced new social protection schemes or modified existing ones, have also introduced instruments or tools which have been partly different than those in advanced economies, as a result of differences in the socio-economic context, financial possibilities and national preferences. Copying schemes from advanced economies have also proved impractical in many cases due to a number of particularities of developing economies, among others large informal labor markets and limited monitoring capacities (Holzmann and Jørgensen, 2001).

The motivation to focus on innovative unemployment protection in this context is twofold. First, households face severe economic constraints when household members become unemployed. While this also holds for advanced economies, employment often constitutes the only source of income generation in emerging and developing countries, since social assistance or governmental transfers in cash and kind are scarce, or only provide minimal benefits. Such a vulnerable situation demands innovative approaches to overcome unemployment spells in a context of limited financial resources and administrative capacities. The exposure to income shocks has initiated a substantial debate on adequate income protection for workers in times of unemployment (van Ginneken, 2003; Vodopivec, 2004; Ferrer and Riddell, 2011; Vodopivec, 2013). Second, labor markets demand flexibility to adjustment processes of the dependent workforce in times of economic 
changes or financial crises, challenging governments to find viable solutions to protect workers during unemployment spells. A protection scheme for formal sector workers that is widespread in developing countries is obligatory severance pay. The lump sum given to laid-off workers mitigates the income shock and supports them during the following search period. However, severance pay also hinders the labor market to adapt to economic changes, as firing becomes a costly procedure for firms (Sehnbruch, 2004; Robalino et al., 2009). It also reduces new hiring, as firms will employ workers with openended contracts only in times of sound economic perspectives (Ferrer and Riddell, 2011). Further disadvantages include the risk of default, as firms do not save up for severance liabilities, and possible long processes involving courts to certify eligibility for severance payments (Robalino et al., 2011).

As developing countries become more developed, they might start looking for alternatives to decrease the rigidities that severance payments introduced to the labor market and switch to more efficient, but also more complex forms of insuring workers from unemployment risks (Cowan and Micco, 2005). One approach in Latin America has been the introduction of mandatory savings schemes, so-called unemployment insurance savings accounts, that smooth income over an individual's life cycle through personalized savings accounts. They stand in contrast to the risk-pooling among all workers that is widespread in many advanced economies (Ferrer and Riddell, 2011). UISA can replace or complement a severance payment system, adding more flexibility to the labor market without entirely giving up an existing protection scheme in the latter case.

A better understanding of unemployment insurance savings accounts in emerging economies could therefore help to design and implement unemployment protection that has the potential to cushion shocks and smooth incomes, while removing labor market rigidities. It simultaneously tackles the problem of moral hazard that is prevalent in unemployment insurance based on risk-pooling, and could therefore also present an interesting alternative for developed countries. The availability of a clear-cut introduction date of UISA in Chile, as well as rich panel data of the Chilean labor force, allows research to provide new insights.

\subsection{Contributions of the Thesis}

The purpose of this thesis is to reduce the research gap that can be described as a general scarcity of research on labor markets and social protection policies in emerging 
and developing countries. Most research in labor economics focuses on Western economies (United States, Europe and other high-income countries), while the developing world has so far been rather neglected with the exception of certain topics (e.g. conditional cash transfers). More specifically, the thesis analyzes labor markets and social protection frameworks to better understand the occupational choices of workers, and how local circumstances and policies can affect their decisions.

This research or knowledge gap has its origin not only in the more limited interest in labor markets of the developing world, but often in the lack of appropriate data to conduct empirical analyses. Most data is not representative, variables are often missing or only available for one period in time. The reasons are multifaceted: data collection is challenging in such a context, since informality is widespread, a large share of the population unregistered and the infrastructure fragmented, especially in isolated rural areas. In order to design questionnaires, to conduct representative sampling and to carry out the interviews, not only a higher, but also a different kind of effort is needed compared to more advanced economies. Furthermore the capacity to conduct such data collection is limited by financial constraints and by the lack of appropriately skilled personnel.

The first topic addressed in this thesis, non-farm entrepreneurship in rural SubSaharan Africa, profits from a new database, the Living Standards Measurement Study - Integrated Surveys on Agriculture (LSMS-ISA). The data collection has been undertaken by the World Bank, and supports governments in six Sub-Saharan African countries to generate nationally representative, household-level panel data with a strong focus on agriculture and rural development, including a separate section on non-farm entrepreneurship and self-employment. In the first part of this thesis I study rural nonfarm entrepreneurship in the six countries covered by the data collection. Micro-level empirical research on African entrepreneurship has largely focused on manufacturing enterprises and enterprises in urban areas. Furthermore most research is based on specific countries where data exists. Cross-country studies that take various years into account and that analyze different aspects of rural entrepreneurship are still scarce.

In this thesis I start the analysis by describing the patterns of rural businesses and continue by identifying which determinants are significant to explain participation in entrepreneurship. In other words, I study the question which individual, household and location characteristics have an effect on the decision of households to engage in entrepreneurial activities. I continue the study by analyzing the types of businesses households operate and finalize the first part by evaluating the performance and productivity of these enterprises. 
The results show that entrepreneurship is ubiquitous in rural Africa and makes a substantial contribution to rural household income. Households operate enterprises both for opportunity and necessity reasons, and are most often active in non-agricultural enterprises, agribusinesses and trade. The results also suggest a link between the household's motivation to operate an enterprise and its subsequent productivity.

The second topic addressed in this thesis, unemployment insurance savings accounts, profits from a panel data collection with a focus on the Chilean labor market and social protection system. I analyze potential effects of the UISA introduction on labor market outcomes, since the new policy led to more comprehensive unemployment protection, while simultaneously reducing labor market rigidities. This type of unemployment protection differs from the schemes found in most advanced economies. Instead of risk-pooling, UISA are based on mandatory individual savings accounts which are only complemented by a risk-pooling element, the solidarity fund. UISA have one major advantage compared to unemployment insurance based on risk-pooling: as unemployed workers internalize the costs of unemployment, the scheme does not suffer from moral hazard as long as the insurance component is not accessed (Reyes et al., 2011). In the thesis I first examine whether the introduction of UISA affected employment duration among affiliated workers, and the magnitude of this effect. Second, I examine whether the introduction of UISA had an impact on the differences in subsequent wages and contract types, two variables used as proxies to assess employment quality. In both chapters I analyze the effects on workers directly changing into a new employment, and on workers experiencing a period of unemployment before reentering the labor market.

The results show that UISA affiliation had a significant effect on employment duration, reducing the time to employment termination by 30 to 45 percent, depending on the termination reason (e.g. change of employment, unemployment, inactivity). Taking reduced employment duration as an indicator for higher labor market flexibility, the findings suggest that the policy introduction achieved the goal of reducing labor market rigidity. However, reduced employment duration can equally imply more unstable employment conditions, resulting in worse conditions for workers. The results also show evidence that UISA affiliation had a small negative effect on wage differences, but no effect on the difference in contract types, implying a more limited impact on subsequent employment quality.

While the two topics of the doctoral thesis diverge with regard to region, context and focus, both address the aspect of occupational choice under restricted conditions. In the first part, the decision to enter entrepreneurship and the opportunities that individuals 
encounter when engaging in self-employment offer them possibilities of securing and improving their livelihoods. Understanding how entrepreneurship fares in rural Africa and which individual, household and location characteristics matter, can help governments to design appropriate policies to further support potential and existing entrepreneurs, as well as to shield them from adverse events. In the second part, the UISA introduction led to changes in opportunity costs and benefit transfers in case of job change or job loss. Understanding the implications that the introduction of this new unemployment protection scheme exhibits on labor market outcomes, can help governments ${ }^{3}$ understand the more indirect consequences on labor market outcomes and to improve the policy design.

This thesis contributes to a better understanding of labor markets and labor market conditions, that allows to develop and formulate adequate policy recommendations based on new insights gained. The main policy recommendations for rural entrepreneurship are based on both demand-side and supply-side policies. The former includes policies that improve the local infrastructure to increase the client base for businesses, the latter includes policies that reduce entrepreneurship motivated by necessity, and that encourage individuals to enter entrepreneurship motivated by opportunity. The main policy recommendations for the Chilean UISA scheme are based on the goal of achieving adequate protection of workers, while maintaining labor market flexibility, since more vulnerable workers, for example with low saving amounts, might not be sufficiently protected. Reforms that target more disadvantaged group of workers to ensure that they are equally protected in case of job loss are therefore recommended. Furthermore policies for the informal labor force are needed, since they are currently left out of the unemployment protection system.

Adequate policies have the potential to increase occupational choices of individuals in emerging and developing countries and to give them the opportunity of engaging in activities that secure and improve their livelihoods and that of their families.

\subsection{Outline}

Two major themes are addressed in this thesis, non-farm entrepreneurship in rural SubSaharan Africa and the introduction of a new unemployment protection scheme in Chile.

3 The Chilean government, as well as governments in other countries, in both emerging and more advanced economies. 
The two themes are studied in three chapters each consisting of, respectively, one chapter providing an overview of the topic, including a comprehensive literature review and a detailed description of the database used, as well as two empirical chapters containing the quantitative analyses and the discussion of the results.

In the first part of the thesis occupational choice under restricted conditions is studied and entrepreneurship in rural Sub-Saharan Africa taken as an example to further analyze employment choices at lower levels of economic development. Chapter 2 provides a literature overview of the current state of research on non-farm entrepreneurship, covering theory, importance and determinants of enterprise operation and productivity, as well as a summary of the literature on entrepreneurship in Sub-Saharan Africa. This chapter also provides an overview of the database used in the empirical analysis. Chapter 3 illustrates patterns of rural entrepreneurship and identifies relevant determinants of business operation, that can be further categorized into push and pull factors. It furthermore studies the entrepreneur's choice to enter a specific type of business activity. Chapter 4 analyzes the performance of these enterprises and explores whether the necessity versus opportunity kind of entrepreneurship also influences the subsequent labor productivity.

In the second part of the thesis, concrete measures of unemployment protection policies are studied. Chapter 5 describes the concept of unemployment insurance savings accounts, provides an overview of existing schemes in Latin America and assesses their performance. Furthermore it describes the Chilean UISA scheme and introduces the database used in the empirical analysis. Chapter 6 analyzes the impact of UISA introduction on labor market flexibility, measured by a possible change in employment duration. Chapter 7 studies the impact of UISA introduction on subsequent employment quality, measured by the differences in wages and contract types.

Finally, Chapter 8 summarizes the findings, discusses policy implications and suggests a set of avenues for future research. 


\title{
Part I
}

Non-Farm Entrepreneurship in

\author{
Rural Africa
}



Chapter 2

\section{Overview and Data}




\subsection{Introduction}

In the year 2000 Wiggens lamented that "little is known" about Africa's rural non-farm economy, beyond an "embryonic set of ideas". ${ }^{1}$ Since then the embryonic set of ideas has been elaborated by scholars, who established that a substantial and rising number of households in rural Africa do not limit their labor to agriculture, but diversify into self-employment and operate enterprises (Start, 2001; Reardon et al., 2006; Davis et al., 2010; Rijkers and Costa, 2012). ${ }^{2}$ Why and how they do so remains however relatively unexplored, especially from an empirical and comparative perspective. As a consequence, most poverty alleviation interventions have so far neglected entrepreneurship in rural Africa (Fox et al., 2013).

Entrepreneurship in the developing world is generally motivated by either necessity or by opportunity, with far-reaching consequences on productivity and growth. The extant scholarly literature ascribes the phenomenon of entrepreneurship in rural Africa to market imperfections, such as a lack of insurance or social protection schemes, that hamper risky farming and force households to diversify their labor supply into various occupational domains as a risk-management strategy. While this presents a plausible explanation, entrepreneurship can be equally motivated by opportunities, where individuals and households engage in the non-farm sector due to demand, specialized skills and other kind of business advantages. Enterprises started in pursuit of an opportunity could fare substantially better compared to enterprises operated due to necessity. The overarching theme can therefore be described as occupational choice and the consequences of necessity or opportunity motivated entrepreneurship in rural Africa, also known as push and pull factors. If the conditions to operate an enterprise either limit or support entrepreneurial success, then productivity is expected to differ between these two types of enterprises.

So far most empirical evidence has been based on one-period, single-country and limited

1 This chapter is based on the working papers: Nagler, P. and W. Naudé (2014b). Non-Farm Entrepreneurship in Rural Africa: Patterns and Determinants, IZA Discussion Paper No. 8008. Nagler, P. and W. Naudé (2014a). Labor Productivity in Rural African Enterprises: Empirical Evidence from the LSMS-ISA, IZA Discussion Paper No. 8524.

2 In this thesis non-farm entrepreneurship is described as any kind of business activity in the non-farm economy that is undertaken by the active rural population. Rural non-farm enterprises are business ventures started and managed by households outside of agriculture. They typically include agroprocessing, trade and sales, various services, as well as construction and transportation activities. Although referred to as non-farm, many of these enterprises are linked to agriculture and are often located on a farm, for example food processing or veterinary services (Rijkers and Costa, 2012). Nonfarm enterprises are part of the broader rural economy. Barrett et al. (2001) contain a more detailed discussion of the concepts of the rural economy in general, including agriculture and the non-farm economy, and Wiggens and Roepstorff (2011) on the concept and measurement of agribusiness. 
survey data, and has furthermore focused on self-employment in urban areas. The first theme of this thesis therefore contributes to filling the literature gap by providing a rich set of descriptive statistics and empirical estimates on non-farm entrepreneurship in rural Sub-Saharan Africa using the Living Standards Measurement Study - Integrated Surveys on Agriculture (LSMS-ISA) data set. In Chapter 3 prevalence and importance of entrepreneurship are presented, and determinants of enterprise operations studied. Furthermore this chapter reviews the determinants of choice of business activity. In Chapter 4 determinants of enterprise productivity are analyzed.

This chapter commences the analysis by providing a comprehensive overview on the theoretical and empirical literature, and is organized as follows. In Section 2.2 the theoretical models that describe rural entrepreneurship are presented, followed by the empirical literature in Section 2.3, covering four areas of interest: prevalence and importance of entrepreneurship, determinants of enterprise operation, determinants of enterprise productivity and the empirical literature on entrepreneurship in Sub-Saharan Africa. In Section 2.4 the database used for the analysis in the Chapters 3 and 4 is outlined. The final section concludes this chapter.

\subsection{Theory}

Three theoretical approaches can be utilized for the understanding of non-farm entrepreneurship. First, Occupational Choice Models that deal with labor market choices of individuals (see e.g. Lucas, 1978; Evans and Jovanovic, 1989; Murphy et al., 1991; Banerjee and Newman, 1993). Second, Agricultural Household Models based on Singh et al. (1986). And third, Non-Unitary Models of Intra-Household Decision Making by Manser and Brown (1980) and Chiappori (1992).

Occupational Choice Models describe an individual's probability to choose selfemployment, for example entrepreneurship, over other occupational alternatives. This choice depends on entrepreneurial abilities and other skills, age and experience, the perceived relative rates of return to self-employment, obstacles such as capital constraints and entry costs, and factors that influence the opportunity cost of self-employment, including regulations and social protection. Standard models deal with stylized developed economies. However, individuals in rural Africa must make their occupational choices across segmented labor markets. The segmentation often occurs between formal and informal labor markets. In rural Africa the large majority of non-farm enterprises are 
informal enterprises. Based on this model, a lack of education, skills and managerial experience may be important reasons for the informality and small size of these enterprises (see also Lucas, 1978).

However, there is a growing appreciation in the literature of the existence of segmentation, or duality, also within the African informal sector (Pietrobelli et al., 2004; Gindling and Newhouse, 2014). Not all employment in the informal sector is a result of crowding out from the formal labor market. Many workers also enter the informal sector in pursuit of opportunities (Guenther and Launov, 2012). In some cases they are attracted by high rates of return in two-tier informal enterprises. High sunk costs in the presence of credit market imperfections may explain why not all rural households enter into this type of enterprises (see also Grimm et al., 2012). Using the two-tier concept, Bezu and Barrett (2012) modify the standard occupational choice model to analyze a rural household's decision to enter into non-farm entrepreneurship.

Following Bezu and Barrett (2012) households can choose between high- and low-return type of business activities, depending on their capital endowment. This model links agricultural risk to rural non-farm investment. As the risk in agriculture declines or becomes more correlated with earnings in the non-farm economy, investments in nonfarm enterprises due to push factors also decline. This means that sunk costs prevent households to access high-return or two-tier business types, that shocks in agriculture encourage diversification into the non-farm economy, and that an external shock (reducing household wealth due to a lack of insurance) can push households to operate a lowreturn enterprise. With regard to the latter, Keats (2012, p. 26) states that "on average individuals give up a substantial portion of their potential income because of these risks and the lack of insurance".

These models focus on the individual entrepreneur. However, the level of decisionmaking may not be on the individual level, but rather on the household level in the rural African context, where most enterprises are small household-centered enterprises. These households are often also involved in agriculture, and occupational choices intertwined with agricultural decisions. ${ }^{3}$ In such a context, the implications from Agricultural Household Models need to be taken into consideration.

Following Singh et al. (1986) Agricultural Household Models describe households as

\footnotetext{
3 The general entrepreneurship literature has neglected the fact of household-level decision-making in case of family firms, focusing most of the time on the individual entrepreneur as the agent. As Alsos et al. (2013, p.10) recognize, household level decisions are "influential on how businesses are started and managed, but rarely garner attention within the entrepreneurship research literature".
} 
both consumers and producers. As producers (farmers) they aim to maximize their profits, that are taken as income into their consumption decisions. Assuming complete markets and information, the production decision is initially modeled separately from the consumption decision (Taylor and Adelman, 2003). However, rural markets are far from perfect (de Janvry and Sadoulet, 2006). In addition to missing, incomplete or imperfect markets, households face many types of external shocks, such as climatic shocks, diseases, economic shocks and conflicts (Sabates-Wheeler et al., 2013). Once market failures and risks are taken into consideration, the separation between consumption and production decisions of rural households no longer holds. The implication that households aim to maintain consumption in the face of risks and incomplete insurance or credit markets, can motivate the entrepreneurial decision as a reduction to shock exposure (de Janvry and Sadoulet, 2006; Dercon, 2009). For instance, failure in insurance markets can influence household-level decisions in terms of when and what type of non-farm enterprise to operate, as households enter less risky activities in the absence of well-functioning insurance markets (Rosenzweig and Binswanger, 1993; de Janvry and Sadoulet, 2006). Furthermore households might not operate their enterprises continuously over the year, ceasing operations once the need or crisis has passed (Loening et al., 2008).

Lack or imperfection of insurance markets in circumstances of high risk may also present a partial explanation for the prevalence of kinship ties. Bridges et al. (2013) explain that the family can be considered as an informal insurance arrangement in the African context due to limited social protection and a risky environment. They discuss the occurrence of labor market shocks, using the example of household members adjusting their labor market occupation if another member loses employment, providing a form of unemployment insurance. One option might be the occupation in an existing non-farm enterprise, or the creation of such a business.

Failures in credit and financial markets similarly lead to interdependence between the agricultural household's production and consumption decisions. A frequently cited example is the accumulation of liquid household assets, for example livestock, as a buffer against shocks (de Janvry and Sadoulet, 2006; McPeak, 2006) and the often inevitable asset-depletion during and after a shock (Sabates-Wheeler et al., 2013). It again leads households to operate low-risk enterprises, as only wealthy households can afford the sunk costs required for accessing two-tier type of informal businesses (Dercon, 1998, 2009).

Although decision-making at the household level is taken into account in Agricultural Household Models, it is important to keep in mind that households in rural Africa are not unitary households that maximize a single, joint utility function (Ngenzebuke 
et al., 2014), but rather described by Non-Unitary Household Models. The decisionmaking process takes place collectively (Chiappori, 1992), either in a cooperative or non-cooperative way (Manser and Brown, 1980), recognizing that full cooperation is limited within a household, and complete pooling of resources does not always take place (Serra, 2009). One of the direct implications is the predicted bias against women in rural entrepreneurship (Serra, 2009). Female labor market participation is often determined by a woman's bargaining position within the household, instead of her preferences or abilities (Udry, 1996). As a result, female participation in rural labor markets is not only constrained by discrimination in financial and labor markets, but also due to rigid social norms that channel their time allocation. Women may not be able to dedicate their time to operate enterprises outside of agriculture, or if they do so they may be restricted to certain types of business activities (Serra, 2009). As a consequence Cramer et al. (2008, p. 4) outline that "the great mass of female workers in rural areas exercise little real choice in their employment". Bridges et al. (2013) describe how women may have to change their occupational status if a family member loses employment. Using data from the Tanzanian Household Urban Panel Survey, they find that women tend to move in and out of labor as a response to labor market shocks, while men generally change the nature of work. ${ }^{4}$

In sum, the theoretical literature provides a number of models that support the understanding of rural non-farm entrepreneurship in a developing country context. I expect to observe the theoretical implications in the empirical analyses of the following chapters. Specifically, the theoretical literature emphasizes the interrelated nature of households and enterprises, and the collective decision-making at the household level with respect to the decision of entering the non-farm economy, the choice which type of business to operate and the allocation of household labor.

\subsection{Literature Review}

\subsubsection{Prevalence and Importance}

The views on the prevalence and importance of non-farm entrepreneurship in the existing literature has shifted over time. In earlier thinking on rural development, influenced by

${ }_{4}^{4}$ Loening et al. (2008) find that women-headed households in Ethiopia have a higher probability to operate a non-farm enterprise. 
the Lewis model of structural change (Lewis, 1954), the rural economy was expected to become less important as a contributor to rural household income over time (Lanjouw and Lanjouw, 2001). Urbanization and industrialization have consequently been the focus of development policies since the 1960s with agriculture often repressed (Havnevik et al., 2003). The bulk of empirical studies on enterprises and entrepreneurship in Sub-Saharan Africa have so far focused on urban areas (Naudé, 2011).

The fact that non-farm enterprises could potentially be important for rural development has only been recognized from the late 1990s onward, when it became clear that the contribution of the non-farm economy had not declined over time, but in fact increased (Reardon et al., 2006; Davis et al., 2010). Today, between 40 to 50 percent of household income in rural Africa originates from non-farm activities (enterprises and other nonfarm activities) (Lanjouw and Lanjouw, 2001; Start, 2001; Reardon et al., 2006; Davis et al., 2010; Rijkers and Costa, 2012). The share of household income that derives from non-farm entrepreneurship varies largely by country. Studies reporting the importance of entrepreneurship in Sub-Saharan Africa find shares of 20 percent in Ethiopia (1999), 64 percent in Malawi (2004), and 54 and 46 percent in Uganda and Tanzania (2000) (Reardon et al., 2006). Using the Rural Income Generating Activities (RIGA) database, ${ }^{5}$ Davis et al. (2010) find that non-farm sources to rural income contribute more than 50 percent to household income in almost two-thirds of the countries in the data set.

Davis et al. (2010) point out that the share of non-farm income is not more important in Africa than in other regions. Studies using data of countries outside of Africa support this conclusion. For instance, de Janvry and Sadoulet (2001) find that the non-farm economy contributes 55 percent to rural household income in Mexico. Escobal (2001) reports a figure of 51 percent for Peru. Lanjouw and Lanjouw (2001) report 39 percent for Brazil, 41 percent for Chile, 50 percent for Colombia and 59 percent for Costa Rica. Shi et al. (2007) report 46 percent for China.

However, it is yet unclear whether the non-farm economy's rising importance contributes to rural economic growth and poverty reduction, or whether it is a symptom of stagnation (Davis and Bezemer, 2004, p. 23). The current literature suggests a potentially positive role in poverty reduction (Fox et al., 2013), but also considers the extent to which households can access opportunities as limited. For instance, Barrett et al. (2001) identify the existence of entry barriers that limit the possibilities to which households can exploit

$\overline{5}$ The RIGA data set covers around 90,000 observations across Albania, Bangladesh, Bulgaria, Ecuador, Ghana, Guatemala, Indonesia, Madagascar, Malawi, Nepal, Nicaragua, Nigeria, Pakistan, Panama and Vietnam. 
profitable opportunities in the non-farm economy.

\subsubsection{Determinants of Enterprise Operation}

Throughout the broader entrepreneurship and small business literature, entrepreneurs and self-employed persons have been described as being motivated by either necessity or opportunity. Although a clear-cut distinction between the motivation and an explicit classification of determinants into opportunity or necessity is not straightforward, the literature recognizes that different qualities of self-employment exist. ${ }^{6}$

In the case of developing countries, and African countries in particular, a common view is that most self-employment is based on necessity (Herrington and Kelly, 2013). This is a result of high poverty in the context of missing or limited social protection and insurance markets. In other words, unemployment is not a viable option in most African countries and formal wage employment out of reach for a large share of the labor force, either due to a lack of aggregate demand or a lack of skills. Households are therefore pushed into enterprise operation outside of agriculture by necessity (Reardon et al., 2006). An important push factor is the high degree of risk in African agriculture (Rijkers and Söderbom, 2013). In the presence of credit and insurance market imperfections, riskaverse farm households are keen to diversify their income ex-ante in anticipation that a crop may fail, or to cope ex-post in the aftermath of a shock (Ackah, 2013). Rural enterprises can therefore be considered as a form of self-insurance or risk-management tool.

Longer-term structural push factors include surplus labor in households, as growing families put pressure on fixed parcels of farmland over time (Reardon, 1997; Reardon et al., 2006; Babatunde and Qaim, 2010). Growing families may also make more resources available, such as labor and finance, that can lead to more opportunities being sought (see also Alsos et al., 2013). Push factors also include seasonality: household members may find it necessary to operate enterprises in the low season, a situation aggravated by a lack of facilities for inter-temporal arbitrage (Lanjouw and Lanjouw, 2001). This conclusion has been supported by empirical studies that describe the non-farm enterprise sector in Africa as a heterogeneous sector (e.g. Barrett et al., 2001; Davis and Bezemer, 2004) that largely consists of small and informal businesses in the commercial, trade and

\footnotetext{
6 Margolis (2014, p.11) states "Although the different types of self-employment go by various names (Opportunity or necessity? Exit or exclusion? Choice or constraint? De Soto or Tokman?), both will typically exist simultaneously in any given country".
} 
services industry (Davis and Bezemer, 2004). Haggblade et al. (1989) report for example that 95 percent of rural enterprises employ less than five workers.

However, rural households also operate enterprises due to their desire to utilize business opportunities, also named pull factors. In this regard household capabilities and assets, as well as individual characteristics have been identified as crucial determinants (Barrett et al., 2001). Household and individual capabilities and assets typically include gender, age (also a proxy for experience), education, marital status (Abdulai and Delgado, 1999), financial assets (Bhaumik et al., 2011; Ackah, 2013), household composition and the size of the household itself. ${ }^{7}$ Schooling is found to be relatively more important to find nonfarm wage employment than for business operation (Elbers and Lanjouw, 2001; Davis and Bezemer, 2004; Reardon et al., 2006; Bayene, 2008).

Irrespective if households are pushed or pulled into entrepreneurship, they also need to make a decision with regard to the type of business activity. However, the literature has so far neglected this aspect of entrepreneurship. In Africa, most empirical enterprise-level studies focus on the manufacturing sector and urban enterprises. If households operate businesses in manufacturing, services, trade, construction or agribusiness, may depend on the initial motivation for enterprise operation and determine the success of the resulting enterprise.

The local and regional context where households reside can further facilitate or mediate their entry choice, as well as their choice of business activity. The rural context is expected to exert a strong influence on the decision to enter entrepreneurship, as well as on the choice of business activity. I therefore expect to find significant differences compared to urban enterprises. The agro-climatic environment determines for instance the extent to which agriculture is productive and risky (Reardon, 1997). Rural entrepreneurship may fare better under favorable agro-climatic conditions, for example sufficient and regular rainfall, that are good for agricultural productivity and where other natural resources can be found (Reardon et al., 2006).

Finally, the household location also determines the distance from urban areas, ports and markets. Depending on distance, transport costs and transport facilities, rural entrepreneurs decide to focus on either tradable or non-tradable local goods and service provision. Fafchamps and Shilpi (2003) find that the share of non-farm wage employment declines the further a household lives away from an urban center, and that a U-shaped

\footnotetext{
7 The presence of children in a household may limit the choices of individual household members within the non-farm economy, particularly women, resulting in activities attached to the household residence (Havnevik et al., 2003).
} 
relationship exists between the distance from an urban center and the share of income from self-employment. This finding also suggests a kind of protection effect of deep rural isolation and could benefit enterprises in the tradable goods sector. However, the closer a household is located to an urban center, the more likely an individual household members migrates instead of starting a business (Reardon, 1997). Generally distance, but also other determinants of market access such as the quality of roads and utilities, can be important determinants of development in both the farm and non-farm economy and of the linkages between the two (Wiggens, 2000; Wiggens and Roepstorff, 2011; Zezza et al., 2011). However, more empirical evidence is needed to identify the specific impact.

\subsubsection{Determinants of Enterprise Productivity}

A review of the literature on determinants of enterprise productivity is provided by Syverson (2011). The large majority of studies have analyzed enterprise performance in developed economies and identified education, work experience and skills levels of managers and workers, as well as market structure as the main determinants of enterprise productivity (Moretti, 2004; van Biesebroeck, 2005; Bloom and van Reenen, 2010). The literature also finds that female-headed enterprises are less productive than male-headed enterprises (Amin, 2011; Kinda et al., 2011; Saliola and Seker, 2011; Rijkers and Costa, 2012). Furthermore enterprises clustered together are more productive due to localization and urbanization economies, such as knowledge and technology spill-overs (Martin et al., 2011; Bloom et al., 2013), horizontal linkages (Nichter and Goldmark, 2009) and more competition (Foster et al., 2008; Ali and Peerlings, 2011). As a result the geographical location of an enterprise, and in particular the proximity to other productive enterprises, have an impact on its productivity.

While I expect these determinants to be potentially relevant in the case of rural enterprises in Africa, a major difference to consider is the previously described imprecise separation between the household and the enterprise as assumed in micro-economic theory and applied in empirical work of more advanced economies. In developed countries most determinants of entrepreneurship and firm productivity relate to the individual entrepreneur and to firm characteristics. In contrast, rural enterprises tend to be household enterprises and hence entrepreneurial decisions largely taken at the household level with different levels of cooperation within the family. Most households are furthermore involved in agriculture and the choice to operate an enterprise equally intertwined with farming decisions. 
In this context, the implications from agricultural household models are taken into account as described in the theoretical literature review. Once market failures and risks are taken into consideration, the agricultural households' desire to smooth consumption, diversify income or cope with shocks in the context of incomplete insurance and credit markets can drive them to create a non-farm enterprise as a risk-coping and income diversification strategy (de Janvry and Sadoulet, 2006; Dercon, 2009). As a consequence, households may choose to operate a business that can easily be started and exited, operated occasionally and that provides employment mainly for household members. This type of business is then likely to be a low-productive enterprise with intermittent operation in the informal sector (Rosenzweig and Binswanger, 1993; de Janvry and Sadoulet, 2006; Loening et al., 2008).

As a result, I expect to find a link between a household's motivation to operate a nonfarm enterprise and its subsequent productivity. I assume that enterprises operated by necessity are less productive than enterprises operated in pursuit of an opportunity. The latter may not only report higher productivity levels due to better capacity utilization, but also due to better access to credit, training and education of household members, all factors associated with higher productivity in the literature.

From the literature review and theoretical considerations I expect that the determinants of labor productivity in rural African enterprises are related to the household's motivation to operate an enterprise, and influenced by agricultural risk and productivity, economic geography and external shocks. The productivity level is further facilitated by individual and household level characteristics such as gender, age, education, access to credit and number of adults within the household.

\subsubsection{Enterprise Productivity in Sub-Saharan Africa}

While a solid body of literature has dealt with the dimensions of enterprise productivity in developed countries, only a few studies have analyzed enterprise productivity in SubSaharan Africa. Most of those that do, focus either on formal or manufacturing enterprises and tend to be overwhelmingly urban-based. Empirical evidence on the performance of non-farm enterprises in rural Africa is still scarce. This lack of knowledge is a serious lacuna, since policies to support rural development have the potential to substantially enhance their effectiveness if they succeed in raising the productivity of these enterprises.

For African countries most work has been conducted on the impact of the business 
environment on enterprise productivity in the formal sector. Various studies, using World Bank data, have found that a poor business environment reduces enterprise productivity and growth. Studies include Dollar et al. (2005), Arnold et al. (2006), Eifert et al. (2008) and Dethier et al. (2010). Less work has been done on clustering and spatial spill-overs. The only study for rural Africa so far conducted uses geo-referenced household data from Ethiopia and Nigeria and finds evidence of significant spatial auto-correlation from the productivity levels of enterprises in one location on that of closely located enterprises (Owoo and Naudé, 2014).

Other studies have mainly focused on manufacturing firms in Africa. Rijkers et al. (2010) analyze the productivity of manufacturing enterprises in rural Ethiopia. The authors find that rural enterprises are less productive than urban ones, and report an output per labor ratio for remote rural enterprises of 0.43 , while it is 0.95 for enterprises in rural towns, and 2.30 for enterprises in urban areas (Rijkers et al., 2010, p. 1282). Furthermore they point out that productivity levels are more dispersed in the case of rural enterprises, and that female-headed enterprises are less productive than male-headed enterprises. Söderbom and Teal (2004) and Söderbom et al. (2006) find that more productive firms tend to survive longer in Africa. However, this happens only in the cases when these enterprises have already attained a certain firm size. Frazer (2005) confirms this finding, using Ghanaian enterprise-level data, that more productive enterprises are more likely to survive compared to less productive ones.

\subsection{The LSMS-ISA Database}

In the following chapters on non-farm entrepreneurship in rural Sub-Saharan Africa, the LSMS-ISA database is used to study the topic. The database is the result of nationally representative, cross-sectional and longitudinal surveys conducted by the World Bank in collaboration with national statistical offices in various countries in Sub-Saharan Africa. ${ }^{8}$ The surveys cover six countries at the time of writing: Ethiopia, Malawi, Niger, Nigeria, Tanzania and Uganda. Cross-sectional data is currently available for all countries, and panel data for Nigeria, Tanzania and Uganda.

The surveys consist of three parts: a community questionnaire, an agricultural questionnaire and a household questionnaire. The community questionnaire collects community-level information and covers access to public services and infrastructure,

8 Additional information on the LSMS-ISA database: www . worldbank.org/lsms-isa 
social networks, governance and retail prices. The agricultural questionnaire collects information on crop production, storage and sales, land holdings, farming practices, input use and technology adaption, access to and use of services, infrastructure and natural resources, livestock and fishery. Finally, the household questionnaire captures household demographics, migration, education, health and nutrition, food consumption and expenditure, non-food expenditure, employment, non-farm enterprises and further income sources, dwelling conditions, durable assets, and participation in projects and programs. All data is furthermore geo-referenced. ${ }^{9}$

Although the data set is new, unique and facilitates the comparability between countries, a feature that has so far been lacking in the available data, shortcomings remain. For instance, while all six countries include a section covering the subject of non-farm enterprises, the availability of specific questions differs between countries and not all aspects are included in all country questionnaires. Questions that are available in all, or at least the majority of countries, can contain different answer possibilities of survey participants, also reflecting the specific country context. Further shortcomings include a lack of data on discontinued enterprises, preventing a comprehensive analysis of enterprise survival and failure. Enterprises are also not explicitly tracked over the survey rounds in Tanzania and Uganda, and enterprises cannot be followed to study their individual performance over time. More general, but less precise estimations, are still possible.

I suggest that in future waves and countries, where the LSMS-ISA surveys is still planned to be conducted, a number of modifications and additions should be made to the questionnaire. Although a full elaboration of these fall outside the scope of the present thesis, I can briefly mention some to illustrate the type of current shortcomings. First and most important, further standardization between the country questionnaires would be desirable. Second, I suggest to clearly track individual enterprises over the survey rounds, as well as to register and collect information of discontinued enterprises. Third, I recommend to add modules to the questionnaires that collect information to estimate production functions and technical efficiency, including price information, information about the final product(s) and their prices, wages paid per worker, input costs, overhead,

\footnotetext{
9 Additionally, the surveys include weights that reflect the inverse of the probability of selecting a household, and is referred to as survey weights in the remainder of this thesis. The surveys follow a two stage sampling process. In the first stage the clusters or enumeration areas (EA) are selected, given the desired level of stratification of the survey (e.g. rural/urban, district level, agroecological zones). The first stage weights are calculated as the probability of any given EA to be selected out the whole population of EA's within a stratum (the selection is typically done with a probability proportional to the estimated population). In the second stage households are selected within a given cluster (EA), typically based on a simple random selection (SRS) or a related process. The second stage weights are then the ratio of the number of household selected in the EA over the total number of households in the EA. The survey weights are the product of the first and second stage weights.
} 
as well as fixed and working assets employed in the enterprise to know more about the capital intensity.

While this additional and improved data collection is cumbersome to undertake, it may be well worth the effort. More precise analyses on the non-farm economy in rural Africa, and more specifically on entrepreneurship, will help to development tailor-made policies and support programs to help entrepreneurs enter the sector in pursuit of opportunities instead of necessity, and to engage in enterprises that have the potential to grow and to provide the employment urgently needed for the large number of young people entering the labor force over the coming years in these countries.

\subsection{Summary and Concluding Remarks}

This chapter provides a comprehensive overview of the theoretical and empirical literature on non-farm entrepreneurship in rural Africa, as well as a description of the data base used for the empirical analyses in Chapters 3 and 4.

In the theoretical section three models are introduced that help understanding the principles of entrepreneurship under restricted conditions. First, Occupational Choice Models that explain an individual's decision to enter entrepreneurship based on opportunities, skills and preferences. Second, Agricultural Household Models that describe the rural African household as both consumer and producer, where decisions are taken at the household level. And third, Non-Unitary Household Models where the decision-making process is undertaken collectively with different levels of cooperation.

In the empirical literature review, prevalence and importance of non-farm entrepreneurship are first summarized, emphasizing the crucial contribution of selfemployment to rural household income. Next, determinants of enterprise operation are discussed by presenting the two motivations to become entrepreneurial: either due to necessity or in pursuit of opportunities. The subsequent enterprise performance is expected to be influenced by the initial motivation to start an enterprise. I also show that empirical studies using African data continue to be scarce and that only limited knowledge exists on the large amount of small and informal enterprises in the rural areas of Sub-Saharan Africa.

Finally, the LSMS-ISA database that is used for the empirical analyses on non-farm 
entrepreneurship is described. The structure of the survey and the topics covered are presented, as well as advantages and shortcomings of the data set. The section also includes a number of suggestions on how to further improve the survey component on entrepreneurship.

In the next chapter I continue with the empirical analysis, examining the patterns of entrepreneurship in rural Africa, as well as identifying determinants of self-employment and the choice of business activity. 

Chapter 3

\section{Patterns and Determinants}




\subsection{Introduction}

This chapter presents new empirical and comparative evidence on patterns and determinants of non-farm entrepreneurship in rural Sub-Saharan Africa. ${ }^{1}$ A large number of households do not limit their occupational choices to agriculture, but diversify into non-farm entrepreneurship. Why they operate enterprises and how these enterprises fare, remains relatively unexplored. Using the World Bank's recent LSMS-ISA data set, this chapter provides evidence on (i) the prevalence and importance of non-farm entrepreneurship, (ii) the determinants of enterprise operation, and (iii) the types of business activities households operate. It is the first time, to the best of my knowledge, that this unique data set has been used to provide an empirical overview of patterns and determinants of non-farm enterprises in rural Africa.

Summarizing the findings, almost one in two households operates one or more nonfarm enterprises, which are in their large majority small, informal household-centered enterprises. Their contribution to overall household income varies significantly between countries. Furthermore self-employment is more prevalent in urban than in rural areas.

Analyzing the determinants of enterprise operation, I find evidence that the necessity to manage risks and to cope with shocks can push rural households into entrepreneurship. These risks and shocks arise due to climate variations, seasonality in agriculture and surplus family labor. The fact that the overwhelming majority of enterprises are small, informal household enterprises that are often operated intermittently during the year also suggests that push factors are prevalent. Nevertheless, opportunities to access markets equally beckon. The evidence provided in this chapter suggests that educated household heads, wealth and access to credit are associated with a higher likelihood to be entrepreneurial.

Finally, I provide a description of the types of business activities rural enterprises engage in, and the determinants of the choice of business type. I find that the determinants of enterprise operation can also influence the choice of business activity. The results show that the explanatory variables included have different effects for different types of business activity, showing a more nuanced picture of rural entrepreneurship. This analysis takes the diverse business requirements into account that are significant to operate a specific enterprise.

1 This chapter is based on the working paper: Nagler, P. and W. Naudé (2014b). Non-Farm Entrepreneurship in Rural Africa: Patterns and Determinants, IZA Discussion Paper No. 8008. 
The chapter is organized as follows. Section 3.2 contains descriptive statistics on the prevalence of non-farm enterprises, the determinants of enterprise operation and the type of business activity that households operate. Section 3.3 outlines the methods used, and Section 3.4 presents and discusses the empirical results. The probit regressions identify determinants of enterprise operation, and the regressions using a multinomial logit model the determinants of the choice of business activity. The final section concludes with a summary and provides policy recommendations.

\subsection{Descriptive Statistics}

\subsubsection{Importance of Non-Farm Enterprises}

Non-farm entrepreneurship is prevalent among households in rural Sub-Saharan Africa. Data from the LSMS-ISA shows that entrepreneurial activities are ubiquitous in the rural areas of the countries surveyed.

Table 3.1 shows that almost 42 percent of the 24,551 rural households operate a nonfarm enterprise (NFE). Overall, the sample comprises 11,064 enterprises in 8,115 rural households, resulting in an average of 1.36 enterprises per household. The country shares vary widely, from a relatively low share of 17 percent in rural Malawi to almost 62 percent in rural Niger. ${ }^{2}$

Table 3.1: Prevalence of Rural Non-Farm Enterprises

\begin{tabular}{lrrrrr}
\hline Country & $\begin{array}{r}\text { Nr of HH } \\
\text { surveyed }\end{array}$ & $\begin{array}{r}\text { HH with } \\
\text { NFE }\end{array}$ & $\begin{array}{r}\text { in } \% \\
\text { weighted }\end{array}$ & $\begin{array}{r}\text { Nr of } \\
\text { NFEs }\end{array}$ & $\begin{array}{r}\text { Avg Nr of } \\
\text { NFE/HH }\end{array}$ \\
\hline Ethiopia & 3,466 & 919 & 22.87 & 1,112 & 1.21 \\
Malawi & 10,038 & 1,755 & 16.88 & 1,872 & 1.07 \\
Niger & 2,430 & 1,427 & 61.73 & 2,188 & 1.53 \\
Nigeria & 3,380 & 1,707 & 52.62 & 2,688 & 1.57 \\
Tanzania & 2,629 & 1,061 & 38.65 & 1,363 & 1.26 \\
Uganda & 2,105 & 953 & 42.24 & 1,471 & 1.54 \\
\hline Total & 24,551 & 8,115 & 41.63 & 11,064 & 1.36 \\
\hline
\end{tabular}

Note(s): Weighted country shares are calculated using survey weights, the total share includes the population weight. Rural areas only.

With regard to the share of household income deriving from these household enterprises,

2 See Table A.1 in Appendix A for the prevalence of non-farm entrepreneurship in urban areas. 
there are only sufficient responses for Ethiopia in the LSMS-ISA data. 27 percent of households that are engaged in non-farm entrepreneurship derive 50 percent or more of their income from these activities, but only 5 percent of households all income, suggesting that most entrepreneurial activities are performed alongside other activities, most commonly agriculture.

To provide a closer perspective on these percentages the RIGA data set is used to calculate the shares of annual net household income by household activity for five countries in the sample: Malawi 2010/11, Niger 2011, Nigeria 2010, Tanzania 2008/09 and Uganda $2010 / 11 .^{3}$

Figure 3.1 suggests that the importance of self-employment varies widely between African countries. While it contributes less than 9 percent to total household income in rural Malawi, the share is approximately four times as high in rural Niger (almost 36 percent), also reflecting the respective share of the sector within the rural economy. Household income deriving from self-employment is smaller in rural than in urban areas (not included in Figure 3.1). In urban areas self-employment contributes 22 percent to household income in Malawi, 48 percent in Niger, 53 percent in Nigeria, 43 percent in Tanzania and 33 percent in Uganda. It can therefore be concluded that (i) the non-farm enterprise sector is not equally important across African countries and that (ii) the contribution of these enterprises to total household income is proportionately lower in rural than in urban areas. These findings also caution against equating the percentage contribution of the sector to total household income as an indicator of its impact on growth and development. In this regard the quality of self-employment may be more essential.

The vast majority of non-farm enterprises in the LSMS-ISA are small household enterprises that operate in the informal economy. Over 80 percent do not employ any non-household workers, and less than 3 percent employ five or more workers. Overall, the rural non-farm enterprise sector is less important in the LSMS-ISA data compared to the extant literature. As a consequence, I propose a more cautious interpretation of the importance of this sector as a contributor to employment creation and rural development at this stage.

${ }^{3}$ Household income is calculated closely following the definition by the International Labour Organization (ILO), where household income consists of all receipts whether monetary or in kind that are received by the household or individual household members at annual or more frequent intervals. It excludes windfall gains and other irregular or one-time receipts. The household income calculated in the RIGA data is based on different sources of income: wage, non-wage, dependent and self-employment, that a household can earn over a well-defined reference period. See also Carletto et al. (2007). 
Figure 3.1: Contribution of Activity to Total Household Income

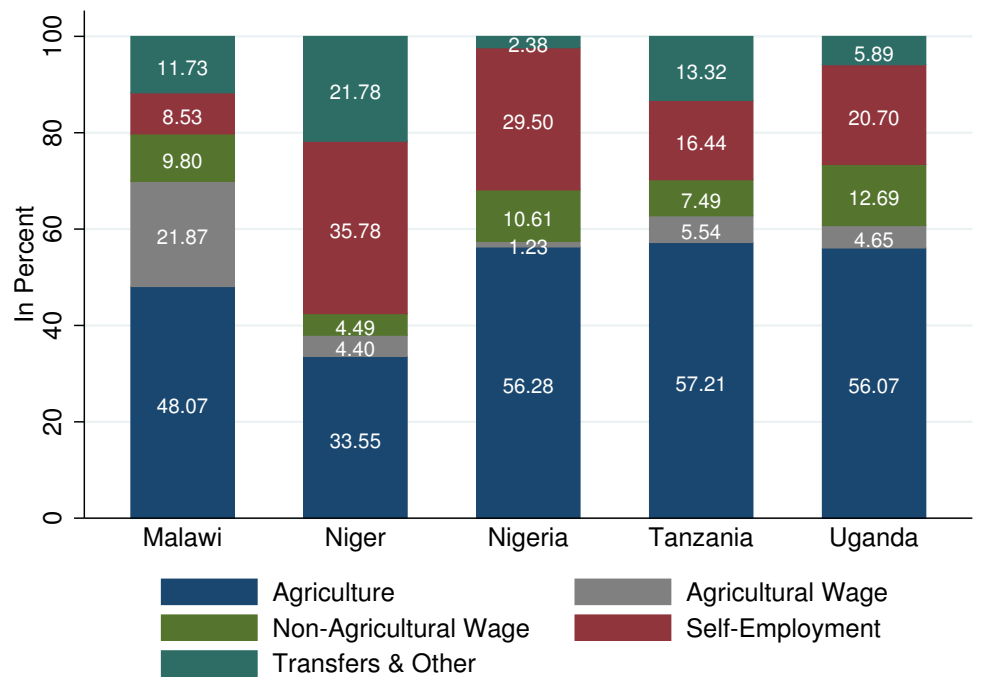

Note(s): Weighted shares. Rural areas only.

\subsubsection{Determinants of Enterprise Operation}

To better understand why households operate non-farm enterprises, this section examines variables that are potential determinants of entrepreneurship and provides a set of descriptive statistics of business characteristics.

Between 91 and almost 100 percent of all enterprises in the sample operate informally. Informal is therefore indeed "normal", as has been argued in the literature (Jütting and de Laiglesia, 2009). In Ethiopia, the country with the highest rate of formality, 8.95 percent of rural enterprises have a formal license to operate, while in Niger only 0.39 percent are registered with the government. ${ }^{4}$ This finding is consistent with the existing literature such as Davis et al. (2010) who show, using the RIGA data set, that most nonfarm entrepreneurial activities consist of small and informal businesses and Haggblade et al. (1989) who find that 95 percent of rural enterprises employ five or less workers using a cross-country sample.

\footnotetext{
4 The definition of informal enterprises differs slightly between the various countries of the LSMS-ISA. In Ethiopia formal firms are those with a license to operate, in Malawi enterprises registered with the Malawi Revenue Authority, in Niger enterprises with a fiscal identification number, in Nigeria whether the enterprise is registered with the government and in Uganda whether the enterprise is registered for income tax and/or VAT. In Tanzania no question is included that records the formality of enterprises.
} 
Almost half of the non-farm businesses in the LSMS-ISA data are operated from the household's residence or in the immediate surroundings. Rural enterprise activity is thus primarily household-based. Most other activities are either located in a traditional market place or performed mobile. Less than 5 percent of rural non-farm enterprise activities are located in a commercial district or shop premises.

Most households indicate that their enterprises are providing consumer goods or services, or are engaged in trading. Only 20 to 30 percent of households report that their enterprises are engaged in the processing of agricultural products. This is a surprising finding and raises the question why agribusiness is not more prevalent among enterprises in rural Africa. This question is reinforced when considering the responses of these enterprises as to the nature of their business clients. They specify that local final consumers are the most important customers, accounting for 77 percent of sales. Most of the remainder of their sales goes to other small local businesses and traders. Rural enterprises sell very limited amounts to governments, NGOs or manufacturing firms, the main actors in rural development support programs.

Although limited prior research exists on the subject, it can be assumed that rural enterprises are affected by seasonality, reflected by the number of months per year an enterprise is in operation. Seasonal variations in agriculture can be a factor for households to operate an enterprise during the off-season, or the high season to make use of peaks in demand. However, seasonal factors may also lead households to close their enterprises temporarily, for instance when household members are required to work in agriculture.

The LSMS-ISA also capture the number of months per year a rural enterprise was operating in the year preceding the survey. Figure 3.2 shows that a significant proportion of these enterprises was operating less than 6 or 12 months per year. Only between 42 and 64 percent of all enterprises operate continuously throughout the whole year, with the highest percentage found in Nigeria.

The same shares are also calculated for enterprises operating in urban areas. ${ }^{5}$ As expected, proportionately more urban enterprises operate continuously throughout the year compared to rural enterprises. This suggests that seasonality has a potentially important impact on the dynamics of entrepreneurship in rural Africa, and might push households into non-farm activities during the off-season or during a poor harvest to assist in consumption smoothing over the year.

5 See Table A.2 in Appendix A. 
Figure 3.2: Months in Operation

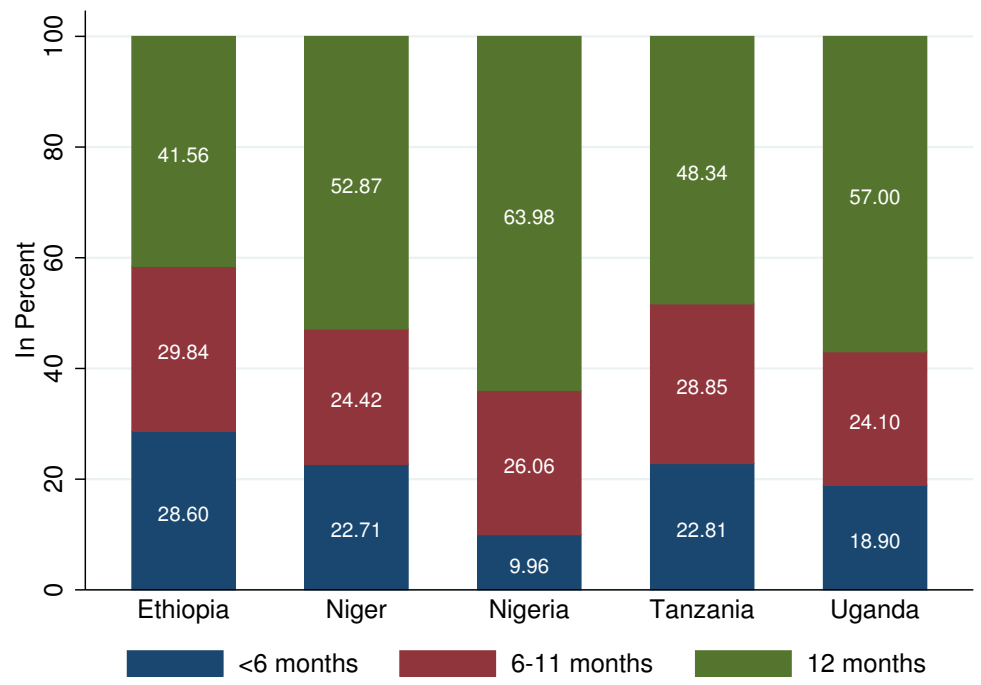

Note(s): Malawi not reported due to a lack of data. Enterprises that are less than one year in operation are excluded. Rural areas only.

\subsubsection{Type of Business Activity}

The following eight types of business activities are captured in the surveys: agricultural business, non-agricultural business, trade, sales, professional services, transportation, bars and restaurants and others. ${ }^{6}$ Table 3.2 summarizes the number of enterprises (absolute number and in percent weighted) for the various types of business activities for rural Ethiopia and Malawi. Note that in the sectors professional services, transport and bar and restaurants there are only a few observations compared to the other sectors. Most enterprises resorted into non-agricultural business, agribusiness, trade and sales.

6 In the LSMS-ISA surveys the different types of business activities are described as follows. The category 'non-agricultural business' comprises a broad variety of business activities, such as car wash owner, metal worker, mechanic, carpenter, tailor, barber (among others). 'Agribusiness' is defined as processing or selling any agricultural by-products, for example flour, local beer, seeds (among others), but excluding livestock by-products and fresh or processed fish. A 'trading business' can be located on a street or a market. Offering any services or selling anything on a street or a market is defined as a 'sales business', for example firewood, mats, weave baskets (among others). The category 'professional services' comprises jobs such as lawyer, doctor, translator, tutor, midwife (among others). 'Transport businesses' comprise transportation or moving services with a home-own taxi or pick-up truck. 'Bars or restaurants' are food and beverage service businesses, while the final category 'other' is not further defined. 
Table 3.2: Type of Business Activity

\begin{tabular}{lcccc}
\hline Type of Business & \multicolumn{2}{c}{ Ethiopia } & \multicolumn{2}{c}{ Malawi } \\
Activity & N & In $\%$ & N & In $\%$ \\
\hline Non-Agric. Business & 202 & 25.69 & 385 & 18.06 \\
Agribusiness & 224 & 26.31 & 406 & 20.09 \\
Trade & 157 & 22.32 & 378 & 19.11 \\
Sales & 144 & 9.17 & 370 & 16.53 \\
Professional Services & 12 & 1.12 & 10 & 0.53 \\
Transport & 12 & 1.23 & 46 & 2.56 \\
Bars and Restaurants & 10 & 0.48 & 39 & 2.40 \\
Other & 142 & 13.69 & 407 & 20.72 \\
\hline Total & 903 & 100.00 & 2,041 & 100.00 \\
\hline
\end{tabular}

Note(s): Survey weights included. Rural areas only.

\subsection{Methodology}

In this section the methodology used for the analysis is presented. To identify determinants of enterprise operation I use a probit model, and to study the choice of business activity I use a multinomial logit model (MNLM).

\section{Probit Model}

I estimate a set of probit regressions to identify individual, household, shock and location characteristics that are potentially associated with a household's decision to operate an enterprise. Based on the literature review I include factors related to both necessity and opportunity motivations.

More formally I estimate,

$\operatorname{Pr}\left(Y_{i} \mid \mathbf{v}_{i}, \mathbf{w}_{i}, \mathbf{x}_{i}, \mathbf{z}_{i}\right)=\Phi\left(\mathbf{v}_{i}^{\prime} \boldsymbol{\alpha}+\mathbf{w}_{i}^{\prime} \boldsymbol{\beta}+\mathbf{x}_{i}^{\prime} \boldsymbol{\gamma}+\mathbf{z}_{i}^{\prime} \boldsymbol{\delta}\right)$

where the dependent variable is a binary variable equal to one if a household operates a non-farm enterprise, and zero if not. $\mathbf{v}^{\prime}{ }_{i}$ represents a vector of individual characteristics including a constant, and comprises the variables gender, age, education (ability to read \& write) and marital status of the household head.

$\mathbf{w}_{i}^{\prime}$ represents a vector of household characteristics, given the importance of 
entrepreneurial decision-making on the household level, including the number of adult household members (age 15 and older), the number of rooms in the dwelling, annual net household income (in 1,000's of USD), and a binary variable if a household member has taken out credit over the past 12 months, indicating the possibility of accessing financial support.

$\mathbf{x}_{i}^{\prime}$ represents a vector of shock variables, including a set of binary variables if the household has experienced an idiosyncratic shock, price shock, geographic shock or other shock over the last 12 months, and if the household has experienced food shortage over the past 12 months. Finally, $\mathbf{z}_{i}^{\prime}$ represents a set of location variables, also named geo variables, including the household's distance to the next population center (in 100's km) and annual precipitation (in 1,000's $\mathrm{mm}$ ). These variables are based on the literature review. ${ }^{7}$

\section{Multinomial Logit Model}

In the MNLM the dependent variable continues to account for households with and without enterprises, but is extended by different types of businesses for the households operating an enterprise. Hence the dependent variable is no longer a binary variable, but a variable with different categories, corresponding to the types of business activity reported in the surveys. The MNLM can be seen as estimating, simultaneously, binary logit regressions for all the categories or alternatives of the dependent categorical variable.

More formally I estimate,

$\ln \Omega_{m \mid b}(x)=\ln \frac{\operatorname{Pr}(y=m \mid x)}{\operatorname{Pr}(y=b \mid x)}=x \beta_{m \mid b} \quad$ for $\quad m=1$ to $J$

where $b$ is the base category and also referred to as the comparison group. The log odds of an outcome compared with itself are always 0 , as $\ln \Omega_{m \mid b}(x)=\ln (1)=0$. And $x \beta_{m \mid b}$ is a vector containing the independent variables (determinants) of interest.

The $J$ equations are solved as follows to compute the predicted probabilities,

$$
\operatorname{Pr}(y=m \mid x)=\frac{\exp \left(x \beta_{m \mid b}\right)}{\sum_{j=1}^{J} \exp \left(x \beta_{j \mid b}\right)}
$$

\footnotetext{
7 Summary statistics and definition of variables can be found in the Tables A.3 and A.4 of Appendix A.
} 
The predicted probabilities will be the same regardless of the base outcome. While the estimated parameters are different, only the parameterizations are different (Long and Freese, 2006).

I take the households that do not operate a non-farm enterprise as the base category, and study a set of individual, household, shock and location characteristics to analyze which variables are significant for the choice of business activity. I take similar variables as before, namely individual characteristics (gender, age, the ability to read \& write), household characteristics (number of adults, access to credit), shock variables and location characteristics (distance to the nearest population center). I can conduct the analysis only for Ethiopia and Malawi due to data availability.

\subsection{Results}

The results section is organized in two parts, where I first estimate probit regressions to identify determinants of enterprise operation, and second multinominal logit models that account for the type of business activity.

\subsubsection{Probit Model}

I start the probit analysis by estimating a set of regressions using the aggregated sample. I include dummies for the different countries, with Ethiopia as the reference category. Second, I estimate separate probit regressions for the six countries of the sample to identify country-level heterogeneity.

Table 3.3 contains the coefficients and average marginal effects of the aggregated data. The first and second column reports the results for all households, the third and fourth column for rural households, and the fifth and sixth column for urban households. Rural households in Africa are on average 17 percentage points less likely to operate a nonfarm enterprise compared to urban households. Cities are more likely places to find enterprises in Africa, as they are across the world. There is also significant country-level heterogeneity. For instance, the probability that a household operates an enterprise is 9 percentage points lower in Malawi than in Ethiopia, but over 30 percentage points higher in Niger or Nigeria. 
Table 3.3: Probit Regressions - Complete Sample

\begin{tabular}{|c|c|c|c|c|c|c|}
\hline $\begin{array}{l}\text { Dependent } \\
\text { NFE }\end{array}$ & $\begin{array}{c}(1) \\
\text { All Countries }\end{array}$ & $\begin{array}{c}(2) \\
\text { AME }\end{array}$ & $\begin{array}{c}(3) \\
\text { Rural }\end{array}$ & $\begin{array}{c}(4) \\
\text { AME }\end{array}$ & $\begin{array}{c}(5) \\
\text { Urban }\end{array}$ & $\begin{array}{c}(6) \\
\mathrm{AME}\end{array}$ \\
\hline Rural & $\begin{array}{c}-0.484^{* * *} \\
(0.05)\end{array}$ & $\begin{array}{c}-0.165^{* * *} \\
(0.02)\end{array}$ & & & & \\
\hline Female & $\begin{array}{l}0.035 \\
(0.05)\end{array}$ & $\begin{array}{l}0.012 \\
(0.02)\end{array}$ & $\begin{array}{l}-0.007 \\
(0.06)\end{array}$ & $\begin{array}{c}-0.002 \\
(0.02)\end{array}$ & $\begin{array}{l}0.128 \\
(0.10)\end{array}$ & $\begin{array}{l}0.045 \\
(0.04)\end{array}$ \\
\hline Age & $\begin{array}{l}0.007 \\
(0.01)\end{array}$ & $\begin{array}{c}-0.003^{* * *} \\
(0.00)\end{array}$ & $\begin{array}{l}0.008 \\
(0.01)\end{array}$ & $\begin{array}{c}-0.003^{* * *} \\
(0.00)\end{array}$ & $\begin{array}{l}0.004 \\
(0.01)\end{array}$ & $\begin{array}{c}-0.002^{* *} \\
(0.00)\end{array}$ \\
\hline $\mathrm{Age}^{2}$ & $\begin{array}{c}-0.000^{* * *} \\
(0.00)\end{array}$ & & $\begin{array}{c}-0.000^{* * *} \\
(0.00)\end{array}$ & & $\begin{array}{l}-0.000 \\
(0.00)\end{array}$ & \\
\hline Married & $\begin{array}{l}0.068 \\
(0.05)\end{array}$ & $\begin{array}{l}0.023 \\
(0.02)\end{array}$ & $\begin{array}{l}-0.028 \\
(0.05)\end{array}$ & $\begin{array}{c}-0.009 \\
(0.02)\end{array}$ & $\begin{array}{c}0.347^{* * *} \\
(0.10)\end{array}$ & $\begin{array}{c}0.126^{* * *} \\
(0.04)\end{array}$ \\
\hline Read \& Write & $\begin{array}{c}0.116^{* * *} \\
(0.04)\end{array}$ & $\begin{array}{c}0.040^{* * * *} \\
(0.01)\end{array}$ & $\begin{array}{c}0.145^{* * * *} \\
(0.04)\end{array}$ & $\begin{array}{c}0.049^{* * *} \\
(0.01)\end{array}$ & $\begin{array}{r}-0.098 \\
(0.10)\end{array}$ & $\begin{array}{c}-0.034 \\
(0.03)\end{array}$ \\
\hline Number of Adults & $\begin{array}{c}0.100^{* * * *} \\
(0.02)\end{array}$ & $\begin{array}{c}0.024^{* * * *} \\
(0.00)\end{array}$ & $\begin{array}{c}0.089^{* * * *} \\
(0.02)\end{array}$ & $\begin{array}{c}0.022^{* * * *} \\
(0.01)\end{array}$ & $\begin{array}{c}0.144^{* * * *} \\
(0.05)\end{array}$ & $\begin{array}{c}0.034^{* * * *} \\
(0.01)\end{array}$ \\
\hline $\begin{array}{l}\text { Number of } \\
\text { Adults }^{2}\end{array}$ & $\begin{array}{c}-0.005^{* * *} \\
(0.00)\end{array}$ & & $\begin{array}{c}-0.004^{* *} \\
(0.00)\end{array}$ & & $\begin{array}{c}-0.008^{* *} \\
(0.00)\end{array}$ & \\
\hline Rooms & $\begin{array}{c}0.046^{* * *} \\
(0.01)\end{array}$ & $\begin{array}{c}0.016^{* * *} \\
(0.00)\end{array}$ & $\begin{array}{c}0.052^{* * * *} \\
(0.01)\end{array}$ & $\begin{array}{c}0.018^{* * *} \\
(0.00)\end{array}$ & $\begin{array}{l}0.018 \\
(0.02)\end{array}$ & $\begin{array}{l}0.006 \\
(0.01)\end{array}$ \\
\hline Credit & $\begin{array}{c}0.235^{* * *} \\
(0.05)\end{array}$ & $\begin{array}{c}0.081^{* * * *} \\
(0.02)\end{array}$ & $\begin{array}{c}0.241^{* * *} \\
(0.05)\end{array}$ & $\begin{array}{c}0.083^{* * *} \\
(0.02)\end{array}$ & $\begin{array}{c}0.221^{* *} \\
(0.11)\end{array}$ & $\begin{array}{c}0.075^{* *} \\
(0.04)\end{array}$ \\
\hline Food Shortage & $\begin{array}{c}0.077^{* *} \\
(0.04)\end{array}$ & $\begin{array}{c}0.026^{* *} \\
(0.01)\end{array}$ & $\begin{array}{l}0.053 \\
(0.04)\end{array}$ & $\begin{array}{l}0.018 \\
(0.01)\end{array}$ & $\begin{array}{l}0.123 \\
(0.09)\end{array}$ & $\begin{array}{l}0.043 \\
(0.03)\end{array}$ \\
\hline Shock (idiosyn.) & $\begin{array}{l}0.066^{*} \\
(0.03)\end{array}$ & $\begin{array}{l}0.023^{*} \\
(0.01)\end{array}$ & $\begin{array}{l}0.085^{* *} \\
(0.04)\end{array}$ & $\begin{array}{c}0.029^{* *} \\
(0.01)\end{array}$ & $\begin{array}{l}-0.019 \\
(0.07)\end{array}$ & $\begin{array}{l}-0.007 \\
(0.02)\end{array}$ \\
\hline Shock (price) & $\begin{array}{l}0.041 \\
(0.05)\end{array}$ & $\begin{array}{l}0.014 \\
(0.02)\end{array}$ & $\begin{array}{l}0.031 \\
(0.05)\end{array}$ & $\begin{array}{l}0.011 \\
(0.02)\end{array}$ & $\begin{array}{l}0.060 \\
(0.10)\end{array}$ & $\begin{array}{l}0.021 \\
(0.03)\end{array}$ \\
\hline Shock (geogr.) & $\begin{array}{l}-0.042 \\
(0.04)\end{array}$ & $\begin{array}{l}-0.014 \\
(0.01)\end{array}$ & $\begin{array}{l}-0.031 \\
(0.05)\end{array}$ & $\begin{array}{l}-0.010 \\
(0.02)\end{array}$ & $\begin{array}{l}-0.110 \\
(0.11)\end{array}$ & $\begin{array}{l}-0.039 \\
(0.04)\end{array}$ \\
\hline Shock (other) & $\begin{array}{c}0.226^{* *} \\
(0.09)\end{array}$ & $\begin{array}{c}0.079^{* *} \\
(0.03)\end{array}$ & $\begin{array}{c}0.306^{* * *} \\
(0.09)\end{array}$ & $\begin{array}{c}0.107^{* * *} \\
(0.03)\end{array}$ & $\begin{array}{l}-0.004 \\
(0.21)\end{array}$ & $\begin{array}{c}-0.002 \\
(0.07)\end{array}$ \\
\hline Distance & $\begin{array}{c}-0.018 \\
(0.16)\end{array}$ & $\begin{array}{c}-0.012 \\
(0.04)\end{array}$ & $\begin{array}{r}-0.112 \\
(0.18)\end{array}$ & $\begin{array}{l}-0.036 \\
(0.04)\end{array}$ & $\begin{array}{l}-0.031 \\
(0.45)\end{array}$ & $\begin{array}{l}0.002 \\
(0.13)\end{array}$ \\
\hline Distance $^{2}$ & $\begin{array}{l}-0.027 \\
(0.09)\end{array}$ & & $\begin{array}{l}0.006 \\
(0.10)\end{array}$ & & $\begin{array}{l}0.135 \\
(0.35)\end{array}$ & \\
\hline Precipitation & $\begin{array}{l}-0.056 \\
(0.05)\end{array}$ & $\begin{array}{c}-0.019 \\
(0.02)\end{array}$ & $\begin{array}{l}-0.059 \\
(0.06)\end{array}$ & $\begin{array}{c}-0.020 \\
(0.02)\end{array}$ & $\begin{array}{l}-0.065 \\
(0.13)\end{array}$ & $\begin{array}{c}-0.023 \\
(0.05)\end{array}$ \\
\hline Malawi & $\begin{array}{c}-0.252^{* * *} \\
(0.06)\end{array}$ & $\begin{array}{c}-0.086^{* * *} \\
(0.02)\end{array}$ & $\begin{array}{c}-0.258^{* * *} \\
(0.06)\end{array}$ & $\begin{array}{c}-0.087^{* * *} \\
(0.02)\end{array}$ & $\begin{array}{c}-0.600^{* * *} \\
(0.12)\end{array}$ & $\begin{array}{c}-0.212^{* * *} \\
(0.04)\end{array}$ \\
\hline Niger & $\begin{array}{c}0.945^{* * *} \\
(0.09)\end{array}$ & $\begin{array}{c}0.323^{* * *} \\
(0.03)\end{array}$ & $\begin{array}{c}1.025^{* * *} \\
(0.10)\end{array}$ & $\begin{array}{c}0.345^{* * *} \\
(0.03)\end{array}$ & $\begin{array}{l}0.201 \\
(0.18)\end{array}$ & $\begin{array}{l}0.071 \\
(0.06)\end{array}$ \\
\hline Nigeria & $\begin{array}{c}0.907^{* * *} \\
(0.08)\end{array}$ & $\begin{array}{c}0.310^{* * * *} \\
(0.02)\end{array}$ & $\begin{array}{c}0.904^{* * *} \\
(0.08)\end{array}$ & $\begin{array}{c}0.304^{* * *} \\
(0.03)\end{array}$ & $\begin{array}{c}0.505^{* * *} \\
(0.17)\end{array}$ & $\begin{array}{c}0.179^{* * *} \\
(0.06)\end{array}$ \\
\hline Tanzania & $\begin{array}{c}0.457^{* * * *} \\
(0.06)\end{array}$ & $\begin{array}{c}0.156^{* * * *} \\
(0.02)\end{array}$ & $\begin{array}{c}0.419^{* * * *} \\
(0.07)\end{array}$ & $\begin{array}{c}0.141^{* * *} \\
(0.02)\end{array}$ & $\begin{array}{l}0.192 \\
(0.12)\end{array}$ & $\begin{array}{l}0.068 \\
(0.04)\end{array}$ \\
\hline Uganda & $\begin{array}{c}0.553^{* * *} \\
(0.07)\end{array}$ & $\begin{array}{c}0.189^{* * * *} \\
(0.02)\end{array}$ & $\begin{array}{c}0.542^{* * *} \\
(0.07)\end{array}$ & $\begin{array}{c}0.182^{* * *} \\
(0.02)\end{array}$ & $\begin{array}{l}0.154 \\
(0.15)\end{array}$ & $\begin{array}{l}0.054 \\
(0.05)\end{array}$ \\
\hline Constant & $\begin{array}{c}-0.677^{* * *} \\
(0.17) \\
\end{array}$ & & $\begin{array}{c}-1.049^{* * *} \\
(0.19)\end{array}$ & & $\begin{array}{l}-0.297 \\
(0.34) \\
\end{array}$ & \\
\hline $\mathrm{N}$ & 27,659 & 27,659 & 21,255 & 21,255 & 6,404 & 6,404 \\
\hline
\end{tabular}

Note $(s)$ : Standard errors in parentheses. ${ }^{*} p<0.1,{ }^{* *} p<0.05,{ }^{* * *} p<0.01$. 
There are also notable differences in the determinants between rural and urban households. For instance, the proxy for educational attainment, the ability to read and write, is significant and positive only for rural households. This result could be interpreted that more educated individuals do not easily find wage employment in the rural non-farm economy, and therefore resort into self-employment as an alternative to agriculture. Significant differences in individual and household level characteristics are also found in the variables age, marital status, educational attainment of the head and the number of adults in a household.

The results also show that shocks and risks can significantly determine the decision of a household to operate a non-farm enterprise in some situations. For instance, households that have experienced food shortage are 3 percentage points more likely to operate an enterprise. The effects of the variables idiosyncratic shock and other shocks are significant for the complete sample, as well as for the rural sample. For rural households they are positively associated with operating an enterprise, consistent with the view that enterprise operation can provide a coping mechanism for households in the absence of social security, and imperfections in insurance and credit markets. However, price and geographic shocks are not significant for any of the samples.

Table 3.4 contains the results (average marginal effects) for rural households by country. In the regressions the same set of variables as in the aggregate sample is included, and annual net household income added to the estimations for the countries where this variable is available.

The results show that the gender of the household head does not have a significant effect on enterprise operation in any of the countries. Age is significant and suggests that households with younger heads are more likely to operate an enterprise in most countries studied. Literate household heads are more likely to operate an enterprise where this variable is significant, suggesting that education can be an important characteristic for enterprise operation. The variable marital status, indicating if the household head is married, has a significant effect in Malawi, where it is associated with a 4 percentage points higher probability of enterprise operation. Interestingly it has the opposite effect in Tanzania where marriage is associated with a 6 percentage points lower probability of enterprise operation. As in the aggregate sample, the effect of number of adults is significant and positive in three countries (Nigeria, Tanzania and Uganda), consistent with the literature that households with more adults can allocate surplus labor into enterprise operation. In this case enterprise operation can be both necessity and opportunity motivated. Necessity motivated if households are pushed into entrepreneurship due to 
surplus labor (e.g. due to a lack of arable land), and opportunity motivated if more adult household members enable households to access opportunities.

One of the most salient determinants of entrepreneurship in the literature is the availability and access to finance. Most studies on entrepreneurship determinants concur that entrepreneurs often face liquidity constraints (Evans and Jovanovic, 1989; Hurst and Lusardi, 2004). In this respect the results confirm that liquidity constraints can be significant. In the regression table a number of liquidity measures are tested. Annual net household income is associated with a higher likelihood of enterprise operation in Niger, Tanzania and Uganda, for example by 15 percentage points per 1,000 USD of additional income per year in rural Niger. Measuring liquidity access through household wealth proxies (such as the number of rooms in a household dwelling) also confirms a significant and positive association in Ethiopia, Malawi and Tanzania. A more direct measure from the survey, access to credit, is also significant and positive for the aggregate sample, as well as in Ethiopia and Malawi on the country-level. Although these findings are consistent with the extant literature on the importance of finance for entrepreneurship, it is not possible to assign a causal relationship using the cross-sectional data set, since the various proxies for liquidity are endogenous and only suggest a correlation.

The results of both probit regression tables are broadly similar with regard to the impact of shocks. In the country-level analysis again most shock variables are not significant, with some interesting exceptions. Households that experience a food shortage over the past 12 months are more likely to operate an enterprise in rural Uganda, but are interestingly less likely to do so in rural Malawi and Niger. Being subject to idiosyncratic shocks (such as death or illness within the household) is positively associated with operating an enterprise in Malawi. A price shock has a significant and negative association with the likelihood of enterprise operation in rural Uganda, geographical shocks a significant and positive association in Malawi, and other shocks a significant and positive association in Niger. The conclusion from this diversity is that external risks have different and even opposing effects depending on the country, reflecting that risk-coping and riskmanagement strategies adjust to local circumstances. However, the results also show that shocks are generally not a good predictor for enterprise operation, even though some shock types are significant and suggest that households do respond to external circumstances and risk.

Finally, I take the local business environment, agglomeration and rainfall as proxies for market access and demand into consideration (Zezza et al., 2011). The results provide significant evidence that opportunity motives are applicable and pull households into 
Table 3.4: Probit Regressions - Average Marginal Effects

\begin{tabular}{lcccccc}
\hline Dependent & $(1)$ & $(2)$ & $(3)$ & $(4)$ & $(5)$ & $(6)$ \\
NFE & Ethiopia & Malawi & Niger & Nigeria & Tanzania & Uganda \\
\cline { 2 - 7 } Female & -0.029 & 0.005 & -0.051 & 0.045 & 0.037 & 0.001 \\
& $(0.04)$ & $(0.02)$ & $(0.06)$ & $(0.10)$ & $(0.03)$ & $(0.04)$ \\
Age & $-0.002^{* * *}$ & $-0.001^{* *}$ & 0.001 & $-0.003^{* *}$ & $-0.004^{* * *}$ & $-0.004^{* * *}$ \\
& $(0.00)$ & $(0.00)$ & $(0.00)$ & $(0.00)$ & $(0.00)$ & $(0.00)$ \\
Married & -0.041 & $0.039^{* * *}$ & -0.036 & 0.083 & $-0.061^{* *}$ & 0.047 \\
& $(0.04)$ & $(0.01)$ & $(0.06)$ & $(0.08)$ & $(0.03)$ & $(0.04)$ \\
Read \& Write & 0.031 & $0.040^{* * *}$ & 0.030 & $0.126^{* * *}$ & $0.054^{*}$ & -0.010 \\
& $(0.02)$ & $(0.01)$ & $(0.04)$ & $(0.04)$ & $(0.03)$ & $(0.03)$ \\
Number of Adults & -0.011 & 0.008 & -0.021 & $0.055^{* * *}$ & $0.032^{* * *}$ & $0.028^{* * *}$ \\
& $(0.01)$ & $(0.01)$ & $(0.01)$ & $(0.01)$ & $(0.01)$ & $(0.01)$ \\
Income in USD & & & $0.151^{* * *}$ & $-0.017^{* *}$ & $0.039^{* * *}$ & $0.101^{* * *}$ \\
& & & $(0.02)$ & $(0.01)$ & $(0.01)$ & $(0.02)$ \\
Rooms & $0.033^{* * *}$ & $0.009^{* *}$ & 0.007 & & $0.023^{* * *}$ & -0.002 \\
& $(0.01)$ & $(0.00)$ & $(0.01)$ & & $(0.01)$ & $(0.01)$ \\
Credit & $0.088^{* * *}$ & $0.071^{* * *}$ & & & 0.021 & \\
Food Shortage & $(0.02)$ & $(0.01)$ & & & $(0.04)$ & \\
& 0.039 & $-0.028^{* * *}$ & $-0.077^{* * *}$ & 0.032 & -0.005 & $0.078^{* *}$ \\
Shock (idiosyn.) & $(0.03)$ & $(0.01)$ & $(0.02)$ & $(0.04)$ & $(0.03)$ & $(0.04)$ \\
Shock (price) & 0.033 & $0.062^{* * *}$ & 0.003 & -0.035 & 0.048 & 0.044 \\
& $(0.02)$ & $(0.01)$ & $(0.04)$ & $(0.04)$ & $(0.03)$ & $(0.03)$ \\
Shock (geogr.) & 0.013 & 0.002 & 0.023 & 0.022 & -0.044 & $-0.187^{* * *}$ \\
& $(0.03)$ & $(0.01)$ & $(0.03)$ & $(0.04)$ & $(0.03)$ & $(0.07)$ \\
Shock (other) & -0.023 & $0.021^{* *}$ & -0.016 & -0.070 & 0.003 & 0.049 \\
& $(0.03)$ & $(0.01)$ & $(0.03)$ & $(0.04)$ & $(0.03)$ & $(0.03)$ \\
Distance & $0.126^{*}$ & 0.019 & $0.097^{* * *}$ & 0.028 & -0.020 & 0.058 \\
& $(0.08)$ & $(0.04)$ & $(0.03)$ & $(0.10)$ & $(0.15)$ & $(0.08)$ \\
Precipitation & -0.034 & $-0.107^{* * *}$ & -0.074 & -0.164 & -0.019 & $-0.214^{*}$ \\
& $(0.07)$ & $(0.03)$ & $(0.07)$ & $(0.13)$ & $(0.04)$ & $(0.12)$ \\
N & 0.024 & $-0.035^{*}$ & $0.612^{* *}$ & $-0.064^{*}$ & -0.011 & 0.039 \\
& $(0.04)$ & $(0.02)$ & $(0.29)$ & $(0.03)$ & $(0.03)$ & $(0.08)$ \\
\hline
\end{tabular}

Note(s): Standard errors in parentheses. Rural areas only. ${ }^{*} p<0.1,{ }^{* *} p<0.05,{ }^{* * *} p<0.01$.

entrepreneurship. The regression results indicate that the effect of the household's distance to the next population center is significant and negative in rural Malawi and Uganda. In Malawi it decreases the likelihood of enterprise operation by 11 percentage points and in Uganda by 21 percentage points per $100 \mathrm{~km}$ of distance from a population center.

These results confirm that agglomeration and infrastructure proxies, measuring potential market access, are significant determinants of enterprise formation in some parts of rural Africa. Rainfall, a proxy for agricultural productivity and hence demand from farming, is significant and negative in Malawi and Nigeria. This means that higher rainfall and the resulting improved agricultural conditions decrease the likelihood of enterprise operation in these two countries, possibly as more household members are required to allocate 
their labor to farming. Another explanation might be that local wage rates increase during bountiful seasons. Interestingly, increased rainfall is associated with an increased likelihood of enterprise operation in rural Niger, reflecting perhaps different farming practices.

I also consider whether land holdings matter for a household's decision to enter the nonfarm sector. ${ }^{8}$ I create the variable land size (in acres) per adult household member, and find that it not significant in four out of six countries for rural areas. The variable is significant and negative in Ethiopia, where it decreases the likelihood of enterprise operation by 3 percentage points per additional acre of land per adult household member, and significant and positive in Uganda where it increases the likelihood of enterprise operation by 1 percent point, again per additional acre of land per adult household member. The significance of land holdings is therefore surprisingly low, when considering the importance of agriculture for rural areas. I also find that the variables land use and farm type are not significant determinants in any of the countries where these variables are available. Furthermore, I find that a community irrigation system is only a significant determinant in rural Niger, where it is associated with a 17 percentage points lower probability of enterprise operation, suggesting that rural enterprises can indeed be responses to risk in agriculture.

As a last step of the probit analysis, I run a set of additional regressions including a number of country-specific variables that are not available for the majority of the countries, or are differently coded per country. While I do not report the detailed tables here, these results are consistent with the picture that has emerged so far. An interesting additional finding is, for example, the effect of the number of phones a household owns, representing another wealth proxy. I find that households are 3 percentage point more likely to operate an enterprise per additional phone in rural Ethiopia, and 7 percentage points more likely in rural Tanzania. I also test the effect of the variable nomad (indicating a nomadic lifestyle) for Niger, a country different from the others in terms of climate and the prevalence of nomadic households. This variable decreases the probability of enterprise operation by a large and significant 42 percentage points compared to nonnomadic households. This finding again underscores the importance of country-level heterogeneity in the determinants of entrepreneurship.

\footnotetext{
8 The variable 'land' registers if households have land, and can be both owned or rented. In this variable is it also not further considered if the land is used for farming or for other purposes.
} 


\subsubsection{Multinomial Logit Model}

Once households decide to enter the non-farm sector, they have to decide which type of business activity they engage in, an aspect that has so far been neglected in the literature. The decision itself may depend on the motivation for operating an enterprise in the first place. This section addresses the research gap by estimating a MNLM using the rural sample.

The Tables 3.5 and 3.6 contain the regression results for rural Ethiopia and Malawi, respectively. I report the relative risk ratios in both tables. The results are consistent with the results of the probit regressions, but provide additional and more nuanced information with regard to the type of business activities the households operate. ${ }^{9}$

The results indicate that a household's motivation to operate an enterprise also influences the type of business activity it chooses. For instance, individual level determinants such as age and education, household level characteristics such as number of adults in a family, as well as credit, shock and location variables are again significant, but to different degrees and with sometimes opposing effects.

Using data of rural Ethiopia the results show that gender is significant for two types of business activities. While I do not find gender to be significant in the probit regressions, it is interesting to note that female household heads have a lower likelihood of operating non-agricultural or sales businesses when entering entrepreneurship. Hence, women may not be constrained as such from operating an enterprise, but may find the choice of business activity to be constrained. The effect of age is significant and smaller than 1 for all types of business activities, confirming the results of the probit regression, and implying that household heads from households operating an enterprise are on average younger compared to heads from households without a business. Educational attainment is significant only for agribusiness and sales, where household heads without education have a lower likelihood of entering these activities, compared to not engaging into entrepreneurship. They also show that the effect of number of adults is only significant and lower than 1 for entry into professional services, and that the effect of credit increases the probability of operating an enterprise in the agribusiness or trade sector, but decreases it in the case of entry into professional services.

The results also show that some of the shock variables, reflecting risk, are significant.

9 If the results in the regression tables report a value of 0.000 , no observations exist in this category. 
Table 3.5: Multinomial Logit Model - Ethiopia

\begin{tabular}{lcccccccc}
\hline & Non-Ag. & Agrib. & Trade & Sales & Prof. Serv. & Transp. & Bars \& Res. & Other \\
\hline Female & $0.535^{* *}$ & 1.343 & 0.861 & $0.408^{* *}$ & 0.561 & 0.948 & 2.423 & 0.682 \\
& $(0.15)$ & $(0.30)$ & $(0.26)$ & $(0.17)$ & $(0.39)$ & $(0.81)$ & $(2.13)$ & $(0.24)$ \\
Age & $0.953^{* * *}$ & $0.952^{* * *}$ & $0.964^{* * *}$ & $0.950^{* * *}$ & $0.932^{* * *}$ & $0.916^{* * *}$ & $0.857^{* * *}$ & $0.945^{* * *}$ \\
& $(0.01)$ & $(0.01)$ & $(0.01)$ & $(0.01)$ & $(0.02)$ & $(0.03)$ & $(0.05)$ & $(0.01)$ \\
Read \& Write & 0.912 & $0.702^{* *}$ & 0.908 & $0.363^{* * *}$ & 0.427 & 0.558 & 0.505 & 1.340 \\
& $(0.17)$ & $(0.12)$ & $(0.21)$ & $(0.11)$ & $(0.34)$ & $(0.33)$ & $(0.25)$ & $(0.29)$ \\
Number of Adults & 0.976 & 0.856 & 0.856 & 0.902 & $0.265^{* * *}$ & 0.914 & 0.989 & 0.894 \\
& $(0.10)$ & $(0.08)$ & $(0.09)$ & $(0.16)$ & $(0.13)$ & $(0.32)$ & $(0.50)$ & $(0.09)$ \\
Credit & 1.145 & $1.935^{* * *}$ & $2.078^{* * *}$ & 0.928 & $0.015^{* * *}$ & 0.973 & 1.276 & 0.952 \\
& $(0.24)$ & $(0.36)$ & $(0.45)$ & $(0.30)$ & $(0.02)$ & $(0.69)$ & $(1.39)$ & $(0.29)$ \\
Shock (idiosyn.) & 1.021 & $1.685^{* *}$ & 1.123 & 1.138 & $6.073^{* * *}$ & $0.013^{* * *}$ & 0.775 & 0.962 \\
& $(0.27)$ & $(0.39)$ & $(0.34)$ & $(0.48)$ & $(3.44)$ & $(0.01)$ & $(0.89)$ & $(0.32)$ \\
Shock (price) & 0.757 & $0.710^{*}$ & 1.228 & 1.000 & $3.612^{* * *}$ & $0.174^{*}$ & $0.167^{* *}$ & 1.059 \\
& $(0.17)$ & $(0.15)$ & $(0.30)$ & $(0.32)$ & $(1.49)$ & $(0.18)$ & $(0.13)$ & $(0.30)$ \\
Shock (geogr.) & 0.711 & $0.640^{* *}$ & 0.843 & 1.066 & $0.146^{* *}$ & 1.012 & 0.421 & 0.640 \\
& $(0.19)$ & $(0.14)$ & $(0.25)$ & $(0.38)$ & $(0.13)$ & $(1.22)$ & $(0.34)$ & $(0.25)$ \\
Shock (other) & 1.938 & 1.376 & $3.560^{* *}$ & $4.455^{* *}$ & $0.000^{* * *}$ & $8.633^{*}$ & $0.000^{* * *}$ & 1.282 \\
& $(1.47)$ & $(0.85)$ & $(1.93)$ & $(2.66)$ & $(0.00)$ & $(9.88)$ & $(0.00)$ & $(1.00)$ \\
Distance & $0.549^{* *}$ & $0.550^{* *}$ & $0.017^{* * *}$ & $0.103^{* * *}$ & 0.603 & $0.023^{* *}$ & 0.187 & $0.144^{* * *}$ \\
& $(0.14)$ & $(0.16)$ & $(0.01)$ & $(0.08)$ & $(0.84)$ & $(0.04)$ & $(0.34)$ & $(0.08)$ \\
\hline $\mathrm{N}$ & 3,450 & & \multicolumn{7}{c}{} & & & & \\
\hline
\end{tabular}

Note $(s)$ : Standard errors in parentheses. Exponentiated coefficients. Rural areas only. ${ }^{*} p<0.1,{ }^{* *}$ $p<0.05,{ }^{* * *} p<0.01$.

While idiosyncratic shocks increase the likelihood of entering agribusiness and professional services, most other significant shock variables rather decrease the likelihood of engaging into entrepreneurship, particularly into agribusiness. Price and geographic shocks have a negative effect on agribusiness, which can be expected since these types of shocks can harm the output of farming, as well as the expected profits. Idiosyncratic shocks have a negative effect on transport businesses, which can possibly be explained that services are generally provided by one person driving a motorcycle or taxi. The effect of distance is smaller than 1 in almost all categories and confirms the importance of market access. The type of business activities where distance is not significant are professional services and bars and restaurants, activities that accommodate local clients in the immediate surroundings.

The results for rural Malawi are broadly similar, with the following differences. First, the effect of gender is significant for more types of business activities than in Ethiopia. Female entrepreneurs show a lower likelihood of operating an enterprise in the non-agricultural sector, in trade, sales, transport and professional services. Second, while credit is equally significant for agribusiness and trade, it is also significant for bars and restaurants and other businesses with a positive effect. Third, idiosyncratic shocks increase the 
Table 3.6: Multinomial Logit Model - Malawi

\begin{tabular}{lcccccccc}
\hline & Non-Ag. & Agrib. & Trade & Sales & Prof. Serv. & Transp. & Bars \& Res. & Other \\
\hline Female & $0.199^{* * *}$ & 1.176 & $0.617^{* * *}$ & $0.288^{* * *}$ & $0.241^{* * *}$ & $0.061^{* * *}$ & 0.525 & $0.674^{* * *}$ \\
& $(0.04)$ & $(0.15)$ & $(0.11)$ & $(0.05)$ & $(0.07)$ & $(0.04)$ & $(0.26)$ & $(0.10)$ \\
Age & $0.955^{* * *}$ & $0.966^{* * *}$ & $0.947^{* * *}$ & $0.973^{* * *}$ & 0.975 & $0.941^{* * *}$ & $0.928^{* * *}$ & $0.959^{* * *}$ \\
& $(0.01)$ & $(0.00)$ & $(0.00)$ & $(0.00)$ & $(0.02)$ & $(0.02)$ & $(0.02)$ & $(0.00)$ \\
Read \& Write & 0.982 & $0.605^{* * *}$ & 1.055 & $0.535^{* * *}$ & $0.256^{* * *}$ & 0.646 & $0.610^{*}$ & 0.910 \\
& $(0.12)$ & $(0.06)$ & $(0.12)$ & $(0.06)$ & $(0.08)$ & $(0.19)$ & $(0.16)$ & $(0.11)$ \\
Number of Adults & 0.980 & $0.884^{*}$ & 1.009 & $0.755^{* * *}$ & $0.133^{* * *}$ & $0.556^{* *}$ & 0.743 & 0.984 \\
& $(0.09)$ & $(0.06)$ & $(0.07)$ & $(0.06)$ & $(0.08)$ & $(0.15)$ & $(0.25)$ & $(0.07)$ \\
Credit & 1.060 & $1.809^{* * *}$ & $1.895^{* * *}$ & 1.182 & 2.717 & 0.905 & $2.366^{* *}$ & $1.895^{* * *}$ \\
& $(0.18)$ & $(0.27)$ & $(0.29)$ & $(0.22)$ & $(1.92)$ & $(0.42)$ & $(0.96)$ & $(0.29)$ \\
Shock (idiosyn.) & $(0.03)$ & $(0.02)$ & $(0.04)$ & $(0.02)$ & $(0.13)$ & $(0.09)$ & $(0.09)$ & $(0.03)$ \\
& $1.468^{* * *}$ & $1.312^{* *}$ & 1.073 & $1.609^{* * *}$ & $3.328^{* * *}$ & $1.907^{*}$ & 0.868 & $1.386^{* *}$ \\
Shock (price) & $(0.19)$ & $(0.16)$ & $(0.14)$ & $(0.20)$ & $(1.45)$ & $(0.66)$ & $(0.28)$ & $(0.18)$ \\
& $0.785^{*}$ & 0.846 & $0.708^{* * *}$ & 1.102 & 0.857 & 0.810 & 0.725 & $0.559^{* * *}$ \\
Shock (geogr.) & $(0.10)$ & $(0.10)$ & $(0.09)$ & $(0.13)$ & $(0.47)$ & $(0.28)$ & $(0.23)$ & $(0.07)$ \\
& 0.857 & $0.816^{*}$ & $0.820^{*}$ & 1.208 & 0.641 & 0.794 & $0.526^{*}$ & $0.674^{* * *}$ \\
Shock (other) & $(0.10)$ & $(0.09)$ & $(0.10)$ & $(0.14)$ & $(0.35)$ & $(0.29)$ & $(0.18)$ & $(0.08)$ \\
& 0.815 & $0.390^{*}$ & 0.456 & 0.877 & $0.000^{* * *}$ & $0.000^{* * *}$ & 2.241 & 1.372 \\
Distance & $(0.45)$ & $(0.21)$ & $(0.23)$ & $(0.37)$ & $(0.00)$ & $(0.00)$ & $(2.25)$ & $(0.50)$ \\
N & $0.093^{* * *}$ & $0.064^{* * *}$ & $0.135^{* * *}$ & $0.051^{* * *}$ & 0.080 & $0.096^{* *}$ & $0.100^{* * *}$ & $0.092^{* * *}$ \\
\hline
\end{tabular}

Note(s): Standard errors in parentheses. Exponentiated coefficients. Rural areas only. ${ }^{*} p<0.1,{ }^{* *}$ $p<0.05,{ }^{* * *} p<0.01$.

likelihood of entering different business types, while price shocks decrease the probability of operating non-agricultural businesses, trade or other businesses. Geographic shocks are marginally significant for agribusiness, trade and bars and restaurants, and decrease the likelihood of entering these business types. The differences between Ethiopia and Malawi, while not extensive, illustrate again the salience of country-level heterogeneity in rural entrepreneurship.

In conclusion, the results of the MNLM are largely consistent with the results of the probit regressions, but further refine the analysis. They show that variables can be significant for only certain types of business activity, with sometimes opposing effects.

\subsection{Summary and Concluding Remarks}

This chapter provides empirical evidence on three aspects of non-farm entrepreneurship in rural Sub-Saharan Africa: (i) the patterns and prevalence of non-farm entrepreneurship, (ii) the determinants of enterprise operation, and (iii) the types of business activities 
households operate. A better understanding of the patterns and determinants of enterprise operation and the type of business activity is required to develop adequate policies that can support opportunity motivated entrepreneurship, while simultaneously shielding household from adverse events, preventing them to be pushed into entrepreneurship due to necessity. I first summarize the findings, before providing policy recommendations and suggestions for further research.

First, the chapter confirms that non-farm enterprises are ubiquitous and make a substantial contribution to rural household income. In the sample 42 percent of households operate one or more enterprises with a large variation by country. Their contribution to household income also varies significantly, from 8 percent in rural Malawi to 36 percent in rural Niger.

Second, I find evidence that households operate enterprises due to both push and pull factors. On the one hand, I show that the necessity to cope and manage risks can push households into entrepreneurship. Given a lack of social protection and insurance schemes, households are managing shocks, dealing with surplus household labor and responding to seasonality by operating enterprises. The necessity motivation is reflected in the nature of these enterprises as small, informal household enterprises that are often operated for only a portion of the year. On the other hand, households also seize opportunities in the non-farm economy, suggested by a positive association of variables capturing higher income and wealth. A closer distance to markets and a favorable local infrastructure also show positive associations with enterprise operation. They suggest that policies that improve the infrastructure could be beneficial for rural entrepreneurship. While such policies support rural entrepreneurship mainly from the demand side, supply side policies that reduce a necessity type of entrepreneurship and encourage a risk-taking opportunity type of entrepreneurship may need more emphasis. This would also include policies to provide or extend social protection and (micro)-insurance schemes.

Third, the evidence further suggests that the focus on both the individual and household level is appropriate. The character of rural enterprises as household enterprises implies that entrepreneurial decisions are taken collectively at both the individual and household level. The education of the household head, the household's wealth, and the household's access to credit are associated with a higher likelihood to be entrepreneurial. The promotion of education and training, credit provision and access, the promotion of aggregate demand and a positive business climate, are expected to be beneficial for rural entrepreneurship. 
Fourth, I find that the motivation of enterprise operation also influences the type of business activity households engage in. Using data from Ethiopia and Malawi, I find that female households heads are less likely to operate certain types of business activity. While gender is not a significant constraint for household heads to operate an enterprise, implying that women do not face significant barriers of entering entrepreneurship, they might face constraints in entering certain sectors. Business types with a lower likelihood of female ownership include non-agricultural businesses, trade, sales and transport services. This finding suggests that potential female entrepreneurs may face entry barriers that are not evident from a first round of analysis. To the extent that these types of businesses also require more capital, collateral and prior education, it may even reflect discrimination. It may further reflect different cultural roles and expectations of women within the household, with more varied demands on a woman's time allocation that can hinder them from operating more time-consuming businesses. The results also show that education is only relevant for certain types of businesses, as well as the number of adults in a household. The credit variable increases the likelihood of entrepreneurship when entering agribusiness or trade in both countries, as well as bars and restaurants in Malawi. This finding also shows that credit it not significant for certain types of businesses, which suggests that certain sectors can be entered without access to finance. The shock variables are once more largely not significant, with again some interesting exceptions. While idiosyncratic shocks tend to increase the likelihood of entering certain types of businesses, price or geographic shocks decrease enterprise operation in certain sectors, for example agribusiness. Finally, distance to a population center is not relevant for business types such as professional services and bars and restaurants that offer nontradable goods and services.

Overall I recommend more research on the choice of business activity households engage in, particularly analyzing the performance and duration of the different types of businesses. Given the evidence that both pull and push factors can lead to enterprise operation, further research may address if these enterprises are in high-risk, high-return type of activities, or low-risk, low-return activities, respectively. Further research is also needed to investigate if these business types are correlated with agricultural risk, and whether the decision to enter into low-productive activities is a result of market and policy failures.

Finally, it is important to remain cautious in generalizing the results of this chapter to other countries in Sub-Saharan Africa. The specific nature of agricultural risk and market imperfections differ substantially across the countries in the sample. Stylized 
facts that I can still identify are (i) the heterogeneous patterns and determinants of nonfarm entrepreneurship across rural Africa, (ii) the lower likelihood of enterprise operation in rural areas, (iii) the more intermittent enterprise operation in rural areas and (iv) the potential risk-coping function of enterprises for some rural households.

In conclusion, rural non-farm entrepreneurship does not suggest to contribute significantly to the creation of a crucial amount of non-vulnerable jobs in a region, where large numbers of young workers are expected to enter the labor force over the coming years. Comparatively high economic growth rates in various African countries over the past decade have not been accompanied by significant structural economic change in rural areas. Although a risk-coping function is important given the risks and shocks rural households have to contend with, I do not expect a major contribution from non-farm entrepreneurship to quality employment creation and poverty reduction in the near future. Entrepreneurship still has the potential to fulfill this role, if market and policy failures associated with the misallocation of labor into necessity forms of entrepreneurship are addressed. This conclusion bears a resemblance to conclusions by other scholars (e.g. Start, 2001; Rijkers and Söderbom, 2013) who have pointed out that Africa's non-farm economy has a limited impact on economic growth and poverty reduction. Generally speaking, the results cannot dispel the rather pessimistic evaluations of the state of non-farm entrepreneurship in rural Africa, although the results also suggest opportunity motivated enterprise operation.

In the next chapter I continue the empirical analysis on non-farm entrepreneurship by examining the patterns and determinants of enterprise performance and productivity. 

Chapter 4

\section{Productivity}




\subsection{Introduction}

This chapter presents new empirical and comparative evidence on labor productivity in non-farm enterprises in rural Sub-Saharan Africa. ${ }^{1}$ While non-farm enterprises are ubiquitous in rural Africa and play an important role in the non-farm economy, as shown in the previous chapter, little is yet known about their productivity. The relative contribution of the non-farm economy to household income is significant and has increased over time (Haggblade et al., 2010; Rijkers and Costa, 2012). These enterprises are further estimated to currently employ 15 percent of Africa's labor force (Fox et al., 2013) and expected to create millions of jobs in rural Africa over the next decade (Fox and Pimhidzai, 2013). They are also expected to contribute to structural transformation (Fox and Sohnesen, 2013), although the non-farm sector largely consists of small, informal household businesses. Nevertheless, the literature so far lacks empirical evidence on the productivity of these enterprises. In contrast, a number of studies have already investigated the productivity of urban enterprises in Africa (e.g. Alene, 2010; Block, 2010), including the impact of non-farm enterprises on agricultural productivity (e.g. Oseni and Winters, 2009). This knowledge gap on rural enterprise productivity presents a serious lacuna, as more productive enterprises have a higher likelihood to survive and to contribute towards rural employment creation (Wennberg and Lindqvist, 2010; Owoo and Naudé, 2014).

This chapter contributes to the literature by exploring the productivity of non-farm enterprises in four African countries using the World Bank's LSMS-ISA database. I focus on Ethiopia, Malawi, Nigeria and Uganda due to data availability. Based on the literature I expect that factors pushing households into entrepreneurship have a negative impact on labor productivity, and that factors pulling households into entrepreneurship to seize opportunities have a positive impact. I use a Heckman selection model and panel data estimators, and take labor productivity, a partial productivity measure, as a proxy for enterprise performance.

The results largely confirm the expectations that push factors decrease and pull factors increase labor productivity, but also show a more complex picture of enterprise performance. To be more specific, the results show that female-owned enterprises are on average less productive than male-owned enterprises, and that age increases labor productivity, a proxy for experience. External shocks have a negative effect on labor

1 This chapter is based on the working paper: Nagler, P. and W. Naudé (2014a). Labor Productivity in Rural African Enterprises: Empirical Evidence from the LSMS-ISA, IZA Discussion Paper No. 8524. 
productivity, even though their effect on the decision to operate an enterprise is limited. Education (proxied by the ability to read \& write) and months of enterprise operation have a positive effect on labor productivity, an indication that pull factors increase enterprise performance. Location also matters. Rural enterprises are less productive than their urban counterparts, and enterprises that are located closer to a population center are more productive than enterprises located further away.

The chapter is structured as follows. Section 4.2 provides descriptive statistics on the dispersal of labor productivity. Section 4.3 describes the methodology used, and Section 4.4 presents and discusses the empirical results. The final section summarizes the findings and discusses policy implications.

\subsection{Descriptive Statistics}

This section reports the patterns of labor productivity dispersal by location, gender, education and the experience of a shock. Enterprise productivity refers to how efficiently enterprises transform inputs into outputs. The most frequently used measures are total factor productivity and partial measures such as output per labor unit. In the present case, a lack of data precludes the calculation of total factor productivity. Hence I can only calculate labor productivity, a partial productivity measure.

Formally I calculate,

labor productivity $=\frac{\text { average monthly sales }}{\text { number of workers }}$

As average monthly sales are not available for all countries, I take total sales during the last month of operation in Malawi and Nigeria, and average gross revenues in Uganda. Once labor productivity is calculated, the log of labor productivity is used for the estimates. I take the survey rounds from 2011/12 for Ethiopia, and from 2010/11 for Malawi, Nigeria and Uganda.

I acknowledge that using this productivity measure is an approximation, and likely to be subject to measurement errors in the present context. First, I do not take into account output or profit due to a lack of data. Second, I do not have information about the time-use of workers, and do not know how many hours of work are allocated by each individual to the enterprise. And third, I assume that the self-reported variable itself is 
imprecise, as most enterprise are informal and do not always record sales or revenues, but provide rough estimates of the business volume. Therefore results have to be interpreted with caution. Due to data availability, however, this productivity measure is the best approximation that is currently at hand for this study.

The kernel density estimates by location is depicted in Figure 4.1. The figure shows that differences in labor productivity confirm the expectations: urban enterprises are more productive than rural enterprises in the four countries studied, with a more pronounced productivity gap in Malawi and Uganda. ${ }^{2}$

Figure 4.1: Productivity Dispersal - by Location

(a) Ethiopia

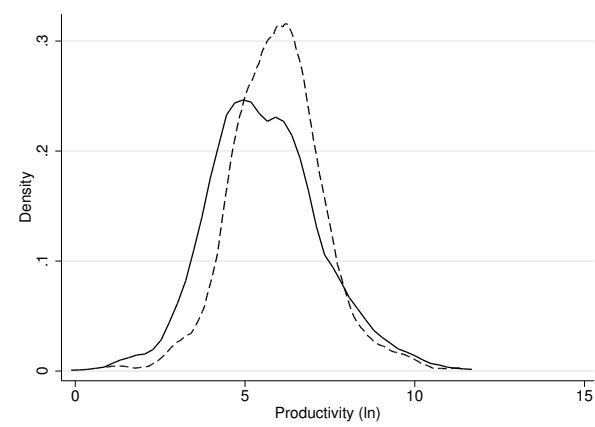

(c) Nigeria

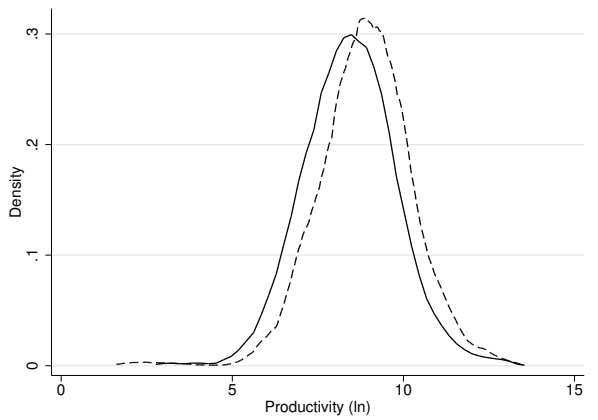

(b) Malawi

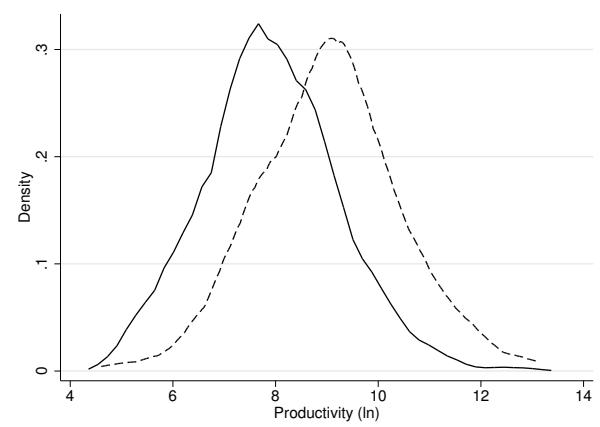

(d) Uganda

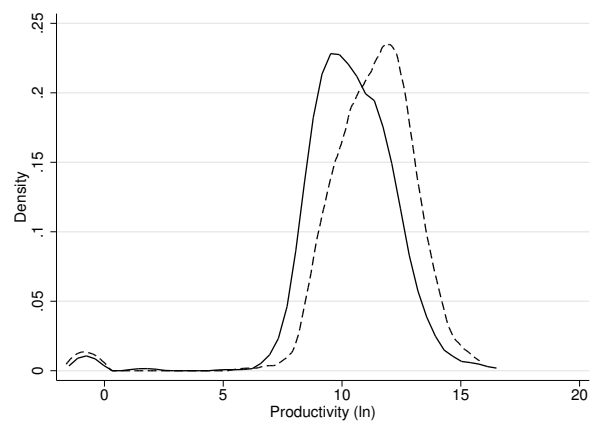

Note(s): In Figures 4.1a, 4.1b, 4.1c and 4.1d the continuous lines represent the productivity of enterprises that are located in rural areas and the dotted lines the productivity of enterprises that are located in urban areas.

However, this simple dichotomy between rural and urban areas may be of limited usefulness. There is a large variation in Africa's economic geography between deep rural,

\footnotetext{
2 The data does not cover urban areas in Ethiopia. Instead the differentiation is made between rural areas and small towns. I assume that the small difference in productivity dispersal in Ethiopia stems from this data limitation.
} 
small towns and major urban areas. The potential importance of secondary towns and rural agglomerations has generally been underestimated. As Christiaensen et al. (2013) argue, productivity might be higher in metropolitan areas, but not all inhabitants from rural areas are or will be able to access opportunities in these areas. Using data from Tanzania, they find that only one in seven people who escaped from poverty did so through migrating to a large city, but that one in two did so by moving to a secondary town.

Therefore I am interested in providing a finer analysis of how spatial location affects labor productivity. I use data from Uganda and analyze differences in the kernel density of the country's four main regions and the capital city: Central, Eastern, Northern, Western and the capital Kampala. These four regions plus the capital city are distinct in terms of population density, business environment and history. Over the past ten years economic growth has been largely concentrated in the Central region that includes the capital city, while violent conflicts affected the Northern region between 1987 and 2006 (Blattmann et al., 2014). The Western region also has not escaped occasional ethnic conflicts (Espeland, 2007). This allows me to obtain some indication of how the local business environment may affect labor productivity, as regions that experienced a conflict are more likely to show a poorer business environment (Brueck et al., 2013). It can also be expected that labor productivity is higher in the capital city, and in the more densely populated and more peaceful regions. Figure $4.2 \mathrm{a}$ confirms these expectations. Kampala has the highest labor productivity, with the Central region following in terms of productivity level. The Northern region, with the lowest population density and a history of conflict, is home to the enterprises with the lowest productivity level.

I also consider the impact of distance to the closest town on labor productivity in nonfarm enterprises. I use again data from Uganda and take different distances of the enterprise location to the closest population center. ${ }^{3}$ I compare the productivity density of the enterprises by various distance categories from these population centers. I expect, following Christiaensen et al. (2013), that proximity to a population center increases labor productivity and that it gradually diminishes over distance, reflecting that spatial spillovers are limited. Figure $4.2 \mathrm{~b}$ confirms the expectations. Enterprises of households located up to $10 \mathrm{~km}$ from a population center are the most productive ones, followed by enterprises in households residing up to $25 \mathrm{~km}$ and $50 \mathrm{~km}$ away, respectively. If households are located more than $50 \mathrm{~km}$ away, the results show a significantly lower labor productivity. These findings support the idea that rural secondary towns and

3 Population center is defined as a town or city with 20,000 or more inhabitants. 
cities, providing links between rural areas and major cities, play an important role in the structural transformation and poverty reduction of agrarian societies like Uganda.

Figure 4.2: Productivity Dispersal - by Region and Distance

(a) Uganda - by Region

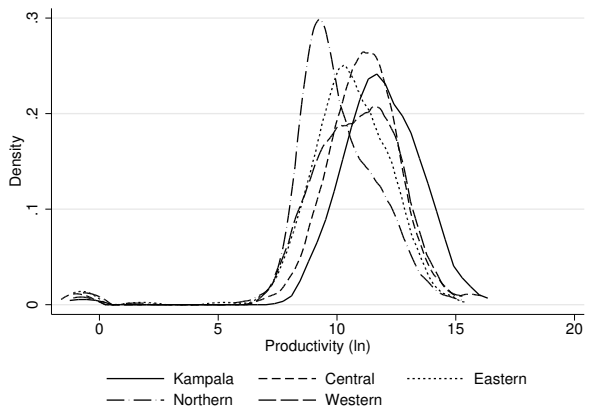

(b) Uganda - by Distance (in km)

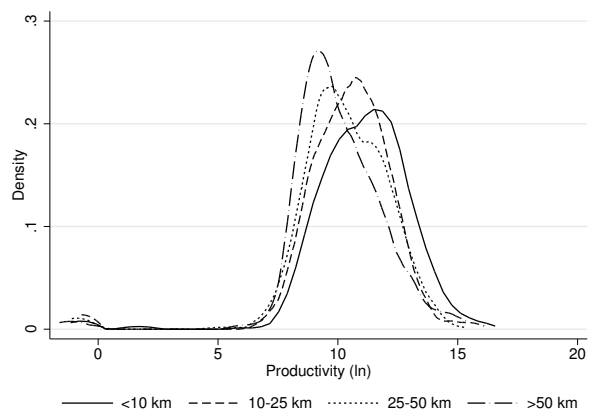

I further depict the productivity dispersal by gender, education (proxied by the ability to read \& write) and the experience of shocks in Figures A.1, A.2 and A.3. ${ }^{4}$ Enterprises with a male owner are on average more productive than enterprises with a female owner in all four countries. A possible explanation could lie in the fact that businesses are timeconsuming to operate, and women tend to be more time-constrained due to household duties (see also Palacios-López and López, 2014). The productivity dispersal by the ability to read \& write shows that literate enterprise owners operate more productive enterprises. However, the ability to read \& write is an imprecise approximation to the educational level of the entrepreneur, capturing individuals with primary education, but also individuals with more comprehensive education, for example secondary schooling.

Finally, the productivity dispersal by the experience of a shock during the last 12 months preceding the survey is reported. As expected, external shocks to the household show a negative association with labor productivity. Labor productivity is higher in enterprises where the household did not experience a shock. While the difference is minor in Ethiopia and Nigeria, it is more pronounced in Malawi and Uganda.

\subsection{Methodology}

This section describes the methodology used to estimate labor productivity in non-farm enterprises. Two econometric models are applied: a Heckman selection model that

4 The figures are reported in Appendix A. 
accounts for selection effects into entrepreneurship, and a panel data model, where I make use of the panel data that is available for Nigeria and Uganda.

\section{Heckman Selection Model}

A Heckman selection model is used to estimate the determinants of labor productivity, since we do not observe the dependent variable for all rural households. Only households that selected into entrepreneurship can also report its labor productivity. However, since the motivation for operating a business can determine its subsequent productivity, the results might be subject to selection effects. For instance, if households are pushed into entrepreneurship as a risk-management tool due to uncertainty in farming, other factors might determine labor productivity compared to a situation, where households perceive an attractive business opportunity, and lead to an upward or downward bias depending on which aspect dominates. This model takes into account the difference between the probability that a particular household operates a non-farm enterprise, called the selection stage, and the level of labor productivity for this subsequent enterprise, called the outcome stage. To estimate the model I use a cross-sectional sample, where I include data from the four countries, taking the same survey rounds as indicated in Section 4.2.

Formally I estimate,

$z_{i}^{*}=w_{i} \gamma+u_{i}$

representing the selection stage of the model, where $z_{i}^{*}$ is a latent variable corresponding to the "outcome" productivity level, which will only be observed once a household operates a non-farm enterprise, thus $z_{i}=1$ if $z_{i}^{*}>0$ and $z_{i}=0$ if $z_{i}^{*} \leq 0 . w_{i}$ is a vector containing the possible determinants of enterprise operation.

Once $z_{i}$ is known, the outcome stage, the dependent variable is the log of labor productivity and can be modeled as,

$y_{i}^{*}=x_{i} \beta+\varepsilon_{i}$

with $y_{i}=y_{i}^{*}$ if $z_{i}=1$ and $y_{i}$ not observed if $y_{i}=0$.

$x_{i}$ is a vector including the individual, household, location and enterprise characteristics. 
In the selection stage the individual characteristics of the household head are taken, and include the variables gender, age and education. In the outcome stage the individual characteristics of the enterprise owner are taken, and include the same variables as in the selection stage. The households characteristics, general access to credit and experience of shocks, remain equal in both stages, as well as the location characteristics, distance to the next population center and agro-ecological zones. Enterprise characteristics are only included in the outcome stage, where I add firm size to the regressions. ${ }^{5}$

\section{Panel Data Analysis}

I make use of the panel properties for Nigeria and Uganda to estimate panel regressions. For the panel data analysis I have data for Nigeria for four survey rounds: post-planting and post-harvest data for the years 2010/11 and 2012/13. Due to a limited questionnaire for the post-harvest interviews, I use the data of the post-planting rounds only. ${ }^{6}$ In the case of Uganda, I have data for three survey rounds: 2009/10, 2010/11 and 2011/12.

Formally I estimate,

$Y_{e h t}=\mathbf{x}_{e h t}^{\prime} \boldsymbol{\beta}^{1}+\mathbf{w}_{h t}^{\prime} \boldsymbol{\gamma}^{1}+\mathbf{z}_{e h t}^{\prime} \boldsymbol{\delta}^{1}+\lambda_{t}^{1}+\mu_{h}^{1}+u_{e h t}^{1}$
$\bar{Y}_{e h t}=\overline{\mathbf{x}}_{\text {eht }}^{\prime} \boldsymbol{\beta}^{2}+\overline{\mathbf{w}}_{h t}^{\prime} \boldsymbol{\gamma}^{2}+\overline{\mathbf{z}}_{\text {eht }}^{\prime} \boldsymbol{\delta}^{2}+\lambda_{t}^{2}+\mu_{h}^{2}+u_{\text {eht }}^{2}$
$\overline{\bar{Y}}_{\text {eht }}=\overline{\overline{\mathbf{x}}}_{\text {eht }}^{\prime} \boldsymbol{\beta}^{3}+\overline{\overline{\mathbf{w}}}_{h t}^{\prime} \boldsymbol{\gamma}^{3}+\overline{\overline{\mathbf{z}}}_{\text {eht }}^{\prime} \boldsymbol{\delta}^{3}+\lambda_{t}^{3}+\mu_{h}^{3}+u_{\text {eht }}^{3}$

where $\left\{Y_{\text {eht }}, \bar{Y}_{e h t}, \overline{\bar{Y}}_{\text {eht }}\right\}$ is labor productivity at the enterprise level. The set $\left\{\mathbf{x}_{\text {eht }}^{\prime}, \overline{\mathbf{x}}_{\text {eht }}^{\prime}, \overline{\mathbf{x}}_{\text {eht }}^{\prime}\right\}$ contains vectors of individual characteristics of the enterprise owner at the enterprise level. The set $\left\{\mathbf{w}_{h t}^{\prime}, \overline{\mathbf{w}}_{h t}^{\prime}, \overline{\mathbf{w}}_{h t}^{\prime}\right\}$ contains vectors of household characteristics observed at the household level. Finally, $\left\{\mathbf{z}_{e h t}^{\prime}, \overline{\mathbf{z}}_{e h t}^{\prime}, \overline{\mathbf{z}}_{e h t}^{\prime}\right\}$ is a set of vectors of enterprise characteristics at the enterprise level. Let $\left\{\boldsymbol{\beta}^{j}, \boldsymbol{\gamma}^{j}, \boldsymbol{\delta}^{j}\right\}$ denote the associated vectors of coefficients for equation $j$, where $j=1,2,3$. $\lambda_{t}^{j}$ are time effects for equation $j, \mu_{h}^{j}$ are fixed effects at level $k \in\{h\}$ for equation $j$, and $u_{e h t}^{j}$ are idiosyncratic errors for equation $j$.

As individual characteristics the gender, age, marital status and education of the enterprise owner are included, and the information if the owner is a migrant. As household

\footnotetext{
5 See Table A.5 in Appendix A for summary statistics and a detailed definition of the variables used in the Heckman selection model.

6 The shock variable is taken from the post-harvest questionnaires due to data availability.
} 
characteristics the number of adults and the experience of shocks are included. As enterprise characteristics the use of credit to expand the business, firm size and months of enterprise operation are included. ${ }^{7}$

\subsection{Results}

The regression results are reported as follows. First, the expectations about the determinants of labor productivity in non-farm enterprises are tested by estimating a Heckman selection model using data from all four countries. Second, panel data methods are applied to refine these results and to study the determinants of labor productivity over time, using data from Nigeria and Uganda.

\subsubsection{Heckman Selection Model}

Table 4.1 shows the estimation results of the Heckman selection model using data from Ethiopia, Malawi, Nigeria and Uganda. In the upper part of the table (the second stage of the estimation) the dependent variable is the log of labor productivity, and the independent variables entail possible determinants of labor productivity. Individual characteristics are taken from the enterprise owner. In the lower part of the table (the first stage of the estimation), the dependent variable is the binary variable NFE, indicating if a household operates a non-farm enterprise. The independent variables entail possible determinants for the household decision to operate a non-farm enterprise. Individual characteristics are taken from the household head, where I make the assumption that the head decides within the household if a household member enters the non-farm sector. For the selection stage I also make the assumption that the number of adults in a household selects households into this sector, as surplus labor can be allocated into enterprises, either as a pull or a push factor. ${ }^{8}$ The reported results in the second stage can then be interpreted as though data was observed for all households in the sample.

\footnotetext{
7 See Table A.6 in Appendix A for summary statistics and a detailed definition of the variables used in the panel data analysis.

8 Additionally I run a set of regressions, where I take the variable land size per adult household member as the selection criteria for entering entrepreneurship. This variable is significant and negative for Ethiopia, suggesting that more land per adult household member has a negative effect on enterprise operation, for example due to a higher importance of farming activities. However, the variable is not significant for Malawi and Nigeria, and has a marginal significant and positive effect in Uganda, suggesting that land holdings can actually motivate household members to operate an enterprise in this country, for example due to more wealth. The results of the regression table using this alternative selection variable are largely comparable to the results shown in Table 4.1 of this chapter.
} 
In the first stage, the selection stage, the number of adults is significant and positive in all four countries. Households located in rural areas have in all cases a lower likelihood of operating an enterprise, but the gender of the household head does not appear to determine enterprise operation, with the exception of Nigeria. Age is significant and negative in all regressions, and education, proxied with the ability to read \& write, significant and positive, with the exception of Uganda. The variable general access to credit, available in Ethiopia and Malawi, is significant and positive for the regressions of these two countries, suggesting that access to credit significantly increases the likelihood of enterprise operation. Shocks are not significant in most cases with the exception of Malawi, where they increase the likelihood of entering the non-farm sector, possibly indicating enterprise operation due to push factors. Significant and negative effects are reported for the distance variable in Ethiopia and Malawi, and a marginally significant and positive outcome identified in Uganda.

In the second stage, the outcome stage, the effect of the variable rural is significant and negative in Malawi and Nigeria, showing that rural enterprises in these countries are less productive than urban ones. The effect of gender (coded as female) is significant and negative in Ethiopia, Malawi and Nigeria, indicating that female enterprise owners operate less productive businesses. Age does not seem to be associated with labor productivity and is only marginally significant and positive in Uganda. The effect of the ability to read \& write is significant and positive in all countries, indicating that more educated enterprise owners also operate more productive businesses. The effect of access to credit is only marginally significant in Malawi and negative, a surprising outcome given that the credit variable has a significant and positive effect on enterprise operation in the selection stage. One explanation could lie in the fact that this variable indicates general access to credit and could be used for any other purpose within the household. The effect of firm size, defined as number of workers per firm, is significant and negative in Ethiopia and Nigeria. While it is expected that larger enterprises are more productive, a possible explanation might lie in the lack of information on the time-use of workers, for example as part-time family workers who allocate only a few hours of labor per week to enterprise operation. The effect of shocks is significant and negative in three out of the four countries. Two possible reasons could explain this finding. First, that exposure to shocks might drive households into operating enterprises in less risky, but also lower return types of activity. And second, that the shock itself reduces enterprise productivity once the business is in operation. Finally, the effect of distance has a significant and positive effect in Malawi, but a significant and negative effect in Uganda. While the negative result can be easily explained by access to demand and markets, the positive 
result is surprising. It could indicate deep rural isolation from competition, and give small, rural enterprises some form of monopolist power.

Table 4.1: Heckman Selection Model

\begin{tabular}{|c|c|c|c|c|}
\hline & $\begin{array}{c}(1) \\
\text { Ethiopia }\end{array}$ & $\begin{array}{c}(2) \\
\text { Malawi }\end{array}$ & $\begin{array}{c}(3) \\
\text { Nigeria }\end{array}$ & $\begin{array}{c}(4) \\
\text { Uganda }\end{array}$ \\
\hline \multicolumn{5}{|l|}{ (ln) Productivity } \\
\hline Rural & $\begin{array}{l}-0.007 \\
(0.26)\end{array}$ & $\begin{array}{c}-0.596^{* * *} \\
(0.11)\end{array}$ & $\begin{array}{c}-0.178^{* *} \\
(0.07)\end{array}$ & $\begin{array}{l}0.365 \\
(0.33)\end{array}$ \\
\hline Female & $\begin{array}{c}-0.596^{* * *} \\
(0.15)\end{array}$ & $\begin{array}{c}-0.587^{* * *} \\
(0.07)\end{array}$ & $\begin{array}{c}-0.238^{* * *} \\
(0.05)\end{array}$ & $\begin{array}{r}-0.085 \\
(0.16)\end{array}$ \\
\hline Age & $\begin{array}{l}0.007 \\
(0.01)\end{array}$ & $\begin{array}{r}-0.000 \\
(0.00)\end{array}$ & $\begin{array}{l}-0.001 \\
(0.00)\end{array}$ & $\begin{array}{l}0.011^{*} \\
(0.01)\end{array}$ \\
\hline Read \& Write & $\begin{array}{c}0.338^{* *} \\
(0.16)\end{array}$ & $\begin{array}{c}0.321^{* * * *} \\
(0.08)\end{array}$ & $\begin{array}{c}0.303^{* * *} \\
(0.06)\end{array}$ & $\begin{array}{c}0.789^{* * *} \\
(0.18)\end{array}$ \\
\hline Credit & $\begin{array}{l}-0.017 \\
(0.17)\end{array}$ & $\begin{array}{c}-0.189^{*} \\
(0.10)\end{array}$ & & \\
\hline Firm Size & $\begin{array}{c}-0.194^{* *} \\
(0.08)\end{array}$ & $\begin{array}{l}0.021 \\
(0.02)\end{array}$ & $\begin{array}{c}-0.143^{* * *} \\
(0.03)\end{array}$ & $\begin{array}{c}-0.015 \\
(0.03)\end{array}$ \\
\hline Shock & $\begin{array}{c}-0.361^{* *} \\
(0.15)\end{array}$ & $\begin{array}{c}-0.412^{* * *} \\
(0.08)\end{array}$ & $\begin{array}{c}-0.131^{* *} \\
(0.07)\end{array}$ & $\begin{array}{l}-0.277 \\
(0.20)\end{array}$ \\
\hline Distance & $\begin{array}{r}-0.243 \\
(0.30) \\
\end{array}$ & $\begin{array}{c}0.526^{* * *} \\
(0.17)\end{array}$ & $\begin{array}{l}-0.261 \\
(0.16) \\
\end{array}$ & $\begin{array}{c}-1.884^{* * *} \\
(0.61)\end{array}$ \\
\hline \multicolumn{5}{|l|}{ NFE } \\
\hline Number of Adults & $\begin{array}{c}0.041^{* *} \\
(0.02)\end{array}$ & $\begin{array}{c}0.112^{* * *} \\
(0.01)\end{array}$ & $\begin{array}{c}0.144^{* * *} \\
(0.02)\end{array}$ & $\begin{array}{c}0.066^{* * *} \\
(0.01)\end{array}$ \\
\hline Rural & $\begin{array}{c}-1.026^{* * * *} \\
(0.09)\end{array}$ & $\begin{array}{c}-0.444^{* * *} \\
(0.06)\end{array}$ & $\begin{array}{c}-0.461^{* * *} \\
(0.05)\end{array}$ & $\begin{array}{c}-0.357^{* * *} \\
(0.10)\end{array}$ \\
\hline Female & $\begin{array}{l}0.110 \\
(0.09)\end{array}$ & $\begin{array}{r}-0.050 \\
(0.04)\end{array}$ & $\begin{array}{c}-0.157^{* *} \\
(0.07)\end{array}$ & $\begin{array}{c}-0.052 \\
(0.06)\end{array}$ \\
\hline Age & $\begin{array}{c}-0.011^{* * *} \\
(0.00)\end{array}$ & $\begin{array}{c}-0.008^{* * *} \\
(0.00)\end{array}$ & $\begin{array}{c}-0.007^{* * *} \\
(0.00)\end{array}$ & $\begin{array}{c}-0.014^{* * *} \\
(0.00)\end{array}$ \\
\hline Read \& Write & $\begin{array}{c}0.176^{* *} \\
(0.08)\end{array}$ & $\begin{array}{c}0.249^{* * * *} \\
(0.04)\end{array}$ & $\begin{array}{c}0.172^{* * *} \\
(0.05)\end{array}$ & $\begin{array}{l}0.042 \\
(0.05)\end{array}$ \\
\hline Credit & $\begin{array}{c}0.340^{* * * *} \\
(0.08)\end{array}$ & $\begin{array}{c}0.257^{* * * *} \\
(0.05)\end{array}$ & & \\
\hline Shock & $\begin{array}{l}0.065 \\
(0.07)\end{array}$ & $\begin{array}{c}0.084^{* *} \\
(0.04)\end{array}$ & $\begin{array}{c}-0.023 \\
(0.05)\end{array}$ & $\begin{array}{l}0.067 \\
(0.07)\end{array}$ \\
\hline Distance & $\begin{array}{c}-0.357^{* * *} \\
(0.13) \\
\end{array}$ & $\begin{array}{c}-0.314^{* * *} \\
(0.09) \\
\end{array}$ & $\begin{array}{l}-0.125 \\
(0.13)\end{array}$ & $\begin{array}{l}0.348^{*} \\
(0.20)\end{array}$ \\
\hline Agro-Ecological Zone & Yes & Yes & Yes & Yes \\
\hline $\mathrm{N}$ & 3,892 & 12,496 & 5,859 & 2,477 \\
\hline rho & -0.297 & -0.611 & -0.488 & -0.935 \\
\hline sigma & 1.577 & 1.500 & 1.368 & 3.099 \\
\hline lambda & -0.469 & -0.916 & -0.667 & -2.899 \\
\hline Prob $>$ chi2 & 0.107 & 0.000 & 0.000 & 0.000 \\
\hline
\end{tabular}

Note(s): Standard errors in parentheses. Household weights included. Clustered at the household level. ${ }^{*} p<0.1,{ }^{* *} p<0.05,{ }^{* * *} p<0.01$.

Summarizing this section, I identify a set of variables that can explain enterprise operation in a first stage, and productivity levels of these enterprises in a second stage. In the first stage, or selection stage, when households decide to operate an enterprise, the number 
of adults, the location of the household in a rural or urban area and the age of the household head are significant factors for all countries. Further education in three out of the four countries studied, and access to credit and distance to the next population center for Ethiopia and Malawi. In the second stage, or outcome stage, the effect of the ability to read \& write has a significant and positive effect on labor productivity in all countries. The effects of a household's location, the gender of the enterprise owner and the experience of shocks are further significant factors in three out of four countries. ${ }^{9}$

\subsubsection{Panel Data Analysis}

As the last part of the analysis I make use of the availability of panel data to further examine the determinants of enterprises productivity over time. Panel regressions are estimated at the enterprise, household and community level using data from Nigeria and Uganda, where fixed effects and time fixed effects are introduced.

In Table 4.2 the results of the panel data analysis are reported. The variable rural shows that location has a significant and negative effect on labor productivity in Nigeria at the enterprise and household level, but no effect in Uganda at all levels. With regard to the individual characteristics, the effect of gender is significant in both countries at all levels, with the exception of the community level in Uganda. If the enterprise owner is female, productivity is significantly lower compared to a male-owned enterprise, holding other factors constant. The interaction term female $\mathrm{x}$ married is significant in Uganda at the enterprise level, and has a negative coefficient, suggesting once more that women might face a different role with respect to her time-use. The variable age is significant at the enterprise and household level in Nigeria, and at all levels in Uganda, and suggests that older enterprise owners operate more productive enterprises, which can be explained by experience. The effect of education, proxied by the ability to read \& write, does not have an impact in most regressions with the exception of Nigeria at the enterprise level, where it is positive. This surprising outcome might be due to the fact that most enterprises are rather small household businesses that do not require high skilled enterprise owners in terms of schooling, and where other abilities that can be learned outside of school might be of higher importance for labor productivity over time. This outcome is in contrast with the results of the Heckman selection model and calls for further research. Finally, the migration status of the enterprise owner is not significant in Uganda.

\footnotetext{
9 See also Table A.9 in Appendix A for the same set of Heckman selection regressions using rural households only. I do not find major differences using the rural sample only, and conclude that both tables report comparable results.
} 
Table 4.2: Panel Data Analysis

\begin{tabular}{|c|c|c|c|c|c|c|}
\hline (ln) Productivity & $\begin{array}{c}(1) \\
\text { Nigeria } \\
\text { Enterprise }\end{array}$ & $\begin{array}{c}(2) \\
\text { Nigeria } \\
\text { Household }\end{array}$ & $\begin{array}{c}(3) \\
\text { Nigeria } \\
\text { Community }\end{array}$ & $\begin{array}{c}(4) \\
\text { Uganda } \\
\text { Enterprise }\end{array}$ & $\begin{array}{c}(5) \\
\text { Uganda } \\
\text { Household }\end{array}$ & $\begin{array}{c}(6) \\
\text { Uganda } \\
\text { Community }\end{array}$ \\
\hline Rural & $\begin{array}{c}-0.990^{* * *} \\
(0.25)\end{array}$ & $\begin{array}{c}-0.992^{* * *} \\
(0.25)\end{array}$ & $\begin{array}{l}-0.373 \\
(0.51)\end{array}$ & $\begin{array}{l}-0.116 \\
(0.47)\end{array}$ & $\begin{array}{l}0.209 \\
(0.47)\end{array}$ & $\begin{array}{l}-0.275 \\
(0.57)\end{array}$ \\
\hline Female & $\begin{array}{c}-0.713^{* * *} \\
(0.12)\end{array}$ & $\begin{array}{c}-0.697^{* * *} \\
(0.21)\end{array}$ & $\begin{array}{l}-0.405 \\
(0.49)\end{array}$ & $\begin{array}{l}-0.146 \\
(0.25)\end{array}$ & $\begin{array}{l}-0.280 \\
(0.33)\end{array}$ & $\begin{array}{c}-0.225 \\
(0.72)\end{array}$ \\
\hline Age & $\begin{array}{c}0.043^{* * *} \\
(0.01)\end{array}$ & $\begin{array}{c}0.049^{* * * *} \\
(0.02)\end{array}$ & $\begin{array}{l}0.045 \\
(0.04)\end{array}$ & $\begin{array}{c}0.090^{* * *} \\
(0.02)\end{array}$ & $\begin{array}{c}0.060^{* * *} \\
(0.03)\end{array}$ & $\begin{array}{c}0.131^{*} \\
(0.07)\end{array}$ \\
\hline $\mathrm{Age}^{2}$ & $\begin{array}{c}-0.000^{* * *} \\
(0.00)\end{array}$ & $\begin{array}{c}-0.000^{* * *} \\
(0.00)\end{array}$ & $\begin{array}{l}-0.001 \\
(0.00)\end{array}$ & $\begin{array}{c}-0.001^{* * *} \\
(0.00)\end{array}$ & $\begin{array}{c}-0.001^{* *} \\
(0.00)\end{array}$ & $\begin{array}{c}-0.002^{* *} \\
(0.00)\end{array}$ \\
\hline Married & $\begin{array}{l}-0.018 \\
(0.10)\end{array}$ & $\begin{array}{c}-0.188 \\
(0.19)\end{array}$ & $\begin{array}{l}-0.051 \\
(0.40)\end{array}$ & $\begin{array}{c}0.620^{* * * *} \\
(0.21)\end{array}$ & $\begin{array}{l}-0.011 \\
(0.30)\end{array}$ & $\begin{array}{l}0.869 \\
(0.60)\end{array}$ \\
\hline Female x Married & $\begin{array}{c}-0.046 \\
(0.12)\end{array}$ & $\begin{array}{l}0.101 \\
(0.24)\end{array}$ & $\begin{array}{l}-0.396 \\
(0.54)\end{array}$ & $\begin{array}{c}-0.619^{* *} \\
(0.26)\end{array}$ & $\begin{array}{c}-0.210 \\
(0.35)\end{array}$ & $\begin{array}{c}-0.669 \\
(0.81)\end{array}$ \\
\hline Read \& Write & $\begin{array}{l}0.105^{*} \\
(0.06)\end{array}$ & $\begin{array}{l}0.091 \\
(0.09)\end{array}$ & $\begin{array}{l}-0.224 \\
(0.23)\end{array}$ & $\begin{array}{c}-0.174 \\
(0.13)\end{array}$ & $\begin{array}{l}-0.201 \\
(0.15)\end{array}$ & $\begin{array}{l}0.304 \\
(0.43)\end{array}$ \\
\hline Firm Size & $\begin{array}{c}-0.125^{* * *} \\
(0.04)\end{array}$ & $\begin{array}{c}-0.084^{* *} \\
(0.04)\end{array}$ & $\begin{array}{c}-0.184^{* * *} \\
(0.04)\end{array}$ & $\begin{array}{c}-0.129^{* * *} \\
(0.02)\end{array}$ & $\begin{array}{c}-0.182^{* * *} \\
(0.02)\end{array}$ & $\begin{array}{l}-0.040 \\
(0.07)\end{array}$ \\
\hline Credit & $\begin{array}{c}0.245^{* * *} \\
(0.07)\end{array}$ & $\begin{array}{c}0.208^{* *} \\
(0.09)\end{array}$ & $\begin{array}{l}-0.231 \\
(0.26)\end{array}$ & $\begin{array}{c}0.441^{* * *} \\
(0.11)\end{array}$ & $\begin{array}{c}0.354^{* * *} \\
(0.11)\end{array}$ & $\begin{array}{c}0.663^{* *} \\
(0.28)\end{array}$ \\
\hline Shock & $\begin{array}{l}0.112^{*} \\
(0.07)\end{array}$ & $\begin{array}{c}0.104^{*} \\
(0.06)\end{array}$ & $\begin{array}{l}0.202 \\
(0.16)\end{array}$ & $\begin{array}{l}-0.037 \\
(0.08)\end{array}$ & $\begin{array}{l}-0.100 \\
(0.08)\end{array}$ & $\begin{array}{c}-0.178 \\
(0.26)\end{array}$ \\
\hline Migration & & & & $\begin{array}{l}0.140 \\
(0.11)\end{array}$ & $\begin{array}{l}0.043 \\
(0.12)\end{array}$ & $\begin{array}{l}-0.159 \\
(0.32)\end{array}$ \\
\hline Months in Operation & & & & $\begin{array}{c}0.062^{* * * *} \\
(0.02)\end{array}$ & $\begin{array}{c}0.047^{* * *} \\
(0.02)\end{array}$ & $\begin{array}{c}0.068^{* *} \\
(0.03)\end{array}$ \\
\hline Constant & $\begin{array}{c}8.491^{* * *} \\
(0.22) \\
\end{array}$ & $\begin{array}{c}8.415^{* * *} \\
(0.41) \\
\end{array}$ & $\begin{array}{c}8.641^{* * *} \\
(0.97) \\
\end{array}$ & $\begin{array}{c}8.715^{* * * *} \\
(0.64)\end{array}$ & $\begin{array}{c}9.574^{* * *} \\
(0.62)\end{array}$ & $\begin{array}{c}7.133^{* * *} \\
(1.60) \\
\end{array}$ \\
\hline $\begin{array}{l}\text { Time FE } \\
\text { FE }\end{array}$ & $\begin{array}{l}\text { Yes } \\
\text { Yes }\end{array}$ & $\begin{array}{l}\text { Yes } \\
\text { Yes }\end{array}$ & $\begin{array}{l}\text { Yes } \\
\text { Yes }\end{array}$ & $\begin{array}{l}\text { Yes } \\
\text { Yes }\end{array}$ & $\begin{array}{l}\text { Yes } \\
\text { Yes }\end{array}$ & $\begin{array}{l}\text { Yes } \\
\text { Yes }\end{array}$ \\
\hline $\begin{array}{l}\text { Female } \\
\text { Age } \\
\text { Married }\end{array}$ & $\begin{array}{l}0.000 \\
0.000 \\
0.868 \\
\end{array}$ & $\begin{array}{l}0.000 \\
0.006 \\
0.538 \\
\end{array}$ & $\begin{array}{l}0.024 \\
0.363 \\
0.442 \\
\end{array}$ & $\begin{array}{l}0.000 \\
0.000 \\
0.011 \\
\end{array}$ & $\begin{array}{l}0.005 \\
0.040 \\
0.441 \\
\end{array}$ & $\begin{array}{l}0.118 \\
0.084 \\
0.280 \\
\end{array}$ \\
\hline $\mathrm{N}$ & 7,749 & 5,048 & 787 & 4,495 & 3,619 & 905 \\
\hline
\end{tabular}

Note(s): Standard errors in parentheses. Household weights included. ${ }^{*} p<0.1,{ }^{* *} p<0.05,{ }^{* * *}$ $p<0.01$.

In terms of household characteristics, the effect of shocks is not significant in Uganda, and marginally significant and positive in Nigeria at the enterprise and household level. This outcome stands again in contrast to the results of the Heckman selection model.

In terms of enterprise characteristics, the effect of firm size has a significant and negative outcome for most regressions. As previously discussed, I assume that this outcome might be explained by the lack of information on the time-use of workers. Having taken out credit to expand the business is positive and significant in most regression results, leading to higher labor productivity. One interesting and significant variable available for Uganda 
is months in operation: the more months per year an enterprise is operated, the higher is its labor productivity, possibly reflecting better capacity utilization.

Summarizing the panel data analysis I find various outcomes that are comparable to the results of the Heckman selection model, for example the effect of the variables rural, gender and firm size. However, I also find diverging outcomes as in the case of education and shocks that call for further research. Different to the Heckman regression model, I use the variable credit to expand the business in the panel data analysis, which has a significant and positive effect on labor productivity. Credit that clearly serves the purpose of expanding the business shows a positive effect on labor productivity, compared to the previously used variable general access to credit. $^{10}$

\subsection{Summary and Concluding Remarks}

This chapter analyzes the determinants of labor productivity in rural African enterprises and provides an exploratory overview of this sector using the World Bank's LSMS-ISA data. The results suggest a link between a household's motivation to operate an enterprise and its subsequent productivity. In the remaining section, I first summarize the findings, before discussing policy implications in the second part.

In the descriptive statistics I find that location, gender, education and the experience of shocks report diverging levels of labor productivity. Using kernel density estimates, the results show that rural enterprises are on average less productive than their urban counterparts, confirming a widely held "stylized fact". In terms of location, the results also reveal a more complex and nuanced reality. Using data from Uganda, differences in regional productivity and by distance to the nearest population center can be identified. Enterprises located in regions that have been subject to a history of conflict are less productive. The closer an enterprise is located to an agglomeration, for example a secondary town, the higher is its productivity. I also find that female-owned enterprises are less productive than male-owned enterprises, that literate owners operate more productive enterprises and that the experience of a shock leads to lower labor productivity.

I further assess labor productivity by estimating two regression models. In the Heckman selection model I find that the ability to read \& write, a proxy for education, is associated

\footnotetext{
${ }^{10}$ See also Table A.10 in Appendix A for the same set of panel regressions using rural households only. I do not find major differences using the rural sample only, and conclude that both tables report comparable results.
} 
with higher labor productivity in all countries studied, and that the experience of a shock reduces labor productivity in Ethiopia, Malawi and Nigeria. If enterprises operated by households that experienced a shock select into low-return, but possibly low-risk activities, or if the shock itself leads to lower labor productivity once the enterprise is in operation, is subject to further research. Female-headed enterprises are also less productive in three out of four countries. In the majority of the countries I also find that rural enterprises are less productive, but that distance can have opposing effects on productivity.

Using panel data from Nigeria and Uganda I establish that enterprises in rural areas are less productive in Nigeria, but not in Uganda, and that female-owned enterprises are less productive in both countries. The results also indicate that productivity increases with age, a proxy for experience. The variable credit to expand the business is significant and positive in both countries, suggesting that credit for business purposes increases labor productivity over time. I also identify a positive association between the months of enterprise operation and labor productivity.

The results suggest a link between a household's motivation to operate a non-farm enterprise and its subsequent labor productivity. Enterprises that experience adverse circumstances in the selection stage, for example illiteracy or distance to urban areas, are less productive than enterprises that are operated as a result of households utilizing an opportunity, for example market access, education or access to finance. Labor productivity is also higher if enterprises operate throughout the year, probably due to better capacity utilization.

While the data reflects a difficult business environment for enterprises in rural Africa, I conclude that productivity improvements, higher enterprise growth and survival, and employment creation are feasible if well-designed policies are implemented to support non-farm entrepreneurship. I therefore recommend a set of policy implications to improve these business conditions. On the one hand, policies that have the potential to increase labor productivity and enterprise growth, on the other hand policies that prevent enterprises from stopping enterprise operations. With regard to the former, I suggest policies that support the enterprise owner or manager, such as education and training, or access to credit to expand business activities. With regard to the latter, I suggest policies that cushion shocks and protect households from negative external events, for example micro-insurance schemes or social protection policies. If policies are considered that tackle the difficulties from both angles (support entrepreneurs and shield households from detrimental events), they could have the potential to boost labor 
productivity, which in turn is expected to lead to higher growth and survival rates for small businesses, and eventually employment creation in rural Sub-Saharan Africa.

This chapter provides a first, explorative analysis of labor productivity in rural African enterprises, but calls for more and better research in this area. One of the principal shortcomings of the current analysis is due to data availability as discussed in Chapter 2. While the LSMS-ISA offer a rich data set, specific data challenges with regard to productivity continue to exist. First, the differences in the questionnaires among the countries studied only allows for limited comparability, for example in the calculation of labor productivity, where the partial productivity measure is calculated by taking either the average monthly sales, total sales of the last month or average gross revenues. Second, the measure of productivity is partial and imprecise. And third, useful variables and information are lacking and therefore limiting the analysis. For example the possibility to match the type of business activity with enterprise information, or more detailed information of enterprises that stopped operating in order to conduct survival analysis. 


\section{Part II}

\section{Unemployment Insurance Savings}

Accounts 

Chapter 5

\section{Overview and Data}




\subsection{Introduction}

Over the past years emerging and developing economies have gained increased interest in introducing sustainable social protection schemes to shield individuals and households from economic shocks when losing employment. ${ }^{1}$ Advanced economies have similarly shown interest in insurance alternatives that tackle long-standing difficulties, for example moral hazard or the costly monitoring of the unemployed, considering unemployment insurance savings accounts (UISA) as a possible option. Various articles have been published discussing theoretical models or simulations with real life data for advanced countries (Orszag and Snower, 2002; Brunner and Colarelli, 2004; Feldstein and Altman, 2007; Bovenberg et al., 2008; Hopenhayn and Hatchondo, 2012). Empirical evidence is however still scarce, as this kind of unemployment protection has not yet been introduced in more advanced economies. It has been argued in the theoretical literature that mandatory savings schemes could offer an alternative for the disadvantages of unemployment insurance based on risk-pooling for developed countries, or of severance pay in the case of developing countries. They could present a more viable social protection design that is more convenient to the framework of emerging economies due to specific features of developing countries, for example a large informal labor market (Robalino et al., 2009; Vodopivec, 2013). UISA originated in Latin America, where they were introduced as early as 1966 in Brazil alongside employment insurance based on riskpooling. They got prominent in various Latin American countries, including Chile, during the 1990s, when unemployment rates increased significantly due to the Asian crisis. According to Latinobarómetro, a public opinion survey performed in the major cities of the continent, unemployment presented the main concern of the population during this decade (Acevedo et al., 2006).

Unemployment insurance based on risk-pooling has been widely studied. Individualized instruments, however, are empirically still an uncharted area of research (Reyes et al., 2011). It continues to be unclear, for example, if different outcomes are consequences of different UISA designs, or if they are consequences of differences in the socio-economic framework of countries. Studying new aspects of unemployment accounts will help to shed light on new aspects of this kind of unemployment protection and provide more insights for countries that have already implemented this scheme. It is equally helpful to illustrate

\footnotetext{
1 This chapter is based on the article: Nagler, P. (2013). How Unemployment Insurance Savings Accounts Affect Employment Duration: Evidence from Chile. IZA Journal of Labor \& Development, 2:9. And on the working paper: Nagler, P. (2015). The Impact of Unemployment Insurance Savings Accounts on Subsequent Employment Quality. UNU-MERIT Working Paper No. 2015-026.
} 
consequences on different labor market outcomes for countries that are interested in implementing UISA, or in modifying and extending existing schemes.

This chapter is structured as follows. In Section 5.2 the general concept of UISA is described, followed by an overview of existing schemes in Latin American countries in Section 5.3. Section 5.4 assesses how the schemes have so far evolved, and in Section 5.5 the Chilean UISA scheme is described in more detail. In Section 5.6 the database used for the analysis in the Chapters 7 and 8 is presented. The final section summarizes the findings and concludes.

\subsection{Description of UISA}

UISA are individualized savings accounts to which employers, and in certain cases also employees, pay monthly contributions to save up for possible unemployment spells in the future. In the event of becoming unemployed, workers can withdraw funds from their individualized savings accounts at a rate dependent on the account balance and the contribution history to smooth consumption over the search period until finding new employment or to mitigate the income shock after the job loss. As the scheme consists of regular mandatory savings, it can be considered a delayed payment to the worker if paid exclusively by the employer. At the end of a person's working life, the account balance is reverted to the worker or added to retirement savings, provided that the balance is positive. The individualized accounts stimulate workers to be quickly re-employed to keep account balances positive, and therefore internalize the costs of unemployment spells. Compared to unemployment insurance that is based on a pay-as-you-go (PAYG) scheme, this form of unemployment protection is fully funded through the monthly payments into the individual accounts (Moreno, 2008).

The design of the UISA varies considerably over countries. Depending on the design, workers can access their accounts for any cause of job loss, or have to be dismissed for certain reasons, most commonly due to firm necessities. In Chile, a solidarity fund from the government tops up the benefits of unemployed workers who have an insufficient balance on their account, combining individual savings with unemployment insurance. In some countries workers can also use their savings as collateral for housing credits or educational investments (see also Table 5.1). A common feature of the scheme is the participation of formal workers only, leaving out workers of the large informal sector in Latin American countries (Ferrer and Riddell, 2011). 


\subsection{UISA in Latin America}

Since the introduction of UISA in October 2002, Chile has been a prominent country example in offering unemployment benefits through individualized savings accounts, even though it has not been the pioneer in implementing this type of unemployment protection. Other countries have provided unemployment protection through UISA for more than 20 years, for example Brazil, Colombia, Panama and Peru, while other countries have recently introduced unemployment accounts, for example Chile and Ecuador.

Different design options show the versatility of UISA. While unemployment accounts cover in most cases all dependent workers, Argentina provides this type of unemployment protection to construction workers only, and Brazil and Peru to dependent workers not covered elsewhere. Contributions come exclusively from the employer's side with the exception of Chile, where workers with permanent contracts are required to pay 0.6 percent of the gross salaries into their accounts. Most countries also allow voluntary contributions to the savings accounts. Contributions vary from as low as one week's wage per year in Panama, to 12 percent of one month's wage during the first year of a new labor contract for construction workers in Argentina. Access to the account balance when terminating the employment relationship can be independent of the cause of job separation, or based on proof of dismissal, requiring that the job loss occurred due to involuntary separation. In general, workers receive the complete account balance at the time of separation, with the exception of Chile and Ecuador, where workers receive their savings in various installments. In some countries (Brazil, Colombia, Panama and Peru) workers can also use their savings for housing or health expenses, as a collateral for housing loans, or as investment in education. Chile is the only country offering a solidarity fund in combination with UISA, adding an insurance component to the scheme.

An overview of UISA in Latin America shows the variety of design options, depending on economic possibilities and country preferences. The following Table 5.1 describes the UISA programs in eight Latin American countries.

\subsection{UISA Assessment}

Unemployment accounts adhere to various advantages compared to unemployment insurance based on risk-pooling or lump-sum cash payments from severance liabilities. 


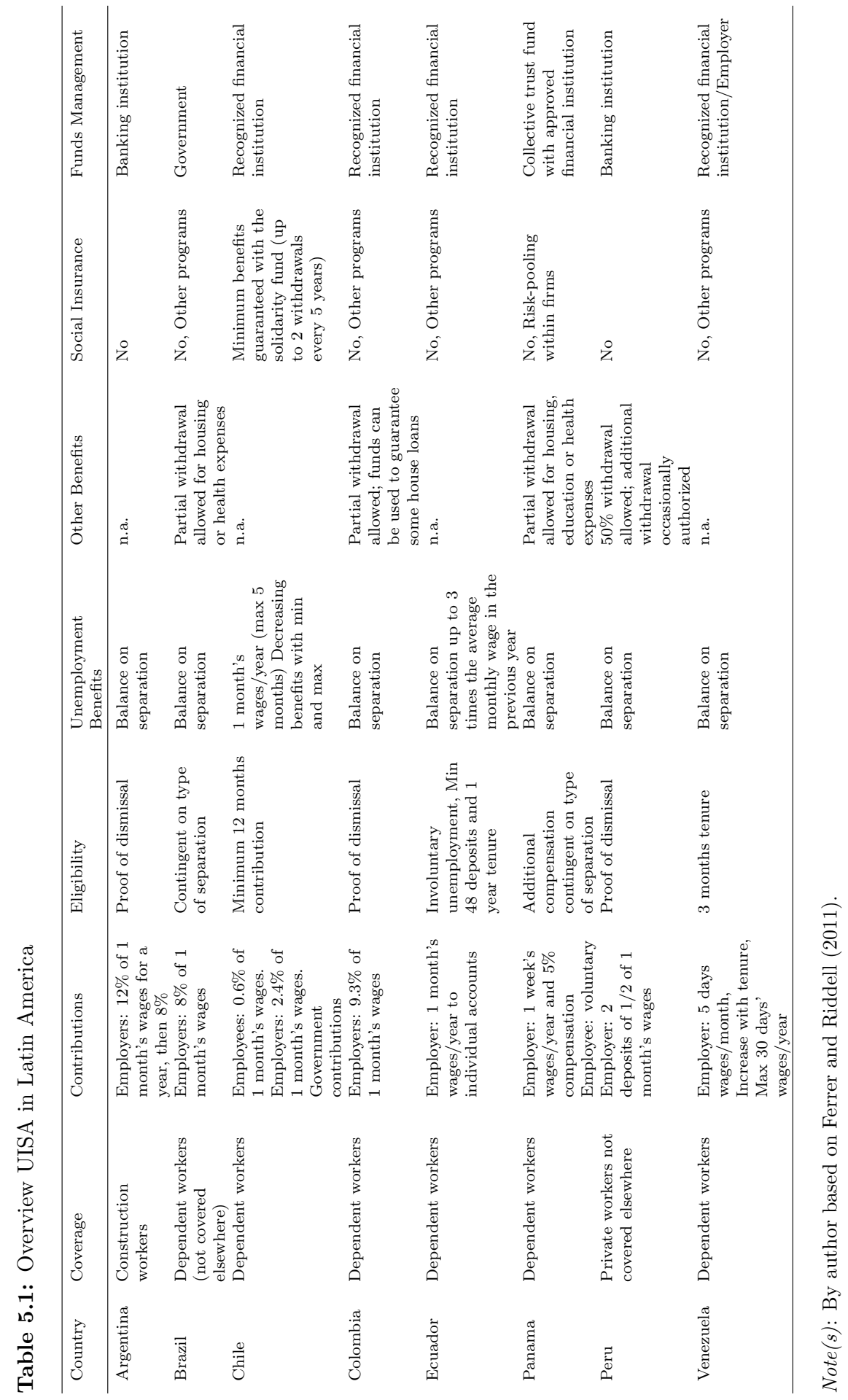


First, they reduce the moral hazard problem prevalent in unemployment insurance schemes by internalizing the costs of unemployment spells. As accumulated savings in the account belong to the worker instead of being channeled into a common risk-pool, it can be expected that unemployed workers show higher efforts to seek quick reemployment instead of depleting the savings. With unemployment insurance, however, workers only tend to considerably increase search efforts when the benefits are close to termination, generally leading to higher insurance costs and a higher unemployment rate. As a result, unemployment insurance requires intensive and well-functioning monitoring capacities, which emerging and developing economies encounter difficult to provide due to lower administrative capacities and a large informal labor market. Workers could, for example, continue receiving unemployment benefits while being officially unemployed and seek employment in the informal economy (Ferrer and Riddell, 2011).

Second, more often than to unemployment insurance, UISA are assessed compared to severance pay, the most common form of unemployment protection in emerging and developing countries for the formal work force. The rationale of severance payments is based on three explanations: (i) they provide an employer-financed safety net for the dismissed worker, mitigating the income shock for workers who lose employment and smoothing consumption while seeking reemployment. (ii) The payments function as a human resource instrument by keeping workers in the firm and promoting longer-lasting employment relationships. Longer employment duration offers various advantages: they can increase firm incentives to invest in more training of the workforce, resulting in higher productivity. They can also increase efficiency by avoiding the loss of firm-specific knowledge and reducing transaction costs of frequent hiring (Holzmann and Vodopivec, 2012). Finally, (iii) longer employment duration can also lead to higher levels of trust, cooperation and loyalty between workers and employers, equally resulting in higher levels of productivity and possibly decreasing resistance of the workers towards the introduction of new technologies (OECD, 1999).

As a third explanation, they function as an employment protection device by imposing a penalty on the employer for dismissing workers due to unjust reasons, economic constraints or downsizing of the firm, reducing high labor turnover. While the first two explanations suggest positive returns of severance payments, economists generally associate these payments with negative outcomes. This form of employment protection can impose additional financial constraints on employers when the economy is facing a downturn or a financial crisis, possibly leaving the employer in times of tight economic constraints in even further financial distress (Sehnbruch, 2004). Overall, however, the 
outcome is ambiguous and not well researched (Holzmann and Vodopivec, 2012).

Although severance payments do not create moral hazard on the worker's side compared to unemployment insurance, they do create moral hazard on the employer's side, as employers have incentives to avoid paying the lump-sum when terminating the labor contract. Severance payments can reach considerable size for workers with various years of tenure, possibly leaving firms in a difficult financial situation when the payment is due (Kugler, 2002; Ferrer and Riddell, 2011). UISA require continuous and regular payments instead, which are paid out to the worker when terminating the labor contract. Some countries grant access to the accounts independent of the reason of ending the employment relationship, avoiding therefore the need to define the termination as "just" or "unjust", preventing judicial processes (Robalino et al., 2011).

Further advantages of UISA consist in the low administrative requirements, as implementing and monitoring the program can be incorporated in existing agencies or institutions, and increased savings rates which are invested in money market instruments, improving the liquidity of the financial market (Sehnbruch, 2006).

Although having a number of advantages over other forms of unemployment protection, UISA also present own problems. Individualizing savings accounts can present a major disadvantage, as specific groups of workers, for example young workers, workers with temporary contracts or certain job categories with a high turnover, fail to build up sufficient savings for periods of unemployment. Taking into consideration that more vulnerable working groups generally face higher unemployment rates, the scheme might not deliver adequate income protection for workers who most need it (Sehnbruch, 2006; Ferrer and Riddell, 2011).

Another controversial aspect concerns distribution and inequality. In highly unequal countries income distribution could be partly conducted through insurance schemes based on risk-pooling, where low-income workers are better protected through higher payments of high-income workers with more stable work relations. With individualized schemes this possibility falls away or can only be partly executed through a solidarity fund, as it is the case in Chile. ${ }^{2}$ Is it therefore arguable, if an unemployment protection scheme that is based on the principle of as little risk sharing as possible, constitutes a good idea for countries suffering from severe inequality (Sehnbruch, 2006).

\footnotetext{
${ }^{2}$ While distribution can be achieved through risk-pooling, it is not clear if this is the case for the Chilean UISA scheme, as no research has yet been conducted that analyzed the distributional effects of the solidarity fund.
} 
Finally, the insurance name of the scheme can be misleading. Pure savings accounts are forced savings schemes, but do not include an insurance component where the unemployment risk is pooled among a larger group of workers. Although both types of protection scheme can be combined, as it is the case in Chile, workers generally need to fulfill specific requirements to access the insurance component (Sehnbruch, 2004).

\subsection{The Chilean UISA Scheme}

This section provides an overview of the Chilean UISA scheme, consisting of a description of how unemployment protection was organized before the new policy introduction, as well as the historical and economic context of the new legislation. Further, the section provides a detailed description of the scheme and a summary of the changes affecting workers and employers. ${ }^{3}$

\subsubsection{Context}

Before the introduction of UISA, severance pay was the principal form of unemployment protection in Chile for workers dismissed according to Labor Code $161,{ }^{4}$ complemented by benefits financed by social security and additional minor support programs. ${ }^{5}$ Severance pay led to labor market rigidities, but offered limited protection to unemployed workers, as only workers dismissed due to economic necessities or bankruptcy of the firm received benefits during unemployment spells, often without the guarantee of payout. ${ }^{6}$ The complementary unemployment benefits by Social Security were minimal and independent of previous salaries. Further support was provided through workfare programs for lowincome workers, hiring subsidies for firms, unemployment insurance for domestic helpers and job search assistance (Acevedo et al., 2006). ${ }^{7}$

3 See also Nagler (2013).

4 Article 161 of the labor code. Dismissal due to company needs (economic reason or downsizing).

${ }^{5}$ For each completed year of employment, workers were entitled to one month severance pay with a maximum of eleven years.

${ }^{6}$ Limited protection can result through restricted access to severance pay, as workers often face strict regulations of severance pay eligibility, and may involve long judicial processes if firms try to evade their payment obligations. Furthermore firms which are in financial distress or go bankrupt may be unable to transfer the required amount to their previous employees (Acevedo et al., 2006).

7 These additional support programs were often uncoordinated and ineffective. For the workfare programs only minimum wages were paid, the discretionary design presented problems, and the rushed implementation in times of crisis led to suboptimal program design. The hiring subsidies in times of high unemployment, in turn, were expensive (about 60 million USD), and abuse of the program 
The political and economic context of UISA introduction was based on two major events: (i) the political change in 1990, when democracy was restored in Chile, and center and left-wing parties formed a coalition giving priority to improving workers' position, leading to an extension in severance pay, and (ii) the sharp increase in the unemployment rate end of the 1990s due to a deterioration in terms of trade and external demand and the negative impact of the Asian crisis, leaving many workers unemployed and without means to smooth consumption (Acevedo et al., 2006).

The development and design of the new scheme involved various parties with different concerns and interests. While the government intended to limit moral hazard, employers were worried about labor market flexibility, and workers, represented by labor unions, did not want to forfeit "hard won rights" as they considered the extension of severance pay after the political change in Chile (Sehnbruch, 2004). With the expansion in unemployment protection in terms of access and amount of benefits transferred, while limiting moral hazard through individualized accounts (Reyes et al., 2011), and moderately relaxing the severance pay obligations, the new unemployment policy was approved 2001 in Congress with a high political consensus, and implemented in October 2002 (Acevedo et al., 2006).

\subsubsection{Detailed Description}

The new unemployment protection consists of two components: (i) individual savings accounts for each worker as a form of self-insurance, backed up by (ii) a solidarity fund (SF) that functions similarly to an unemployment insurance based on risk-pooling. The scheme covers all private sector workers over 18 years, with either a temporary or permanent contract. Enrollment into the new scheme is mandatory for all workers starting a new employment contract after October 2002, avoiding adverse selection. Workers who started a new employment before the introduction date can voluntarily switch to the new system, but only very few decided to do so. ${ }^{8}$

The financing of UISA is regulated differently by contract type. For employees with a permanent contract UISA contributions are financed by both employer and employee $(2.4$

was widely reported. Unemployment insurance for domestic helpers only covered this small sector of domestic employees, and job search assistance was performed at the local level leading to limited geographical coverage (Acevedo et al., 2006).

8 In my sample only 8 out of 3,384 workers who started a new employment during the two years before UISA introduction are voluntarily affiliated to the new scheme, presenting below 0.5 percent of the sample. Huneeus et al. (2012) report 2 percent voluntary affiliation by December 2010. 
percent and 0.6 percent, respectively), and are split between the individual account to save up for possible unemployment spells (2.2 percent) and the common SF (0.8 percent). The latter is also co-financed by the government with approximately 16 million USD per year (Huneeus et al., 2012). ${ }^{9}$ For employees with a temporary contract only the employer contributes to the savings account with 3.0 percent and workers do not have access to the SF. ${ }^{10}$

Benefits were considerably extended in terms of eligibility and total amount transferred. Although the previously existing unemployment subsidy lasting for twelve months was replaced by transfers lasting for a maximum of five months, the current support system is more generous, translating into overall higher transfers. The accumulated benefits in the individual accounts are transferred to workers terminating their employment for any cause, ${ }^{11}$ conditional that they have worked for a certain minimum period of time: six months for workers with temporary contracts, and twelve months for workers with permanent contracts, continuous or discontinuous, since they became affiliated to the scheme or since the last time they requested and were granted benefits (Huneeus et al., 2012). Workers with permanent contracts who lose their employment according to Labor Code 161 are equally better protected, as they have, apart from the severance pay and their accumulated savings, access to the SF in case of low individual savings. In this case access to the SF is optional, and if workers decide to receive these benefits they have to accept additional conditions: (i) they have to pay monthly visits to the municipal employment office, (ii) they must be willing to participate in training programs and (iii) they must accept job offers paying at least 50 percent of their pre-unemployment wage (Reyes et al., 2011). Finally, workers who do not become unemployed during their working life receive their accumulated account balance when retiring (Sehnbruch, 2004).

Table 5.2 summarizes the changes in unemployment benefits before and after UISA introduction. For all events (job change, unemployment, inactivity, retirement and death of the worker) the current situation with UISA is more beneficial for the worker or his/her dependents: for a change in employment, opportunity costs decreased, while in all other cases accumulated savings are directly transferred to the worker or the dependents.

Since the UISA reform, severance pay continues to be paid out in case of dismissal due to economic necessities of the firm with the possibility of deducting accumulated savings

\footnotetext{
9 See also Figures B.1 and B.2 in Appendix B.

${ }^{10}$ Since a reform in May 2009 workers with temporary contracts are also eligible to receive unemployment benefits through the solidarity pillar. Huneeus et al. (2012) describe the 2009 reform in more detail.

${ }^{11}$ Also in case of just cause, including the following events: expiration of contract, voluntary resignation or misconduct.
} 
Table 5.2: Benefit Changes Before and After UISA Introduction

\begin{tabular}{|c|c|c|}
\hline EVENT & Before UISA & After UISA \\
\hline Job change & $\begin{array}{l}\text { Loss of accumulated rights to severance } \\
\text { pay }\end{array}$ & $\begin{array}{l}\text { Loss of severance pay (as before), keeps } \\
\text { accumulated savings in UISA account }\end{array}$ \\
\hline Unemployment & $\begin{array}{l}\text { Severance pay if job loss occurred due to } \\
\text { Labor Code } 161 \\
\text { All other cases: nothing }\end{array}$ & $\begin{array}{l}\text { Severance pay (as before), transfer } \\
\text { of accumulated savings (maximum five } \\
\text { months), solidarity fund if applicable }\end{array}$ \\
\hline Inactivity & $\begin{array}{l}\text { Severance pay if job loss occurred due to } \\
\text { Labor Code } 161 \\
\text { All other cases: nothing }\end{array}$ & $\begin{array}{l}\text { Severance pay (as before), transfer } \\
\text { of accumulated savings (maximum five } \\
\text { months) }\end{array}$ \\
\hline Retirement & Nothing & $\begin{array}{l}\text { Transfer of accumulated savings given } \\
\text { account balance is positive }\end{array}$ \\
\hline Death & Nothing & $\begin{array}{l}\text { Transfer of accumulated savings given } \\
\text { account balance is positive to surviving } \\
\text { dependents }\end{array}$ \\
\hline
\end{tabular}

Note(s): By author based on Acevedo et al. (2006).

from the severance pay liabilities. While it does not directly improve the situation of employers, it alleviates the ad-hoc obligation of the firm when the severance pay is due.

\subsection{The EPS Database}

The database used in the second part of the thesis is the Chilean EPS database, ${ }^{12}$ a longitudinal survey with questions on the individual and household level about the Chilean labor market and social protection system. ${ }^{13}$ The survey was conducted in 2002, 2004, 2006 and 2009 and contains retrospective data since January 1980. When the first round was conducted in 2002, the sample was drawn from a frame of 8.1 million current and former affiliates of the Chilean pension system included for at least one month in the time frame 1980 to 2001 containing 17,246 individuals, 937 of them reported by surviving relatives. The survey was extended in 2004 with non-affiliated individuals, completing the base sample, and has since then been representative on the regional and national level for the entire Chilean population. Since 2004 the data is linked to the administrative records of the pension scheme, health insurance, the cash transfer program "Chile Solidario" and other welfare programs. In 2004 new health and wealth questions were added to the questionnaire. In 2006 and 2009 the sample was kept and includes

\footnotetext{
12 The acronym EPS stands for Encuesta de Protección Social in Spanish, or Social Protection Survey in English (Subsecretaría de Previsión Social Chile, 2009).

${ }^{13}$ The survey is conducted by the Centre for Microdata, Department of Economics, of the University of Chile (Centro Microdatos, Universidad de Chile) with the support of the University of Pennsylvania.
} 
approximately 16,000 individuals (15 years and older) of all regions. ${ }^{14}$ The EPS is the first panel survey conducted in Chile with four rounds of data collection covering this range of thematic areas. The questionnaires contain sections on labor history and social security, education, health, social protection, labor training, property and patrimony, family history and housing. ${ }^{15}$

\subsection{Summary and Concluding Remarks}

This chapter provides an overview of unemployment insurance savings account. It explains the concept of the scheme and presents an overview of Latin American countries that have implemented this type of unemployment protection, showing a broad range of options on how the scheme can be designed. The assessment outlines the advantages of UISA, but also points to disadvantages, such as insufficient unemployment protection for specific group of workers, and the limitations with regard to distributional aspects due to a lack of risk-pooling. The Chilean scheme is presented in detail, including a discussion on the historical and economic context, the design of the scheme and a summary of changes that affect both workers and employers. Finally, the database used in the Chapters 6 and 7 is described.

This chapter also suggests that labor market outcomes can be expected to differ from work that has so far been conducted on the labor market effects of unemployment insurance. The literature analyzing unemployment accounts still has a large research gap. The review also suggests that labor market conditions are very different in emerging and developing economies compared to an advanced country's context. The extant literature, however, illustrates a clear emphasis on advanced economies, using largely data from Europe, the United States and other Western countries. In the second thematic block of this thesis, I address these two shortcoming by providing an analysis of unemployment insurance savings accounts using the Chilean social protection survey. In Chapter 6 I analyze if the introduction of UISA had an effect on the employment duration, and in Chapter 7 if the unemployment protection scheme had an impact on the subsequent employment quality of affiliated workers.

\footnotetext{
${ }^{14}$ In each survey round three different types of questionnaires account for repeated, new and deceased participants.

${ }^{15}$ See also Nagler (2013).
} 
Chapter 6

\section{Employment Duration}




\subsection{Introduction}

This chapter analyzes if the introduction of unemployment insurance savings accounts had an impact on employment duration of workers affiliated to the scheme. ${ }^{1}$ Due to the introduction of the new unemployment protection scheme in Chile, labor market conditions changed for formal private sector workers. Before the introduction, unemployment protection was practically limited to severance pay in case of job termination due to economic necessities of the firm. Additionally, high opportunity costs were involved in a job change, and employers had to deal with rigid labor market regulations. After the introduction of UISA, the access to and amount of benefits transferred to workers in case of unemployment or inactivity increased, and opportunity costs of workers changing employment decreased, while ad-hoc obligations of employers to lay off workforce were reduced.

While incentives to exit unemployment have been studied in this context (Reyes et al., 2011; Huneeus et al., 2012), this chapter is the first to my knowledge to empirically investigate the effect of UISA on employment duration. I fill the gap by using longitudinal social protection data containing information of employment duration of formal private sector workers before and after the introduction of the policy. The chapter examines (i) whether the introduction of UISA affected employment duration among formal private sector workers, and (ii) the magnitude of this effect. Following the policy introduction, I expect that workers reacted to the changes by reduced employment duration.

I conduct an empirical analysis using survival analysis techniques to analyze employment duration. First, I focus exclusively on the failure of the employment relation: if the current employment relation was terminated, irrespective of the event that follows. Second, I apply a competing-risk model, where the different events following employment termination are taken into account.

The results confirm that workers affiliated to the scheme show an increased hazard ratio of leaving employment, or accelerated time to employment termination, suggesting shorter employment duration and higher mobility of the workforce. They have a higher hazard of leaving employment in the Cox model, or accelerated time to failure in the parametric analysis, with this effect being statistically significant throughout the analysis. In the competing-risk analysis, the outcome is equally significant if the following event is a new

\footnotetext{
1 This chapter is based on the article: Nagler, P. (2013). How Unemployment Insurance Savings Accounts Affect Employment Duration: Evidence from Chile. IZA Journal of Labor \& Development, 2:9.
} 
employment relation or unemployment, and for the final regression model in the case of inactivity. The effect is larger for workers becoming unemployed or inactive compared to workers changing jobs.

The chapter is organized as follows. In Section 6.2 the extant literature on severance pay and labor mobility is discussed. Section 6.3 presents descriptive statistics of relevant variables and Section 6.4 describes the method used for the analysis. In Section 6.5 I apply survival analysis techniques for the empirical analysis and discuss the results. I start with the non-parametric analysis using the Kaplan-Meier (KM) estimator, continue with the semi-parametric Cox model and parametric models, before finalizing the analysis with competing-risk models where three different possible endpoints are taken into account. The final section concludes with a summary and provides policy recommendations and suggestions for future research.

\subsection{Literature Review}

Severance pay is a widespread form of unemployment protection, particularly in developing countries (Vodopivec, 2004, 2013) due to large informal labor markets and limited administrative and financial capacities to introduce unemployment insurance (Holzmann et al., 2011). Severance pay is however widely criticized and considered an inappropriate option for income protection. While severance pay intends to provide compensation for job loss and to stabilize the economy by discouraging layoffs and encouraging long-term work relations, it can distort the behavior of workers and firms, and often provides workers with limited protection during unemployment spells (Feldstein and Altman, 2007; Hopenhayn and Hatchondo, 2012). Labor market distortions are caused by negative effects on both worker accession and separation, and consequently on labor turnover and mobility. ${ }^{2}$ Severance pay increases firing costs and reduces consequently the probability that workers become unemployed, but also hinders job creation and prolongs unemployment spells (Nickell, 1997; Blanchard, 2000). It further decreases the dynamics of structural change due to reduced mobility of the workforce as firms face high payment obligations (Calmfors and Holmlund, 2000). A number of studies additionally confirm the link between higher job security and lower employment levels. ${ }^{3,4}$ Limited protection can result through restricted access to severance pay, as workers often face strict regulations of

2 Cross-country evidence, among others: Gomez-Salvador et al. (2004), Messina and Vallanti (2007) and Boeri and Garibaldi (2009).

3 Among others: Heckman and Pagés (2000), Haffner et al. (2001) and Haltiwanger et al. (2003).

4 For a more extensive literature overview on severance pay, see also Holzmann and Vodopivec (2012). 
severance pay eligibility, and may involve long judicial processes if firms try to evade their payment obligations. Furthermore firms which are in financial distress or go bankrupt may be unable to transfer the required amount to their previous employees (Acevedo et al., 2006).

While unemployment protection through severance pay is often criticized, some form of unemployment protection can be beneficial not only for the individual worker, but for the economy as a whole. Higher unemployment protection entails, for example, positive outcomes for workers through consumption smoothing and the promotion of higher reemployment stability (Wulfgramm and Fervers, 2013), and for the economy through higher productivity levels (Acemoglu and Shimer, 2000).

In the case of Chile severance pay implied financial support to a restricted group of workers during unemployment spells, as only workers who lost their employment before the expiration of the contractual agreement due to economic or other needs of the firm received benefits. What is more, severance pay obligations did not guarantee the payout of the severance liabilities, as previously explained. ${ }^{5}$ In addition, workers lost their accumulated rights to severance pay in case of a job change, leading to high opportunity costs. On the one hand, due to reduced transfers that are based on tenure in case of job loss. On the other hand, due to a more likely lay off during bad economic times, as workers with less tenure are "cheaper" to fire. In the case of Chile Montenegro and Pagés (2004) show that severance pay resulted in increased protection rights for older and high-skilled workers, while it reduced labor market opportunities for younger and unskilled workers in the period from 1960 to 1998 through the link with tenure.

Empirical papers on the effects of UISA after the transition from severance pay to UISA, and particularly on changes in workers' behavior are still rare and many researchers have relied on simulations instead. ${ }^{6}$ Kugler (2002) documents the transition from severance pay to UISA in Colombia in 1990. Her results show that although UISA partly substituted employer insurance with self-insurance in form of lower wages, the scheme smoothed consumption for the unemployed. The introduction of UISA also reduced distortions in the labor market by increasing both hiring and dismissals, and led to higher labor mobility.

\footnotetext{
5 In my sample only 56 percent of workers received severance pay if employment was terminated by economic necessities or a shutdown of the firm. Before the introduction of UISA 59 percent received severance pay compared to 51 percent after the policy introduction. This difference is however not significant due to a small number of observations.

${ }^{6}$ Among others: Fölster (1999, 2001), Feldstein and Altman (2007) and Vodopivec (2010).
} 
A number of papers have analyzed the transition in Chile in a more general context: Acevedo et al. (2006) discuss the political, social and economic situation in which this program was implemented and assess the challenges. Sehnbruch (2004) concentrates on embedding the new Chilean unemployment scheme into the context of Latin American labor market legislation, while Sehnbruch (2006) examines how the scheme works in practice and whether it can serve as a model for other emerging and developing economics. Berstein et al. (2012) analyze the Chilean UISA scheme as a whole and provide an overview of outcomes and reforms since its implementation. More specific issues have been address by Reyes et al. (2011) who analyze the job-finding rates of unemployment benefit recipients and Huneeus et al. (2012) who look specifically at the change in search efforts of unemployed workers before and after the UISA reform in May 2009.

The effect of UISA on employment duration (and consequently on labor mobility) for Chile is hitherto unclear and provides little evidence. While Berstein et al. (2008) show that formal private sector workers value the new unemployment benefits more than its costs, ${ }^{7}$ limited knowledge about UISA and its design could however work against a change in labor mobility (Poblete, 2011). A first study by Reyes (2005) on the duration of employment contracts using life tables suggests that workers affiliated to UISA show shorter employment duration with 33 percent "surviving" the first year of employment, compared to 52 percent for workers who are not affiliated. The author then focuses on workers below the age of 30 to reduce selection bias and finds that workers affiliated to UISA still show a difference of 7 percentage points compared to workers not affiliated. The author uses a different database ${ }^{8}$ and concentrates specifically on methodological issues to assess the question.

\subsection{Descriptive Statistics}

The database used in this chapter is the Chilean EPS database, as described in Section 5.6 of Chapter 5. For the analysis I focus on specific variables of the EPS database. The dependent variable is employment duration for private sector workers measured in months, the main explanatory variable UISA affiliation. I define affiliation to the

\footnotetext{
7 They value the benefits to different extent, depending on risk aversion, gender and educational level, but always equal or more than its costs. The authors conduct an evaluation of workers' lifetime utility with and without UISA: lifetime consumption preferences of individuals are described with a constant absolute risk aversion (CARA), allowing them to smooth consumption while economically active.

8 Database used: Administrative records of the contribution history and benefits paid to the workers affiliated to the unemployment benefit program by the Superintendencia de Pensiones.
} 
UISA scheme as follows: I allocate a binary variable UISA $(=0)$ to all employment relations that started during the year before the UISA introduction (October 2001 to September 2002), and I allocate UISA (=1) to all employment relations that started during the year after the UISA introduction (October 2002 to September 2003). As affiliation to the new scheme is mandatory for all private sector workers who started a new employment after the introduction date, I make the assumption that all these workers are affiliated to the scheme. ${ }^{9}$ Further explanatory variables included are general information of the worker: gender, age, education, risk aversion, household size, working household members, number of children and civil status, as well as work related information of the worker: contract type, hours worked per week, monthly net wage, firm size, region of employment and knowledge of UISA. ${ }^{10}$

The additional explanatory variables are defined as follows. Gender is coded as female $(=1)$, age is the age of the worker in years. Education is split into four dummy variables: basic education (the reference category), high school, professional formation and higher education (university and higher). Risk aversion was measured by asking survey participants about their individual risk assessment on a scale from 0 (for individuals considering themselves as highly risk averse) to 10 (for individuals stating they are highly disposed to take risk). Household size, working household members and children are defined as number of people in the household and working, and number of children in the household. Civil status is defined as married $(=1)$ and includes cohabiting. Contract type is coded as temporary contract $(=1)$, and the variable hours are the average hours worked per week. Wage is split into five dummy variables: zero wage (the reference category), wage up to 100,000 CLP, between 100,000 and 200,000 CLP, between 200,000 and 300,000 CLP, and above 300,000 CLP. ${ }^{11}$ Firm size is the number of workers in the firm. Region of work is captured by a binary variable indicating if the worker lives in the metropolitan region of Santiago $(=1)$, and knowledge of UISA $(=1)$ is a self-reported variable of workers indicating if they know or have heard about the new unemployment protection.

The final sample for the analysis consists of 2,323 employment relations composed by formal private sectors workers of 18 years and older who started a new employment during the year before or after UISA introduction. 1,489 employment relations started during the year before the policy introduction (between October 2001 and September

\footnotetext{
9 This binary variable is not a self-reported variable, nor does it include any information on benefit collection.

${ }^{10}$ Summary statistics of all variables can be found in Table B.1 of Appendix B. See the same appendix for the construction and definitions of these variables.

${ }^{11}$ On 23 July 2015: 1 USD = 654 CLP [www.xe.com].
} 
2002), and workers are not affiliated to the UISA scheme. ${ }^{12} 834$ employment relations started in the year after the policy introduction (between October 2002 and September 2003), and workers compulsorily joined the new unemployment scheme. As workers can start more than one employment during the two years period, the 2,323 employment relations represent 1,848 single individuals.

Table 6.1 reports longer employment duration for workers not affiliated to the UISA scheme. However, this outcome can be misleading, as these workers started employment in the year before the workers affiliated to the scheme. Additionally, 343 observations are censored, therefore still ongoing at the moment of the last survey round, leading to an expected downward bias of the estimated mean. Some individuals were also observed more than once, if they ended their employment within the considered time frame and started a new employment, and cannot be considered independent observations. ${ }^{13}$

Table 6.1: Change in Employment Duration - by UISA Introduction

\begin{tabular}{lccccc}
\hline UISA & Months & St. Err. & {$[95 \%$ Conf. Interval $]$} & Freq. \\
\hline Before & 31.9 & 0.80 & 30.37 & 33.50 & 1,489 \\
After & 22.8 & 0.87 & 21.04 & 24.47 & 834 \\
\hline Total & 28.6 & & & & 2,323 \\
\hline
\end{tabular}

For the competing-risk analysis, I additionally take the following event into account, after finishing the initial employment relation. For workers who ended their employment within the survey rounds, the distribution of the following event is divided into: 798 individuals changed into a new employment, 864 became unemployed, and 318 became inactive. The following event is approximately equally distributed between change in employment and unemployment with ca. 40 percent each. Slightly more workers face unemployment after terminating their current employment relation, compared to a new employment contract. Inactivity is observed among 16 percent of the workers.

I can observe further characteristics of the following employment relation. Among all workers changing into a new employment 85 percent find again a formal employment,

\footnotetext{
${ }^{12}$ I exclude all workers who voluntarily changed to the new UISA scheme. Only 5 workers in my sample did so, representing less than 0.5 percent of the sample.

${ }^{13}$ Repeated spells: throughout the analysis I run the regressions by clustering the observations by their unique identifier. By specifying clusters the single observations are not considered independent, but the clusters defined. Due to repeated spells in the data set, I clustered the ID of the observations, as the same worker can be observed more than once since more than one job can be started during the two year period considered. It is reasonable to assume independence of individuals, but not within different observations of the same individual. Specifying the ID clusters in the regressions, I obtain robust standard errors. In case of observing intra-cluster correlations, the robust standard errors are better indicators for estimator variability, resulting in more accurate outcomes.

Models with individual-level frailties (random-effect models in survival analysis) did not converge in the semi-parametric analysis.
} 
slightly more than half (52 percent) find a permanent position, and approximately 82 percent continue as private sector employees. Another 10 percent decide to work on their own account (self-employed), 3 percent become employers themselves, another 3 percent change into the public sector and the remainder works in the domestic service or as family workers. ${ }^{14}$

I also analyze the duration of the following unemployment spell, if workers who terminate the first employment relation become unemployed. On average the length amounts to 6.28 months for the complete sample. For workers who are not affiliated to UISA, the average unemployment spell amounts to 2.26 months, and for workers affiliated to UISA to 6.30 months. The unemployment spell lengths of both groups are not significantly differently from each other. However, here again various observations are censored and would require additional analysis using survival analysis techniques. ${ }^{15}$ Therefore the longer-term impact of UISA introduction on unemployment duration calls for more research, in order to analyze if UISA affiliation not only leads to a more flexible and dynamic labor market, but ideally also to shorter unemployment spells for worker who terminate their initial employment.

\subsection{Methodolody}

The analysis is conducted using survival analysis techniques, also known as event history or duration analysis. Survival analysis is defined as the analysis of time until the occurrence of a specific event, from a pre-defined starting point to the transition from one state to another, conditional that it has not yet occurred. The time of interest is represented by the duration in one employment relation, the event of interest is represented by the termination of this employment period. Workers are throughout time "at risk" of terminating their employment and experiencing the failure event (BoxSteffensmeier and Jones, 2004).

Survival analysis is different from ordinary least squares (OLS) regressions for a number of reasons and hence requires a special framework. First, the normality distribution of residuals cannot be assumed, as normality of time is unreasonable for many events.

\footnotetext{
${ }^{14}$ Separating the employment characteristics by UISA affiliation, the differences are not statistically significant, except for contract type, marginally significant at the 10 percent level: while 54.6 percent find a permanent contract in their next employment relation if they are not affiliated to UISA, 48.5 percent find one if affiliated.

${ }^{15}$ Not provided in this chapter.
} 
The risk of the event occurring is generally not constant over time and almost certainly non-symmetric. Second, duration (or time to failure) is always positive. And third, the data encounters the problem of right censoring: the observed individual participates in the survey, but the event might not have yet occurred when the survey finishes. In my analysis the policy was introduced in October 2002, and the last survey round available records data until early 2010. The workers remaining in their current employment are no longer observed until the following survey round is conducted and published, and are censored. In the analysis I assume non-informative censoring meaning that the censoring time of an individual tells nothing about the risk after that time.

There are three main approaches in survival analysis: non-parametric analysis, the semi-parametric Cox proportional hazards ( $\mathrm{PH})$ model and parametric models. While non-parametric and semi-parametric models compare subjects at the time when failures actually occur, parametric models use probabilities that describe what occurs over the whole interval given the information of the subject during time $x_{j}$ (Cleves et al., 2010). To be more specific, non-parametric analysis assumes no functional form of the survivor function and makes therefore no assumption about the hazard or cumulative hazard, so "letting the data set speak for itself". The effects of additional sets of covariates are not modeled either, and the comparison is performed on a qualitative level. In the semiparametric Cox model the parametric shape is equally left unspecified, but the model assumes that covariates have proportional baseline hazards. Parametric models are either written in the hazard parameterization, or in the log-time parameterization, also known as accelerated failure time (AFT) metric. All parametric models make assumptions about the shape of the hazard function, with the simplest being the exponential model assuming a constant hazard over time. Other models include Weibull or Gompertz distributions (flat, monotonically increasing or decreasing hazard rates), log-normal and log-logistic models (non-monotonic hazard rates) and the flexible three-parameter generalized gamma distribution (Cleves et al., 2010).

Estimates are obtained by calculating the maximum likelihood for parametric, and by calculating the partial likelihood for semi-parametric models. Breslow or Efron approximations are used to compute the partial likelihood in case failure events are tied in the data set (Cleves et al., 2010; Rodríguez, 2010). The maximum likelihood function assuming non-informative censoring includes censored observations with survival time $t_{i}$ and failure indicator $d_{i}$ (taking the value 1 for failures and 0 for censored observations) 
and has the form,

$L=\prod_{i=1}^{n} S\left(t_{i} \mid x_{i}, \beta\right) \lambda\left(t_{i} \mid x_{i, \beta}\right)^{d_{i}}$

and the partial likelihood with $k$ distinct observed failure times and no ties,

$L=\prod_{j=1}^{k}\left\{\frac{\exp \left(x_{j} \beta_{x}\right)}{\sum_{i \in R_{j}} \exp \left(x_{j} \beta_{x}\right)}\right.$

In a first step, I estimate the survivor function without assuming any particular functional form. The Kaplan-Meier estimator, the non-parametric estimator of the survivor function $S(t)$, estimates the probability of survival past a certain time $t$ and is given by,

$\hat{S}(t)=\prod_{j \mid t_{j} \leq t} \frac{n_{j}-d_{j}}{n_{j}}$

where $n_{j}$ represents the number of individuals at risk at time $t_{j}$ and $d_{j}$ represents the number of failures at time $t_{j}$. This step-wise function shows the survival of workers in their employment, presenting first results of survival between workers who are affiliated to the UISA scheme compared to those who are not.

In a second step, I analyze the survival of employment using the semi-parametric Cox model. The Cox proportional hazards model (Cox, 1972) and (Cox, 1975) is given by,

$\lambda\left(t \mid x_{j}\right)=\lambda_{0}(t) \exp \left(x_{j} \beta_{x}\right)$

where $\lambda_{0}(t)$ is the baseline hazard and $x_{j} \beta_{x}$ the covariates and regression parameters. The baseline hazard is not given a particular parameterization and is left unestimated. The model makes no assumption about the hazard shape over time, but all individuals are assumed to have the same hazard over time, meaning that the hazard rate for any two individuals at any point in time is proportional (Cleves et al., 2010).

In a third step, I select a functional form for the hazard rate using the Akaike Information Criterion (AIC) and parameterize the shape of the hazard function. Parametric estimations use probabilities that describe the data over the whole time interval given what is known about the observations during this time. Parametric models are written 
in two different ways.

First, in the hazard metric,

$h\left(t \mid x_{j}\right)=h_{0}(t) \exp \left(x_{j} \beta_{x}\right)$

Or second, in the log-time metric, also known as the AFT metric,

$\ln \left(t_{j}\right)=x_{j} \beta_{x}+\epsilon_{j}$

Hazard parameterizations can fit exponential, Weibull and Gompertz distributions. Widely used log-time parameterizations are exponential, Weibull, log-normal, log-logistic and the generalized gamma distribution (Cleves et al., 2010).

In a fourth and final step, I apply a competing-risk model, where the endpoint consists of several distinct events and the failure can be attributed exclusively to one event. In a competing risk model I am interested in the cause-specific hazard function,

$\lambda_{j}(t)=\lim _{\Delta \rightarrow 0+} \frac{P(t \leq T<t+\Delta t \mid T \geq t)}{\Delta t}$

where $\lambda_{j}$ indicates the hazard rate for a single-state process where the hazard rate is subscripted for each of the $j$ events that can occur. To conduct the analysis I censor all events, but the event of interest. Each part of the product can then be estimated separately and I obtain risk-specific hazard rates. As before, I can equally conduct nonparametric, semi-parametric and parametric analysis.

\subsection{Results}

The analysis is conducted by dividing the sample into two groups: workers who started during the year before UISA introduction and who are not affiliated to the scheme, and workers who started during the year after UISA introduction and had to compulsory join the scheme. This binary variable $(\mathrm{UISA}=0 / 1)$ allows a comparison of employment duration before and after the policy introduction.

The main results of the empirical analysis can be summarized as follows. In the first 
part of the analysis I focus on the failure event of terminating the current employment. Affiliation to UISA is significant and increases the hazard of leaving employment, or accelerates time to failure, throughout all regressions irrespective of the method selected or the covariates included in the regressions. In the second part of the analysis, results are comparable if the following event is a new employment relation or unemployment: affiliation to UISA is significant throughout all regressions. This is however not the case for workers becoming inactive after terminating their current employment. The difference between both groups is not significant for the Kaplan-Meier estimator, the simple regression or the base specification. Only in the final model is UISA affiliation significant. Quantitatively the effect is larger for workers becoming unemployed or inactive, compared to workers changing employment. ${ }^{16}$

\subsubsection{Survival Model}

\section{Non-Parametric Analysis}

I start the empirical analysis with the Kaplan-Meier (KM) estimator. Figure 6.1a plots the overall Kaplan-Meier survival estimate and Figure 6.1b the estimates before and after UISA introduction. Figure 6.1a shows a high hazard rate of employment termination during the first year of employment. After approximately twelve months, half of all workers have terminated their current employment contract. From twelve to approximately 45 months another quarter of workers terminate employment. Afterwards the number of surviving workers continues declining in a steady and moderate pace, until the final survey round finishes and approximately 15 percent of the sample is still employed and therefore censored. In Figure 6.1b survival is similar during the first months of employment and starts diverging after approximately ten months, showing higher employment survival for workers not affiliated to the UISA scheme. The logrank and the Wilcoxon test confirm that the estimates are significantly different: with a p-value of 0.000 the logrank test rejects the null hypothesis that both estimates are equal and concludes that the difference in employment survival is statistically significant. Reporting

\footnotetext{
${ }^{16}$ In addition to the continuous time analysis, I run the regressions based on discrete time analysis and use the complementary log-log regression (the discrete-time proportional hazards model) to compare if results are similar. The cloglog regressions report qualitatively comparable results, where the UISA variable is statistically significant at a 1 percent level throughout the regressions and equally increases the hazard of leaving employment. Coefficients are quantitatively above the results of continuous time analysis, the differences are however minor.
} 
a p-value of 0.000 , the Wilcoxon result equally rejects the null-hypothesis. ${ }^{17}$

Figure 6.1: KM Survival Estimates

(a) Overall

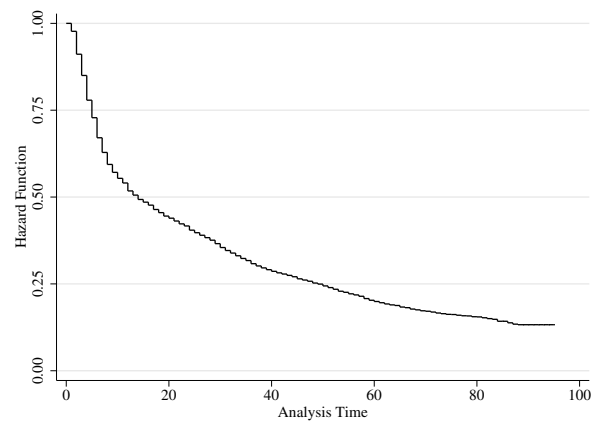

(b) Before and After UISA Introduction

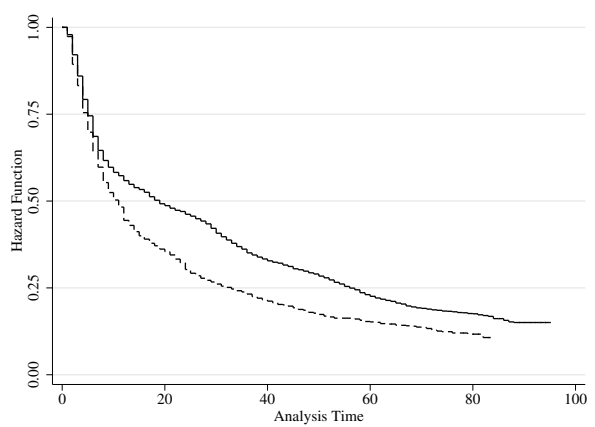

Note $(s)$ : In Figure $6.1 \mathrm{~b}$ the continuous line represents UISA $=0$ and the dotted line UISA $=1$.

\section{Cox Proportional Hazards Model}

I continue with the simple Cox model, where I regress the main independent variable UISA on employment duration. Regression (1) in Table 6.2 reports a coefficient of 0.273. Expressed in hazard rates the hazard of leaving employment is approximately 1.314 times higher for workers affiliated to the UISA scheme (hazard increases by 31.4 percent) and is statistically significant at the 1 percent level.

Next, the PH assumption of the simple Cox model is tested. I start with a graphical analysis and plot the hazards of both groups. The hazards are estimated over the range of observed failure times, and all failure times contribute to the estimate of the baseline hazard. The hazard ratios in the figures are approximately proportional. I also conduct a formal test based on Schoenfeld residuals. This test retrieves the residuals, fits a smooth function of time to them, and tests whether there is a relationship. For this test time is log-transformed. The result $\mathrm{p}=0.441$ suggests that there is no evidence of nonproportionality. I do an additional formal test by introducing an interaction between the UISA variable and time. For the test time is log-transformed and the result $(\mathrm{p}=0.427)$ equally suggests that there is no evidence that the UISA effect changes with $\ln ($ time).

\footnotetext{
${ }^{17}$ With the logrank test I test the null hypothesis that the probability of employment survival of both groups is the same at any point of time. It compares the survival of both groups by taking the follow-up period into account (Bland and Altman, 2004). The Wilcoxon test is a rank test which places additional weight to earlier failure times than failures later in the distribution compared to the logrank test. In case the hazard functions are not proportional, this test is preferred over the logrank test (Cleves et al., 2010). I conduct both tests, as the proportionality assumption has not yet been tested.
} 
I start the multiple Cox regressions by specifying a base specification. I expect the following variables to have an effect on the decision of remaining in employment: gender, age, contract type and education. All variables are statistically significant at the 1 percent level, except for age that is significant at the 5 percent level. The education dummies are collectively significant at the 1 percent level. While UISA affiliation, female and a temporary contract increase the hazard of leaving employment, the hazard decreases with age and a higher educational level. With a coefficient of 0.282 the effect of the UISA variable is similar to the simple regression, translating into a hazard ratio of 1.327 , or a 32.7 percent increase in the hazard of terminating employment.

Afterwards I test additional sets of covariates. First, I add average net wage, total hours worked per week and firm size to capture information on type, place and quality of work. Second, individual risk aversion, third, number of household members, working household members, civil status and number of children to capture information on the household composition, fourth, region of work, and fifth, knowledge of the UISA scheme. Affiliation to UISA, gender, and contract type remain statistically significant throughout all regressions, while age and education vary over the regressions. The UISA coefficient almost doubles after including the wage dummies, increasing the effect of UISA affiliation when wage is hold constant. Throughout all regressions, wage is collectively significant at the 1 percent level. Hours worked per week is significant at the 5 percent level, while firm size, individual risk aversion, working household members, civil status, number of children, region and knowledge of UISA are not significant. Although household size is not significant in the Cox model, I decide to keep this variable as it shows significant results in other regressions. Regression (8) in Table 6.2 contains the final Cox model, including all variables of the base specification, hours worked, average net wage and household size. The UISA coefficient increases to 0.517 in the final model, translating into a hazard ratio of 1.677 , or a 67.7 percent increase in the hazard of terminating employment when affiliated to the UISA scheme.

Finally, a number of interaction terms are tested in regression (9). ${ }^{18}$ The following interaction terms are significant: UISA x contract type, and UISA x education dummies. Having a temporary contract and affiliation to the UISA scheme additionally increases the hazard of terminating employment, above and beyond the single effects of the variables. For the other interaction term, UISA $\mathrm{x}$ education dummies, the hazard decreases with

\footnotetext{
${ }^{18}$ Interactions tested: UISA $x$ Female, UISA $x$ Age, UISA x Temp.Contract, UISA x Education Dummies, UISA x Wage Categories, UISA x Household Size, Female x Age, Female x Temp.Contract, Age $\mathrm{x}$ Temp.Contract, Temp.Contract $\mathrm{x}$ Hours, Temp.Contract $\mathrm{x}$ Wage Categories, Temp.Contract $\mathrm{x}$ Household Size.
} 


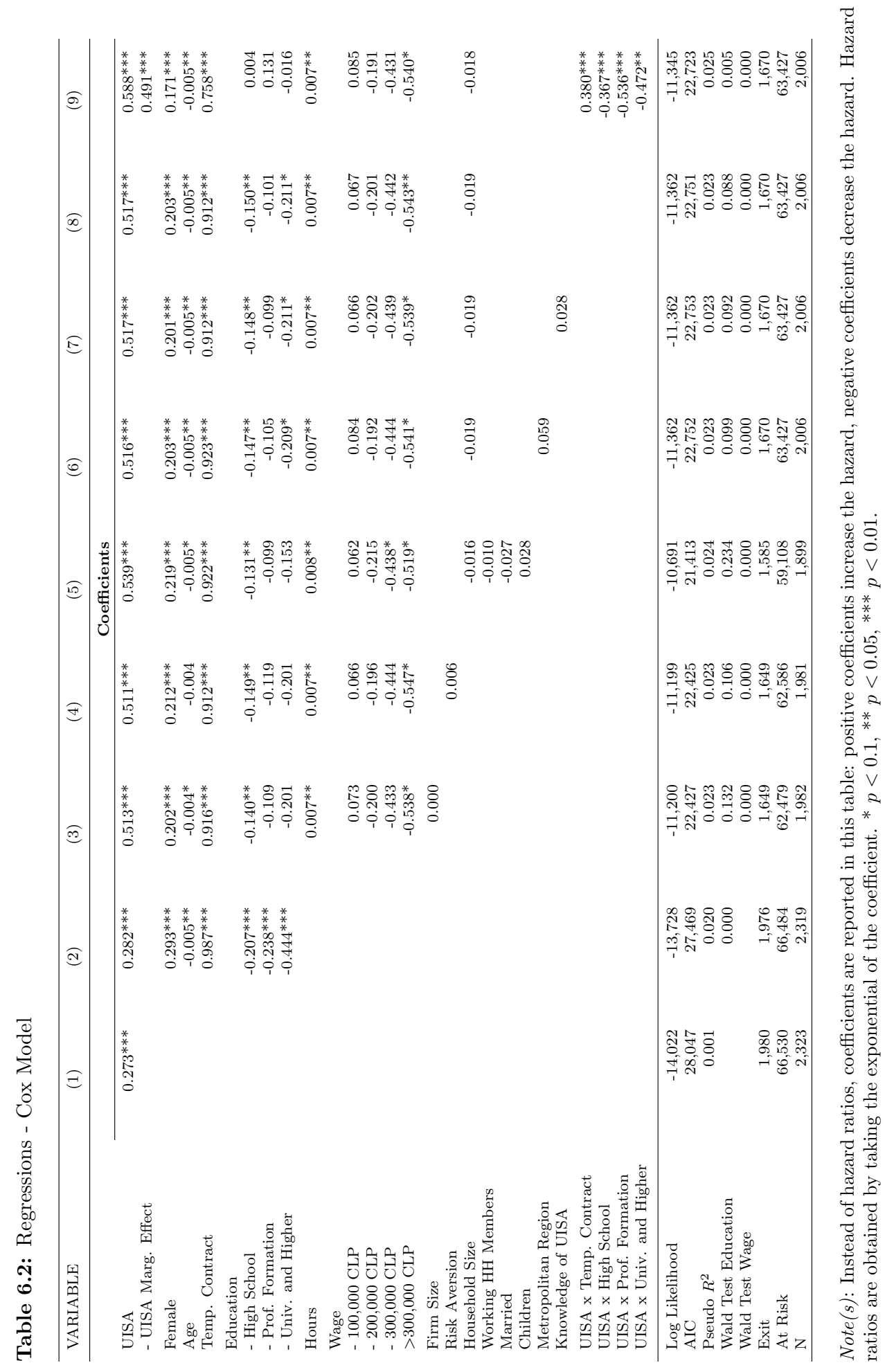


higher education if workers are affiliated to the UISA scheme.

Next the PH assumption is tested for the base specification, the final Cox model and the Cox model with interactions. For the Cox model to be valid and to satisfy the PH assumption, the global PH test must report p-values above the threshold of 10 percent. The global PH test reports for the three regressions p-values of 0.000 , rejecting the $\mathrm{PH}$ assumption and making the Cox model invalid. ${ }^{19}$ While UISA affiliation and education suggest that there is no evidence of non-proportionality in the base specification, gender, age and contract type report p-values below the 10 percent threshold. In the final Cox model various variables have low p-values: UISA affiliation, gender, age, contract type and the wage dummies. The results are similar for the interaction model, except for UISA affiliation and gender, where the p-values are above the threshold value. A stratified Cox model presents a possible solution when certain covariates do not satisfy the PH assumption (Ata and Sözer, 2007).

\section{Stratified Cox Model}

Due to the previous results, I relax the assumption that every individual faces the same baseline hazard,

$h\left(t \mid x_{j}\right)=h_{0}(t) \exp \left(x_{j} \beta_{x}\right)$

in favor of

$h\left(t \mid x_{j}\right)=h_{01}(t) \exp \left(x_{j} \beta_{x}\right)$, if $j$ is in group 1

$h\left(t \mid x_{j}\right)=h_{02}(t) \exp \left(x_{j} \beta_{x}\right)$, if $j$ is in group 2

The baseline hazards can now differ across the levels of stratified variables, but the coefficients $\beta_{x}$ continue to be the same (Cleves et al., 2010). Covariates reporting high p-values are assumed to satisfy the PH assumption and are included in the model, while covariates that do not fulfill this criterion and report low p-values are stratified (Ata and Sözer, 2007).

I apply the stratified model to the data. After testing different sets of stratified regressions, I stratify contract type in the base specification, and age, contract type and hours in the final model and the interaction model. The global PH tests report a p-value

${ }^{19}$ See Table B.4 in Appendix B. 
of 0.182 for the base specification, a p-value of 0.813 for the final model and a p-value of 0.717 for the interaction model, rejecting the evidence of non-proportionality. Using the stratified Cox model is therefore more appropriate for the data. The coefficients of UISA affiliation remain similar, suggesting quantitatively comparable effects as in the previous Cox regression table. ${ }^{20}$

\section{Parametric Models}

I start the parametric analysis by comparing the six parametric model shapes using the Akaike Information Criterion. The AIC penalizes each model's log likelihood to reflect the number of parameters estimated (Akaike, 1974). The preferred model distribution is the one with the lowest AIC value, in my case the generalized gamma distribution. Using this distribution, I run four regressions (simple model, base specification, final model and interaction model) and compare the results in Table 6.3.

The UISA variable is statistically significant at the 1 percent level in all regressions, as well as age, contract type, hours worked and wage. In all four regressions the UISA coefficient is negative, implying "accelerated" time to failure. Expressed as time ratios, the simple model reports a value of 0.781 , suggesting that time to failure is approximately 21.9 percent lower compared to workers not affiliated to the scheme. In the base specification time to failure is less accelerated for UISA affiliates with a time ratio of 0.850. When adding the wage variables to the regressions in the final and interaction model, the UISA coefficient value decreases. The results report a time ratio of 0.627 and 0.628 (marginal effect). Education is not significant in the final model, while wage is significant at the 1 and 10 percent level in the base specification and the interaction model, respectively. The interaction terms are significant at the 5 percent level, and confirm the previous interpretation. Affiliation to the UISA scheme and having a temporary contract accelerate time to failure, while the interaction UISA $\mathrm{x}$ education decelerates time to employment termination. Analyzing the parameters, the special cases of the generalized gamma distribution Weibull $(\kappa=1)$, log-normal $(\kappa=0)$ and the exponential distribution $(\kappa=\sigma=1)$ are not fulfilled.

As a last step in the parametric analysis, I run the final model, and estimate the hazard functions based on the generalized gamma distribution. ${ }^{21}$ Figure $6.2 \mathrm{a}$ shows the overall

\footnotetext{
${ }^{20}$ See Table B.6 in Appendix B.

${ }^{21}$ I concentrate on the final model, as the AIC reports only marginally lower values for the interaction model. I additionally run the hazard functions with the interactions model, and the figures show qualitatively and quantitatively similar results.
} 
Table 6.3: Generalized Gamma Regressions

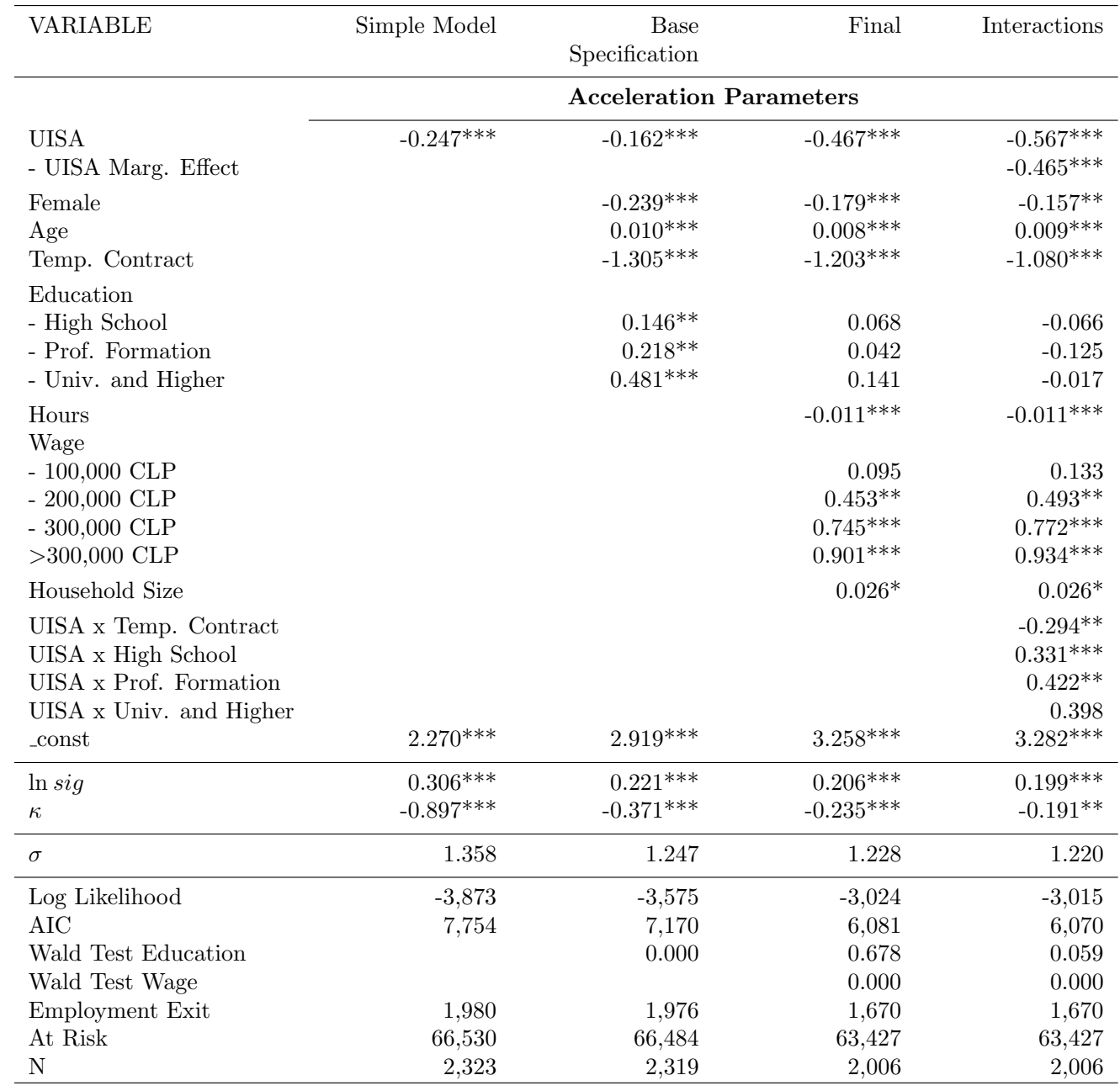

Note(s): The coefficients reported in this table are expressed as $\tau_{j}=\exp \left(-x_{j} \beta_{x}\right) t_{j}$ and are called the acceleration parameters. If coefficients are negative, they "accelerate" time, so failure is expected to occur sooner; if coefficients are positive, they "decelerate" time, so failure is expected to occur later. If coefficients are equal to zero, then time passes at its "normal" rate (Cleves et al., 2010). Another option are exponentiated coefficients, which are interpreted as time ratios. ${ }^{*} p<0.1,{ }^{* *} p<0.05,{ }^{* * *} p<0.01$.

hazard, indicating a steep increase in the hazard rate during the first year of employment, with a peak after approximately 12 months, and a steady decline thereafter. Figure $6.2 \mathrm{~b}$ shows the hazard function before and after UISA introduction, with a considerably higher hazard rate for UISA affiliates, diverging especially during the first two years of employment, and converging over the remaining time. The peak after approximately one year is more pronounced for workers affiliated to UISA. 
Figure 6.2: Hazard Functions

(a) Overall

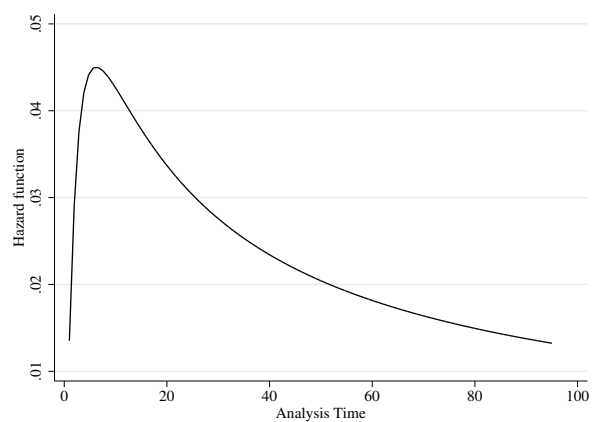

(b) Before and After UISA Introduction

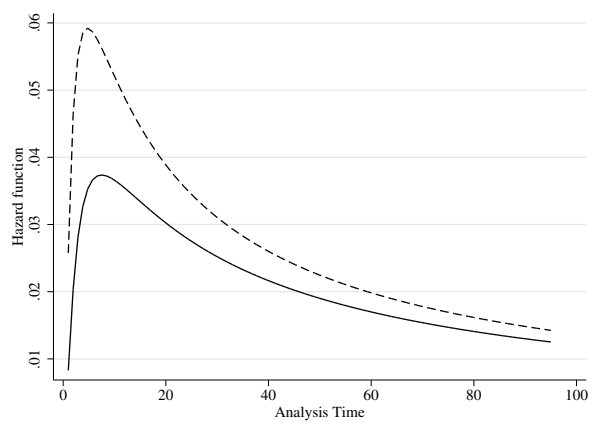

Note(s): Hazard functions are based on the final model. In Figure $6.2 \mathrm{~b}$ the continuous line represents $\mathrm{UISA}=0$ and the dotted line $\mathrm{UISA}=1$.

\subsubsection{Competing-Risk Model}

In a competing-risk model the failure event can occur for more than one reason. In this data set terminating employment can lead to three different events: to another employment contract $\left(T_{1}\right)$, to unemployment $\left(T_{2}\right)$, or to inactivity $\left(T_{3}\right)$. As before, the analysis starts with non-parametric Kaplan-Meier estimates, continues with the semiparametric Cox model and is finalized by fitting parametric models.

\section{Non-Parametric Analysis}

The Kaplan-Meier survival estimates show employment survival before and after UISA introduction in Figure 6.3, depending on the event that follows the current employment termination. For Figures $6.3 \mathrm{a}$ and $6.3 \mathrm{~b}$ the logrank and Wilcoxon test report p-values of 0.000 , however not for Figure 6.3c. For inactivity as the following event, the logrank test reports a p-value of 0.451 , and the Wilcoxon test a p-value of 0.206 , translating into no significant difference between both groups. While UISA affiliation makes a difference if workers change employment or become unemployed, it appears to be irrelevant for workers becoming inactive. In the first two cases the hazard ratio of UISA affiliates is higher compared to the workers not affiliated to the scheme. 
Figure 6.3: KM Survival Estimates

(a) $T_{1}$ - Employment

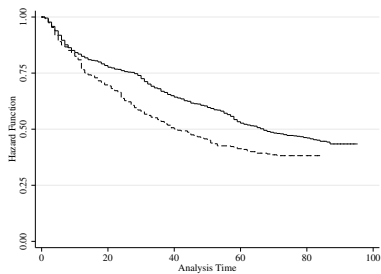

(b) $T_{2}$ - Unemployment

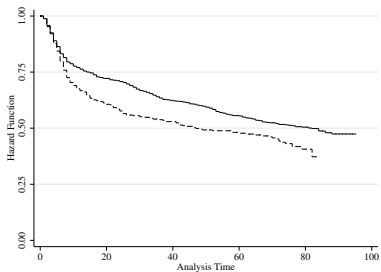

(c) $T_{3}$ - Inactivity

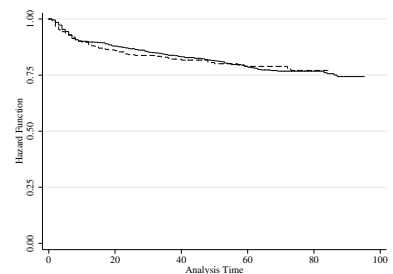

Note(s): In Figures $6.3 \mathrm{a}, 6.3 \mathrm{~b}$ and $6.3 \mathrm{c}$ the continuous lines represent UISA $=0$ and the dotted lines $\mathrm{UISA}=1$.

\section{Cox Proportional Hazards Model}

Based on the regression Table 6.2 of the semi-parametric analysis, I run the simple regression (1), the base specification (2) and the final model (3). ${ }^{22}$ The results in Table 6.4 vary depending on the event following employment termination. If workers change their employment, UISA affiliation, gender and contract type are statistically significant variables, while age, education, hours worked, wage and household size do not report significant results. If workers become unemployed all variables are significant at the 1 percent level, except of household size. For the last option, inactivity, the picture changes over the regressions. While UISA affiliation does not report significant results for the simple model and the base specification, it is statistically significant at the 1 percent level in the final model. The remaining variables are significant at the 1 or 5 percent level, except of hours and household size.

The magnitude of the UISA effect varies according to the next event. ${ }^{23}$ While the coefficient reports a value of 0.375 , translating into a hazard ratio of 1.455 or a 45.5 percent increase in the hazard of terminating employment when the next event is a new employment relation, the coefficient almost doubles to 0.645 , translating into a hazard ratio of 1.906 or a 90.6 percent increase in the hazard of terminating employment when the following event is unemployment. For inactivity as the next event, the coefficient reports a value of 0.504 , or a hazard ratio of 1.655 (65.5 percent increase in the hazard of terminating employment). While UISA affiliation has an effect on the duration of employment in all three cases and increases the hazard of terminating employment, the effect is highest for workers becoming unemployed. The effect is also higher for inactivity compared to changing employment. A possible explanation could present

\footnotetext{
${ }^{22}$ I exclude the interaction model to consolidate the competing-risk analysis.

${ }^{23}$ I concentrate on the coefficients of the final model.
} 


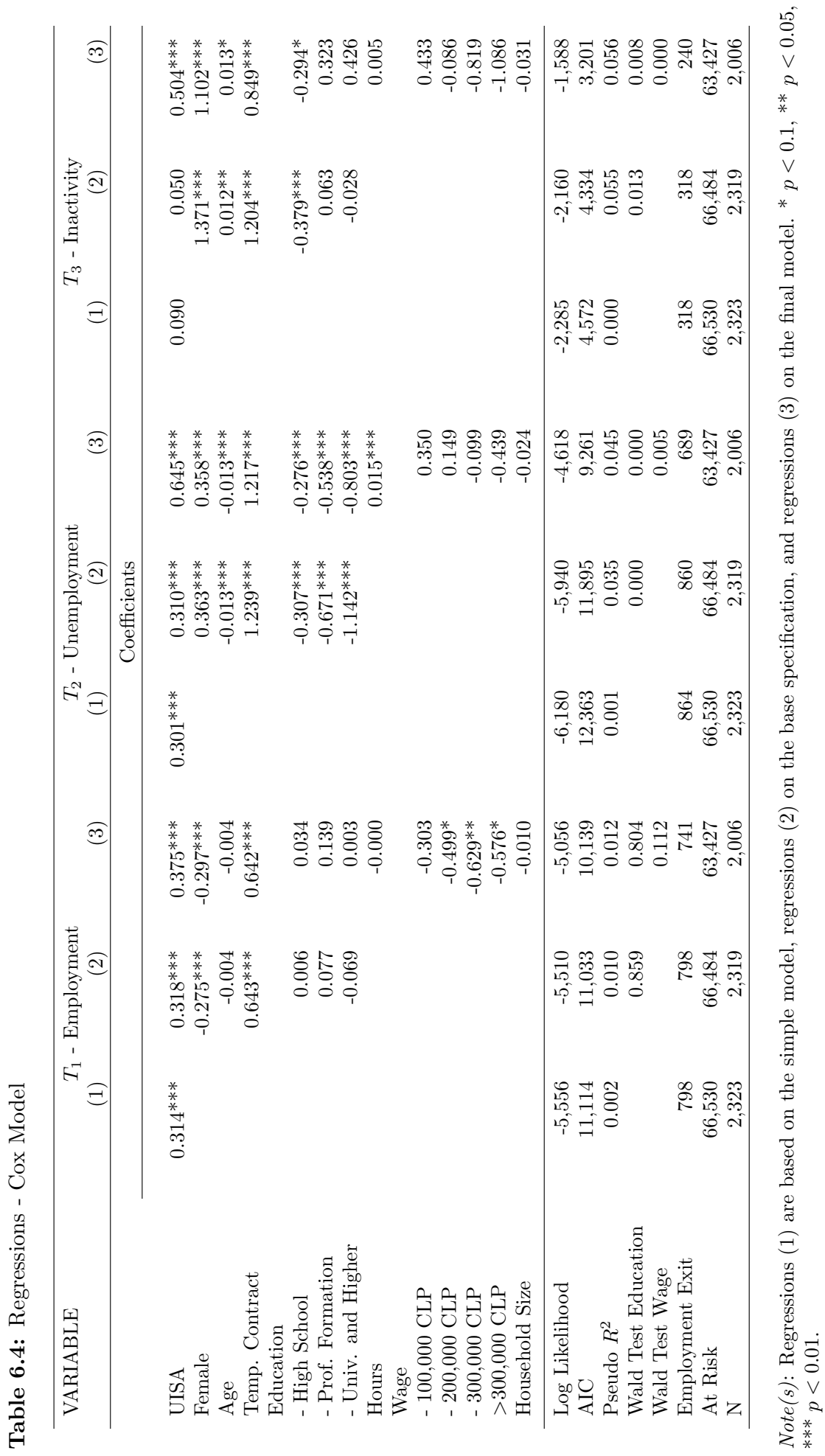


the direct benefit of receiving the accumulated savings in the case of unemployment or inactivity, while a job change does not result in immediate monetary benefits, but reduced opportunity costs.

I test again the $\mathrm{PH}$ assumption, and to consolidate the analysis I test the assumption for the final model only. None of the regressions fulfill the PH assumption. The values reported for the global PH test are 0.000 in all cases, suggesting that hazards are nonproportional. ${ }^{24}$ Age and contract type are stratified and the global PH test results suggest that the stratified Cox model is valid in all three cases.

The coefficients of the stratified Cox model report qualitatively and quantitatively comparable results as in Table 6.4. Irrelevant of the event following employment termination, UISA affiliation is positive and statistically significant at the 1 percent level. Affiliation to the new scheme increases the hazard of workers leaving their current employment and is quantitatively similar to the previous Cox regressions: the hazard of terminating employment increases by 42.6 percent if workers change their employment, by 75.6 percent if workers become unemployed, and by 83.1 percent if workers become inactive. $^{25}$

\section{Parametric Analysis}

As a last step I fit parametric models and proceed as before. I concentrate on the final model, and test the preferred hazard shape for the different parametric models. The gamma distribution is the preferred model shape for $T_{1}$ and $T_{2}$ and the log-normal distribution for $T_{3}$. As the AIC of the log-normal distribution is only marginally below the AIC of the gamma distribution, I also use the latter shape for $T_{3}$.

In Table 6.5 all UISA coefficients are statistically significant at the 1 percent level. The UISA coefficients report again considerably lower acceleration parameters for unemployment and inactivity: while UISA affiliation accelerates failure in all cases, the effect is more pronounced if workers become unemployed or inactive after terminating their current employment. The time ratios are 0.705 for employment, 0.563 for unemployment and 0.535 for inactivity when taking the exponentiated coefficient.

An interesting aspect is the coefficient of gender. Women have a lower hazard of

\footnotetext{
${ }^{24}$ See Table B.5 in Appendix B.

${ }^{25}$ See Table B.7 in Appendix B.
} 
Table 6.5: Generalized Gamma Regressions

\begin{tabular}{lrrr}
\hline VARIABLE & $T_{1}$ - Employment & $T_{2}$ - Unemployment & $T_{3}$ - Inactivity \\
\hline & & Acceleration Parameters & \\
\cline { 2 - 4 } UISA & $-0.349^{* * *}$ & $-0.575^{* * *}$ & $-0.625^{* * *}$ \\
Female & $0.362^{* * *}$ & $-0.375^{* * *}$ & $-1.234^{* * *}$ \\
Age & 0.006 & $0.013^{* * *}$ & -0.007 \\
Temp. Contract & $-0.966^{* * *}$ & $-1.474^{* * *}$ & $-1.095^{* * *}$ \\
Education & & & \\
- High School & -0.103 & $0.194^{*}$ & 0.254 \\
- Prof. Formation & $-0.280^{*}$ & $0.616^{* * *}$ & -0.455 \\
- Univ. and Higher & -0.025 & $0.754^{* * *}$ & $-0.712^{* *}$ \\
Hours & -0.002 & $-0.019^{* * *}$ & -0.014 \\
Wage & & & \\
- 100,000 CLP & $0.484^{*}$ & -0.075 & -0.390 \\
- 200,000 CLP & $0.811^{* * *}$ & 0.178 & 0.294 \\
- 300,000 CLP & $0.980^{* * *}$ & 0.477 & 1.054 \\
$>300,000$ CLP & $0.903^{* * *}$ & $0.891^{* *}$ & $1.423^{*}$ \\
Household Size & 0.017 & $0.034^{*}$ & 0.036 \\
Constant & $3.163^{* * *}$ & $4.885^{* * *}$ & $7.109^{* * *}$ \\
\hline ln sig & $0.497^{* * *}$ & $0.465^{* * *}$ & $0.820^{* * *}$ \\
$\kappa$ & $-0.624^{* * *}$ & -0.209 & -0.410 \\
\hline$\sigma$ & 1.644 & 1.592 & 2.270 \\
\hline Log Likelihood & $-1,913$ & $-1,817$ & -876 \\
AIC & 3,857 & 3,666 & 1,783 \\
Wald Test Education & 0.362 & 0.001 & 0.003 \\
Wald Test Wage & 0.002 & 0.001 & 0.000 \\
Employment Exit & 741 & 689 & 240 \\
At Risk & 63,427 & 63,427 & 63,427 \\
N & 2,006 & 2,006 & 2,006 \\
\hline & & &
\end{tabular}

Note(s): All regressions are based on the final model. ${ }^{*} p<0.1,{ }^{* *} p<0.05,{ }^{* * *} p<0.01$.

terminating employment if the following event is a new employment relation, but have an increased hazard of terminating employment if the following event is unemployment and particularly when becoming inactive. Different contribution patterns by women towards household wage might present one possible explanation. While a job change can enhance career perspectives and often implies higher earnings, it might be more actively pursued by male workers, still expected to earn the bulk of wage within the household. Female employees earn on average 45,000 CLP less compared to male employees in my sample, and female earnings might be seen for many families as an additional contribution to household wage, but not as the principal salary. Women are therefore more likely to give up participation in the labor market and become inactive to dedicate more time to family and household labor.

Among the other explanatory variables education is not significant for a job change, but decelerates time to failure when the following event is unemployment and is significant 
at the 1 percent level, while the effect is the opposite for inactivity. The variable hour is only significant when the following event is unemployment and accelerates time to failure. Wage is significant in all cases and decelerates time to failure with increasing wage. Household size is significant at the 10 percent level when becoming unemployed and slightly decelerates time.

In Figure 6.4 I compare the hazard functions before and after UISA introduction, and in all cases UISA affiliates have a higher hazard of terminating employment, irrespective of the following event. The shape is comparable, with a steep hazard increase during the first months of employment, a peak after the first year and a steady decline thereafter.

Figure 6.4: Hazard Functions - by UISA Introduction

(a) $T_{1}$ - Employment

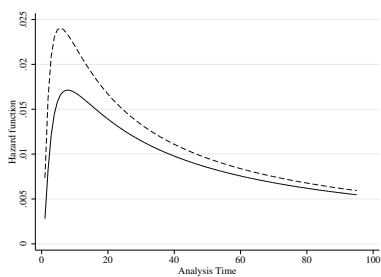

(b) $T_{2}$ - Unemployment

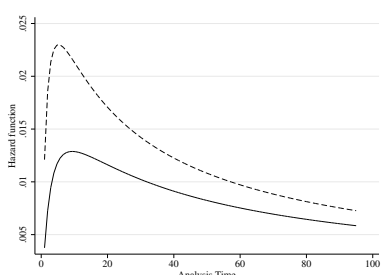

(c) $T_{3}$ - Inactivity

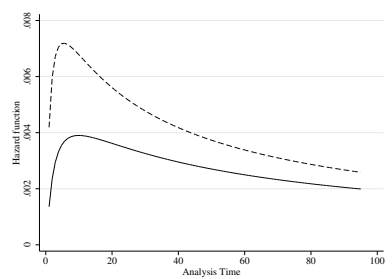

Note(s): Hazard functions are based on the final model. In Figures $6.4 \mathrm{a}, 6.4 \mathrm{~b}$ and $6.4 \mathrm{c}$ the continuous lines represent UISA $=0$ and the dotted lines UISA $=1$.

\subsubsection{Robustness}

To examine the causal impact I conduct four different falsification tests. First, I change the cut-off date from October 2002 to October 2003 "as if" the introduction date began one year later. If this alternative cut-off date is used, the UISA variable is no longer significant when running the same set of regressions.

Second, I use an extended time frame including workers who started a new employment during the two years before and the two years after UISA introduction. This sample reports qualitatively the same, and quantitatively similar results as in the one year sample used for the analysis. A more detailed explanation, including regression results, can be found in Appendix B.

Third, I select formal public sector workers as a control group and introduce the UISA variable with the same cut-off date "as if" this group had experienced the policy introduction. In this sample the UISA variable is not significant, indicating that 
public sectors employees that were not affected by this policy do indeed not show a significant difference in employment duration. A more detailed explanation can be found in Appendix B.

Fourth and last, I check the unemployment rate in Chile during the year before and after UISA introduction. While the average unemployment rate was 8.4 percent in the year before, it marginally decreased to 8.3 percent in the year after. In the time period September to November 2001 it amounted to 8.3 percent, during the period September to November 2002 to 8.5 and during the period September to November 2003 it slightly decreased to 7.8 percent. ${ }^{26}$ Therefore no sharp change in unemployment was experienced during the two year period considered in the analysis.

While these tests give confidence in effectively observing a causal impact of UISA introduction on employment duration, a number of issues remain uncertain. Although the policy demands compulsory affiliation to the policy, it is not clear if firms could circumvent affiliation when offering a new employment contract after October 2002. Another aspect is the limited knowledge and use of UISA benefits, as shown by Poblete (2011), and might therefore not affect employment duration among workers with no or little knowledge of the new policy. Further aspects to take into consideration are the rather low benefit transfers and the one month waiting period to access account savings, that might also limit the impact on the workers' behavior.

\subsection{Summary and Concluding Remarks}

This chapter analyzes the impact of UISA on employment duration in Chile and is motivated by two questions: (i) whether the introduction of UISA had an effect on employment duration and therefore on labor mobility, and (ii) the magnitude of this effect. Based on the results, I conclude that the introduction of UISA significantly affected employment duration, characterized by an increased hazard ratio of exiting the current employment in the semi-parametric Cox regressions and by accelerated time to failure in the parametric models. In the remaining section I first summarize the results, before discussing policy implications and suggestions for further research in the second part.

In the simple Cox regression the hazard is elevated by 31.4 percent for UISA affiliates,

\footnotetext{
${ }^{26}$ Unemployment statistics are taken from the "Instituto Nacional de Estadística" (National Statistics Institute) [09.10.2013].
} 
and amounts to 67.7 percent in the final model. The results of the stratified models are similar. The parametric models, based on the generalized gamma distribution, report qualitatively the same result: time to failure is accelerated if workers are affiliated to UISA. The time ratio reports a coefficient of 0.627 for UISA affiliates in the final model, suggesting that time to failure is 37.3 percent lower.

The results of the competing-risk analysis, using the final model, are summarized as follows. In the Cox model the hazard of leaving employment increases by 45.5 percent if another employment relation follows employment termination, by 90.6 percent if workers become unemployed, and by 65.5 percent if workers become inactive. The parametric generalized gamma regressions report qualitatively comparable results, where time is accelerated for all following events if workers are affiliated to UISA. The time ratios are $0.705,0.563$ and 0.535 , respectively, suggesting that time to failure is 29.5 percent lower for employment and approximately 45 percent lower for unemployment or inactivity as the next event, compared to workers with the same next event who are not affiliated to the scheme. A possible explanation for the relative lower hazard (or higher time ratio) in case of employment change, is the lack of direct monetary benefits, as a decrease in opportunity costs is not immediately perceived.

Taking reduced employment duration as an indicator for higher labor market flexibility, my results suggest that the policy achieved the goal of tackling previously more rigid labor markets in Chile. UISA can therefore present an alternative for emerging and developing economies that seek to protect their workforce in times of unemployment and to improve labor market rigidities, while avoiding some problems related to unemployment insurance (e.g. high monitoring costs to reduce moral hazard). However, reduced employment duration can also imply negative consequences for the workforce. While labor market flexibility increases the dynamic and productivity of labor, it could also lead to more unstable labor relations, where workers can be more easily fired. Additionally, it might not adequately protect the more vulnerable workers, who cannot access benefits as they are unable to fulfill the minimal conditions. A more comprehensive analysis of the consequences of reduced employment duration for workers would therefore complement the current study and broaden the understanding of the UISA impact, and is therefore recommended as a possible theme for future research.

Based on the analysis, a number of additional issues continue to stand out, namely a low female labor market participation, a high share of temporary and often precarious employment contracts, limited knowledge of UISA and the rather low amount of benefits. Women and workers with a temporary contract show significant higher hazard rates of 
terminating employment throughout the analysis. In the competing risk analysis the results further show that women have a lower hazard of changing into a new employment, but a higher hazard of becoming unemployed or inactive compared to men, hinting to a more traditional attitude towards female labor market participation. While limited knowledge of UISA does not have a significant impact on employment duration in my sample, it might still prevent a share of workers from receiving benefits. And although the new UISA scheme certainly increases overall benefits, total amounts continue to be low, leading to restricted consumption smoothing and a possible severe drop in household income during unemployment spells.

Furthermore it is important to keep in mind that only formal private sector employees are covered under this policy in Chile, and that informal workers continue to be unprotected and excluded from any kind of unemployment protection (Sehnbruch, 2004). While Chile has a relatively large formal labor market, informality is significantly higher in other developing countries, restricting this scheme to workers that already have access to often comprehensive social security rights.

This policy certainly presents an alternative design in unemployment protection for developing nations with limited financial and monitoring capacities, but could also present an option for advanced economies, for example as an additional component combined with unemployment insurance based on risk-pooling. Moral hazard has been widely reported. Depleting the individual savings account before receiving access to the common fund could present a possible approach to restrict misuse.

Since the introduction of the UISA scheme in Chile about a decade ago, one reform has been implemented in May 2009. Huneeus et al. (2012) assess changes in job search behavior between workers who decide to use unemployment benefits compared to those who decide against it before and after the reform. Future research may therefore focus on a more detailed examination of the UISA design and in particular on reforms, for example on the effect of specific scheme requirements after which workers become eligible to withdraw accumulated benefits or receive access to the solidarity fund. Another relevant topic for further research is the type and quality of the new jobs workers find after they change employment or after unemployment spells, since a short employment duration can imply both positive and negative consequences for the labor market.

In the next chapter I address the topic last mentioned. The changes in wage and contract types are assessed for workers who started a new employment relation before and after UISA introduction to analyze if the unemployment protection scheme had an impact on 
subsequent employment quality. 
Chapter 7

Subsequent Employment Quality 


\subsection{Introduction}

Chile introduced a new unemployment protection scheme for formal private sector workers in October 2002. ${ }^{1}$ Before, unemployment protection was limited to severance pay in case of job termination due to economic necessities of the firm, complemented by low unemployment insurance (UI) benefits. The new law introduced individual unemployment insurance savings accounts (UISA) in addition to severance pay and abolished the low unemployment insurance. Access to accumulated savings was extended to workers losing employment due to just cause or voluntarily leaving the current employment. ${ }^{2}$ Furthermore opportunity costs of workers were reduced in case of job change, as accumulated benefits are kept in the individual savings account. Employers can similarly benefit from the new policy introduction by reduced ad-hoc obligations in case of severance payments.

Due to the extension in unemployment protection and the reduction in opportunity costs, this chapter examines if the policy introduction had an effect on the subsequent employment quality of two groups of workers who leave their initial employment by analyzing the differences in wages and contract types. The first group changes directly into a new job, the second group retakes a job after experiencing a period of unemployment. ${ }^{3}$ Workers who terminate their initial employment relation face reduced opportunity costs in case of a job change, or increased financial leeway to search for a better job in case of unemployment, if they are affiliated to UISA. To my knowledge this chapter is the first to empirically investigate the impact of the Chilean UISA scheme on subsequent employment characteristics, measured by the differences in wages and contract types between the initial and subsequent employment relation. Different to unemployment insurance schemes, where numerous studies have analyzed the impact on subsequent employment characteristics, this scheme presents an alternative kind of unemployment protection. It is not based on risk-pooling as in an insurance type of scheme, but presents a forced savings scheme that is financed by both the employer and the employee in case of permanent contracts, or by the employer only in case of temporary

1 This chapter is based on the working paper: Nagler, P. (2015). The Impact of Unemployment Insurance Savings Accounts on Subsequent Employment Quality. UNU-MERIT Working Paper No. 2015-026.

2 Just cause includes: expiration of contract or misconduct.

3 In the remainder of the chapter I use the expressions "post-employment" and "post-unemployment" for these two groups. Post-employment refers to workers who directly start a new job after terminating their initial work relation, and post-employment wages (contract types) refer to wages earned (or contract types signed) in this subsequent job. Post-unemployment refers to workers who terminate their initial work relation, experience a period of unemployment, and then re-enter the labor market. Post-unemployment wages (contract types) refer to wages earned (or contract types signed) in this subsequent job, after experiencing a period of unemployment. 
contracts, and entails a solidarity fund as a minor component that is accessible when certain conditions are fulfilled.

I use longitudinal data from the Chilean Social Protection Survey and expect the following results. First, workers who directly change into a new employment relation and who are affiliated to UISA have reduced opportunity costs, as accumulated savings remain in the worker's individual unemployment account, although they still lose their right to severance pay. I expect that workers are more willing to change employment for other (better) work opportunities, even if wages of the new employment are not higher, ${ }^{4}$ since they forgo less unemployment protection loss when changing jobs. With regard to contract types I expect that workers with a permanent contract only change to a new employment if receiving the same contract type, while workers with a temporary contract are willing to accept an employment with the same (temporary) or permanent contract type. ${ }^{5}$ However, workers affiliated to UISA might put less emphasis to permanent contracts due to extended unemployment protection. These expected outcomes are not substantially different compared to a situation without the UISA scheme, but the willingness to change for a new employment is higher due to reduced opportunity costs and could therefore have an impact on the differences in wages and contract types. ${ }^{6}$

Second, workers who are unemployed before re-entering the labor market and who are affiliated to UISA, face reduced pressure to find a new employment. Therefore they have more time to find a job that offers adequate payment and contract type. This is expected to have a positive impact on the wage difference compared to a situation without unemployment protection. I also expect the impact on the following contract type to be similar or superior, as workers can spend more time to search for a permanent contract. However, the outcome also depends on whether the worker experiences a short- or medium length of unemployment, or if the worker is a long-term unemployed. During longterm unemployment skills decline with a negative effect on the subsequent employment characteristics.

Using a difference-in-differences approach, I find a significant and negative effect on the wage difference between workers who started before or after the UISA introduction, but no effect on the difference in contract types for workers of both groups. Using informal private sector workers as a control group, only the wage difference for the post-

\footnotetext{
4 "Better" work opportunities could entail a wide range of more preferable characteristics to the employee that exclude a higher wage, for example more adequate job requirements for the worker's qualifications, distance to travel to the work location, or opportunities to develop within the company, among others.

5 I make the assumption that workers consider a permanent contract superior to a temporary contract.

6 See also Nagler (2013) on the impact of UISA accounts on employment duration.
} 
unemployment group is statistically different and positive for the treatment group, while the overall effect continues to be negative. I therefore conclude that UISA had a small negative effect on the difference in wages, with a magnitude of 5 to 7 percent less compared to workers who are not affiliated, but had no effect on contract types. In comparison with the control group, the difference in wage growth is statistically significant and slightly positive. The subsequent employment quality is therefore only partially affected (wages), and as expected: the wage difference is overall negative for UISA affiliates compared to workers not affiliated, but the difference in differences positive when compared to the control group.

The chapter is organized as follows. Section 7.2 reviews the theoretical and empirical literature of the impact of unemployment protection on subsequent employment quality and Section 7.3 provides a set of descriptive statistics. Section 7.4 explains the method used for the analysis and Section 7.5 presents and discusses the results. The final section concludes with a summary of the findings, policy recommendations and suggestions for further research.

\subsection{Literature Review}

The literature on unemployment protection suggests that unemployment benefits lead to ambiguous labor market outcomes. First, they improve the overall labor market efficiency, as risk-averse workers would seek low-risk, but also lower-paid employment, leading to an equilibrium with low unemployment, but also lower capital and labor ratios and a worse job quality. Unemployment protection therefore encourages workers to seek higherpaid and higher-quality jobs that also include higher unemployment risk (Acemoglu and Shimer, 1999). The composition of the labor market changes, and consequently total output and welfare increase (Acemoglu and Shimer, 2000). Second, it shields households from a sharp fall in income during unemployment by providing unemployed workers a financial cushion while searching for reemployment. And third, it leads to longer unemployment duration and overall higher unemployment as shown by a large body of literature, among others van Ours and Vodopivec (2008), Tatsiramos (2009) and Caliendo et al. (2013). ${ }^{7}$ Longer unemployment duration arises due to two reasons. Unemployed workers can be more selective with regard to incoming job offers compared to a situation where they would have to accept the first employment irrespective of wage and quality,

7 Other empirical studies include Card and Levine (2000), Lalive and Zweimüller (2004) and Addison and Portugal (2008). 
and due to lower search effort (Katz and Meyer, 1990; Acemoglu and Shimer, 2000).

While unemployment benefits lead to prolonged unemployment duration, as workers can be more selective when searching for a job, they might simultaneously lead to favorable outcomes in terms of subsequent job quality. In standard job search theory, unemployment benefits have been interpreted as a search subsidy, allowing job seekers to spend more time searching for adequate jobs that match their abilities and satisfy certain conditions. The potentially favorable outcomes are based on Burdett (1979) who argues that job seekers searching for employment do not have perfect information about all job positions that are currently available. Therefore, they need time to search for new positions that match their qualifications and offer adequate conditions. Consequently generous unemployment protection is expected to increase the job match quality for the subsequent employment, for example through better employment stability and higher wages. Positive outcomes are expected to apply primarily to short- and medium-term unemployed workers, but to a more limited extent to long-term unemployed workers due to a decline in skills and other negative effects of long unemployment spells.

Unemployment protection can assume various forms and designs, depending on a country's context and preferences, for instance unemployment insurance based on riskpooling, severance pay or individualized savings accounts. Most studies that evaluated unemployment protection have focused on unemployment insurance due to its prevalence in advanced economies. Severance pay, in particular, is widespread in developing countries, which is often restrictive and can lead to a situation of rigid labor markets (Vodopivec, 2013). Unemployment accounts are a relatively new design of unemployment protection and have gained increased attention over the past decade, although they have already been implemented in the 1970s and 1980s in various Latin American countries alongside unemployment insurance, or for specific subgroups of workers (Ferrer and Riddell, 2011). Unemployment accounts are not only discussed as a form of unemployment protection to replace restrictive severance pay, but to also improve the efficiency of unemployment insurance schemes in advanced economies due to problems of moral hazard.

In the literature the theoretical and empirical effects of unemployment protection on subsequent employment quality have been analyzed in their large majority for unemployment insurance schemes. For unemployment accounts a number of theoretical studies have been conducted to analyze the expected outcomes if unemployment insurance was replaced by individualized savings schemes, among others Orszag and Snower (2002), Brunner and Colarelli (2004), Feldstein and Altman (2007) and Brown et al. (2008). 
Orszag and Snower (2002) argue that unemployed workers who receive benefits from unemployment accounts internalize the social costs of their unemployment to a greater extent compared to unemployment insurance and have a higher incentive to actively search for employment. Unemployment accounts are therefore expected to lead to higher employment, lower unemployment and higher productivity. Brunner and Colarelli (2004) point out that unemployment accounts give the unemployed more financial security compared to unemployment insurance and furthermore allows them to take the time to retrain and to find employment if necessary. Feldstein and Altman (2007) also argue that it would facilitate a substantial improvement in the incentives of unemployed workers. Brown et al. (2008) analyze the incentive effects of unemployment accounts and simulate a model using data from high-unemployment countries in Europe, and find that they change people's incentives and could achieve significant reductions in the unemployment level without reducing the overall benefit level for the unemployed.

The studies compare primarily the theoretical model to unemployment insurance schemes, but do not take the effect on subsequent unemployment quality into account. However, if the theoretical argumentation of the papers also holds in practice, both better and worse outcomes for subsequent employment quality can be expected. Better outcomes due to a higher effort to find employment, financial leeway to retrain and higher labor productivity, while keeping the unemployment protection at a similar level compared to unemployment insurance schemes. Worse outcomes due to a higher pressure to find quick reemployment before depleting the individual account, even if the new job does not offer adequate conditions. The outcome is also expected to depend largely on the design of the scheme, for example on the generosity of benefits or on additional governmental support.

Empirical evidence of the impact of unemployment benefits on subsequent job characteristics only exists for unemployment insurance schemes and results have so far been mixed. Most research has been conducted using data from the United States, Canada and, more recently, European countries. Positive effects, defined as higher wages, employment stability and better access to permanent contracts, are found by Gangl (2002) and Tatsiramos (2009), weak positive effects by Belzil (2001) and Centeno and Novo (2009), and positive effects for certain subgroups of workers by Ehrenberg and Oaxaca (1976) and Caliendo et al. (2013). Wulfgramm and Fervers (2013) equally find positive effects, but include and study labor market support programs. Card et al. (2007), Lalive (2007), van Ours and Vodopivec (2008) and Schmieder et al. (2010) do not find significant outcomes.

A number of studies establish positive, weak positive or partly positive effects with regard 
to subsequent employment stability and wages. Gangl (2002) studies unemployment duration and post-unemployment wages using US and German data. In the United States the negative effect on unemployment duration slightly outweighs the wage increase, while in Germany the positive effect on post-unemployment wages is more pronounced. Stronger UI effects are furthermore found in the lower tails of the wage distribution. Using data from the European Community Household Panel Tatsiramos (2009) provides evidence for increased duration of subsequent employment, suggesting a positive matching effect of unemployment benefits. Belzil (2001) finds a weak matching effect between benefit duration and subsequent job duration using Canadian labor force data. Increasing the maximum benefit duration by one week increases unemployment duration by 1 to 1.5 days, but increases the expected subsequent job duration by 0.5 to 0.8 days only. Centeno and Novo (2009) analyze the liquidity effect of unemployment insurance and find a large impact on employment duration, but only a small impact on subsequent wages. Wage gains are concentrated among workers at the bottom of the preunemployment income distribution. Ehrenberg and Oaxaca (1976) find that an increase in unemployment benefits results in productive job search for a subsample of older workers, with positive outcomes on both wages and the duration of subsequent employment. In contrast, the authors do not find any wage difference for the younger cohort of workers, while it still increases the unemployment spell. Caliendo et al. (2013) provide evidence that unemployed workers who find a job close to benefit exhaustion (or shortly after) experience less stability in their subsequent employment and receive lower wages compared to other unemployed workers with extended benefits who exit employment at the same time. However, this result is only significant for men. Wulfgramm and Fervers (2013) take furthermore active labor market policies into account and find that unemployment benefits function as a search subsidy, and that training programs and counseling services lead to higher reemployment stability.

In contrast, Card et al. (2007), Lalive (2007), van Ours and Vodopivec (2008) and Schmieder et al. (2010) do not find significant outcomes. Card et al. (2007) estimate job search behavior to cash-on-hands using Austrian data, and make use of sharp discontinuities in the eligibility for severance pay and extended UI benefits. They find that an increase in severance pay and an extension of UI benefit duration lead to reduced job finding rates, but that an increase in search duration has little or no effect on subsequent job match quality. Lalive (2007) equally uses Austrian data and concludes, using a regression discontinuity design, that changes in benefit duration do not affect the subsequent employment quality measured by wages. In their paper van Ours and Vodopivec (2008) analyze how job quality is affected after a change in Slovenia's 
unemployment insurance law, but do not find significant effects on subsequent wages, the probability to secure a permanent contract or employment duration. Finally, Schmieder et al. (2010) analyze the impact of different unemployment insurance lengths on labor supply and search outcomes using data from Germany, and equally do not find any effect of increased UI duration on employment quality, expressed as subsequent wages.

While extensive research has been conducted analyzing the effect of unemployment insurance on subsequent job quality, there is still a general lack of research with regard to a possible impact of unemployment insurance savings accounts. However, the outcomes can widely differ, as unemployment accounts primarily present a forced savings scheme compared to unemployment insurance based on risk-pooling. The only research in this area so far conducted has analyzed the impact of savings on search intensity in a job search model with unemployment insurance (Lentz, 2009; Vejlin, 2011). Both articles find, using Danish data, that wealthy individuals experience longer unemployment duration which is explained by lower search intensity. While the case of Denmark analyzes the impact of wealth in a context of unemployment insurance provision, the case of Chile is described as a forced savings scheme with monthly contributions into an individual savings account complemented by a solidarity pillar. Reyes et al. (2011) analyze the Chilean UISA scheme and provide evidence that individuals internalize the cost of unemployment by reduced moral hazard. Therefore, the impact of UISA introduction on subsequent wages, contract types or employment stability continues to be unclear.

Finally, it is important to remark that labor market evaluations using emerging and developing country data are still limited, as the bulk of research has so far been conducted with advanced country data with a focus on North America and Europe. However, the labor market functions differently in developing economies, for example due to a large informal labor market, where unemployed workers could potentially find employment during "official" unemployment spells.

\subsection{Descriptive Statistics}

The database used in this chapter is the Chilean EPS database, as described in Section 5.6 of Chapter 5. For this analysis I select as the dependent variables the differences in average net wage and contract type between the initial and subsequent employment relation, as the main independent variable UISA affiliation, and as further covariates changes in labor characteristics of private sector workers. Average net wage is expressed 
in 2002 prices $^{8}$ and contract type is coded as permanent contract. Affiliation to the UISA scheme is expressed as a binary variable, where I allocate UISA $=1$ to all workers who started a new employment after UISA introduction in October 2002 and UISA $=0$ to all workers who started their employment before. ${ }^{9}$

Table 7.1 shows the initial and subsequent average net wage and contract type of formal private sector workers who started a new employment during the two years before or after the policy introduction. I take the subgroup of workers who directly changed into a new employment after terminating this initial employment relation. The wage difference is higher among the workers who started their initial employment before UISA introduction compared to those who started during the two years after. The change in the differences is negative for both men and women, and larger for men than for women. A possible explanation could present the fact that a change of employment included large opportunity costs before the policy introduction, motivating workers to only change employment if the new job conditions clearly improved. The wage outcome in terms of gender is contradictory. Before UISA introduction the difference for women is smaller compared to men, but larger afterwards. The differences in contract type are minor, namely -2 percentage points for women before and 1 percentage point after, and -4 percentage points for men before and 0 percentage point difference after UISA introduction. The change in the differences is positive for both men and women, and larger for men than for women.

Further I tabulate the subsequent type of employment of workers who directly change into a new employment before or after UISA introduction. For wages I have a sample of 787 before UISA and 636 after UISA. From the 787 workers before UISA introduction 81 percent remain in the private sector, 11 percent become self-employed, 3 percent change into the public sector and the remaining observations can be found among employers and domestic workers. 43 percent of the subsequent contracts are temporary and 57 percent permanent. After UISA introduction the shares are similar. From the 636 workers 84 percent remain in the private sector, 10 percent become self-employed and 3 percent change into the public sector. The difference in contract types is a bit larger, with 50 percent of the contracts being temporary and 50 percent permanent. Finally, I assert that 30 percent of the observations are censored, identifying the workers who started a new employment in the time period observed and continue to be in the same employment

\footnotetext{
8 Data from the International Monetary Fund: inflation of average consumer prices for Chile 2000-2010 (index and percentage change). Data last updated 03/2013.

9 This binary variable is not a self-reported variable, nor does it include any information on benefit collection. See also Nagler (2013).
} 
Table 7.1: Descriptive Statistics - Post-Employment

\begin{tabular}{|c|c|c|c|c|c|c|c|c|c|}
\hline \multirow[b]{2}{*}{ Wage } & \multicolumn{4}{|c|}{ Before UISA } & \multicolumn{5}{|c|}{ After UISA } \\
\hline & Obs & Initial & Subs & Diff & Obs & Initial & Subs & Diff & Change \\
\hline Female & 206 & $\begin{array}{c}143.60 \\
(110.74)\end{array}$ & $\begin{array}{c}160.19 \\
(126.83)\end{array}$ & 16.59 & 164 & $\begin{array}{l}152.04 \\
(90.48)\end{array}$ & $\begin{array}{c}166.59 \\
(129.54)\end{array}$ & 14.55 & -2.04 \\
\hline Male & 581 & $\begin{array}{c}178.80 \\
(145.48)\end{array}$ & $\begin{array}{c}202.32 \\
(167.19)\end{array}$ & 23.52 & 472 & $\begin{array}{c}200.08 \\
(140.80)\end{array}$ & $\begin{array}{c}214.44 \\
(169.78)\end{array}$ & 14.36 & -9.16 \\
\hline Contract & Obs & Initial & Subs & Diff & Obs & Initial & Subs & Diff & Change \\
\hline Female & 241 & $\begin{array}{c}0.62 \\
(0.49)\end{array}$ & $\begin{array}{c}0.60 \\
(0.49)\end{array}$ & -0.02 & 174 & $\begin{array}{c}0.53 \\
(0.50)\end{array}$ & $\begin{array}{c}0.52 \\
(0.50)\end{array}$ & -0.01 & 0.01 \\
\hline Male & 661 & $\begin{array}{c}0.58 \\
(0.49)\end{array}$ & $\begin{array}{c}0.54 \\
(0.50)\end{array}$ & -0.04 & 486 & $\begin{array}{c}0.49 \\
(0.50)\end{array}$ & $\begin{array}{c}0.49 \\
(0.50)\end{array}$ & 0.00 & 0.04 \\
\hline
\end{tabular}

Note(s): Standard deviation in parenthesis. Differences in bold if difference is statistically significant at the 5 percent level. Wage: average monthly net wage in 1,000's of CLP (in 2002 prices). Contract: binary variable; the variable takes the value 1 if the contract is permanent. Subs $=$ subsequent wage or contract type.

at the time of the last survey.

Table 7.2 shows the initial and subsequent average net wage and contract type of private sector workers who started a new employment during the two years before or after the policy introduction. I take the subgroup of workers who experienced a period of unemployment after terminating the initial employment relation before re-entering the labor market. ${ }^{10}$ While there is a positive difference in subsequent wages among the workers who started their initial employment before UISA, it is slightly negative for women afterwards. For men the wage level practically remains unchanged. In terms of gender the difference for women is smaller compared to men before UISA introduction and negative afterwards. The differences in contract type are again minor, namely -1 percentage point for women before and 4 percentage points after, and 1 percentage point for men before and 3 percentage points difference after UISA introduction.

Further I tabulate the subsequent type of employment of workers who experienced a period of unemployment before re-entering the labor market before or after UISA introduction. For wages I have a sample of 453 before UISA and 590 after UISA. From the 453 workers before UISA introduction 87 percent remain in the private sector, 5 percent become self-employed, 4 percent change into the public sector and the remaining observations can be found among employers and domestic workers. 60 percent of the contracts are temporary and 40 percent are permanent. After UISA introduction the

\footnotetext{
$\overline{10}$ The period of unemployment is of different length and can include short-, medium- and longer-term unemployment.
} 
Table 7.2: Descriptive Statistics - Post-Unemployment

\begin{tabular}{|c|c|c|c|c|c|c|c|c|c|}
\hline \multirow[b]{2}{*}{ Wage } & \multicolumn{4}{|c|}{ Before UISA } & \multicolumn{5}{|c|}{ After UISA } \\
\hline & Obs & Initial & Subs & Diff & Obs & Initial & Subs & Diff & Change \\
\hline Female & 143 & $\begin{array}{l}124.32 \\
(68.26)\end{array}$ & $\begin{array}{l}126.06 \\
(74.90)\end{array}$ & 1.74 & 249 & $\begin{array}{l}123.66 \\
(65.83)\end{array}$ & $\begin{array}{l}118.37 \\
(57.11)\end{array}$ & -5.29 & -7.03 \\
\hline Male & 310 & $\begin{array}{c}159.93 \\
(100.93)\end{array}$ & $\begin{array}{c}167.46 \\
(105.42)\end{array}$ & 7.53 & 341 & $\begin{array}{c}168.03 \\
(116.08)\end{array}$ & $\begin{array}{c}167.21 \\
(112.75)\end{array}$ & -0.82 & -8.35 \\
\hline Contract & Obs & Initial & Subs & Diff & Obs & Initial & Subs & Diff & Change \\
\hline Female & 226 & $\begin{array}{c}0.38 \\
(0.49)\end{array}$ & $\begin{array}{c}0.33 \\
(0.47)\end{array}$ & -0.05 & 255 & $\begin{array}{c}0.20 \\
(0.40)\end{array}$ & $\begin{array}{c}0.23 \\
(0.42)\end{array}$ & 0.03 & 0.08 \\
\hline Male & 456 & $\begin{array}{c}0.42 \\
(0.49)\end{array}$ & $\begin{array}{c}0.40 \\
(0.49)\end{array}$ & -0.02 & 344 & $\begin{array}{c}0.28 \\
(0.45)\end{array}$ & $\begin{array}{c}0.28 \\
(0.45)\end{array}$ & 0.00 & 0.02 \\
\hline
\end{tabular}

Note(s): Standard errors in parenthesis. Differences in bold if difference is statistically significant at the 5 percent level. Wage: average monthly net wage in 1,000's of CLP (in 2002 prices). Contract: binary variable, the variable takes the value 1 if the contract is permanent. Subs $=$ subsequent wage or contract type.

shares of employment type are similar. From the 590 workers 90 percent remain in the private sector, 5 percent become self-employed and 2 percent change into the public sector. The share of contract types, however, differs considerably. 74 percent of the contracts are temporary and only 26 percent are permanent. Finally, I assert that 4 percent of the observations are censored, identifying the workers that became unemployed and continue to be unemployed at the time of the last survey.

The descriptive statistics report the average differences of the initial and subsequent wages and contract types of workers who started their initial employment in the two years before or after UISA introduction. They give a first indication of differences explained by UISA affiliation in the two subgroups of workers that I study. Next, I conduct an empirical analysis using econometric techniques to further analyze a possible impact of UISA introduction on subsequent job quality.

\subsection{Methodology}

For the analysis I use a difference-in-differences approach and proceed in two steps. First I estimate regressions with a sample of formal private sector workers only, where I use the differences in wages and contract types from the initial and subsequent employment relation as the dependent variables. As main explanatory variable I take UISA affiliation, 
and as further explanatory variables changes in the workers' characteristics. In these regressions I therefore compare workers who started before with workers who started after UISA introduction, analyzing the differences in wages and contract types. Second, I use an untreated comparison group. The difference-in-differences is then defined as a comparison of two sample results studied before and after the introduction of a policy scheme or a policy intervention, but where only one of the groups was exposed to treatment. In other words, I analyze potentially significant differences in wages and contract types for two different groups and for two different periods in time.

A simple example of a difference-in-differences approach would be,

$y_{i t}=\alpha+\beta D_{t}+\varepsilon_{i t}, \quad i=1, \ldots, N, \quad t=0,1$

where $D_{t}=1$ after the policy was introduced and $D_{t}=0$ before, and where $y_{i t}$ measures the outcome studied. The regression result, estimated using the sample data, yields $\beta$ as the measure of the policy impact.

However, this approach makes the assumption that the sample remains comparable over the time period observed, assuming no other changes or time trends, that could actually falsify $\beta$. One solution to improve the estimation is to include data from an untreated comparison group. The regression then is,

$y_{i t}=\alpha+\alpha_{1} D_{t}+\alpha^{1} D_{j}+\beta D_{t}^{j}+\varepsilon_{i t}^{t}, \quad i=1, \ldots, N, \quad t=0,1$

where $j$ is the group subscript, where $D^{j}=1$ if $j=1$ and $D^{j}=0$ if $j=0$, and where $D_{t}^{j}=1$ if both $j$ and $t$ are equal to 1 , and $D_{t}^{j}=0$ otherwise.

For the treated sample the equation before the policy intervention is,

$y_{i 0}^{1}=\alpha+\alpha^{1} D^{1}+\varepsilon_{i 0}^{1}$

and the equation after the policy intervention is,

$y_{i 1}^{1}=\alpha+\alpha_{1}+\alpha^{1} D^{1}+\beta+\varepsilon_{i 1}^{1}$ 
The impact can then be calculated as,

$y_{i 1}^{1}-y_{i 0}^{1}=\alpha_{1}+\beta+\varepsilon_{i 1}^{1}-\varepsilon_{i 0}^{1}$

The corresponding equations for the untreated sample are,

$y_{i 0}^{0}=\alpha+\varepsilon_{i 0}^{0}$

$y_{i 1}^{0}=\alpha+\alpha_{1}+\varepsilon_{i 1}^{0}$

And where the difference can then be calculated as,

$y_{i 1}^{0}-y_{i 0}^{0}=\alpha_{1}+\varepsilon_{i 1}^{0}-\varepsilon_{i 0}^{0}$

The post-intervention specific effect $\alpha_{1}$ can be eliminated using the control sample by taking the difference of the equations (5) and (8).

$\left(y_{i 1}^{1}-y_{i 0}^{1}\right)-\left(y_{i 1}^{1}-y_{i 0}^{1}\right)=\beta+\left(\varepsilon_{i 1}^{1}-\varepsilon_{i 0}^{1}\right)-\left(\varepsilon_{i 1}^{0}-\varepsilon_{i 0}^{0}\right)$

The difference of the error terms is assumed to equal 0 , and therefore it is possible to estimate $\beta$ by taking the sample average of $\left(y_{i 1}^{1}-y_{i 0}^{1}\right)-\left(y_{i 1}^{1}-y_{i 0}^{1}\right)$, leading to the results in a difference-in-differences estimate (Cameron and Trivedi, 2009).

In the first part of the analysis the two groups are represented by workers who started their employment before or after the policy introduction, and are therefore distinguished by UISA affiliation. In the second part, I take informal private sector workers as the control group, defined as workers without a contract, who are not exposed to the new unemployment protection scheme. The two different time periods are the month of the initial employment and the month of the subsequent employment. In each point in time I take the wage (log transformed) or contract type, and calculate the difference.

\subsection{Results}

The results are organized in three sections. In Section 7.5.1 I analyze the data graphically to identify a possible discontinuity in the differences of wages and contract types of 
workers who started a new employment relation before or after UISA introduction. In Section 7.5.2 I conduct an econometric analysis, where I use the methodology previously described. Finally, I conduct a set of robustness tests in Section 7.5.3.

\subsubsection{Graphical Analysis}

The graphical analysis is the first step in the empirical analysis. The value of the outcome is computed on both sides of the cutoff point, the UISA introduction date, to visually analyze a possible difference in the differences of wages and contract types before and after the policy was introduced. Assessing the graph gives a first evidence of a possible jump in the mean of the differences. If the graphs do not show a jump at the cutoff point, there is already a reduced chance that further analysis will lead to robust estimates with a statistically significant and substantial differences for both groups of workers.

Figure 7.1 shows the differences in wages (log transformed) and contract types of the initial compared to the subsequent employment relation of workers who started their initial employment in the two years before or the two years after UISA introduction, and who directly changed into a new employment. ${ }^{11}$ The dots on the $\mathrm{X}$-axis therefore show the month of the initial employment start (24 months before and 24 months after the introductory date), while the dots on the Y-axis show the differences in wages (log transformed) and contract types between the initial and subsequent employment relation. ${ }^{12}$

Figure 7.1a does not show a significant jump in the wages of workers around the policy introduction, nor any significant changes over the time period analyzed. The difference in wages seems to be approximately stable and independent of UISA affiliation. In Figure $7.1 \mathrm{~b}$ the picture is similar. The discontinuity is not very pronounced around the UISA introduction, and only a small drop in the difference in contract types can be observed. In both time periods the fitted linear lines show a small, but steady increase, implying an overall small improvement in the contract type difference over the time period observed.

Figure 7.2 shows the differences in wages (log transformed) and contract types between the initial and the subsequent employment relation of workers who started their initial

\footnotetext{
${ }^{11} \mathrm{I}$ do not take the length of the initial employment into account. It can last from one month to various years.

${ }^{12}$ For the contract type the value -1 represents a switch from permanent to temporary contract type, the value +1 a switch from temporary to permanent contract type, and the value 0 represents no change: either two temporary or two permanent subsequent contracts.
} 
Figure 7.1: Wage and Contract Type Differences - Post-Employment

(a) Wage Difference (ln)

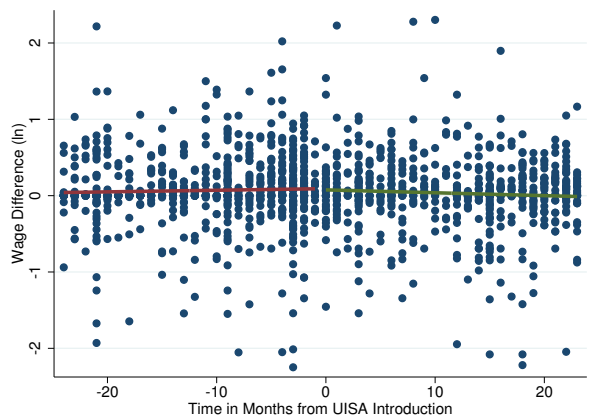

(b) Contract Type Difference

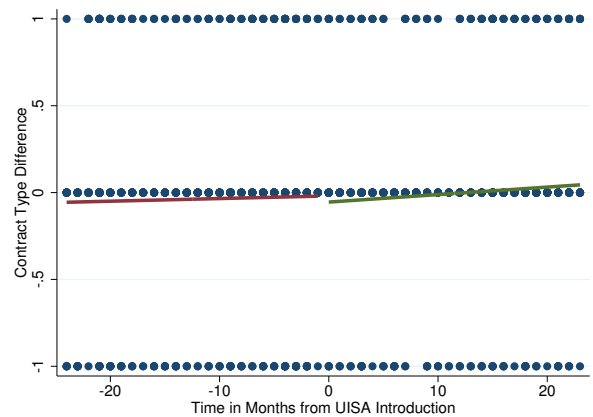

employment in the two years before or after UISA introduction, and who started a new employment after experiencing a period of unemployment. ${ }^{13}$ The dots on the X-axis therefore show the month of the initial employment start (24 months before and 24 months after the introductory date), while the dots on the Y-axis show the differences in wages and contract types between the initial and the subsequent employment relation.

Figure 7.2a shows again a very smooth level in the wage difference for workers who experienced a period of unemployment, and no discontinuity can be observed around the UISA introduction. In Figure $7.2 \mathrm{~b}$ the discontinuity is small around the cutoff point, but a difference can be observed in the slope over the time period observed. Before UISA introduction the slope is positive and rising, afterwards the slope is largely stable.

Figure 7.2: Wage and Contract Type Differences - Post-Unemployment

(a) Wage Difference (ln)

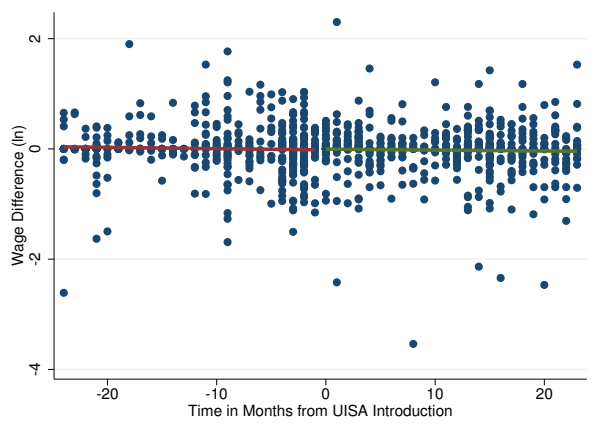

(b) Contract Type Difference

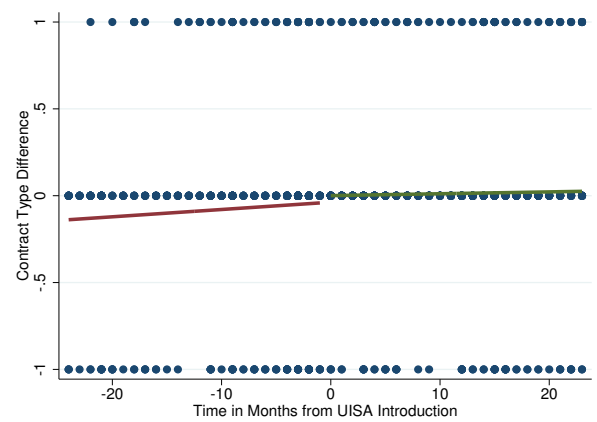

In sum, I do not find indications for a sharp discontinuity in the differences of wages

\footnotetext{
${ }^{13}$ I do not take the length of the initial employment, nor the length of the unemployment period into account. Both can last from one month to various years.
} 
or contract types for workers in both samples. The difference in wages is largely stable over the time period observed, and the difference in contract types shows only a small discontinuity around the cutoff point for both samples. To identify if these differences are statistically significant, I estimate a set of regressions, accounting for the observational type of data. In the following subsection I use a difference-in-differences methodology to account for further aspects in the study of subsequent employment quality since UISA affiliation of workers was not randomized.

\subsubsection{Difference-in-Differences}

For the econometric analysis I estimate a set of regressions. First, I analyze the sample of formal private sector workers and use the differences in wages and contract types between the initial and the subsequent employment relation as the dependent variables. Second, I use a difference-in-differences methodology to account for time trends, where I take informal private sector workers as the control group. I make the assumption that informal private sector workers experience similar trends in the labor market and are therefore comparable to the formal private sector workers, with the difference that they do not have a contract. Consequently these workers are not affiliated to the new UISA scheme if they started a new work relation after October 2002 since their work relation is informal, and are excluded from unemployment protection.

Table 7.3 shows the results for the sample of formal private sector workers using the differences in wages (log transformed) and contract types as dependent variables. For the change in contract type I estimate an ordered probit model. In the upper part of the table, where (ln)wage change is the dependent variable, the results are not significant for wages when taking only UISA affiliation as explanatory variable. However, with additional covariates, the wage change is significant at the 5 or 10 percent level and negative. In the regressions (2) and (5) I add a binary variable indicating if the workers started the initial employment before UISA introduction and the subsequent employment relation afterwards, since the wage of the subsequent employment is potentially affected by the policy scheme. In the post-unemployment sample this binary variable is indeed significant and negative. In the regressions (3) and (6) I also add the length of the initial employment relation in months and the information if the worker changed the sector for the subsequent employment relation. ${ }^{14}$ The variable "same sector" is significant and

\footnotetext{
${ }^{14}$ The variable "same sector" is equal to 1 if the worker remains in the private sector. The change of sector can be into different types of employment relations: employer, self-employed, the public sector, domestic worker, non-renumerated family worker or military service.
} 
positive, indicating that remaining in the private sector has a positive effect on the wage difference compared to workers who find employment elsewhere. For the postunemployment sample I also add the length of unemployment duration, which is not significant for the wage difference. Overall the results show that the wage difference is 5 to 6 percent lower for UISA affiliates in the post-employment sample, and 6 to 7 percent lower in the post-unemployment sample.

In the lower part of the regression table, where the change in contract types is the dependent variable, the coefficients for UISA affiliation are positive, but not significant in all regressions. The binary variable D2 is significant for both samples with contradicting effects (negative in regression (2), but positive in the regressions (3) and (6)), and previous employment duration significant and negative. Remaining in the same sector is positive at the 1 percent level for the post-employment sample, while unemployment duration has no significant effect.

In summary the results indicate that UISA introduction had a significant and small negative effect on the wage difference (of about 5 to 7 percent), but did not have an effect on the difference in contract types. To further study the negative effect on the difference in wage change, I take next a control group to account for labor market trends.

The results in Table 7.4 largely confirm the outcomes of the previous table. In the difference-in-differences analysis with the control group I estimate wage growth only, since informal private sector employees do not have a contract and a differentiation between permanent and temporary contract is therefore not possible. The overall effect (marginal effect) of UISA affiliation is again significant and negative for the wage difference. However, using the control group, it is now furthermore possible to study if the difference in the differences is significant when comparing the treatment group, formal private sector workers, to this control group. The interaction term UISA $\mathrm{x}$ Formal suggests that the difference in the differences of wages between treatment and control group is not significant for the post-employment group, but positive and significant for the post-unemployment group. While the difference in wages is overall negative, the difference in the differences is positive. This outcome suggests that the UISA introduction only had a significant effect on the wage difference for workers experiencing a period of unemployment before re-entering the labor market, but that the effect on the post-employment group might be insignificant. The positive effect on the post-unemployment group further suggests that UISA affiliation, and therefore financial benefits during unemployment, fulfills the goal of allowing unemployment workers to be more selective while searching for new employment, leading to an advantageous wage 
Table 7.3: Before-After Regression Analysis (Without Control Group)

\begin{tabular}{|c|c|c|c|c|c|c|}
\hline \multirow[b]{2}{*}{$\Delta(\ln )$ wage } & \multicolumn{3}{|c|}{ Post-Employment } & \multicolumn{3}{|c|}{ Post-Unemployment } \\
\hline & (1) & (2) & $(3)$ & (4) & $(5)$ & $(6)$ \\
\hline UISA & $\begin{array}{c}-0.036 \\
(0.03)\end{array}$ & $\begin{array}{c}-0.047^{*} \\
(0.03)\end{array}$ & $\begin{array}{c}-0.055^{* *} \\
(0.03)\end{array}$ & $\begin{array}{l}-0.025 \\
(0.03)\end{array}$ & $\begin{array}{c}-0.063^{* *} \\
(0.03)\end{array}$ & $\begin{array}{c}-0.065^{* *} \\
(0.03)\end{array}$ \\
\hline D2 & & $\begin{array}{c}-0.043 \\
(0.04)\end{array}$ & $\begin{array}{c}-0.065 \\
(0.05)\end{array}$ & & $\begin{array}{c}-0.105^{* *} \\
(0.05)\end{array}$ & $\begin{array}{c}-0.098^{*} \\
(0.05)\end{array}$ \\
\hline Emp. Duration & & & $\begin{array}{l}0.002 \\
(0.00)\end{array}$ & & & $\begin{array}{l}-0.000 \\
(0.00)\end{array}$ \\
\hline Same Sector & & & $\begin{array}{c}0.159^{* *} \\
(0.04)\end{array}$ & & & $\begin{array}{c}0.211^{* * *} \\
(0.06)\end{array}$ \\
\hline Unemp. Duration & & & & & & $\begin{array}{r}-0.002 \\
(0.00)\end{array}$ \\
\hline Constant & $\begin{array}{c}0.068^{* * *} \\
(0.02)\end{array}$ & $\begin{array}{c}0.079^{* * *} \\
(0.02)\end{array}$ & $\begin{array}{c}-0.108^{* *} \\
(0.04)\end{array}$ & $\begin{array}{l}0.004 \\
(0.02)\end{array}$ & $\begin{array}{l}0.041 \\
(0.03)\end{array}$ & $\begin{array}{l}-0.091 \\
(0.07)\end{array}$ \\
\hline $\mathrm{N}$ & 1,386 & 1,386 & 1,386 & 1,019 & 1,019 & 1,019 \\
\hline & Po & -Employ & ent & Pos & Jnemploy & nent \\
\hline$\Delta$ contract type & (1) & $(2)$ & $(3)$ & (4) & (5) & (6) \\
\hline UISA & $\begin{array}{l}0.063 \\
(0.06)\end{array}$ & $\begin{array}{l}0.027 \\
(0.06)\end{array}$ & $\begin{array}{l}0.093 \\
(0.06)\end{array}$ & $\begin{array}{l}0.100 \\
(0.07)\end{array}$ & $\begin{array}{l}0.083 \\
(0.07)\end{array}$ & $\begin{array}{l}0.115 \\
(0.07)\end{array}$ \\
\hline D2 & & $\begin{array}{c}-0.165^{*} \\
(0.09)\end{array}$ & $\begin{array}{c}0.322^{* * *} \\
(0.12)\end{array}$ & & $\begin{array}{l}-0.071 \\
(0.12)\end{array}$ & $\begin{array}{c}0.321^{* *} \\
(0.14)\end{array}$ \\
\hline Emp. Duration & & & $\begin{array}{c}-0.025^{* * *} \\
(0.00)\end{array}$ & & & $\begin{array}{c}-0.025^{* * *} \\
(0.01)\end{array}$ \\
\hline Same Sector & & & $\begin{array}{c}0.253^{* * *} \\
(0.09)\end{array}$ & & & $\begin{array}{c}0.049 \\
(0.13)\end{array}$ \\
\hline Unemp. Duration & & & & & & $\begin{array}{l}-0.010 \\
(0.01)\end{array}$ \\
\hline Cut 1 & $\begin{array}{l}-1.009 \\
(0.05)\end{array}$ & $\begin{array}{l}-1.045 \\
(0.05)\end{array}$ & $\begin{array}{l}-1.037 \\
(0.10)\end{array}$ & $\begin{array}{l}-1.083 \\
(0.06)\end{array}$ & $\begin{array}{l}-1.100 \\
(0.06)\end{array}$ & $\begin{array}{l}-1.261 \\
(0.15)\end{array}$ \\
\hline Cut 2 & $\begin{array}{l}1.169 \\
(0.05)\end{array}$ & $\begin{array}{l}1.135 \\
(0.05)\end{array}$ & $\begin{array}{l}1.199 \\
(0.10) \\
\end{array}$ & $\begin{array}{l}1.218 \\
(0.06) \\
\end{array}$ & $\begin{array}{l}1.201 \\
(0.06) \\
\end{array}$ & $\begin{array}{l}1.077 \\
(0.14) \\
\end{array}$ \\
\hline $\mathrm{N}$ & 1,562 & 1,562 & 1,562 & 1,281 & 1,281 & 1,281 \\
\hline
\end{tabular}

Note(s): Standard errors in parentheses and clustered at the individual level. In the ordered probit analysis coefficients are reported. See Table B.10 in Appendix B for marginal effects. ${ }^{*} p<0.1, * *$ $p<0.05,{ }^{* * *} p<0.01$.

difference compared to the control group.

Summarizing the econometric analysis I find only significant effects for the difference in wages, which are negative for both groups. Taking informal private sector workers as control group, I find that the difference in the differences is only significant for the postunemployment sample, and positive. Since the effect on the wage difference is negative, 
Table 7.4: Difference-in-Differences (With Control Group)

\begin{tabular}{lcccccc}
\hline & \multicolumn{3}{c}{ Post-Employment } & \multicolumn{3}{c}{ Post-Unemployment } \\
$\Delta$ (ln)wage & $(1)$ & $(2)$ & $(3)$ & $(1)$ & $(2)$ & $(3)$ \\
\hline UISA x Formal & 0.069 & 0.070 & 0.058 & $0.147^{* *}$ & $0.140^{* *}$ & $0.140^{* *}$ \\
& $(0.059)$ & $(0.059)$ & $(0.059)$ & $(0.064)$ & $(0.064)$ & $(0.064)$ \\
UISA & $-0.106^{* *}$ & $-0.117^{* *}$ & $-0.114^{* *}$ & $-0.172^{* * *}$ & $-0.200^{* * *}$ & $-0.203^{* * *}$ \\
& $(0.052)$ & $(0.053)$ & $(0.053)$ & $(0.058)$ & $(0.060)$ & $(0.061)$ \\
Formal & $-0.134^{* * *}$ & $-0.134^{* * *}$ & $-0.134^{* * *}$ & $-0.234^{* * *}$ & $-0.227^{* * *}$ & $-0.230^{* * *}$ \\
& $(0.040)$ & $(0.040)$ & $(0.039)$ & $(0.053)$ & $(0.053)$ & $(0.054)$ \\
D2 & & -0.045 & -0.067 & & $-0.098^{* *}$ & $-0.092^{*}$ \\
& & $(0.040)$ & $(0.046)$ & & $(0.042)$ & $(0.049)$ \\
Emp. Duration & & & 0.002 & & & -0.000 \\
& & & $(0.002)$ & & & $(0.002)$ \\
Same Sector & & & $0.217^{* * *}$ & & & $\left(0.144^{* * *}\right.$ \\
& & & $(0.037)$ & & & $0.054)$ \\
Unemp. Duration & & & & & & $(0.003)$ \\
Constant & $0.202^{* * *}$ & $0.213^{* * *}$ & 0.023 & 0.238 & $0.118^{* * *}$ & $0.144^{* *}$ \\
& $(0.036)$ & $(0.037)$ & $(0.048)$ & $(0.049)$ & $(0.034)$ & $(0.073)$ \\
\hline - Marg. Effect & $-0.036^{* *}$ & $-0.047^{* *}$ & $-0.056^{* *}$ & $-0.025^{* * *}$ & $-0.060^{* * *}$ & $-0.063^{* * *}$ \\
UISA & & & & & \\
- Marg. Effect & $-0.064^{* * *}$ & $-0.064^{* * *}$ & $-0.075^{* * *}$ & $-0.088^{* * *}$ & $-0.088^{* * *}$ & $-0.090^{* * *}$ \\
Formal & & & & & \\
\hline Wald Test UISA & 0.043 & 0.021 & 0.012 & 0.009 & 0.001 & 0.001 \\
Wald Test Formal & 0.001 & 0.001 & 0.001 & 0.000 & 0.000 & 0.000 \\
N & 1,902 & 1,902 & 1,902 & 1,331 & 1,331 & 1,331 \\
\hline
\end{tabular}

Note(s): Standard errors in parentheses. Clustered at the individual level. ${ }^{*} p<0.1,{ }^{* *} p<0.05, * * *$ $p<0.01$.

three explanations are at hands. First, the cost of the new unemployment protection was passed on to the workers' wages by their employers. While the subsequent wage is higher for post-employment workers with and without UISA affiliation, the difference is smaller for UISA affiliates. In the post-unemployment group the subsequent wage is even lower than the initial wage for UISA affiliates. Second, workers affiliated to the UISA scheme might give less importance to an equal or higher wage in the subsequent employment compared to workers without unemployment protection. They are more willing to leave their current employment relation and change into another job, even if wages are similar or below their initial employment wage (see also Nagler, 2013). Third, workers experiencing a period of unemployment might take more time to find a new job due to unemployment protection. While this gives unemployed workers more leeway to find a job with adequate conditions, it could equally lead to skills depreciation and constitute the dominant effect in this case. Workers who are longer unemployed might 
face inferior conditions when re-entering the labor market. This last hypothesis, however, casts doubts since the regressions in Tables 7.3 and 7.4 do not indicate a significant negative effect of unemployment duration on wage growth.

\subsubsection{Robustness}

To test the robustness of my previous estimates I conduct two falsification tests and furthermore estimate additional regressions, adding the UISA amount to net wages. ${ }^{15}$ In the first falsification test I change the introduction date "as if" the UISA scheme had been introduced two years later, in October 2004. In the second falsification test I estimate the same set of regressions for the difference-in-differences analysis using public sector employees as an alternative control group. In the additional regressions I add the UISA amount to net wages of UISA affiliates to test if the costs of the protection scheme have been deducted from the wages, presenting a delayed payment.

The first robustness test takes an alternative introduction date for UISA affiliation, "as if" the unemployment insurance had been introduced two years later. I choose the alternative introduction date of two years, since the sample for the analysis is taken from all formal private sector employees who started two years before or two years after the official UISA introductory date. Therefore the alternative sample only includes workers who are affiliated to UISA, and where no official introductory date in between could falsify the differences in wages or contract types. For the wage difference the results show that the "as if" UISA variable is not significant in all regressions. For the difference in contract types, the UISA variable is significant at the 5 percent level and positive in the simple regression for the post-employment sample, but no longer significant when adding covariates. The results for the UISA variable are all insignificant for the postunemployment sample. I therefore conclude that the results in the analysis with the official introduction date, showing significant results for the wage change of UISA affiliates and insignificant results for the change in contract types, can be considered valid.

The second robustness test takes a different control group for the difference-in-differences estimations. The drawback of this alternative control group is the relatively small sample size. Therefore the larger group of informal private sector employees were previously selected for a more comprehensive analysis. ${ }^{16}$ However, it has the advantage of allowing

\footnotetext{
${ }^{15}$ I also examine the economic cycle in Chile during the time period studied and summarize the results in Appendix B. Overall Chile showed a stable economic performance, leading to limited concerns about the impact of external factors that could influence the results of this chapter.

16 The sizes of the control groups are: 84 (wages, post-employment), 105 (wages, post-unemployment),
} 
to include the difference in contract types. A permanent contract is more prevalent among public sector employees, with a difference of approximately 10 percentage points in both samples. I concentrate on the simple regressions and the regressions including the D2 variable for this robustness test, where the only covariate is UISA affiliation for the former, and UISA affiliation plus the D2 variable for the latter. The results of the difference-in-differences analysis show that the differences between the treatment and control group are not statistically significant for all regressions. UISA affiliation is not significant in any of the simple regressions and equally insignificant for the regressions including the D2 variable, with the exception of the difference in contract types for the post-employment sample, where UISA affiliation is significant at the 10 percent level and positive. Therefore I cannot identify a difference in the differences of wages or contract types using this alternate control group. However, these results could be also caused by the small sample size of public sector employees. ${ }^{17}$

Finally, I add the UISA amount that is paid by the employer (2.2 percent for a permanent contract and 3.0 percent for a temporary contract) to net wages. In the regressions of the post-employment sample, the UISA variable is significant at the 1 percent level and positive, but wage growth very small with a 0.4 percent increase compared to non-UISA affiliates. In the post-unemployment sample, UISA is significant at the 1 or 5 percent level and positive, but the wage growth with a 0.1 to 0.2 percent increase even smaller compared to non-UISA affiliates.

Summarizing the analysis after conducting the two falsification tests and the additional regressions, the first falsification test (using the alternative "as if" introductory date) shows that the alternative UISA variable does not have a significant effect on the wage difference. It only has a significant effect on the simple regression for the difference in contract types for the post-employment sample. It therefore shows that the UISA variable using the "as if" UISA introductory date largely reports no significant results, strengthening the outcomes of the econometric analysis. Using the different control group the results show that the differences between treatment and control group are not statistically significant. While this outcome does not support the findings in the econometric analysis, it needs to be interpreted with care, since the control group is relatively small. Finally, running the additional regressions including the UISA amount to net wages shows that the difference for UISA affiliates is significant and positive, but very small. If the UISA amount is taken as a delayed payment and added to net wages,

61 (contract type, post-employment), 70 (contract type, post-unemployment).

${ }^{17} \mathrm{I}$ do not report the regression tables for both falsification tests in this chapter, they are available upon request. 
then UISA have a small positive effect on subsequent employment quality measured by wages.

\subsection{Summary and Concluding Remarks}

This chapter analyzes whether the introduction of UISA in Chile had an impact on the differences in wages and contract types of (i) workers directly changing into a new employment, and (ii) workers experiencing a period of unemployment before re-entering the labor market. Based on the results, I find evidence that the introduction of the UISA scheme had a small negative effect on the wage difference, a small positive effect on the difference in the differences compared to a control group, and no effect on the difference in contract types. In the remaining section I first summarize the empirical results, before discussing policy implications and proposing areas of future research.

Summarizing the results of the econometric analysis, I find evidence that the wage difference was negatively affected by the UISA introduction, but that the new unemployment insurance had no effect on the difference in contract types. With regard to wage growth I find that the difference is between 5 to 7 percent lower compared to workers who are not affiliated to the UISA scheme. Apart from the costs of UISA affiliation that might be passed on to the employees' wages, two other explanations are possible: that employees with UISA affiliation put less emphasis on their subsequent wage since they face lower opportunity costs when changing employment. And that workers with UISA affiliation who experienced a period of unemployment take more time to re-enter the labor market and suffer from declining skills and other negative effects of longer unemployment duration. In the empirical analysis, however, I do not find evidence that unemployment duration had a significant effect on wage difference. Using a control group, the results show that the difference in wage growth is significant and positive for the treatment compared to the control group in the post-unemployment sample, suggesting that the unemployment protection allowed unemployed workers to search for a new employment with more favorable conditions.

Testing the robustness of these results, I find the following. The first falsification test, taking another date "as if" the UISA scheme had been introduced two years later, supports the results. The outcomes of this artificial UISA variable are not significant for wage growth and, in their majority, not significant for the difference in contract types. The second test does not show any statistically significant difference between treatment 
and control group, suggesting that the difference in wages could also be explained by labor market trends of the Chilean economy. However, this outcome must be interpreted with care, since the sample size of the alternative control group is small. Finally, adding the UISA amount to net wages shows that wage growth is significant and positive, but that the difference is very small and amounts to less than 1 percent.

These findings may be explained by the nature of the UISA scheme. The scheme is in fact not an insurance, but a forced savings scheme. Employers and employees contribute with a share of the monthly gross wage to an individual savings account from which transfers are withdrawn in case of unemployment. In the case of wages, costs can easily be shifted onto the employees' wages, since they will eventually have access to the accumulated savings. The point in time when they can access the money, has simply changed and is now delayed. In the case of contract types the introduction is of limited importance, since the costs are similar for temporary and permanent contracts. For workers changing directly into a new employment, the new scheme presents reduced opportunity costs for UISA affiliates. For workers experiencing a period of unemployment, UISA affiliates have access to their accounts, but since savings are individualized and belong to the worker, the motivation to extend the job search to find better jobs is limited (see also Reyes et al., 2011). Furthermore the savings amount is rather small and can only provide partial consumption smoothing during unemployment. Only for workers who have access to the solidarity fund, the job search period was found to be significantly longer (Huneeus et al., 2012).

The policy implications depend on the goals of the Chilean government with regard to this new unemployment insurance. While the literature provides inconsistent results of subsequent employment quality for unemployment insurance schemes based on riskpooling, a number of studies do find positive effects on subsequent wages, contract types and employment stability. If the Chilean government aims to improve subsequent job quality, the insurance component of the scheme (the solidarity fund) might need to be extended to provide better and more generous protection to workers, since the contributions to the individual accounts can simply be deducted from the workers' wages. However, this goal might still not be achieved as outcomes are controversial (as shown in the literature review), and furthermore stand in contrast to the other goals of the scheme, such as the intended avoidance of moral hazard and financial sustainability.

Research on the impact of unemployment insurance savings accounts on labor market outcomes is still limited. To the best of my knowledge, this chapter provides for the first time an evaluation of the impact of this type of unemployment protection on subsequent 
employment quality. This type of analysis is also conducted for the first time using data from an emerging economy. Labor market research continues to be largely concentrated on advanced economies and well-known social protection schemes. More research is needed to evaluate policies and schemes that are not only different to the schemes found in advanced economies, but that also face a diverging labor market context, for example a large informal economy.

With regard to the impact of the Chilean UISA scheme on subsequent employment quality more research is recommended on differentiating the analysis by unemployed workers with and without access to the solidarity fund to investigate the impact of the insurance component. Furthermore I suggest studying the impact on subsequent employment duration, another indicator for job quality, and the impact of a change in the policy scheme that was introduced in 2009. Another aspect involves the unemployment duration for workers who experience a period of unemployment before re-entering the work force, as unemployment leads to skills depreciation of workers, and different lengths of unemployment spells can therefore be expected to have a different impact on subsequent job quality. Finally, employment quality can be measured by a range of different variables, as mentioned in footnote 4 of this chapter, for example more adequate matching of job requirements and worker's qualifications, distance to travel to the work place, or development opportunities within the company. Since these aspects are more challenging to study using quantitative methods, further research could also entail a qualitative research approach. Due to the importance of labor income, and given limited social protection and underdeveloped financial markets in developing countries, further research is highly recommended. 
Chapter 8

Conclusion 


\subsection{Introduction}

The broader theme of this thesis can be defined as occupational choice in the developing world. The first part of the dissertation analyzes non-farm entrepreneurship in rural SubSaharan Africa, the second part the impact of a new unemployment protection scheme on labor market outcomes in Chile. With the availability of new data, providing the basis to gain novel insights on labor markets in developing countries, more in-depth research has been made possible in areas so far neglected or under-researched. Over the past years a growing interest has furthermore emerged to provide evidence-based findings to policymakers and governments, allowing them to make better informed choices and introduce policies that will have a positive impact on the economy.

The final chapter is organized as follows. In Section 8.2 the findings of the first and the second part of the thesis are summarized. In Section 8.3 policy implications are discussed, before presenting avenues for future research in Section 8.4. The last section concludes the dissertation.

\subsection{Summary}

\subsubsection{Non-Farm Entrepreneurship in Rural Africa}

The first part of the thesis analyzes non-farm entrepreneurship in rural Africa. Chapter 2 presents various economic models that account for the specific characteristics of the rural African labor market, summarizes the existing empirical literature and introduces the LSMS-ISA database used for the econometric analyses.

Chapter 3 provides a set of descriptive statistics, presenting patterns of rural entrepreneurship in six Sub-Saharan African countries which confirm that non-farm enterprises are ubiquitous and make a substantial contribution to rural household income. It further includes an econometric analysis that identifies determinants of enterprise operation and provides evidence that households operate enterprises due to both push and pull factors. Determinants of enterprise operation can be found on the individual, household and location level. I also find that the motivation of becoming self-employed in the non-farm economy influences the choice of business activity. 
Chapter 4 analyzes the determinants of performance of rural African enterprises by taking labor productivity as a proxy. The results show that location, gender, education and the experience of shocks matter for labor productivity. The results also suggest a link between a household's motivation to operate an enterprise and its subsequent labor productivity.

Based on the findings, I conclude that non-farm entrepreneurship is prevalent in rural SubSaharan Africa and that households engage in self-employment due to both necessity and opportunity kinds of motivation. However, the results also show that entrepreneurship continues to present a largely low-performance sector with small, informal enterprises that often function as an insurance-type of income diversification ex-ante or ex-post. Entrepreneurship can be stimulated by government policies that encourage and assist entrepreneurship on the one hand, and that shield entrepreneurs from adverse events on the other hand. Based on these findings, I suggest policies that can overcome obstacles to become entrepreneurial, and that increase the positive impact of sound enterprise performance in Section 8.3.

\subsubsection{Unemployment Insurance Savings Accounts}

The second part of the thesis analyzes unemployment insurance savings accounts in Chile. Chapter 5 provides an overview of UISA, where the concept of the scheme is explained, as well as an overview of Latin American countries that implemented this type of unemployment protection. The advantages and possible disadvantages of the scheme are also outlined. Furthermore the Chilean UISA scheme is presented in detail, including an overview of the historical and economic context, the design of the scheme and a summary of the changes for workers and employers. Finally, the database used for the empirical analysis, the Chilean Social Protection Survey, is described.

Chapter 6 analyzes the impact of UISA on employment duration, by studying whether the introduction of UISA had an effect on employment duration and the magnitude of this effect. The findings show that UISA introduction had a significant and negative effect on employment duration, suggesting that the policy achieved the goal of tackling a previously more rigid labor market, if reduced employment duration is taken as an indicator for higher labor market flexibility. However, the overall effect on workers calls for more research, since reduced employment duration could also hint at more unstable labor relations.

Finally, Chapter 7 analyzes whether the introduction of UISA had an impact on the 
differences in wages and contracts types, which are taken as proxies for subsequent employment quality. The results show that the new policy scheme had a small negative effect on wage growth, but had no effect on the difference in contract types when comparing workers with and without UISA affiliation. Taking informal private sector workers as the control group to account for labor market trends, the difference-indifferences analysis is positive for formal private sector workers, the treatment group, if they experienced a period of unemployment, suggesting that the UISA introduction had a positive impact on the difference in wage growth compared to informal workers.

Based on the findings, I conclude that the introduction of unemployment insurance savings accounts had various indirect labor market effects. The reduction in employment duration and the decrease in wage growth of subsequent employment relations, including a positive impact compared to the control group, suggest more labor market flexibility and more comprehensive unemployment protection. However, the findings also call for more research to obtain a broader picture of labor market consequences for workers. Based on these findings, I suggest and discuss a set of policy recommendations that could be useful for the Chilean labor market, but that could be equally appealing to other emerging and developing economies, or to developed countries in Section 8.3.

\subsection{Policy Implications}

This section suggests and discusses various policy implications that are based on the findings of the dissertation. They have the potential to improve labor market conditions and to increase occupational choices of workers in emerging and developing economies by expanding employment opportunities or by improving current labor conditions, as well as by providing more comprehensive protection in case of adverse events.

For the entrepreneurial sector in rural Sub-Saharan Africa I suggest both demand-side and supply-side policies. Demand-side policies could entail policies that foster agglomeration and improve the local infrastructure to enhance business opportunities in rural areas, with the goal of augmenting the market size and the client base for entrepreneurs. Possible avenues to achieve this goal are the construction of better roads and the provision of public transportation to decrease travel time to key markets. I also recommend supplyside policies that reduce entrepreneurship motivated by necessity on the one hand, and that encourage a risk-taking opportunity type of entrepreneurship on the other hand. With regard to the former, policies could include social protection policies that shield 
households from adverse events and prevent them from falling into poverty traps, as well as (micro)-insurance schemes. For the latter, access to credit and other financing possibilities, as well as information and training programs.

Furthermore I suggest policies that have the potential to improve the performance of existing enterprises, or to prevent them from stopping operations. For example, programs that help enterprise owners or managers to enhance labor productivity, such as education and training, or access to credit to expand business activities. To ensure higher enterprise survival, I suggest policies that cushion shocks and protect households from negative external events, for example (micro)-insurance schemes in case of adverse occurrences that endanger business activities.

Finally, I suggest policies that create conditions to attract and facilitate non-farm entrepreneurship of young adults interested in entering this sector. They might find different obstacles to start a business compared to middle-aged and older adults, for example more difficulties in accessing finance or a lack of work experience. It is also important to ensure that their businesses can be productive once they become entrepreneurial, and to equally offer them possibilities that enhance their business skills and that protect them in case of difficulties or failure.

If policies are considered that support the entrepreneurial sector and that tackle the challenges for rural businesses from various angles, they have the potential to encourage business creation and to boost enterprise performance and labor productivity. This, in turn, is expected to lead to enterprise growth and higher survival rates, and consequently to employment creation in rural Africa. Especially with regard to the demographic profile in Sub-Saharan Africa, where millions of young people are expected to enter the labor market and search for employment over the coming years (Bezu and Barrett, 2012; Fox et al., 2013), it is fundamental to create a sufficient number of decent jobs that can ensure the livelihoods of these young people and that help them to overcome the poverty trap. It is important to create a policy framework that shields the population from negative events and that gives them the opportunity and choice to engage in productive labor activities.

For the unemployment insurance savings accounts I recommend policies that have the potential to further improve the labor market conditions in Chile. Since UISA differ in their design from both severance pay and unemployment insurance based on risk-pooling, the labor market outcomes can also be expected to diverge, and consequently the policy recommendations need to be adapted. Since the introduction of UISA in Chile is studied 
in this thesis, I concentrate my advice on the Chilean context.

UISA led to the expected labor market flexibility, if shorter employment duration is considered as an indicator of higher employment mobility, and lower wage growth as an indicator of a higher willingness to change employment and accept new jobs. While labor market flexibility has the potential to support structural change and to enhance labor productivity in an emerging economy, it can also lead to more unstable labor relations and create situations where vulnerable workers are more easily fired and left without or with limited protection, since they cannot fulfill the minimum requirements to access the savings accounts or only accumulated small amounts of savings.

Further topics that need to be taken into account when recommending improvements for the UISA scheme are also on the agenda. For example short labor relations of specific groups of workers, a high share of temporary and precarious employment contracts, limited knowledge of UISA and the relatively low benefit amounts. Women and workers with a temporary contract show significantly higher hazard rates of leaving employment compared to men or workers with a permanent contract. Therefore I propose that reforms should particularly target more disadvantaged groups of workers and ensure that they are sufficiently protected in case of job loss. The low female labor market participation also hints at a more traditional attitude towards female employment, with women showing a lower hazard of changing into a new employment, but a higher hazard of becoming unemployed or inactive. Accordingly, more support of female labor market participation is recommended to prevent them of involuntarily dropping out of the labor force or becoming unemployed, equally increasing their occupational choice. Furthermore I suggest to better promote the knowledge of UISA and to ensure that companies inform their work force about the scheme, as well as about the possibility to voluntarily change into the new system. Finally, the UISA benefits continue to be low, even though the overall benefits were increased through the introduction of the scheme, which can lead to restricted consumption smoothing during unemployment spells. If and how UISA benefits should be extended, however, need to be considered with care and included in a broader debate about the financial sustainability of the unemployment protection scheme.

If reforms are considered and implemented that ensure sufficient unemployment protection to workers (and particularly to more vulnerable workers), while keeping opportunity costs of job change low, UISA have the potential to be an attractive alternative to unemployment insurance based on risk-pooling due to reduced moral hazard and low monitoring costs. They also present an attractive alternative to severance pay due to reduced labor market rigidities. Tackling these areas of concern will enable the 
Chilean labor market to increase productivity and to help the economy to further grow.

\subsection{Avenues for Future Research}

In this section research gaps are summarized that continue to exist in both topics, and ideas for data collection and further research suggested. While the suggestions cover a wide range of under-researched areas, this list does not try to be exhaustive.

Non-farm entrepreneurship in rural Sub-Saharan Africa continues to be a topic where limited research has been conducted. While this thesis provides new comparative insights using the recently available LSMS-ISA database, data improvements and more data collection would help to better understand rural labor markets, since data availability continues to present a major challenge. The LSMS-ISA surveys have significantly contributed to overcome this limitation, but further improvement of the questionnaires would allow to enhance research. Some important shortcomings of this database include poorly aligned questionnaires that hinder more comprehensive comparative studies, inconsistent tracking of enterprises over time, as well as the lack of relevant variables that prevent studying certain aspects of entrepreneurship. Additional data collection efforts, covering different countries and different thematic areas, would therefore open up new possibilities for research.

Taking the current data availability into account, as well as the anticipated realization of new surveys in the near future, the following recommendations can be made. One first avenue of research relates to the expected availability of rich panel data sets of the LSMSISA surveys that will facilitate research on enterprise dynamics, for example to study the growth and survival patterns of small businesses over time. Second, I recommend to expand the research on entrepreneurship to additional countries in Sub-Saharan Africa, since significant country-level heterogeneity was found in the results of the six countries studied in this thesis. Third, more in-depth country analyses that account for the specific socio-economic context, such as education systems, geographic and agricultural patterns, and labor market conditions, could be useful sources of information for national governments and institutions when designing and implementing national or regional policies. Fourth, I recommend to analyze specific business sectors and conduct additional research on the influence of the choice of business activity on enterprise performance and job creation. Fifth, studying the impact of agriculture (and other sectors) on entrepreneurship, and vice versa, could provide useful insights into understanding the 
interrelations between different areas of labor, for example with regard to seasonality, and how changes in one sector might affect entrepreneurship. Finally, regular evaluations of existing programs and policies in rural areas would be of great value to further fine-tune entrepreneurial support.

Unemployment insurance savings accounts also continue to be an uncharted area of research, both in Chile and in other Latin American countries where UISA have been implemented alongside unemployment insurance or severance pay. In Chile one first avenue could be to study the impact of an UISA reform that was implemented in May 2009, for example the changes in specific scheme requirements after which workers become eligible to withdraw savings from the account or gain access to the solidarity fund. Second, I recommend research into the role of the solidarity fund, to better understand the role and impact of the insurance component. For example, which workers become eligible to access the fund, if and to what extent accompanying measures have an impact (e.g. mandatory visits to the job center), if redistribution takes place, and if labor outcomes differ in terms of subsequent employment quality. Third, another topic that could be studied is the impact of UISA on subsequent employment duration, another indicator for employment stability. Fourth, I recommend to further examine a possible impact of the UISA scheme on gross wages, since the savings scheme actually presents a delayed payment to workers. Fifth, I recommend further research into the UISA schemes of other countries where unemployment accounts have been implemented. ${ }^{1}$ Finally, simulations of how this kind of unemployment protection would affect labor market outcomes in developed economies can present useful projections for policy makers to examine if the advantages of UISA could outweigh potential disadvantages.

\subsection{Concluding Remarks}

Labor markets and labor policies in the developing world have been considerably less studied in the economic literature compared to labor markets in advanced economies. This thesis contributes to filling the gap by analyzing two recent databases with regard to occupational choices under restricted conditions in Sub-Saharan Africa and Chile. Due to the development and emergence of economies that had a more limited contribution to the global economy in the past, but that are now rising in importance, it is well worth studying the labor conditions and policy schemes of these regions. Since the labor market

1 See also Table 5.1 for an overview of UISA schemes in Latin America, and Vodopivec (2013) for country examples in other regions. 
frameworks largely differ, particularly with regard to the large informal sector, a lack of adequate infrastructure and a more limited financial market, findings of more advanced countries might not be applicable. Since the changes in the global economic structure are not only expected to persist, but to even further accelerate, research is urgently needed.

Occupational choice hereby constitutes a fundamental aspect due to the importance of labor income. Having the possibility to engage in an economic activity of choice while allowing households to secure their livelihoods, is expected to result in higher labor productivity, higher economic growth and faster structural change. If this expectation holds, labor will move into more productive sectors with higher returns, poverty will decline and life quality increase. Removing the frictions in the occupational choice process will ultimately enable people to make better decisions on where and how to allocate their labor based more closely on their preferences and abilities, hence leading to higher wellbeing. 



\section{Bibliography}

Abdulai, A. and Delgado, C. (1999). Determinants of Non-Farm Earnings of Farm-Based Husbands and Wives in Northern Ghana. American Journal of Agricultural Economics, 81 (1):117-130.

Acemoglu, D. and Shimer, R. (1999). Efficient Unemployment Insurance. Journal of Political Economy, 107 (5):893-928.

Acemoglu, D. and Shimer, R. (2000). Productivity Gains from Unemployment Insurance. European Economic Review, 44 (7):1195-1224.

Acevedo, G., Eskenazi, P., and Pagés, C. (2006). Unemployment Insurance in Chile: A New Model of Income Support for Unemployed Workers. SP Discussion Paper No. 0612, Social Protection. Washington, DC: The World Bank.

Ackah, C. (2013). Non-Farm Employment and Income in Rural Ghana. Journal of International Development, 25 (3):325-339.

Addison, J. and Portugal, P. (2008). How Do Different Entitlement to Unemployment Benefits Affect the Transition from Unemployment into Employment? Economics Letters, 101 (3):206-209.

Akaike, H. (1974). A New Look at the Statistical Model Identification. IEEE Transaction on Automatic Control, 19 (6):716-723.

Alene, A. (2010). Productivity Growth and the Effects of R\&D in African Agriculture. Agricultural Economics, 41 (3-4):223-238.

Ali, M. and Peerlings, J. (2011). Value Added of Cluster Membership for Micro Enterprises of the Handloom Sector in Ethiopia. World Development, 39 (3):363-374.

Alsos, G., Carter, S., and Llunggren, E. (2013). Entrepreneurial Families and Households. ERC Research Paper No.10.

Amin, M. (2011). Labor Productivity, Firm-Size and Gender: The Case of Informal Firms in Argentina and Peru. Enterprise Note No. 22. Washington, DC: The World Bank.

Amorós, J. and Cristi, O. (2011). Poverty, Human Development and Entrepreneurship. In Minniti, M., editor, The Dynamics of Entrepreneurship: Evidence from Global Entrepreneurship Monitor Data, pages 209-230. Oxford: Oxford University Press. 
Anokhin, S., Grichnik, D., and Hisrich, R. (2008). The Journey from Novice to Serial Entrepreneurship in China and Germany: Are the Drivers the Same? Managing Global Transitions, 6 (2):117-142.

Arnold, J., Mattoo, A., and Narciso, G. (2006). Services Inputs and Firm Productivity in Sub-Saharan Africa: Evidence from Firm-Level Data. Policy Research Working Paper No. 4048. Washington, DC: The World Bank.

Ata, N. and Sözer, M. (2007). Cox Regression Models with Nonproportional Hazards Applied to Lung Cancer Survival Data. Hacettepe Journal of Mathematics and Statistics, 36 (2):157-167.

Babatunde, R. and Qaim, M. (2010). Impact of Off-Farm Income on Food Security and Nutrition in Nigeria. Food Policy, 35 (4):303-311.

Banerjee, A. and Newman, A. (1993). Occupational Choice and the Process of Development. Journal of Political Economy, 101 (2):274-298.

Barrett, C., Reardon, T., and Webb, P. (2001). Non-Farm Income Diversification and Household Livelihood Strategies in Rural Africa: Concepts, Issues, and Policy Implications. Food Policy, 26 (4):315-331.

Bayene, A. (2008). Determinants of Off-Farm Participation Decision of Farm Households in Ethiopia. Agrekon, 47 (1):140-161.

Belzil, C. (2001). Unemployment Insurance and Subsequent Job Duration: Job Match versus Unobserved Heterogeneity. Journal of Applied Econometrics, 16 (5):619-636.

Berstein, S., Contreras, C., and Benvin, E. (2008). Valoración del Seguro de Cesantía: Simulación de Beneficios con Datos Individuales. Serie Documentos de Trabajo No. $2 \%$. Santiago de Chile: Superintendencia de Pensiones.

Berstein, S., Fajnzylber, E., and Gana, P. (2012). The New Chilean Unemployment Insurance System: Combining Individual Accounts and Redistribution in an Emerging Economy. In Holzmann, R. and Vodopivec, M., editors, Reforming Severance Pay, pages 259-284. Washington, DC: The World Bank.

Bezu, S. and Barrett, C. (2012). Employment Dynamics in the Rural Non-Farm Sector in Ethiopia: Do the Poor Have Time on their Side? Journal of Development Studies, 48 (9):1223-1240.

Bhaumik, S., Dimova, R., and Nugent, J. (2011). Off-Farm Labor Supply and Labor Markets in Rapidly Changing Circumstances: Bulgaria during Transition. Economic Systems, 35 (3):378-389.

Blanchard, O. (2000). The Economics of Unemployment. Shocks, Institutions, and Interactions. London: Lionel Robbins Lecture, London School of Economics.

Bland, M. and Altman, D. (2004). The Logrank Test. BMJ: British Medical Journal, 328 (7447):1073. 
Blattmann, C., Fiala, N., and Martinez, S. (2014). Generating Skilled Self-Employment in Developing Countries: Experimental Evidence from Uganda. Quarterly Journal of Economics, 129 (2):697-752.

Blau, P., Gustad, J., Jessor, R., Parnes, H., and Wilcock, R. (1956). Occupational Choice: A Conceptual Framework. Industrial and Labor Relations Review, 9 (4):531-543.

Block, S. (2010). The Decline and Rise of Agricultural Productivity in Sub-Saharan Africa since 1961. NBER Working Paper No. 16481. Cambridge, MA: National Bureau of Economic Research.

Bloom, N., Schankerman, M., and van Reenen, J. (2013). Identifying Technology Spillovers and Product Market Rivalry. Econometrica, 81 (4):1347-1393.

Bloom, N. and van Reenen, J. (2010). Why Do Management Practices Differ across Firms and Countries? Journal of Economic Perspectives, 24 (1):203-224.

Boeri, T. and Garibaldi, P. (2009). Beyond Euroslerosis. Economic Policy, 24 (7):409461.

Bovenberg, A., Hansen, M., and Sørensen, P. (2008). Individual Savings Accounts for Social Insurance: Rationale and Alternative Designs. International Tax and Public Finance, 15 (1):67-86.

Box-Steffensmeier, J. and Jones, B. (2004). History Modeling - A Guide for Social Scientists. Cambridge: Cambridge University Press.

Bridges, S., Gaggero, A., and Owens, T. (2013). Jobs Come and Go, But the Family will Always be There. Mimeo: University of Nottingham.

Brown, A., Orszag, J., and Snower, D. (2008). Unemployment Accounts and Employment Incentives. European Journal of Political Economy, 24 (3):587-604.

Brueck, T., Naudé, W., and Verwimp, P. (2013). Business under Fire: Entrepreneurship and Violent Conflict in Developing Countries. Journal of Conflict Resolution, 57 (1):319.

Brunner, L. and Colarelli, S. (2004). Individual Unemployment Accounts. The Independent Review, 4 (8):569-585.

Burdett, K. (1979). Unemployment Insurance Payments as a Search Subsidy: A Theoretical Analysis. Economic Inquiry, 17 (3):333-343.

Caliendo, M., Tatsiramos, K., and Uhlendorff, A. (2013). Benefit Duration, Unemployment Duration and Job Match Quality: A Regression-Discontinuity Approach. Journal of Applied Econometrics, 28 (4):604-627.

Calmfors, L. and Holmlund, B. (2000). Unemployment and Economic Growth: A Partial Survey. Swedish Economic Policy Review, 7 (1):107-153.

Cameron, A. and Trivedi, P. (2009). Microeconometrics Methods and Applications. Cambridge, MA: Cambridge University Press. 
Card, D., Chetty, R., and Weber, A. (2007). Cash-On-Hands and Competing Model of Intertemporal Behavior: New Evidence from the Labor Market. The Quarterly Journal of Economics, 122 (4):1511-1560.

Card, D. and Levine, P. (2000). Extended Benefits and the Duration of UI Spells: Evidence from the New Jersey Extended Benefits Program. Journal of Public Economics, 78 (1-2):107-138.

Carletto, G., Covarrubias, K., Davis, B., Krausova, M., and Winters, P. (2007). Rural Income Generating Activities Study: Methodological Note on the Construction of Income Aggregates. Technical report, Rome: FAO.

Centeno, M. and Novo, A. (2009). Reemployment Wages and UI Liquidity Effect: A Regression Discontinuity Approach. Portuguese Economic Journal, 8 (1):45-52.

Chiappori, P. (1992). Collective Labor Supply and Welfare. Journal of Political Economy, $100(3): 437-467$.

Cho, Y., Margolis, D., Newhouse, D., and Robalino, D. (2012). Labor Markets in Lowand Middle-Income Countries: Trends and Implications for Social Protection and Labor Policies. Background Paper for the World Bank 2012-2022, Social Protection and Labor Strategy.

Christiaensen, L., Weerdt, J., and Todo, Y. (2013). Urbanization and Poverty Reduction: the Role of Rural Diversification and Secondary Towns. Agricultural Economics, 44 $(4-5): 435-447$.

Cleves, M., Gutierrez, R., Gould, W., and Marchenko, Y. (2010). An Introduction to Survival Analysis using Stata. College Station, Texas: Stata Press.

Cowan, K. and Micco, A. (2005). El Seguro de Desempleo en Chile: Reformas Pendientes. Expansiva, En Foco 53.

Cox, D. (1972). Regression Models and Life-Tables. Journal of the Royal Statistical Society, 34 (2):187-200.

Cox, D. (1975). Partial Likelihood. Biometrika, 62 (2):269-276.

Cramer, C., Oya, C., and Sender, J. (2008). Rural Labor Markets in Sub-Saharan Africa: A New View of Poverty, Power and Policy. Centre for Development Policy and Research, Policy Brief No. 1.

Davis, B., Winters, P., Carletto, G., Covarrubias, K., Quinones, E., Zezza, A., Stamoulis, K., Bonomi, G., and DiGuiseppe, S. (2010). A Cross-Country Comparison of Rural Income Generating Activities. World Development, 38 (1):48-63.

Davis, J. and Bezemer, D. (2004). The Development of the Rural Non-Farm Economy in Developing Countries and Transition Economies: Key Emerging and Conceptual Issues. Chatham, UK: Natural Resources Institute.

de Janvry, A. and Sadoulet, E. (2001). Income Strategies among Rural Households in Mexico: The Role of Off-Farm Activities. World Development, 29 (3):467-480. 
de Janvry, A. and Sadoulet, E. (2006). Progress in the Modelling of Rural Households. In de Janvry, A. and Kanbur, R., editors, Poverty, Inequality and Development, pages 155-181. Springer.

de Paula, A. and Scheinkman, J. (2007). The Informal Sector. NBER Working Paper No. 13486. Cambridge, MA: National Bureau of Economic Research.

Dejardin, M. (2000). Entrepreneurship and Economic Growth: An Obvious Conjunction? Namur: University of Namur.

Dejardin, M. (2011). Linking Net Entry to Regional Economic Growth. Small Business Economics, 36 (4):443-460.

Dercon, S. (1998). Wealth, Risk and Activity Choice: Cattle in Western Tanzania. Journal of Development Economics, 55 (1):1-42.

Dercon, S. (2009). Rural Poverty: Old Challenges in New Contexts. World Bank Research Observer, 24 (1):1-28.

Desai, S. (2009). Measuring Entrepreneurship in Developing Countries. Research Paper/ UNU-WIDER, No. 2009.10.

Dethier, J., Hirn, M., and Straub, S. (2010). Explaining Enterprise Performance in Developing Countries with Business Climate Survey Data. World Bank Research Observer, 26 (2):258-309.

Dollar, D., Hallword-Driemeier, M., and Mengistae, T. (2005). Investment Climate and Firm Performance in Developing Countries. Economic Development and Cultural Change, 54 (1):1-31.

Ehrenberg, R. and Oaxaca, R. (1976). Unemployment Insurance, Duration of Unemployment, and Subsequent Wage Gain. American Economic Association, 66 (5):754-766.

Eifert, B., Gelb, A., and Ramachandran, V. (2008). The Cost of Doing Business in Africa: Evidence from Enterprise Survey Data. World Development, 36 (9):1531-1546.

Elbers, C. and Lanjouw, P. (2001). Intersectoral Transfer, Growth and Inequality in Rural Ecuador. World Development, 29 (3):481-496.

Escobal, J. (2001). The Determinants of Non-Farm Income Diversification in Rural Peru. World Development, 29 (3):497-508.

Espeland, R. (2007). When Neighbours Become Killers: Ethnic Conflict and Communal Violence in Western Uganda. CMI Working Paper No. $200 \%$ :3.

Estevez-Abe, M., Iversen, T., and Soskice, D. (1999). Social Protection and the Formation of Skills: A Reinterpretation of the Welfare State. Original Version Prepared for Presentation at the 95th American Political Association Meeting at the Atlanta Hilton and the Marriott Marquis, September 2-5.

Evans, D. and Jovanovic, B. (1989). An Estimated Model of Entrepreneurial Choice under Liquidity Constraints. Journal of Political Economy, 97 (4):808-827. 
Fafchamps, M. and Shilpi, F. (2003). The Spatial Division of Labour in Nepal. Journal of Development Studies, 39 (6):23-66.

Feldstein, M. and Altman, D. (2007). Unemployment Insurance Savings Accounts. Tax Policy and the Economy, 21 (1):35-63.

Ferrer, A. and Riddell, W. (2011). Unemployment Insurance Savings Accounts in Latin America: Overview and Assessment. IZA Discussion Paper No. 5577.

Fölster, S. (1999). Social Insurance based on Personal Savings. Economic Record, 75 (228):5-18.

Fölster, S. (2001). An Evaluation of Social Insurance Savings Accounts. Public Finance and Management, 1 (4):420-448.

Foster, L., Haltiwanger, J., and Syverson, C. (2008). Reallocation, Firm Turnover, and Efficiency: Selection on Productivity and Profitability? American Economic Review, 98 (1):394-425.

Fox, L., Haines, G., Muñoz, J., and Thomas, A. (2013). Africa's Got Work to Do: Employment Prospects in the New Century. IMF Working Paper No. WP/13/201.

Fox, L. and Pimhidzai, O. (2013). Household Non-Farm Enterprises and Structural Transformation: Evidence from Uganda. Paper Presented at the UNU-WIDER Conference on Inclusive Growth in Africa, Helsinki.

Fox, L. and Sohnesen, T. (2013). Household Enterprises in Mozambique: Key to Poverty Reduction but not on the Development Agenda? Policy Research Working Paper No. 6570. Washington, DC: The World Bank.

Frazer, G. (2005). Which Firms Die? A Look at Manufacturing Firm Exit in Ghana. Economic Development and Cultural Change, 53 (3):585-617.

Gangl, M. (2002). Unemployment Benefits as a Search Subsidy: New Evidence on Duration and Wage Effects of Unemployment Insurance. Discussion Paper No. FS I 02-208.

Gindling, T. and Newhouse, D. (2014). Self-Employment in the Developing World. World Development, 56 (1):313-331.

Gomez-Salvador, R., Messina, J., and Vallanti, G. (2004). Gross Job Flows and Institutions in Europe. Labour Economics, 11 (4):469-485.

Grimm, M., Knorringa, P., and Lay, J. (2012). Informal Entrepreneurs in Western Africa: Constrained Gazelles in the Lower Tier. World Development, 40 (7):1352-1368.

Guenther, I. and Launov, A. (2012). Informal Employment in Developing Countries: Opportunity or Last Resort? Journal of Development Economics, 97 (1):88-98.

Haffner, R., Nicoletti, G., Scarpetta, S., and Zoega, G. (2001). European Integration, Liberalization and Labour Market Performance. In Bertola, G., Boeri, T., and Nicoletti, G., editors, Welfare and Employment in a United Europe, pages 147-250. Boston, MA: MIT Press. 
Haggblade, S., Hazell, P., and Brown, J. (1989). Farm-Non-Farm Linkages in Rural Sub-Saharan Africa. World Development, 17 (8):1173-1201.

Haggblade, S., Hazell, P., and Reardon, T. (2010). The Rural Non-Farm Economy: Prospects for Growth and Poverty Reduction. World Development, 38 (10):1429-1441.

Haltiwanger, J., Scarpetta, S., and Vodopivec, M. (2003). How Institutions Affect Labor Market Outcomes: Evidence from Transition Countries. Washington, DC: Paper Presented at the World Bank Economist Forum.

Havnevik, K., Haarsmar, M., and Sandström, E. (2003). Rural Development and the Private Sector in Sub-Saharan Africa: SIDA's Experiences and Approaches in the 1990s. Stockholm: SIDA Evaluation No. 03/18.

Heckman, J. and Pagés, C. (2000). The Cost of Job Security Regulation: Evidence from Latin American Labor Markets. NBER Working Paper No. 7773. Cambridge, MA: National Bureau of Economic Research.

Herrington, M. and Kelly, D. (2013). Global Entrepreneurship Monitor. African Entrepreneurship: Sub-Saharan African Regional Report. Cape Town: GERA-IDRC.

Holcombe, R. (1998). Entrepreneurship and Economic Growth. Quarterly Journal of Austrian Economics, 1 (2):45-62.

Holzmann, R. and Jørgensen, S. (2001). Social Risk Management: A New Conceptual Framework for Social Protection, and Beyond. International Tax and Public Finance, $8(4): 529-556$.

Holzmann, R., Pouget, Y., Vodopivec, M., and Weber, M. (2011). Severance Pay Program around the World: History, Rationale, Status, and Reforms. IZA Discussion Paper No. 5731.

Holzmann, R. and Vodopivec, M., editors (2012). Reforming Severance Pay. Washington, DC: The World Bank.

Hopenhayn, H. and Hatchondo, J. (2012). The Welfare Consequences of Alternative Designs of Unemployment Insurance Savings Accounts. In Holzman, R. and Vodopivec, M., editors, Reforming Severance Pay, pages 239-257. Washington, DC: The World Bank.

Huneeus, C., Leiva, S., and Micco, A. (2012). Unemployment Insurance and Search Effort in Chile. IBD Working Paper Series No. IDB-WP-313.

Hurst, E. and Lusardi, A. (2004). Liquidity Constraints, Household Wealth and Entrepreneurship. Journal of Political Economy, 112 (1):319-327.

Jütting, J. and de Laiglesia, J., editors (2009). Is Informal Normal? Towards More and Better Jobs in Developing Countries. Paris: OECD Development Centre.

Katz, L. and Meyer, B. (1990). The Impact of the Potential Duration of Unemployment Benefits on the Duration of Unemployment. Journal of Public Economics, 41 (1):45-72. 
Keats, A. (2012). Essays on Development Economics. PhD Dissertation, University of California, Los Angeles.

Kinda, T., Plane, P., and Veganzones-Veroudakis, M. (2011). Firm Productivity and Investment Climate in Developing Countries: How Does the Middle East and North Africa Perform? The Developing Economies, 49 (4):429-462.

Kugler, A. (2002). From Severance Pay to Self-Insurance: Effects of Severance Payments Savings Accounts in Colombia. IZA Discussion Paper No. 434.

Lalive, R. (2007). Unemployment Benefits, Unemployment Duration, and PostUnemployment Jobs: A Regression Discontinuity Approach. American Economic Review, 97 (2):108-112.

Lalive, R. and Zweimüller, J. (2004). Benefit Entitlement and Unemployent Duration: Accounting for Public Endogeneity. Journal of Public Economics, 88 (12):2587-2616.

Lanjouw, J. and Lanjouw, P. (2001). The Rural Non-Farm Sector: Issues and Evidence from Developing Countries. Agricultural Economics, 26 (1):1-23.

Lentz, R. (2009). Optimal Unemployment Insurance in an Estimated Job Search Model with Savings. Review of Economic Dynamics, 12 (1):37-57.

Lewis, W. (1954). Economic Development with Unlimited Supplies of Labour. The Manchester School.

Loening, J., Rijkers, B., and Söderbom, M. (2008). Nonfarm Microenterprise Performance and the Investment Climate: Evidence from Rural Ethiopia. Policy Research Working Paper No. 457\%. Washington, DC: The World Bank.

Long, J. and Freese, J. (2006). Regression Models for Categorical Dependent Variables Using Stata. Stata Press.

Lucas, R. (1978). On the Size Distribution of Business Firms. Bell Journal of Economics, $9(1): 508-523$.

Malchow-Møller, N., Schjerning, B., and Sørensen, A. (2011). Entrepreneurship, Job Creation and Wage Growth. Small Business Economics, 36 (1):15-32.

Manser, M. and Brown, M. (1980). Marriage and Household Decision-Making: A Bargaining Analysis. International Economic Review, 21 (1):31-44.

Margolis, D. (2014). By Choice and by Necessity: Entrepreneurship and Self-Employment in the Developing World. IZA Discussion Paper No. 8273.

Martin, P., Mayer, J., and Mayneris, F. (2011). Spatial Concentration and Plant-Level Productivity in France. Journal of Urban Economics, 69 (2):182-195.

McPeak, J. (2006). Confronting the Risk of Asset Loss: What Role do Livestock Transfers in Northern Kenya Play? Journal of Development Economics, 81 (2):415-437.

Messina, J. and Vallanti, G. (2007). Job Flow Dynamics and Firing Restrictions: Evidence from Europe. Economic Journal, 117 (521):279-301. 
Montenegro, C. and Pagés, C. (2004). Who Benefits from Labor Market Regulations? Chile, 1960-1998. In Heckmann, J. and Pagés, C., editors, Law and Employment: Lessons from Latin America and the Caribbean, pages 401-434. Chicago, IL: University of Chicago Press.

Moreno, C. (2008). Unemployment Insurance: A General Equilibrium Model for the Chilean Economy. Superintendencia de Pensiones, Serie Documentos de Trabajo No. 28.

Moretti, E. (2004). Workers Education, Spillovers, and Productivity: Evidence from Plant-Level Production Functions. American Economic Review, 94 (3):656-690.

Murphy, K., Schleifer, A., and Vishny, R. (1991). The Allocation of Talent: Implications for Growth. Quarterly Journal of Economics, 106 (2):503-530.

Nagler, P. (2013). How Unemployment Insurance Savings Accounts Affect Employment Euration: Evidence from Chile. IZA Journal of Labor \&5 Development, 2:9.

Nagler, P. (2015). The Impact of Unemployment Insurance Savings Accounts on Subsequent Employment Quality. UNU-MERIT Working Paper No. 2015-026. Maastricht: United Nations University.

Nagler, P. and Naudé, W. (2014a). Labor Productivity in Rural African Enterprises: Empirical Evidence from the LSMS-ISA. IZA Discussion Paper No. 8524.

Nagler, P. and Naudé, W. (2014b). Non-Farm Entrepreneurship in Rural Africa: Patterns and Determinants. IZA Discussion Paper No. 8008.

Naudé, W. (2009). Out With the Sleaze, in with the Ease: Insufficient for Entrepreneurial Development? UNU-WIDER Research Paper No. 2009/01. Helsinki: United Nations University.

Naudé, W. (2010). Entrepreneurship, Developing Countries, and Development Economics: New Approaches and Insights. Small Business Economics, 34 (1):1-12.

Naudé, W. (2011). Entrepreneurship is not a Binding Constraint on Growth and Development in the Poorest Countries. World Development, 39 (1):33-44.

Naudé, W., Amorós, J., and Cristi, O. (2014). "Surfeiting, the Appetite May Sicken": Entrepreneurship and Happiness. Small Business Economics, 42 (3):523-540.

Ngenzebuke, R., de Rock, B., and Verwimp, P. (2014). The Power of the Family: Kinship and Intra-Household Decision-Making in Rural Burundi. Brussels: ECARES Working Paper 2014-29.

Nichter, S. and Goldmark, L. (2009). Small Firm Growth in Developing Countries. World Development, 37 (9):1435-1464.

Nickell, S. (1997). Unemployment and Labor Market Rigidities: Europe versus North America. Journal of Economic Perspectives, 11 (3):55-74.

OECD (1999). OECD Employment Outlook 1999. Technical report, Paris: OECD. 
OECD (2007). OECD Economic Surveys Chile. Technical report, Paris: OECD.

OECD (2013). OECD Economic Surveys Chile. Technical report, Paris: OECD.

Orszag, J. and Snower, D. (2002). From Unemployment Benefits to Unemployment Accounts. IZA Discussion Paper No. 532.

Oseni, G. and Winters, P. (2009). Rural Nonfarm Activities and Agricultural Crop Production in Nigeria. Agricultural Economics, 40 (2):189-201.

Owoo, N. and Naudé, W. (2014). Non-Farm Enterprise Performance and Spatial Autocorrelation in Rural Africa: Evidence from Ethiopia and Nigeria. IZA Discussion Paper No. 8295.

Palacios-López, A. and López, R. (2014). Gender Differences in Agricultural Productivity: The Role of Market Imperfections. Working Paper No. 164061. University of Maryland, Department of Agricultural and Resource Economics.

Pietrobelli, C., Rabelotti, R., and Aquilina, M. (2004). An Empirical Study of SelfEmployment in Developing Countries. Journal of International Development, 16 (6):803-820.

Poblete, I. (2011). Análisis del Uso de Beneficios en el Seguro de Cesantía Chileno. Serie Documentos de Trabajo No. 51. Santiago de Chile: Superintendencia de Pensiones.

Quatraro, F. and Vivarelli, M. (2013). Drivers of Entrepreneurship and Post-Entry Performance of Newborn Firms in Developing Countries. IZA Discussion Paper No. 7436 .

Reardon, T. (1997). Using Evidence of Household Income Diversification to Inform Study of the Rural Non-Farm Labor Market in Africa. World Development, 25 (5):735-747.

Reardon, T., Berdegue, J., Barrett, C., and Stamoulis, K. (2006). Household Income Diversification into Rural Non-Farm Activities. In Haggblade, S., Hazell, P., and Reardon, T., editors, Transforming the Rural Nonfarm Economy, pages 115-140. Baltimore, MD: Johns Hopkins University Press.

Reyes, G. (2005). Duración de las Relaciones Laborales de los Afiliados al Seguro de Cesantía: Análisis y Problemas Metodológicos. Serie Documentos de Trabajo No. 11. Santiago de Chile: Superintendencia de Pensiones.

Reyes, G., van Ours, J., and Vodopivec, M. (2011). Incentive Effects of Unemployment Insurance Savings Accounts: Evidence from Chile. Labour Economics, 18 (6):798-809.

Rijkers, B. and Costa, R. (2012). Gender and Rural Non-Farm Entrepreneurship. World Development, 40 (12):2411-2426.

Rijkers, B. and Söderbom, M. (2013). The Effects of Risk and Shocks on Non-Farm Enterprise Development in Rural Ethiopia. World Development, 45 (1):119-136.

Rijkers, B., Söderbom, M., and Loening, J. (2010). A Rural-Urban Comparison of Manufacturing Enterprise Performance in Ethiopia. World Development, 38 (9):12781296. 
Robalino, D., Vodopivec, M., and Bodor, A. (2009). Savings for Unemployment in Good or Bad Times: Options for Developing Countries. IZA Discussion Paper No. 4516.

Robalino, D., Zylberstajn, E., and Robalino, J. (2011). Incentive Effects of Risk Pooling, Redistributive and Savings Arrangements in Unemployment Benefit Systems: Evidence from a Job-Search Model for Brazil. IZA Discussion Paper No. 5476.

Rodríguez, G. (2010). Parametric Survival Models. Technical report, Princeton, NJ: Princeton University.

Rosenzweig, M. and Binswanger, H. (1993). Wealth, Weather, Risk and the Composition and Profitability of Agricultural Investments. Economic Journal, 103 (2):56-78.

Sabates-Wheeler, R., Lind, J., and Hoddinott, J. (2013). Implementing Social Protection in Agro-Pastoralist and Pastoralist Areas: How Local Distribution Structures Moderate PSNP Outcomes in Ethiopia. World Development, 50 (1):1-12.

Saliola, F. and Seker, M. (2011). Total Factor Productivity across the Developing World. Enterprise Note No. 23. Washington, DC: The World Bank, The World Bank.

Schmieder, J., von Wachter, T., and Bender, S. (2010). The Effects of Unemployment Insurance on Labour Supply and Search Outcomes. Regression Discontinuity Estimates from Germany. IAB Discussion Paper No. 4/2010.

Sehnbruch, K. (2004). Privatized Unemployment Insurance: Can Chile's New Unemployment Insurance Scheme Serve as a Model for Other Developing Countries? Working Paper No. 12, Center for Latin American Studies. Berkeley, CA: University of California.

Sehnbruch, K. (2006). Unemployment Insurance or Individual Savings Accounts: Can Chile's New Scheme Serve as a Model for Other Developing Countries? International Social Security Review, 59 (1):27-48.

Serra, R. (2009). Gender and Occupational Choice in Africa: The Role of Time Poverty and Associated Risks. Paper Presented at the FAO-IFAD-ILO Workshop on Gaps, Trends and Current Research in Gender Dimensions of Agricultural and Rural Employment, Rome, 31 March - 2 April.

Shi, X., Heerink, N., and Qu, F. (2007). Choices between Different Off-Farm Employment Sub-Categories: An Empirical Analysis for Jiangxi Province, China. China Economic Review, 18 (4):438-455.

Simanovska, I. and Söderling, L. (2008). Business Cycle Accounting for Chile. IMF Working Paper No. WP/08/61.

Singh, I., Squire, L., and Strauss, J., editors (1986). Agricultural Household Models: Extensions, Applications and Policy. Baltimore, MD: Johns Hopkins University Press.

Söderbom, M. and Teal, F. (2004). Size and Efficiency in African Manufacturing Firms: Evidence from Firm-Level Panel Data. Journal of Development Economics, 73 (1):369394. 
Söderbom, M., Teal, F., and Harding, A. (2006). The Determinants of Survival among African Manufacturing Firms. Economic Development and Cultural Change, $54(3): 533-555$.

Start, D. (2001). The Rise and Fall of the Rural Non-Farm Economy: Poverty Impacts and Policy Options. Development Policy Review, 19 (4):491-505.

Subsecretaría de Previsión Social Chile (2002-2009). Encuesta de Protección Social. Available at www.proteccionsocial.cl [accessed on 18 December 2013].

Syverson, C. (2011). What Determines Productivity? Journal of Economic Literature, 49 (2):326-365.

Tatsiramos, K. (2009). Unemployment Insurance in Europe: Unemployment Duration and Subsequent Employment Stability. Journal of the European Economic Association, 7 (6):1225-1260.

Taylor, J. and Adelman, I. (2003). Agricultural Household Models: Genesis, Evolution, and Extensions. Review of Economics of the Household, 1 (1):33-58.

Udry, C. (1996). Gender, Agricultural Production and the Theory of the Household. Journal of Political Economy, 104 (5):1018-1046.

van Biesebroeck, J. (2005). Exporting Raises Productivity in Sub-Saharan Manufacturing Firms. Journal of International Economics, 67 (2):373-391.

van Ginneken, W. (2003). Extending Social Security: Policies for Developing Countries. International Labour Review, 142 (3):277-294.

van Ours, J. and Vodopivec, M. (2008). Does Reducing Unemployment Insurance Generosity Reduce Job Match Quality? Journal of Public Economics, 92 (3-4):684-695.

Vejlin, R. (2011). Optimal Unemployment Insurance: How Important is the Demand Side? Aarhus University and $L M D G$.

Vodopivec, M. (2004). Income Support for the Unemployed: Issues and Options. Regional and Sectoral Studies Series. Washington, DC: The World Bank.

Vodopivec, M. (2010). How Viable are Unemployment Insurance Savings Accounts: Simulation Results for Slovenia. Comparative Economic Studies, 52 (2):225-247.

Vodopivec, M. (2013). Introducing Unemployment Insurance to Developing Countries. IZA Journal of Labor Policy, 2:1.

Wennberg, K. and Lindqvist, G. (2010). The Effect of Clusters on the Survival and Performance of New Firms. Small Business Economics, 34 (3):221-241.

Wennekers, S. and Thurik, A. (1999). Linking Entrepreneurship and Economic Growth. Small Business Economics, 13 (1):27-55.

Wiggens, S. (2000). Interpreting Changes from the 1970s to the 1990s in African Agriculture through Village Studies. World Development, 28 (4):631-662. 
Wiggens, S. and Roepstorff, T. (2011). New Global Realities Governing Agribusiness. In Yumkella, K., Kormawa, P., Roepstorff, T., and Hawkins, A., editors, Agribusiness for Africa's Prosperity, pages 24-37. Vienna: UNIDO.

Wulfgramm, M. and Fervers, L. (2013). Unemployment and Subsequent Employment Stability: Does Labour Market Policy Matter? IZA Discussion Paper No. 7193.

Yamada, G. (1996). Urban Informal Employment and Self-Employment in Developing Countries: Theory and Evidence. Economic Development and Cultural Change, 44 (2):289-314.

Zenou, Y. (2008). Job Search and Mobility in Developing Countries: Theory and Policy Implications. Journal of Development Economics, 86 (2):336-355.

Zezza, A., Winter, P., Davis, B., Carletto, G., Covarrubias, K., Tasciotti, L., and Quinones, E. (2011). Rural Household Access to Assets and Markets: A Cross-Country Comparison. European Journal of Development Research, 23 (4):569-597. 

Appendix A

Non-Farm Entrepreneurship in Rural

Africa 


\section{A.1 Data Appendix}

\section{$\underline{\text { All Estimates }}$}

I replace the age of the household head or enterprise owner with the median age in case the age variable is missing, below 15 or above 99 . This happens however only for very few observations.

\section{$\underline{\text { Shocks }}$}

I recode the shock variable as follows. Idiosyncratic shocks consist of shocks that are particular to the household, for example illness or death of a family member, or loss of employment. Price shocks consist of unexpected prices changes of food prices, input- or output prices, and can go in both direction (increase or fall). Geographical shocks consist of natural disasters such as floods, droughts or pests. The category other shocks is taken from the survey questionnaire and does not further specify the type of shock.

Panel Data Analysis

Households are visited and interviewed during the first survey round, and households operating a non-farm enterprise are registered in the respective section. Due to the panel design, the same households are visited again in the consecutive survey rounds. If a household of the previous round is no longer operating an enterprise, the household is still registered in the respective section, but does not fill out the questions on nonfarm entrepreneurship. Therefore it is possible to identify the enterprises that were discontinued since the last survey round if the enterprises can clearly be tracked over the waves. If not, it is possible to know the number of enterprises that were discontinued. In Uganda, various "empty" observations in follow-up surveys do not have observations in the previous survey round(s), and I decide to exclude these observations, as it is not clear what kind of information they present, if they are discontinued enterprises or false observations. I delete 82 out of 7,985 observations, resulting in a final database of 7,903 enterprises for the panel data analysis. I do not encounter this issue in Nigeria.

Further data manipulation includes the following: prices are inflation deflated to prices of the first survey round of the respective country, using the IMF's inflation index of average consumer prices (percentage change). Furthermore prices are "winsorized" at 1 
percent. I also "winsorize" the number of employees at 1 percent. I further replace a few outlier values, for example if the months in operation exceed 12 months. 


\section{A.2 Summary Statistics}

Table A.1: Prevalence of Urban Non-Farm Enterprises

\begin{tabular}{lrrrrr}
\hline Country & $\begin{array}{r}\text { Nr of HH } \\
\text { surveyed }\end{array}$ & $\begin{array}{r}\text { HH with } \\
\text { NFE }\end{array}$ & $\begin{array}{r}\text { in } \% \\
\text { weighted }\end{array}$ & $\begin{array}{r}\text { Nr of } \\
\text { NFEs }\end{array}$ & $\begin{array}{r}\text { Avg Nr of } \\
\text { NFE/HH }\end{array}$ \\
\hline Ethiopia & 503 & 293 & 56.11 & 370 & 1.26 \\
Malawi & 2,233 & 817 & 35.11 & 938 & 1.15 \\
Niger & 1,538 & 998 & 67.78 & 1,539 & 1.54 \\
Nigeria & 1,620 & 1,108 & 70.50 & 1,760 & 1.59 \\
Tanzania & 1,295 & 746 & 60.28 & 960 & 1.29 \\
Uganda & 611 & 354 & 54.21 & 572 & 1.62 \\
\hline Total & 7,297 & 4,023 & 64.59 & 11,064 & 1.36 \\
\hline
\end{tabular}

Note(s): Weighted country shares are calculated using survey weights, the total share includes population weight. Urban areas only.

Table A.2: Months in Operation

\begin{tabular}{|c|c|c|c|c|c|c|c|c|}
\hline & \multicolumn{2}{|c|}{ Niger } & \multicolumn{2}{|c|}{ Nigeria } & \multicolumn{2}{|c|}{ Tanzania } & \multicolumn{2}{|c|}{ Uganda } \\
\hline & rural & urban & rural & urban & rural & urban & rural & urban \\
\hline$<6$ & 23 & 9 & 10 & 7 & 23 & 12 & 19 & 7 \\
\hline $6-11$ & 24 & 16 & 26 & 24 & 29 & 25 & 24 & 16 \\
\hline 12 & 53 & 75 & 64 & 69 & 48 & 63 & 57 & 77 \\
\hline
\end{tabular}

Note(s): Weighted shares. 


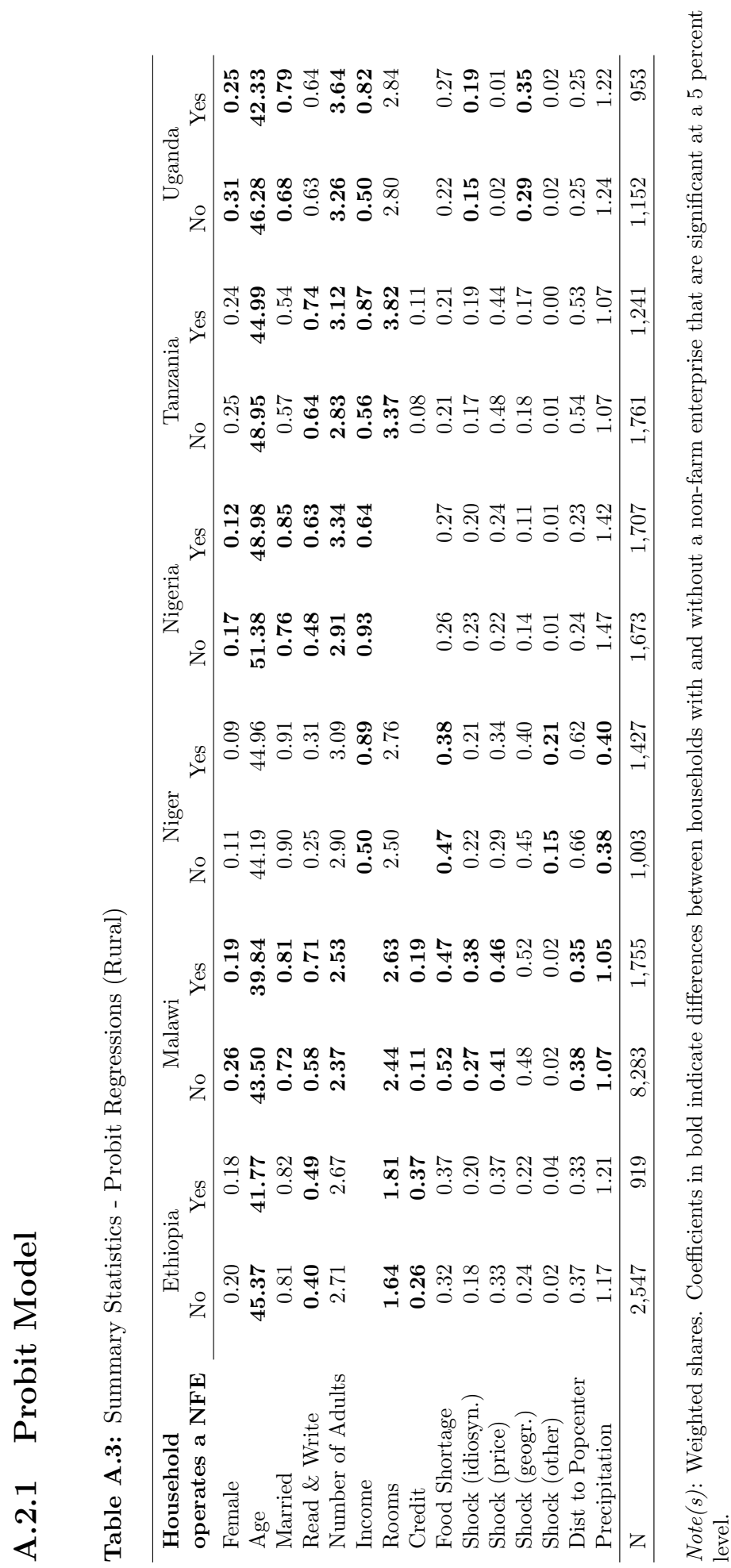




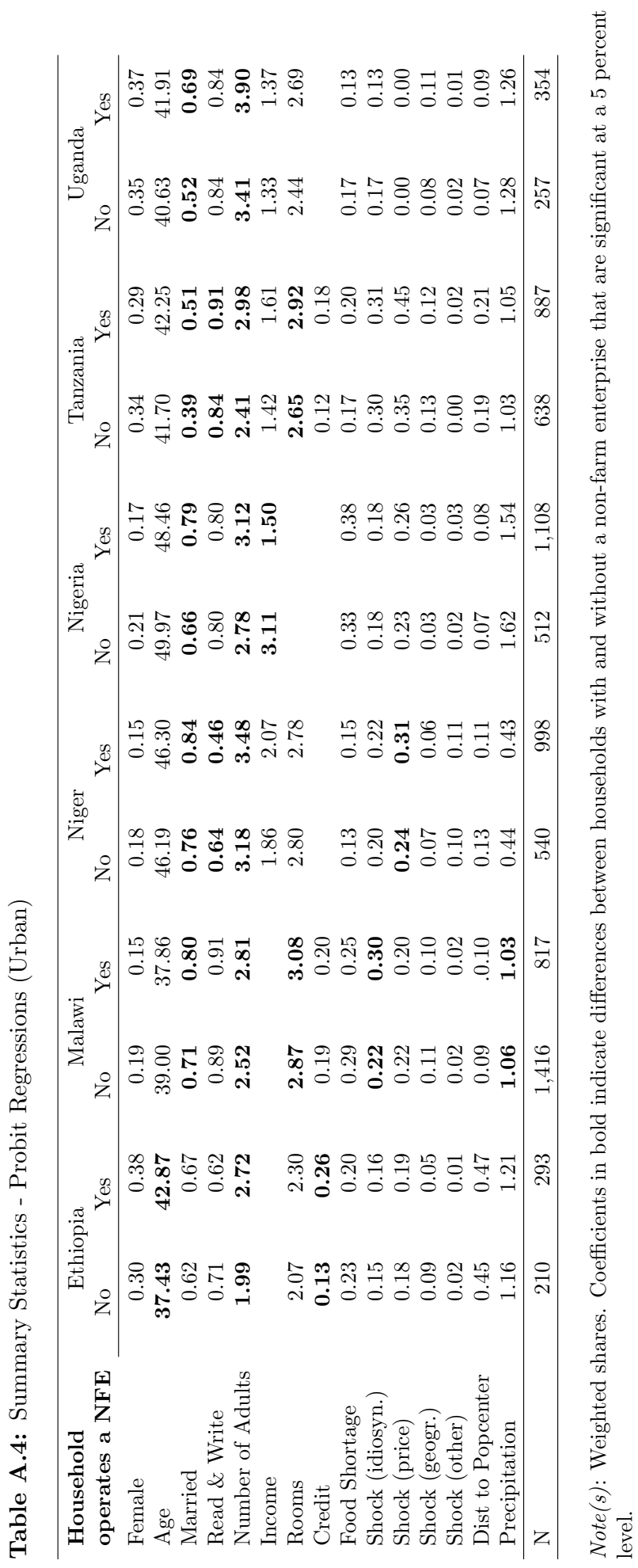




\section{Definition of Variables for Probit Regressions*}

Rural

Female

Age

Married

Read \& Write

Number of Adults

Income in USD

Rooms

Credit

Food Shortage

Shock

Distance

Precipitation
1 if household is located in a rural area.

1 if female.

In years (15 to 99$)$.

1 if married.

1 if individual can read and write in any language.

Number of adults age 15 or older in the household.

Annual net household income in 1,000's of USD.

Number of rooms in the household dwelling.

1 if household has access to credit. This variable is defined as general access to credit, and does not further specify for which purpose the household used it.

1 if household has experience food shortage over the past 12 months (self-reported variable).

1 if household experienced a shock. Shocks can be idiosyncratic (e.g. death or illness of a household member), related to prices (e.g. increase in the price level of certain goods and services), related to agriculture (e.g. droughts or floods), or other types of shocks (not further specified in the questionnaire).

Defined as distance to next population center of 20,000 or more inhabitants, in 100's of km.

Annual Precipitation in 1,000's of mm.

* The definition of variables also holds for the multinomial logit models. 


\section{A.2.2 Heckman Selection Model}

Table A.5: Summary Statistics - Heckman Selection Model

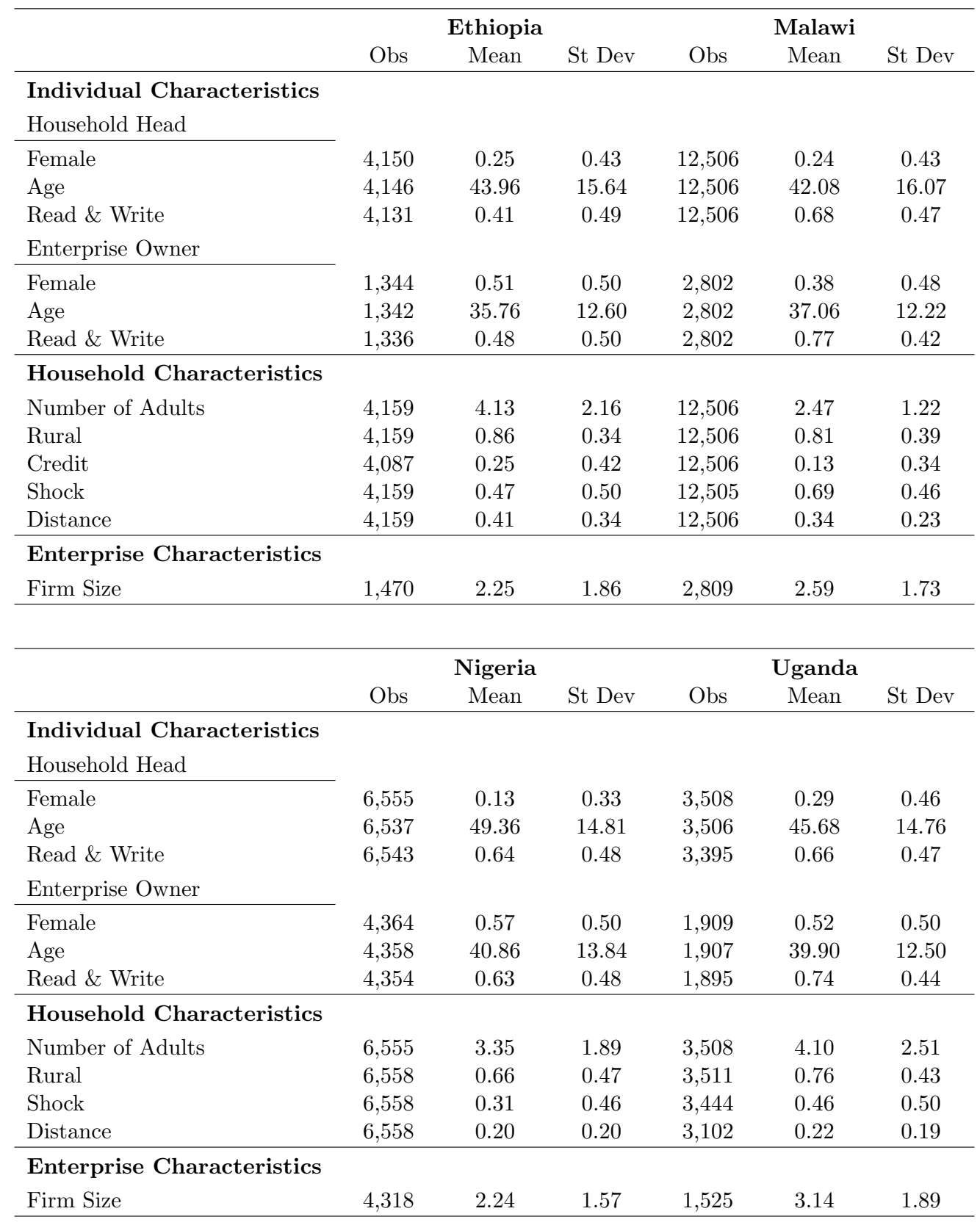


Definition of Variables for the Heckman Selection Model

Rural 1 if household is located in a rural area.

Female

1 if female.

Age In years.

Read \& Write

1 if individual can read and write in any language.

Number of Adults Number of adults age 15 or older in the household.

Credit

1 if household has access to credit. This variable is defined as general access to credit, and does not further specify for which purpose the household used it.

Shock 1 if household experienced a shock. Shocks can be idiosyncratic (e.g. death or illness of a household member), related to prices (e.g. increase in the price level of certain goods and services), related to agriculture (e.g. droughts or floods), or other types of shocks (not further specified in the questionnaire).

Distance Defined as distance to next population center of 20,000 or more inhabitants, in 100's of km.

Firm Size Number of workers in the enterprise.

Agro-Ecological Zones Tropic-warm or tropic-cool, combined with different precipitation levels: arid, semi arid, sub humid, humid. 


\section{A.2.3 Panel Data Analysis}

Table A.6: Summary Statistics - Panel Data Analysis

\begin{tabular}{lcccccc}
\hline & \multicolumn{3}{c}{ Nigeria } & \multicolumn{3}{c}{ Uganda } \\
& Obs & Mean & St Dev & Obs & Mean & St Dev \\
\hline Individual Characteristics & & & & & & \\
Female & 8,715 & 0.56 & 0.50 & 4,686 & 0.49 & 0.50 \\
Age & 8,711 & 2.96 & 0.99 & 4,684 & 2.83 & 0.98 \\
Read \& Write & 8,687 & 0.64 & 0.48 & 4,530 & 0.75 & 0.43 \\
Migration & & & 4,796 & 0.64 & 0.48 \\
\hline Household Characteristics & & & & & & \\
Rural & 8,715 & 0.62 & 0.49 & 4,795 & 0.71 & 0.45 \\
Number of Adults & 8,715 & 3.90 & 2.15 & 4,686 & 3.71 & 2.16 \\
Shock & 8,715 & 0.24 & 0.43 & 4,796 & 0.48 & 0.50 \\
\hline Enterprise Characteristics & & & & & & \\
Credit & 8,666 & 0.08 & 0.26 & 4,785 & 0.12 & 0.33 \\
Firm Size & 8,715 & 2.21 & 2.06 & 4,796 & 4.04 & 2.28 \\
Months in Operation & & & & 4,779 & 9.59 & 3.49 \\
\hline
\end{tabular}

Definition of Variables for the Panel Data Analysis

Rural 1 if household is located in a rural area.

Female $\quad 1$ if female.

Age In years.

Read \& Write $\quad 1$ if individual can read and write in any language.

Number of Adults Number of adults age 15 or older in the household.

Shock 1 if household experienced a shock. Shocks can be

idiosyncratic (e.g. death or illness of a household member),

related to prices (e.g. increase in the price level of certain goods and services), related to agriculture (e.g. droughts or floods), or other types of shocks (not further specified in the questionnaire).

Credit $\quad 1$ if household has taken out credit to expand the business.

The use of credit is clearly related to the purpose of operating and expanding the business, and not used for other purposes within the household.

Firm Size Number of workers in the enterprise.

Migration $\quad 1$ if individual migrated. It indicates if the individual moved from another district or country to the current place of residence.

Months in Operation Number of months the enterprise was in operation during the past 12 months (max. 12). 


\section{A.3 Productivity Dispersal}

Figure A.1: Productivity Dispersal - by Gender

(a) Ethiopia

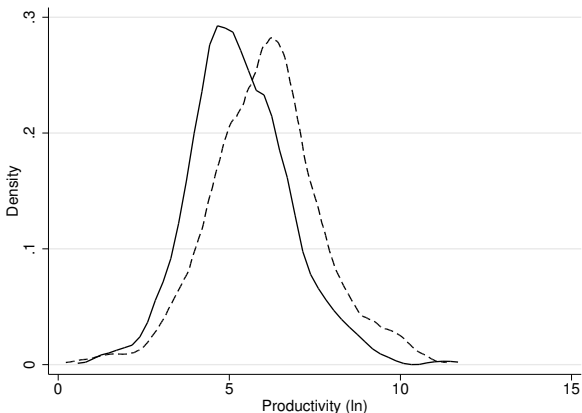

(c) Nigeria

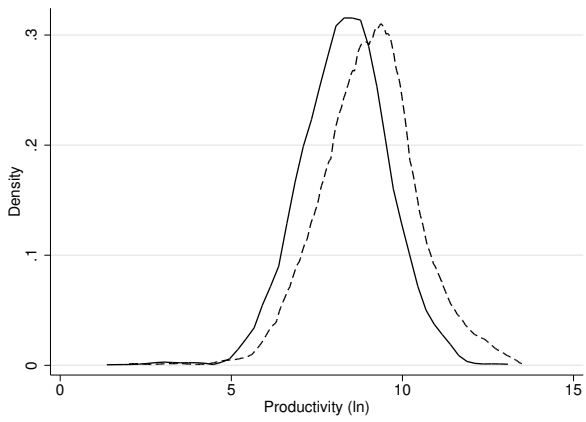

(b) Malawi

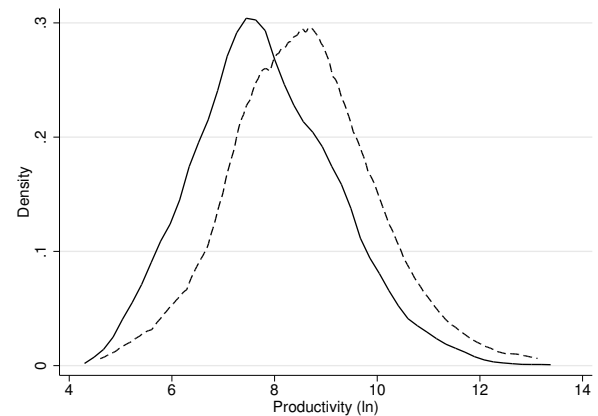

(d) Uganda

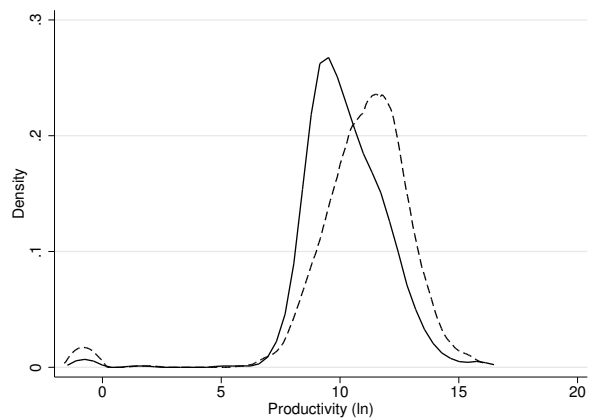

Note(s): In Figures A.1a, A.1b, A.1c and A.1d the continuous lines represent the productivity of enterprises with a female enterprise owner and the dotted lines the productivity of enterprises with a male enterprise owner. Author's own calculations based on LSMS-ISA data. 
Figure A.2: Productivity Dispersal - by Ability to Read \& Write

(a) Ethiopia

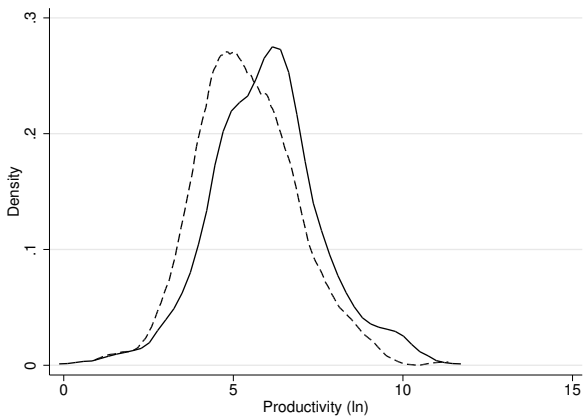

(c) Nigeria

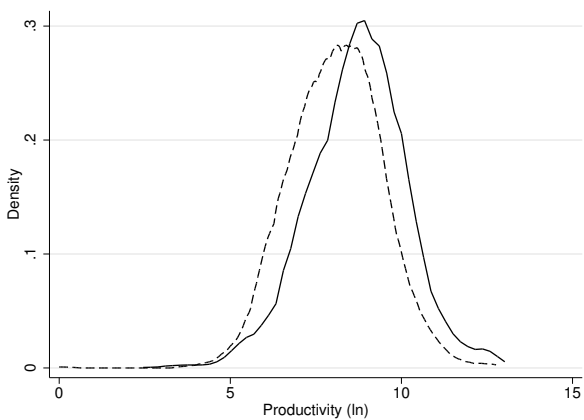

(b) Malawi

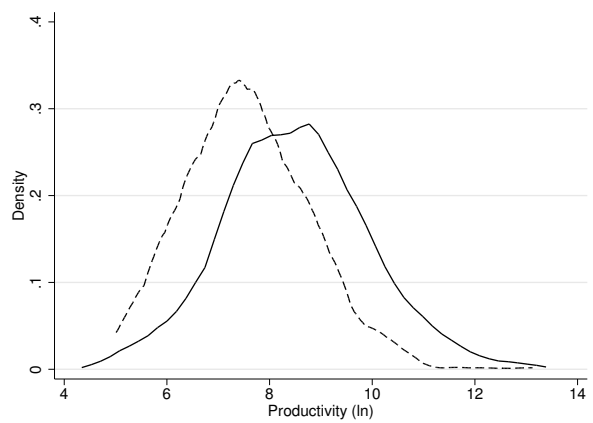

(d) Uganda

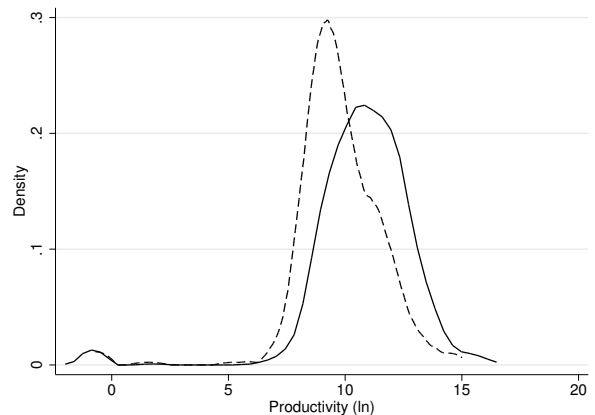

Note(s): In Figures A.2a, A.2b, A.2c and A.2d the continuous lines represent the productivity of enterprises where the enterprise owner has the ability to read \& write and the dotted lines the productivity of enterprises with an illiterate enterprise owner. Author's own calculations based on LSMS-ISA data. 
Figure A.3: Productivity Dispersal - by Shock Experience

(a) Ethiopia

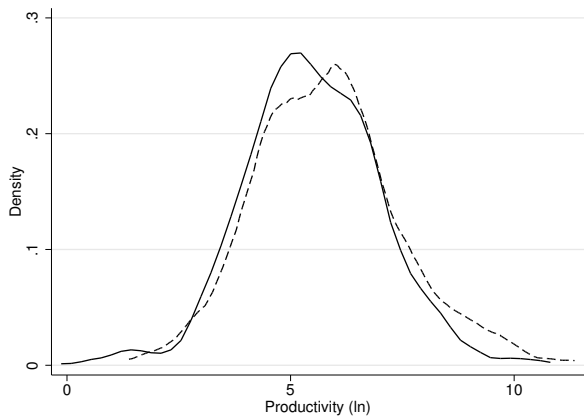

(c) Nigeria

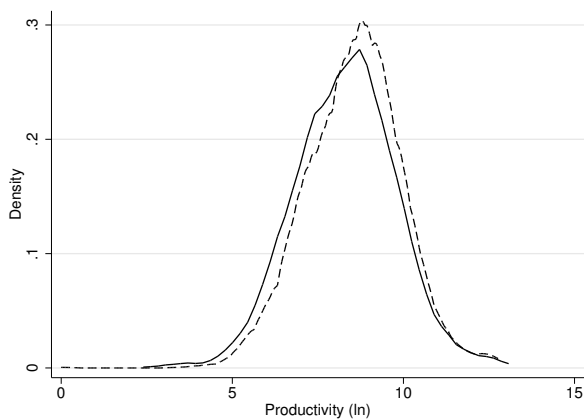

(b) Malawi

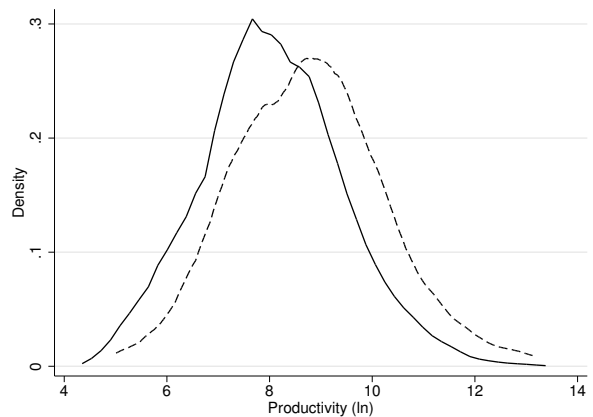

(d) Uganda

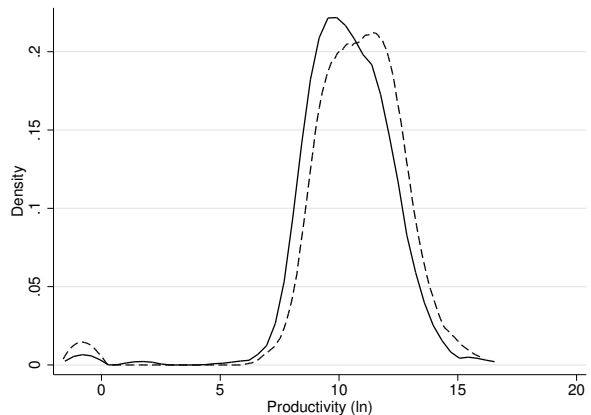

Note(s): In Figures A.3a, A.3b, A.3c and A.3d the continuous lines represent the productivity of enterprises where the corresponding household experienced a shock during the 12 previous months and the dotted lines the productivity of enterprises where the corresponding household did not experience a shock. Author's own calculations based on LSMS-ISA data. 


\section{A.4 Regressions}

\section{A.4.1 Probit Model}

Table A.7: Probit Regressions - Coefficients and Average Marginal Effects (Rural)

\begin{tabular}{|c|c|c|c|c|c|c|}
\hline $\begin{array}{l}\text { Dependent } \\
\text { NFE }\end{array}$ & $\begin{array}{c}(1) \\
\text { Ethiopia }\end{array}$ & $\begin{array}{c}(2) \\
\mathrm{AME} \\
\end{array}$ & $\begin{array}{c}(3) \\
\text { Malawi }\end{array}$ & $\begin{array}{c}(4) \\
\text { AME }\end{array}$ & $\begin{array}{c}(5) \\
\text { Niger } \\
\end{array}$ & $\begin{array}{c}(6) \\
\text { AME }\end{array}$ \\
\hline Female & $\begin{array}{l}-0.099 \\
(0.12)\end{array}$ & $\begin{array}{l}-0.029 \\
(0.04)\end{array}$ & $\begin{array}{l}0.019 \\
(0.07)\end{array}$ & $\begin{array}{l}0.005 \\
(0.02)\end{array}$ & $\begin{array}{c}-0.144 \\
(0.18)\end{array}$ & $\begin{array}{l}-0.051 \\
(0.06)\end{array}$ \\
\hline Age & $\begin{array}{l}0.001 \\
(0.01)\end{array}$ & $\begin{array}{c}-0.002^{* * *} \\
(0.00)\end{array}$ & $\begin{array}{l}0.009 \\
(0.01)\end{array}$ & $\begin{array}{c}-0.001^{* *} \\
(0.00)\end{array}$ & $\begin{array}{c}0.030^{* *} \\
(0.01)\end{array}$ & $\begin{array}{l}0.001 \\
(0.00)\end{array}$ \\
\hline $\mathrm{Age}^{2}$ & $\begin{array}{r}-0.000 \\
(0.00)\end{array}$ & & $\begin{array}{c}-0.000^{* *} \\
(0.00)\end{array}$ & & $\begin{array}{c}-0.000^{* *} \\
(0.00)\end{array}$ & \\
\hline Married & $\begin{array}{l}-0.135 \\
(0.12)\end{array}$ & $\begin{array}{l}-0.041 \\
(0.04)\end{array}$ & $\begin{array}{c}0.166^{* *} \\
(0.07)\end{array}$ & $\begin{array}{c}0.039^{* * *} \\
(0.01)\end{array}$ & $\begin{array}{r}-0.102 \\
(0.17)\end{array}$ & $\begin{array}{r}-0.036 \\
(0.06)\end{array}$ \\
\hline Read \& Write & $\begin{array}{l}0.105 \\
(0.08)\end{array}$ & $\begin{array}{l}0.031 \\
(0.02)\end{array}$ & $\begin{array}{c}0.170^{* * *} \\
(0.04)\end{array}$ & $\begin{array}{c}0.040^{* * *} \\
(0.01)\end{array}$ & $\begin{array}{l}0.084 \\
(0.10)\end{array}$ & $\begin{array}{l}0.030 \\
(0.04)\end{array}$ \\
\hline Number of Adults & $\begin{array}{r}-0.135 \\
(0.10)\end{array}$ & $\begin{array}{l}-0.011 \\
(0.01)\end{array}$ & $\begin{array}{l}0.012 \\
(0.05)\end{array}$ & $\begin{array}{l}0.008 \\
(0.01)\end{array}$ & $\begin{array}{r}-0.128 \\
(0.08)\end{array}$ & $\begin{array}{r}-0.021 \\
(0.01)\end{array}$ \\
\hline Number of Adults ${ }^{2}$ & $\begin{array}{l}0.018 \\
(0.01)\end{array}$ & & $\begin{array}{l}0.005 \\
(0.01)\end{array}$ & & $\begin{array}{l}0.011 \\
(0.01)\end{array}$ & \\
\hline Income in USD & & & & & $\begin{array}{c}0.427^{* * *} \\
(0.06)\end{array}$ & $\begin{array}{c}0.151^{* * *} \\
(0.02)\end{array}$ \\
\hline Rooms & $\begin{array}{c}0.112^{* * *} \\
(0.04)\end{array}$ & $\begin{array}{c}0.033^{* * *} \\
(0.01)\end{array}$ & $\begin{array}{c}0.036^{* *} \\
(0.02)\end{array}$ & $\begin{array}{c}0.009^{* *} \\
(0.00)\end{array}$ & $\begin{array}{l}0.021 \\
(0.04)\end{array}$ & $\begin{array}{l}0.007 \\
(0.01)\end{array}$ \\
\hline Credit & $\begin{array}{c}0.288^{* * *} \\
(0.07)\end{array}$ & $\begin{array}{c}0.088^{* * * *} \\
(0.02)\end{array}$ & $\begin{array}{c}0.269^{* * *} \\
(0.05)\end{array}$ & $\begin{array}{c}0.071^{* * *} \\
(0.01)\end{array}$ & & \\
\hline Food Shortage & $\begin{array}{c}0.131 \\
(0.09)\end{array}$ & $\begin{array}{c}0.039 \\
(0.03)\end{array}$ & $\begin{array}{c}-0.118^{* * *} \\
(0.04)\end{array}$ & $\begin{array}{c}-0.028^{* * *} \\
(0.01)\end{array}$ & $\begin{array}{c}-0.215^{* * *} \\
(0.07)\end{array}$ & $\begin{array}{c}-0.077^{* * *} \\
(0.02)\end{array}$ \\
\hline Shock (idiosyn.) & $\begin{array}{l}0.111 \\
(0.08)\end{array}$ & $\begin{array}{l}0.033 \\
(0.02)\end{array}$ & $\begin{array}{c}0.243^{* * *} \\
(0.04)\end{array}$ & $\begin{array}{c}0.062^{* * *} \\
(0.01)\end{array}$ & $\begin{array}{r}0.010 \\
(0.10)\end{array}$ & $\begin{array}{l}0.003 \\
(0.04)\end{array}$ \\
\hline Shock (price) & $\begin{array}{l}0.043 \\
(0.10)\end{array}$ & $\begin{array}{l}0.013 \\
(0.03)\end{array}$ & $\begin{array}{l}0.007 \\
(0.04)\end{array}$ & $\begin{array}{l}0.002 \\
(0.01)\end{array}$ & $\begin{array}{l}0.066 \\
(0.10)\end{array}$ & $\begin{array}{l}0.023 \\
(0.03)\end{array}$ \\
\hline Shock (geogr.) & $\begin{array}{r}-0.081 \\
(0.12)\end{array}$ & $\begin{array}{l}-0.023 \\
(0.03)\end{array}$ & $\begin{array}{c}0.086^{* *} \\
(0.04)\end{array}$ & $\begin{array}{c}0.021^{* *} \\
(0.01)\end{array}$ & $\begin{array}{l}-0.044 \\
(0.08)\end{array}$ & $\begin{array}{c}-0.016 \\
(0.03)\end{array}$ \\
\hline Shock (other) & $\begin{array}{l}0.387^{*} \\
(0.21)\end{array}$ & $\begin{array}{l}0.126^{*} \\
(0.08)\end{array}$ & $\begin{array}{c}0.077 \\
(0.15)\end{array}$ & $\begin{array}{c}0.019 \\
(0.04)\end{array}$ & $\begin{array}{c}0.283^{* * *} \\
(0.10)\end{array}$ & $\begin{array}{c}0.097^{* * *} \\
(0.03)\end{array}$ \\
\hline Distance & $\begin{array}{r}-0.080 \\
(0.40)\end{array}$ & $\begin{array}{c}-0.034 \\
(0.07)\end{array}$ & $\begin{array}{c}-1.242^{* * *} \\
(0.34)\end{array}$ & $\begin{array}{c}-0.107^{* * *} \\
(0.03)\end{array}$ & $\begin{array}{c}-0.464 \\
(0.47)\end{array}$ & $\begin{array}{c}-0.074 \\
(0.07)\end{array}$ \\
\hline Distance $^{2}$ & $\begin{array}{r}-0.056 \\
(0.24)\end{array}$ & & $\begin{array}{c}1.106^{* * *} \\
(0.35)\end{array}$ & & $\begin{array}{l}0.198 \\
(0.24)\end{array}$ & \\
\hline Precipitation & $\begin{array}{l}0.083 \\
(0.13)\end{array}$ & $\begin{array}{l}0.024 \\
(0.04)\end{array}$ & $\begin{array}{c}-0.144^{*} \\
(0.08)\end{array}$ & $\begin{array}{c}-0.035^{*} \\
(0.02)\end{array}$ & $\begin{array}{c}1.733^{* *} \\
(0.83)\end{array}$ & $\begin{array}{c}0.612^{* *} \\
(0.29)\end{array}$ \\
\hline Constant & $\begin{array}{c}-0.697^{*} \\
(0.39)\end{array}$ & & $\begin{array}{c}-1.092^{* * *} \\
(0.20)\end{array}$ & & $\begin{array}{r}-0.845 \\
(0.55) \\
\end{array}$ & \\
\hline $\mathrm{N}$ & 3,366 & 3,366 & 10,017 & 10,017 & 2,430 & 2,430 \\
\hline
\end{tabular}

Note(s): Standard errors in parentheses. Survey weights included. ${ }^{*} p<0.1,{ }^{* *} p<0.05,{ }^{* * *} p<0.01$. 


\begin{tabular}{|c|c|c|c|c|c|c|}
\hline $\begin{array}{l}\text { Dependent } \\
\text { NFE }\end{array}$ & $\begin{array}{c}(7) \\
\text { Nigeria } \\
\end{array}$ & $\begin{array}{c}(8) \\
\text { AME }\end{array}$ & $\begin{array}{c}(9) \\
\text { Tanzania } \\
\end{array}$ & $\begin{array}{c}(10) \\
\text { AME }\end{array}$ & $\begin{array}{c}(11) \\
\text { Uganda }\end{array}$ & $\begin{array}{c}(12) \\
\text { AME }\end{array}$ \\
\hline Female & $\begin{array}{l}0.119 \\
(0.27)\end{array}$ & $\begin{array}{l}0.045 \\
(0.10)\end{array}$ & $\begin{array}{l}0.101 \\
(0.09)\end{array}$ & $\begin{array}{l}0.037 \\
(0.03)\end{array}$ & $\begin{array}{l}0.003 \\
(0.10)\end{array}$ & $\begin{array}{l}0.001 \\
(0.04)\end{array}$ \\
\hline Age & $\begin{array}{l}-0.001 \\
(0.02)\end{array}$ & $\begin{array}{c}-0.003^{* *} \\
(0.00)\end{array}$ & $\begin{array}{l}0.003 \\
(0.01)\end{array}$ & $\begin{array}{c}-0.004^{* * *} \\
(0.00)\end{array}$ & $\begin{array}{c}0.036^{* *} \\
(0.02)\end{array}$ & $\begin{array}{c}-0.004^{* * *} \\
(0.00)\end{array}$ \\
\hline $\mathrm{Age}^{2}$ & $\begin{array}{l}-0.000 \\
(0.00)\end{array}$ & & $\begin{array}{l}-0.000 \\
(0.00)\end{array}$ & & $\begin{array}{c}-0.001^{* * * *} \\
(0.00)\end{array}$ & \\
\hline Married & $\begin{array}{l}0.219 \\
(0.22)\end{array}$ & $\begin{array}{l}0.083 \\
(0.08)\end{array}$ & $\begin{array}{c}-0.167^{* *} \\
(0.07)\end{array}$ & $\begin{array}{c}-0.061^{* *} \\
(0.03)\end{array}$ & $\begin{array}{l}0.131 \\
(0.11)\end{array}$ & $\begin{array}{l}0.047 \\
(0.04)\end{array}$ \\
\hline Read \& Write & $\begin{array}{c}0.331^{* * *} \\
(0.11)\end{array}$ & $\begin{array}{c}0.126^{* * *} \\
(0.04)\end{array}$ & $\begin{array}{l}0.148^{*} \\
(0.08)\end{array}$ & $\begin{array}{l}0.054^{*} \\
(0.03)\end{array}$ & $\begin{array}{r}-0.027 \\
(0.07)\end{array}$ & $\begin{array}{l}-0.010 \\
(0.03)\end{array}$ \\
\hline Number of Adults & $\begin{array}{c}0.253^{* *} \\
(0.10)\end{array}$ & $\begin{array}{c}0.055^{* * *} \\
(0.01)\end{array}$ & $\begin{array}{c}0.114^{* *} \\
(0.05)\end{array}$ & $\begin{array}{c}0.032^{* * * *} \\
(0.01)\end{array}$ & $\begin{array}{c}0.128^{* * *} \\
(0.04)\end{array}$ & $\begin{array}{c}0.028^{* * *} \\
(0.01)\end{array}$ \\
\hline Number of Adults ${ }^{2}$ & $\begin{array}{l}-0.017 \\
(0.01)\end{array}$ & & $\begin{array}{l}-0.004 \\
(0.00)\end{array}$ & & $\begin{array}{c}-0.007^{* *} \\
(0.00)\end{array}$ & \\
\hline Income in USD & $\begin{array}{c}-0.044^{* *} \\
(0.02)\end{array}$ & $\begin{array}{c}-0.017^{* *} \\
(0.01)\end{array}$ & $\begin{array}{c}0.107^{* * *} \\
(0.04)\end{array}$ & $\begin{array}{c}0.039^{* * *} \\
(0.01)\end{array}$ & $\begin{array}{c}0.285^{* * *} \\
(0.06)\end{array}$ & $\begin{array}{c}0.101^{* * *} \\
(0.02)\end{array}$ \\
\hline Rooms & & & $\begin{array}{c}0.062^{* * *} \\
(0.02)\end{array}$ & $\begin{array}{c}0.023^{* * *} \\
(0.01)\end{array}$ & $\begin{array}{l}-0.005 \\
(0.03)\end{array}$ & $\begin{array}{c}-0.002 \\
(0.01)\end{array}$ \\
\hline Credit & & & $\begin{array}{l}0.058 \\
(0.11)\end{array}$ & $\begin{array}{l}0.021 \\
(0.04)\end{array}$ & & \\
\hline Food Shortage & $\begin{array}{l}0.085 \\
(0.10)\end{array}$ & $\begin{array}{l}0.032 \\
(0.04)\end{array}$ & $\begin{array}{l}-0.015 \\
(0.08)\end{array}$ & $\begin{array}{l}-0.005 \\
(0.03)\end{array}$ & $\begin{array}{c}0.218^{* *} \\
(0.10)\end{array}$ & $\begin{array}{c}0.078^{* *} \\
(0.04)\end{array}$ \\
\hline Shock (idiosyn.) & $\begin{array}{l}-0.093 \\
(0.11)\end{array}$ & $\begin{array}{l}-0.035 \\
(0.04)\end{array}$ & $\begin{array}{l}0.131 \\
(0.09)\end{array}$ & $\begin{array}{l}0.048 \\
(0.03)\end{array}$ & $\begin{array}{l}0.124 \\
(0.09)\end{array}$ & $\begin{array}{l}0.044 \\
(0.03)\end{array}$ \\
\hline Shock (price) & $\begin{array}{l}0.059 \\
(0.12)\end{array}$ & $\begin{array}{l}0.022 \\
(0.04)\end{array}$ & $\begin{array}{l}-0.121 \\
(0.10)\end{array}$ & $\begin{array}{l}-0.044 \\
(0.03)\end{array}$ & $\begin{array}{c}-0.573^{* *} \\
(0.25)\end{array}$ & $\begin{array}{c}-0.187^{* * *} \\
(0.07)\end{array}$ \\
\hline Shock (geogr.) & $\begin{array}{l}-0.187 \\
(0.12)\end{array}$ & $\begin{array}{l}-0.070 \\
(0.04)\end{array}$ & $\begin{array}{l}0.008 \\
(0.09)\end{array}$ & $\begin{array}{l}0.003 \\
(0.03)\end{array}$ & $\begin{array}{l}0.137 \\
(0.09)\end{array}$ & $\begin{array}{l}0.049 \\
(0.03)\end{array}$ \\
\hline Shock (other) & $\begin{array}{l}0.073 \\
(0.26)\end{array}$ & $\begin{array}{l}0.028 \\
(0.10)\end{array}$ & $\begin{array}{l}-0.055 \\
(0.41)\end{array}$ & $\begin{array}{l}-0.020 \\
(0.15)\end{array}$ & $\begin{array}{l}0.161 \\
(0.23)\end{array}$ & $\begin{array}{l}0.058 \\
(0.08)\end{array}$ \\
\hline Distance & $\begin{array}{r}-1.122 \\
(0.78)\end{array}$ & $\begin{array}{l}-0.164 \\
(0.13)\end{array}$ & $\begin{array}{l}-0.019 \\
(0.24)\end{array}$ & $\begin{array}{l}-0.019 \\
(0.04)\end{array}$ & $\begin{array}{c}-2.252^{* * * *} \\
(0.86)\end{array}$ & $\begin{array}{c}-0.214^{*} \\
(0.12)\end{array}$ \\
\hline Distance $^{2}$ & $\begin{array}{l}1.413 \\
(1.10)\end{array}$ & & $\begin{array}{l}-0.032 \\
(0.12)\end{array}$ & & $\begin{array}{c}3.373^{* * *} \\
(1.30)\end{array}$ & \\
\hline Precipitation & $\begin{array}{c}-0.171^{*} \\
(0.09)\end{array}$ & $\begin{array}{r}-0.064^{*} \\
(0.03)\end{array}$ & $\begin{array}{l}-0.029 \\
(0.09)\end{array}$ & $\begin{array}{r}-0.011 \\
(0.03)\end{array}$ & $\begin{array}{l}0.110 \\
(0.24)\end{array}$ & $\begin{array}{l}0.039 \\
(0.08)\end{array}$ \\
\hline Constant & $\begin{array}{l}-0.229 \\
(0.57) \\
\end{array}$ & & $\begin{array}{c}-0.611^{* *} \\
(0.30) \\
\end{array}$ & & $\begin{array}{c}-1.193^{* *} \\
(0.52) \\
\end{array}$ & \\
\hline $\mathrm{N}$ & 1,074 & 1,074 & 2,579 & 2,579 & 1,789 & 1,789 \\
\hline
\end{tabular}

Note(s): Standard errors in parentheses. Survey weights included. ${ }^{*} p<0.1,{ }^{* *} p<0.05,{ }^{* * *} p<0.01$. 
Table A.8: Probit Regressions - Coefficients and Average Marginal Effects (Urban)

\begin{tabular}{|c|c|c|c|c|c|c|}
\hline $\begin{array}{l}\text { Dependent } \\
\text { NFE }\end{array}$ & $\begin{array}{c}(1) \\
\text { Ethiopia }\end{array}$ & $\begin{array}{c}(2) \\
\text { AME } \\
\end{array}$ & $\begin{array}{c}(3) \\
\text { Malawi } \\
\end{array}$ & $\begin{array}{c}(4) \\
\text { AME }\end{array}$ & $\begin{array}{c}(5) \\
\text { Niger } \\
\end{array}$ & $\begin{array}{c}(6) \\
\text { AME }\end{array}$ \\
\hline Female & $\begin{array}{l}0.404 \\
(0.24)\end{array}$ & $\begin{array}{l}0.140^{*} \\
(0.08)\end{array}$ & $\begin{array}{l}0.082 \\
(0.16)\end{array}$ & $\begin{array}{l}0.029 \\
(0.06)\end{array}$ & $\begin{array}{l}0.062 \\
(0.17)\end{array}$ & $\begin{array}{l}0.021 \\
(0.06)\end{array}$ \\
\hline Age & $\begin{array}{l}0.015 \\
(0.03)\end{array}$ & $\begin{array}{l}0.002 \\
(0.00)\end{array}$ & $\begin{array}{c}0.031^{* *} \\
(0.01)\end{array}$ & $\begin{array}{l}-0.001 \\
(0.00)\end{array}$ & $\begin{array}{l}0.006 \\
(0.02)\end{array}$ & $\begin{array}{c}-0.002 \\
(0.00)\end{array}$ \\
\hline $\mathrm{Age}^{2}$ & $\begin{array}{l}-0.000 \\
(0.00)\end{array}$ & & $\begin{array}{c}-0.000^{* * *} \\
(0.00)\end{array}$ & & $\begin{array}{l}-0.000 \\
(0.00)\end{array}$ & \\
\hline Married & $\begin{array}{l}0.063 \\
(0.18)\end{array}$ & $\begin{array}{l}0.022 \\
(0.06)\end{array}$ & $\begin{array}{l}0.204^{*} \\
(0.12)\end{array}$ & $\begin{array}{l}0.071^{*} \\
(0.04)\end{array}$ & $\begin{array}{c}0.339^{* *} \\
(0.16)\end{array}$ & $\begin{array}{c}0.121^{* *} \\
(0.06)\end{array}$ \\
\hline Read \& Write & $\begin{array}{l}-0.179 \\
(0.22)\end{array}$ & $\begin{array}{c}-0.062 \\
(0.08)\end{array}$ & $\begin{array}{l}-0.087 \\
(0.15)\end{array}$ & $\begin{array}{l}-0.031 \\
(0.05)\end{array}$ & $\begin{array}{c}-0.509^{* * *} \\
(0.09)\end{array}$ & $\begin{array}{c}-0.175^{* * *} \\
(0.03)\end{array}$ \\
\hline Number of Adults & $\begin{array}{l}0.184 \\
(0.24)\end{array}$ & $\begin{array}{c}0.091^{* * *} \\
(0.03)\end{array}$ & $\begin{array}{c}0.242^{* *} \\
(0.11)\end{array}$ & $\begin{array}{c}0.050^{* * *} \\
(0.02)\end{array}$ & $\begin{array}{c}0.128^{* *} \\
(0.06)\end{array}$ & $\begin{array}{c}0.027^{* *} \\
(0.01)\end{array}$ \\
\hline Number of Adults ${ }^{2}$ & $\begin{array}{l}0.018 \\
(0.04)\end{array}$ & & $\begin{array}{l}-0.019 \\
(0.01)\end{array}$ & & $\begin{array}{l}-0.007 \\
(0.01)\end{array}$ & \\
\hline Income in USD & & & & & $\begin{array}{l}0.034^{*} \\
(0.02)\end{array}$ & $\begin{array}{l}0.012^{*} \\
(0.01)\end{array}$ \\
\hline Rooms & $\begin{array}{l}0.008 \\
(0.07)\end{array}$ & $\begin{array}{l}0.003 \\
(0.02)\end{array}$ & $\begin{array}{l}0.041 \\
(0.04)\end{array}$ & $\begin{array}{l}0.014 \\
(0.01)\end{array}$ & $\begin{array}{l}-0.018 \\
(0.03)\end{array}$ & $\begin{array}{l}-0.006 \\
(0.01)\end{array}$ \\
\hline Credit & $\begin{array}{c}0.666^{* * *} \\
(0.21)\end{array}$ & $\begin{array}{c}0.221^{* * *} \\
(0.06)\end{array}$ & $\begin{array}{l}0.015 \\
(0.12)\end{array}$ & $\begin{array}{l}0.005 \\
(0.04)\end{array}$ & & \\
\hline Food Shortage & $\begin{array}{l}-0.020 \\
(0.25)\end{array}$ & $\begin{array}{l}-0.007 \\
(0.08)\end{array}$ & $\begin{array}{l}-0.113 \\
(0.08)\end{array}$ & $\begin{array}{c}-0.040 \\
(0.03)\end{array}$ & $\begin{array}{l}0.015 \\
(0.14)\end{array}$ & $\begin{array}{l}0.005 \\
(0.05)\end{array}$ \\
\hline Shock (idiosyn.) & $\begin{array}{l}-0.047 \\
(0.22)\end{array}$ & $\begin{array}{l}-0.016 \\
(0.07)\end{array}$ & $\begin{array}{c}0.258^{* * *} \\
(0.09)\end{array}$ & $\begin{array}{c}0.094^{* * *} \\
(0.03)\end{array}$ & $\begin{array}{l}0.024 \\
(0.10)\end{array}$ & $\begin{array}{l}0.008 \\
(0.03)\end{array}$ \\
\hline Shock (price) & $\begin{array}{l}0.109 \\
(0.13)\end{array}$ & $\begin{array}{l}0.037 \\
(0.04)\end{array}$ & $\begin{array}{c}-0.118 \\
(0.10)\end{array}$ & $\begin{array}{l}-0.041 \\
(0.03)\end{array}$ & $\begin{array}{l}0.177^{*} \\
(0.09)\end{array}$ & $\begin{array}{c}0.059^{* *} \\
(0.03)\end{array}$ \\
\hline Shock (geogr.) & $\begin{array}{l}-0.541 \\
(0.34)\end{array}$ & $\begin{array}{l}-0.188 \\
(0.11)\end{array}$ & $\begin{array}{l}-0.004 \\
(0.14)\end{array}$ & $\begin{array}{l}-0.001 \\
(0.05)\end{array}$ & $\begin{array}{l}-0.150 \\
(0.15)\end{array}$ & $\begin{array}{l}-0.053 \\
(0.05)\end{array}$ \\
\hline Shock (other) & $\begin{array}{l}-0.755 \\
(0.61)\end{array}$ & $\begin{array}{l}-0.257 \\
(0.19)\end{array}$ & $\begin{array}{l}-0.161 \\
(0.23)\end{array}$ & $\begin{array}{l}-0.055 \\
(0.08)\end{array}$ & $\begin{array}{l}0.036 \\
(0.13)\end{array}$ & $\begin{array}{l}0.012 \\
(0.04)\end{array}$ \\
\hline Distance & $\begin{array}{l}0.398 \\
(0.58)\end{array}$ & $\begin{array}{l}0.105 \\
(0.11)\end{array}$ & $\begin{array}{l}-0.588 \\
(0.74)\end{array}$ & $\begin{array}{l}-0.140 \\
(0.21)\end{array}$ & $\begin{array}{l}0.009 \\
(0.60)\end{array}$ & $\begin{array}{l}-0.008 \\
(0.17)\end{array}$ \\
\hline Distance $^{2}$ & $\begin{array}{l}-0.105 \\
(0.35)\end{array}$ & & $\begin{array}{l}1.004 \\
(0.83)\end{array}$ & & $\begin{array}{r}-0.128 \\
(0.43)\end{array}$ & \\
\hline Precipitation & $\begin{array}{l}0.161 \\
(0.22)\end{array}$ & $\begin{array}{l}0.056 \\
(0.08)\end{array}$ & $\begin{array}{c}-0.568^{* *} \\
(0.26)\end{array}$ & $\begin{array}{c}-0.202^{* *} \\
(0.09)\end{array}$ & $\begin{array}{r}-0.327 \\
(0.46)\end{array}$ & $\begin{array}{c}-0.111 \\
(0.16)\end{array}$ \\
\hline Constant & $\begin{array}{c}-1.269^{*} \\
(0.64) \\
\end{array}$ & & $\begin{array}{c}-0.920^{*} \\
(0.51) \\
\end{array}$ & & $\begin{array}{l}0.228 \\
(0.42) \\
\end{array}$ & \\
\hline $\mathrm{N}$ & 483 & 483 & 2,229 & 2,229 & 1,538 & 1,538 \\
\hline
\end{tabular}

Note(s): Standard errors in parentheses. Survey weights included. ${ }^{*} p<0.1,{ }^{* *} p<0.05,{ }^{* * *} p<0.01$. 


\begin{tabular}{|c|c|c|c|c|c|c|}
\hline $\begin{array}{l}\text { Dependent } \\
\text { NFE }\end{array}$ & $\begin{array}{c}(7) \\
\text { Nigeria } \\
\end{array}$ & $\begin{array}{c}(8) \\
\text { AME }\end{array}$ & $\begin{array}{c}(9) \\
\text { Tanzania } \\
\end{array}$ & $\begin{array}{c}(10) \\
\text { AME }\end{array}$ & $\begin{array}{c}(11) \\
\text { Uganda }\end{array}$ & $\begin{array}{c}(12) \\
\text { AME }\end{array}$ \\
\hline Female & $\begin{array}{l}0.326 \\
(0.29)\end{array}$ & $\begin{array}{l}0.105 \\
(0.09)\end{array}$ & $\begin{array}{l}0.056 \\
(0.12)\end{array}$ & $\begin{array}{l}0.020 \\
(0.04)\end{array}$ & $\begin{array}{l}0.141 \\
(0.19)\end{array}$ & $\begin{array}{l}0.050 \\
(0.07)\end{array}$ \\
\hline Age & $\begin{array}{l}-0.030 \\
(0.04)\end{array}$ & $\begin{array}{c}-0.004^{* *} \\
(0.00)\end{array}$ & $\begin{array}{l}0.015 \\
(0.02)\end{array}$ & $\begin{array}{l}-0.001 \\
(0.00)\end{array}$ & $\begin{array}{l}0.027 \\
(0.03)\end{array}$ & $\begin{array}{l}0.001 \\
(0.00)\end{array}$ \\
\hline $\mathrm{Age}^{2}$ & $\begin{array}{l}0.000 \\
(0.00)\end{array}$ & & $\begin{array}{l}-0.000 \\
(0.00)\end{array}$ & & $\begin{array}{l}-0.000 \\
(0.00)\end{array}$ & \\
\hline Married & $\begin{array}{c}0.796^{* * *} \\
(0.25)\end{array}$ & $\begin{array}{c}0.282^{* * *} \\
(0.09)\end{array}$ & $\begin{array}{l}0.114 \\
(0.13)\end{array}$ & $\begin{array}{l}0.042 \\
(0.05)\end{array}$ & $\begin{array}{l}0.286 \\
(0.21)\end{array}$ & $\begin{array}{l}0.103 \\
(0.08)\end{array}$ \\
\hline Read \& Write & $\begin{array}{l}-0.180 \\
(0.20)\end{array}$ & $\begin{array}{l}-0.056 \\
(0.06)\end{array}$ & $\begin{array}{l}0.164 \\
(0.18)\end{array}$ & $\begin{array}{l}0.061 \\
(0.07)\end{array}$ & $\begin{array}{l}-0.040 \\
(0.20)\end{array}$ & $\begin{array}{l}-0.014 \\
(0.07)\end{array}$ \\
\hline Number of Adults & $\begin{array}{c}-0.032 \\
(0.16)\end{array}$ & $\begin{array}{l}0.003 \\
(0.02)\end{array}$ & $\begin{array}{c}0.185^{* *} \\
(0.07)\end{array}$ & $\begin{array}{c}0.058^{* * * *} \\
(0.02)\end{array}$ & $\begin{array}{c}0.244^{* * * *} \\
(0.08)\end{array}$ & $\begin{array}{c}0.041^{* * * *} \\
(0.01)\end{array}$ \\
\hline Number of Adults ${ }^{2}$ & $\begin{array}{l}0.007 \\
(0.02)\end{array}$ & & $\begin{array}{l}-0.005 \\
(0.01)\end{array}$ & & $\begin{array}{c}-0.017^{* *} \\
(0.01)\end{array}$ & \\
\hline Income in USD & $\begin{array}{l}-0.007 \\
(0.01)\end{array}$ & $\begin{array}{c}-0.002 \\
(0.00)\end{array}$ & $\begin{array}{l}0.010 \\
(0.02)\end{array}$ & $\begin{array}{l}0.004 \\
(0.01)\end{array}$ & $\begin{array}{r}-0.020 \\
(0.03)\end{array}$ & $\begin{array}{c}-0.007 \\
(0.01)\end{array}$ \\
\hline Rooms & & & $\begin{array}{l}-0.009 \\
(0.03)\end{array}$ & $\begin{array}{l}-0.003 \\
(0.01)\end{array}$ & $\begin{array}{l}-0.016 \\
(0.06)\end{array}$ & $\begin{array}{l}-0.006 \\
(0.02)\end{array}$ \\
\hline Credit & & & $\begin{array}{l}0.205 \\
(0.13)\end{array}$ & $\begin{array}{l}0.074 \\
(0.05)\end{array}$ & & \\
\hline Food Shortage & $\begin{array}{l}0.186 \\
(0.14)\end{array}$ & $\begin{array}{l}0.059 \\
(0.05)\end{array}$ & $\begin{array}{l}0.171 \\
(0.13)\end{array}$ & $\begin{array}{l}0.062 \\
(0.05)\end{array}$ & $\begin{array}{c}-0.135 \\
(0.22)\end{array}$ & $\begin{array}{c}-0.048 \\
(0.08)\end{array}$ \\
\hline Shock (idiosyn.) & $\begin{array}{l}-0.017 \\
(0.20)\end{array}$ & $\begin{array}{l}-0.005 \\
(0.06)\end{array}$ & $\begin{array}{l}-0.004 \\
(0.10)\end{array}$ & $\begin{array}{l}-0.001 \\
(0.04)\end{array}$ & $\begin{array}{c}-0.335^{*} \\
(0.19)\end{array}$ & $\begin{array}{c}-0.123^{*} \\
(0.07)\end{array}$ \\
\hline Shock (price) & $\begin{array}{l}0.034 \\
(0.22)\end{array}$ & $\begin{array}{l}0.011 \\
(0.07)\end{array}$ & $\begin{array}{l}0.128 \\
(0.13)\end{array}$ & $\begin{array}{l}0.046 \\
(0.05)\end{array}$ & $\begin{array}{c}-1.700^{* * * *} \\
(0.57)\end{array}$ & $\begin{array}{c}-0.522^{* * *} \\
(0.09)\end{array}$ \\
\hline Shock (geogr.) & $\begin{array}{l}-0.186 \\
(0.25)\end{array}$ & $\begin{array}{l}-0.062 \\
(0.08)\end{array}$ & $\begin{array}{l}-0.160 \\
(0.15)\end{array}$ & $\begin{array}{c}-0.060 \\
(0.06)\end{array}$ & $\begin{array}{l}0.375 \\
(0.23)\end{array}$ & $\begin{array}{l}0.126^{*} \\
(0.07)\end{array}$ \\
\hline Shock (other) & $\begin{array}{l}0.106 \\
(0.33)\end{array}$ & $\begin{array}{l}0.033 \\
(0.10)\end{array}$ & $\begin{array}{l}0.474 \\
(0.42)\end{array}$ & $\begin{array}{l}0.159 \\
(0.12)\end{array}$ & $\begin{array}{c}-1.008^{* *} \\
(0.47)\end{array}$ & $\begin{array}{c}-0.360^{* *} \\
(0.15)\end{array}$ \\
\hline Distance & $\begin{array}{l}2.309^{*} \\
(1.35)\end{array}$ & $\begin{array}{l}0.556 \\
(0.38)\end{array}$ & $\begin{array}{l}-0.355 \\
(0.64)\end{array}$ & $\begin{array}{l}-0.061 \\
(0.16)\end{array}$ & $\begin{array}{l}1.616 \\
(1.41)\end{array}$ & $\begin{array}{l}0.510 \\
(0.40)\end{array}$ \\
\hline Distance $^{2}$ & $\begin{array}{c}-4.068^{* *} \\
(1.59)\end{array}$ & & $\begin{array}{l}0.477 \\
(0.48)\end{array}$ & & $\begin{array}{l}-1.177 \\
(2.05)\end{array}$ & \\
\hline Precipitation & $\begin{array}{l}-0.120 \\
(0.17)\end{array}$ & $\begin{array}{l}-0.039 \\
(0.05)\end{array}$ & $\begin{array}{l}0.201 \\
(0.17)\end{array}$ & $\begin{array}{l}0.074 \\
(0.06)\end{array}$ & $\begin{array}{l}-0.656 \\
(0.56)\end{array}$ & $\begin{array}{l}-0.232 \\
(0.20)\end{array}$ \\
\hline Constant & $\begin{array}{l}1.104 \\
(0.98) \\
\end{array}$ & & $\begin{array}{c}-0.848^{* *} \\
(0.43) \\
\end{array}$ & & $\begin{array}{l}-0.170 \\
(1.09) \\
\end{array}$ & \\
\hline $\mathrm{N}$ & 421 & 421 & 1,254 & 1,254 & 479 & 479 \\
\hline
\end{tabular}

Note(s): Standard errors in parentheses. Survey weights included. ${ }^{*} p<0.1,{ }^{* *} p<0.05,{ }^{* * *} p<0.01$. 


\section{A.4.2 Heckman Selection Model}

Table A.9: Heckman Selection Model (Rural)

\begin{tabular}{|c|c|c|c|c|}
\hline & $\begin{array}{c}(1) \\
\text { Ethiopia }\end{array}$ & $\begin{array}{c}(2) \\
\text { Malawi }\end{array}$ & $\begin{array}{c}(3) \\
\text { Nigeria }\end{array}$ & $\begin{array}{c}(4) \\
\text { Uganda }\end{array}$ \\
\hline \multicolumn{5}{|l|}{ (ln) Productivity } \\
\hline Female & $\begin{array}{c}-0.593^{* * *} \\
(0.15)\end{array}$ & $\begin{array}{c}-0.614^{* * *} \\
(0.07)\end{array}$ & $\begin{array}{c}-0.333^{* * *} \\
(0.07)\end{array}$ & $\begin{array}{c}-0.137 \\
(0.17)\end{array}$ \\
\hline Age & $\begin{array}{l}0.007 \\
(0.01)\end{array}$ & $\begin{array}{r}-0.003 \\
(0.00)\end{array}$ & $\begin{array}{c}-0.004 \\
(0.00)\end{array}$ & $\begin{array}{c}0.013^{* *} \\
(0.01)\end{array}$ \\
\hline Read \& Write & $\begin{array}{c}0.344^{* *} \\
(0.16)\end{array}$ & $\begin{array}{c}0.302^{* * *} \\
(0.08)\end{array}$ & $\begin{array}{c}0.178^{* *} \\
(0.08)\end{array}$ & $\begin{array}{c}0.766^{* * *} \\
(0.20)\end{array}$ \\
\hline Credit & $\begin{array}{l}-0.005 \\
(0.18)\end{array}$ & $\begin{array}{c}-0.227^{* *} \\
(0.09)\end{array}$ & & \\
\hline Firm Size & $\begin{array}{c}-0.204^{* *} \\
(0.09)\end{array}$ & $\begin{array}{l}-0.021 \\
(0.03)\end{array}$ & $\begin{array}{c}-0.179^{* * *} \\
(0.03)\end{array}$ & $\begin{array}{l}-0.025 \\
(0.04)\end{array}$ \\
\hline Shock & $\begin{array}{c}-0.363^{* *} \\
(0.15)\end{array}$ & $\begin{array}{c}-0.488^{* * *} \\
(0.09)\end{array}$ & $\begin{array}{c}-0.254^{* * *} \\
(0.08)\end{array}$ & $\begin{array}{c}-0.405^{*} \\
(0.22)\end{array}$ \\
\hline Distance & $\begin{array}{l}-0.272 \\
(0.32) \\
\end{array}$ & $\begin{array}{c}0.510^{* * *} \\
(0.18) \\
\end{array}$ & $\begin{array}{l}-0.263 \\
(0.18) \\
\end{array}$ & $\begin{array}{c}-1.485^{* * *} \\
(0.54) \\
\end{array}$ \\
\hline \multicolumn{5}{|l|}{ NFE } \\
\hline Number of Adults & $\begin{array}{c}0.039^{*} \\
(0.02)\end{array}$ & $\begin{array}{c}0.094^{* * *} \\
(0.02)\end{array}$ & $\begin{array}{c}0.153^{* * *} \\
(0.02)\end{array}$ & $\begin{array}{c}0.071^{* * *} \\
(0.01)\end{array}$ \\
\hline Female & $\begin{array}{l}0.106 \\
(0.09)\end{array}$ & $\begin{array}{l}-0.069 \\
(0.05)\end{array}$ & $\begin{array}{c}-0.163^{* *} \\
(0.08)\end{array}$ & $\begin{array}{l}-0.047 \\
(0.07)\end{array}$ \\
\hline Age & $\begin{array}{c}-0.011^{* * *} \\
(0.00)\end{array}$ & $\begin{array}{c}-0.007^{* * *} \\
(0.00)\end{array}$ & $\begin{array}{c}-0.005^{* * *} \\
(0.00)\end{array}$ & $\begin{array}{c}-0.016^{* * *} \\
(0.00)\end{array}$ \\
\hline Read \& Write & $\begin{array}{c}0.179^{* *} \\
(0.08)\end{array}$ & $\begin{array}{c}0.260^{* * * *} \\
(0.04)\end{array}$ & $\begin{array}{c}0.263^{* * *} \\
(0.06)\end{array}$ & $\begin{array}{l}0.045 \\
(0.05)\end{array}$ \\
\hline Credit & $\begin{array}{c}0.338^{* * *} \\
(0.08)\end{array}$ & $\begin{array}{c}0.320^{* * *} \\
(0.05)\end{array}$ & & \\
\hline Shock & $\begin{array}{l}0.069 \\
(0.07)\end{array}$ & $\begin{array}{c}0.084^{* *} \\
(0.04)\end{array}$ & $\begin{array}{r}-0.047 \\
(0.06)\end{array}$ & $\begin{array}{l}0.102 \\
(0.07)\end{array}$ \\
\hline Distance & $\begin{array}{c}-0.373^{* * * *} \\
(0.14)\end{array}$ & $\begin{array}{c}-0.401^{* * * *} \\
(0.10)\end{array}$ & $\begin{array}{c}-0.124 \\
(0.14) \\
\end{array}$ & $\begin{array}{l}0.218 \\
(0.21)\end{array}$ \\
\hline Agro-Ecological Zone & Yes & Yes & Yes & Yes \\
\hline $\mathrm{N}$ & 3,376 & 10,146 & 3,891 & 1,940 \\
\hline rho & -0.277 & -0.554 & -0.494 & -0.916 \\
\hline sigma & 1.577 & 1.407 & 1.423 & 2.897 \\
\hline lambda & -0.437 & -0.780 & -0.703 & -2.655 \\
\hline Prob > chi2 & 0.149 & 0.000 & 0.000 & 0.000 \\
\hline
\end{tabular}

Note(s): Standard errors in parentheses. Household weights included. Clustered at the household level. ${ }^{*} p<0.1,{ }^{* *} p<0.05,{ }^{* * *} p<0.01$. 


\section{A.4.3 Panel Data Analysis}

Table A.10: Panel Data Analysis (Rural)

\begin{tabular}{|c|c|c|c|c|c|c|}
\hline (ln) Productivity & $\begin{array}{c}(1) \\
\text { Nigeria } \\
\text { Enterprise }\end{array}$ & $\begin{array}{c}(2) \\
\text { Nigeria } \\
\text { Household }\end{array}$ & $\begin{array}{c}(3) \\
\text { Nigeria } \\
\text { Community }\end{array}$ & $\begin{array}{c}(4) \\
\text { Uganda } \\
\text { Enterprise }\end{array}$ & $\begin{array}{c}(5) \\
\text { Uganda } \\
\text { Household }\end{array}$ & $\begin{array}{c}(6) \\
\text { Uganda } \\
\text { Community }\end{array}$ \\
\hline Female & $\begin{array}{c}-0.807^{* * *} \\
(0.17)\end{array}$ & $\begin{array}{c}-0.837^{* * *} \\
(0.30)\end{array}$ & $\begin{array}{l}-0.228 \\
(0.56)\end{array}$ & $\begin{array}{c}-0.196 \\
(0.32)\end{array}$ & $\begin{array}{l}-0.217 \\
(0.40)\end{array}$ & $\begin{array}{l}-0.205 \\
(0.80)\end{array}$ \\
\hline Age & $\begin{array}{c}0.034^{* * *} \\
(0.01)\end{array}$ & $\begin{array}{l}0.019 \\
(0.02)\end{array}$ & $\begin{array}{l}0.036 \\
(0.05)\end{array}$ & $\begin{array}{c}0.109^{* * * *} \\
(0.03)\end{array}$ & $\begin{array}{c}0.065^{* *} \\
(0.03)\end{array}$ & $\begin{array}{l}0.154^{*} \\
(0.09)\end{array}$ \\
\hline $\mathrm{Age}^{2}$ & $\begin{array}{c}-0.000^{* * *} \\
(0.00)\end{array}$ & $\begin{array}{r}-0.000 \\
(0.00)\end{array}$ & $\begin{array}{r}-0.001 \\
(0.00)\end{array}$ & $\begin{array}{c}-0.001^{* * *} \\
(0.00)\end{array}$ & $\begin{array}{c}-0.001^{*} \\
(0.00)\end{array}$ & $\begin{array}{c}-0.002^{*} \\
(0.00)\end{array}$ \\
\hline Married & $\begin{array}{l}-0.020 \\
(0.13)\end{array}$ & $\begin{array}{c}-0.062 \\
(0.23)\end{array}$ & $\begin{array}{l}0.193 \\
(0.46)\end{array}$ & $\begin{array}{l}0.453^{*} \\
(0.24)\end{array}$ & $\begin{array}{l}0.151 \\
(0.30)\end{array}$ & $\begin{array}{c}1.448^{* *} \\
(0.66)\end{array}$ \\
\hline Female x Married & $\begin{array}{l}0.014 \\
(0.19)\end{array}$ & $\begin{array}{l}0.160 \\
(0.32)\end{array}$ & $\begin{array}{r}-0.489 \\
(0.62)\end{array}$ & $\begin{array}{l}-0.505 \\
(0.33)\end{array}$ & $\begin{array}{l}-0.219 \\
(0.41)\end{array}$ & $\begin{array}{r}-0.890 \\
(0.88)\end{array}$ \\
\hline Read \& Write & $\begin{array}{l}0.029 \\
(0.07)\end{array}$ & $\begin{array}{c}-0.061 \\
(0.10)\end{array}$ & $\begin{array}{r}-0.270 \\
(0.25)\end{array}$ & $\begin{array}{c}-0.095 \\
(0.16)\end{array}$ & $\begin{array}{c}-0.133 \\
(0.18)\end{array}$ & $\begin{array}{l}0.357 \\
(0.51)\end{array}$ \\
\hline Migration & & & & $\begin{array}{l}0.106 \\
(0.12)\end{array}$ & $\begin{array}{l}0.106 \\
(0.14)\end{array}$ & $\begin{array}{l}-0.421 \\
(0.41)\end{array}$ \\
\hline Number of Adults & $\begin{array}{l}-0.048 \\
(0.04)\end{array}$ & $\begin{array}{c}-0.045 \\
(0.04)\end{array}$ & $\begin{array}{c}-0.045 \\
(0.07)\end{array}$ & $\begin{array}{c}0.094^{* *} \\
(0.04)\end{array}$ & $\begin{array}{l}0.057 \\
(0.04)\end{array}$ & $\begin{array}{l}0.042 \\
(0.10)\end{array}$ \\
\hline Shock & $\begin{array}{l}0.106 \\
(0.09)\end{array}$ & $\begin{array}{l}0.072 \\
(0.07)\end{array}$ & $\begin{array}{l}0.073 \\
(0.18)\end{array}$ & $\begin{array}{c}-0.006 \\
(0.09)\end{array}$ & $\begin{array}{c}-0.068 \\
(0.10)\end{array}$ & $\begin{array}{l}-0.306 \\
(0.32)\end{array}$ \\
\hline Credit & $\begin{array}{c}0.326^{* * *} \\
(0.09)\end{array}$ & $\begin{array}{l}0.211^{*} \\
(0.12)\end{array}$ & $\begin{array}{l}-0.229 \\
(0.30)\end{array}$ & $\begin{array}{c}0.426^{* * *} \\
(0.13)\end{array}$ & $\begin{array}{c}0.394^{* * *} \\
(0.14)\end{array}$ & $\begin{array}{l}0.392 \\
(0.36)\end{array}$ \\
\hline Firm Size & $\begin{array}{c}-0.201^{* * *} \\
(0.04)\end{array}$ & $\begin{array}{c}-0.285^{* * *} \\
(0.04)\end{array}$ & $\begin{array}{c}-0.185^{* * *} \\
(0.06)\end{array}$ & $\begin{array}{c}-0.129^{* * *} \\
(0.03)\end{array}$ & $\begin{array}{c}-0.180^{* * *} \\
(0.03)\end{array}$ & $\begin{array}{c}-0.125 \\
(0.10)\end{array}$ \\
\hline Months in Operation & & & & $\begin{array}{l}0.035^{*} \\
(0.02)\end{array}$ & $\begin{array}{c}0.037^{* *} \\
(0.02)\end{array}$ & $\begin{array}{l}0.064 \\
(0.04)\end{array}$ \\
\hline Constant & $\begin{array}{c}8.177^{* * *} \\
(0.26)\end{array}$ & $\begin{array}{c}8.828^{* * *} \\
(0.48)\end{array}$ & $\begin{array}{c}8.347^{* * *} \\
(1.09)\end{array}$ & $\begin{array}{c}7.914^{* * *} \\
(0.73)\end{array}$ & $\begin{array}{c}8.991^{* * *} \\
(0.67)\end{array}$ & $\begin{array}{c}6.168^{* * *} \\
(1.93)\end{array}$ \\
\hline $\begin{array}{l}\text { Time FE } \\
\text { FE }\end{array}$ & $\begin{array}{l}\text { Yes } \\
\text { Yes }\end{array}$ & $\begin{array}{l}\text { Yes } \\
\text { Yes }\end{array}$ & $\begin{array}{l}\text { Yes } \\
\text { Yes }\end{array}$ & $\begin{array}{l}\text { Yes } \\
\text { Yes }\end{array}$ & $\begin{array}{l}\text { Yes } \\
\text { Yes }\end{array}$ & $\begin{array}{l}\text { Yes } \\
\text { Yes }\end{array}$ \\
\hline $\begin{array}{l}\text { Female } \\
\text { Age } \\
\text { Married }\end{array}$ & $\begin{array}{l}0.000 \\
0.001 \\
0.988\end{array}$ & $\begin{array}{l}0.000 \\
0.583 \\
0.881\end{array}$ & $\begin{array}{l}0.100 \\
0.141 \\
0.705\end{array}$ & $\begin{array}{l}0.000 \\
0.001 \\
0.172\end{array}$ & $\begin{array}{l}0.065 \\
0.099 \\
0.864\end{array}$ & $\begin{array}{l}0.062 \\
0.134 \\
0.056\end{array}$ \\
\hline $\mathrm{N}$ & 4,805 & 3,116 & 558 & 3,228 & 2,650 & 658 \\
\hline
\end{tabular}

Note $(s)$ : Standard errors in parentheses. Household weights included. ${ }^{*} p<0.1,{ }^{* *} p<0.05,{ }^{* * *}$ $p<0.01$. 

Appendix B

\section{Unemployment Insurance Savings}

Accounts 


\section{B.1 Overview UISA Scheme}

Figure B.1: Permanent Contract

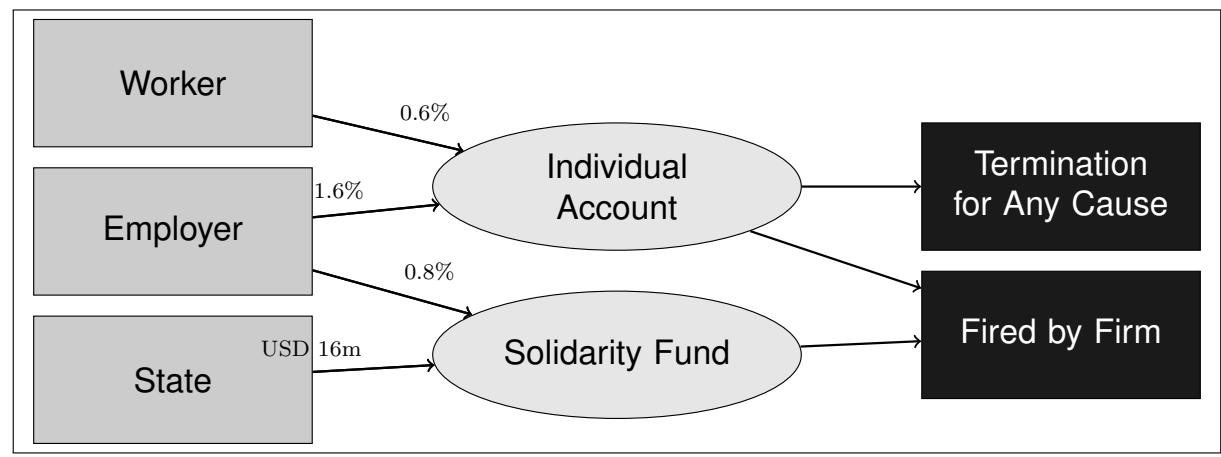

Figure B.2: Temporary Contract

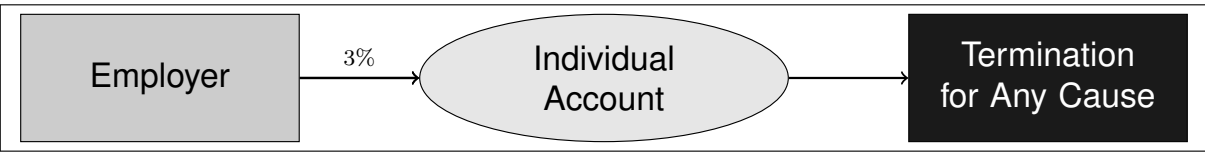

Note(s): Berstein et al. (2012, p.263). 


\section{B.2 Summary Statistics}

\section{B.2.1 Employment Duration}

Table B.1: Summary Statistics

\begin{tabular}{|c|c|c|c|c|}
\hline VARIABLE & $\begin{array}{r}\text { Number of } \\
\text { observations }\end{array}$ & Mean overall & $\begin{array}{r}\text { Mean before } \\
\text { UISA }\end{array}$ & $\begin{array}{r}\text { Mean after } \\
\text { UISA }\end{array}$ \\
\hline \multicolumn{5}{|l|}{ Binary Variables } \\
\hline Temporary Contract & 2,323 & $\begin{array}{r}0.50 \\
(0.50)\end{array}$ & $\begin{array}{r}\mathbf{0 . 4 7} \\
(0.50)\end{array}$ & $\begin{array}{r}\mathbf{0 . 5 6} \\
(0.50)\end{array}$ \\
\hline Female & 2,323 & $\begin{array}{r}0.38 \\
(0.48)\end{array}$ & $\begin{array}{r}0.36 \\
(0.48)\end{array}$ & $\begin{array}{r}0.40 \\
(0.49)\end{array}$ \\
\hline Knowledge of UISA & 2,323 & $\begin{array}{r}0.78 \\
(0.42)\end{array}$ & $\begin{array}{r}0.77 \\
(0.42)\end{array}$ & $\begin{array}{r}0.79 \\
(0.41)\end{array}$ \\
\hline Metropolitan Region & 2,323 & $\begin{array}{r}0.36 \\
(0.48)\end{array}$ & $\begin{array}{r}0.36 \\
(0.48)\end{array}$ & $\begin{array}{r}0.36 \\
(0.48)\end{array}$ \\
\hline UISA & 2,323 & $\begin{array}{r}0.36 \\
(0.48)\end{array}$ & $\begin{array}{r}\mathbf{0} \\
(0.00)\end{array}$ & $\begin{array}{r}1 \\
(0.00)\end{array}$ \\
\hline Married & 2,210 & $\begin{array}{r}0.56 \\
(0.50)\end{array}$ & $\begin{array}{r}\mathbf{0 . 5 8} \\
(0.49)\end{array}$ & $\begin{array}{r}\mathbf{0 . 5 2} \\
(0.50)\end{array}$ \\
\hline Categorical Variables & & & & \\
\hline Education Categories & 2,319 & $\begin{array}{r}1.90 \\
(0.83)\end{array}$ & $\begin{array}{r}1.88 \\
(0.83)\end{array}$ & $\begin{array}{r}1.94 \\
(0.83)\end{array}$ \\
\hline Wage Categories & 2,032 & $\begin{array}{r}3.09 \\
(0.83)\end{array}$ & $\begin{array}{r}\mathbf{3 . 0 5} \\
(0.88)\end{array}$ & $\begin{array}{r}\mathbf{3 . 1 5} \\
(0.75)\end{array}$ \\
\hline Next Event & 1,980 & $\begin{array}{r}1.76 \\
(0.71)\end{array}$ & $\begin{array}{r}1.77 \\
(0.72)\end{array}$ & $\begin{array}{r}1.74 \\
(0.70)\end{array}$ \\
\hline Continuous Variables & & & & \\
\hline Age & 2,323 & $\begin{array}{r}33.15 \\
(11.39)\end{array}$ & $\begin{array}{r}33.38 \\
(11.61)\end{array}$ & $\begin{array}{r}32.73 \\
(10.98)\end{array}$ \\
\hline Children & 2,323 & $\begin{array}{r}0.89 \\
(0.74)\end{array}$ & $\begin{array}{r}0.89 \\
(0.70)\end{array}$ & $\begin{array}{r}0.90 \\
(0.81)\end{array}$ \\
\hline Employment Duration & 2,323 & $\begin{array}{r}28.64 \\
(29.26)\end{array}$ & $\begin{array}{r}\mathbf{3 1 . 9 4} \\
(30.81)\end{array}$ & $\begin{array}{r}\mathbf{2 2 . 7 5} \\
(25.23)\end{array}$ \\
\hline Firm Size & 2,294 & $\begin{array}{r}18.76 \\
(282.75)\end{array}$ & $\begin{array}{r}14.97 \\
(160.78)\end{array}$ & $\begin{array}{r}25.49 \\
(419.52)\end{array}$ \\
\hline Hours & 2,296 & $\begin{array}{r}48.48 \\
(8.47)\end{array}$ & $\begin{array}{r}48.44 \\
(8.40)\end{array}$ & $\begin{array}{r}48.53 \\
(8.61)\end{array}$ \\
\hline Household Size & 2,323 & $\begin{array}{r}4.77 \\
(2.09)\end{array}$ & $\begin{array}{r}\mathbf{4 . 6 8} \\
(2.08)\end{array}$ & $\begin{array}{r}4.93 \\
(2.09)\end{array}$ \\
\hline Risk Aversion & 2,293 & $\begin{array}{r}5.48 \\
(3.18)\end{array}$ & $\begin{array}{r}5.47 \\
(3.20)\end{array}$ & $\begin{array}{r}5.49 \\
(3.14)\end{array}$ \\
\hline Working Household Members & 2,323 & $\begin{array}{r}0.98 \\
(0.97)\end{array}$ & $\begin{array}{r}\mathbf{0 . 9 4} \\
(0.95)\end{array}$ & $\begin{array}{r}\mathbf{1 . 0 6} \\
(0.98) \\
\end{array}$ \\
\hline
\end{tabular}

Note(s): Standard deviation in row below the mean. Coefficients in bold indicate differences between workers before and after UISA introduction that are significant at the 5 percent level. 14 observations of variable "hours" changed to missing, as workers reported to work over 84 hours per week. 


\section{Definition of Variables}

Temporary Contract Temporary contract $(=1)$; the category temporary contract includes the following contract types: temporary, seasonal, occasional, probationary.

Female Gender of the worker, female $(=1)$.

Knowledge of UISA

Self-reported answer. Worker knows or has heard of the UISA scheme $(=1)$.

Metropolitan Region

UISA

Residency in Santiago $(=1)$ at the moment employment was started.

Married

Start of employment in October 2002 or after that date $(=1)$. As affiliation to UISA is mandatory for employment relations that started in October 2002 or after that date, I allocate UISA $(=1)$ to all workers starting an employment in the corresponding time period.

Married (=1) if married or cohabiting at the moment employment was started.

Education

Wage

Four categories in education are defined as follows: basic $(=1)$ includes illiterate workers and workers with primary education; high school (=2) includes workers who obtained a high school degree from two different tracks (scientific-humanist and technical); professional formation $(=3)$ includes workers who obtained a degree in a technical institute or an institute for professional formation; university and higher $(=4)$ includes workers with a university degree (bachelor, master, post-graduate).

The five wage categories are defined as follows (in 1,000s): zero wage $(=0) ;<100$ CLP $(=1) ; 100-200$ CLP $(=2) ; 200-300$ CLP $(=3)$; and $>300$ CLP $(=4)$. Exchange rate on 23 July 2015: 1 $\mathrm{USD}=654$ CLP [www.xe.com].

Next Event After terminating the current employment relation the workers in this sample exit into three different "states": new employment $(=1)$, unemployment $(=2)$, inactivity $(=3)$.

Age

Children

Employment

Duration Age of the worker in years at the moment employment was started. Only individuals 18 years and older.

Number of children living in the household (15 years or younger).

Duration of employment in months (censored for 343 observations and therefore still ongoing at the moment of the last survey round).

Firm Size

Hours

Household Size

Risk Aversion

Working Household Number of workers in the firm where the worker is employed. Average number of hours worked per week.

Number of household members.

Measured by asking survey participants about their individual risk assessment on a scale from 0 (for individuals considering themselves as highly risk averse) to 10 (for individuals stating they are highly disposed to take risk). 


\section{B.2.2 Subsequent Employment Quality}

Table B.2: Summary Statistics - Post-Employment

\begin{tabular}{|c|c|c|c|c|}
\hline VARIABLE & $\begin{array}{r}\text { Number of } \\
\text { observations }\end{array}$ & $\begin{array}{r}\text { Mean } \\
\text { overall }\end{array}$ & $\begin{array}{r}\text { Mean } \\
\text { before UISA }\end{array}$ & $\begin{array}{r}\text { Mean } \\
\text { after UISA } \\
\end{array}$ \\
\hline \multicolumn{5}{|l|}{ Binary Variables } \\
\hline Female & 1,562 & $\begin{array}{r}0.27 \\
(0.44)\end{array}$ & $\begin{array}{r}0.27 \\
(0.44)\end{array}$ & $\begin{array}{r}0.26 \\
(0.44)\end{array}$ \\
\hline Knowledge of UISA & 1,562 & $\begin{array}{r}0.18 \\
(0.39)\end{array}$ & $\begin{array}{r}0.18 \\
(0.39)\end{array}$ & $\begin{array}{r}0.18 \\
(0.39)\end{array}$ \\
\hline Married & 1,500 & $\begin{array}{r}0.58 \\
(0.49)\end{array}$ & $\begin{array}{r}0.58 \\
(0.49)\end{array}$ & $\begin{array}{r}0.57 \\
(0.49)\end{array}$ \\
\hline Metropolitan Region & 1,562 & $\begin{array}{r}0.37 \\
(0.48)\end{array}$ & $\begin{array}{r}0.37 \\
(0.48)\end{array}$ & $\begin{array}{r}0.36 \\
(0.48)\end{array}$ \\
\hline Permanent Contract & 1,562 & $\begin{array}{r}0.55 \\
(0.50)\end{array}$ & $\begin{array}{r}\mathbf{0 . 5 9} \\
(0.49)\end{array}$ & $\begin{array}{r}\mathbf{0 . 5 0} \\
(0.50)\end{array}$ \\
\hline UISA & 1,562 & $\begin{array}{r}0.42 \\
(0.49)\end{array}$ & $\begin{array}{r}\mathbf{0 . 0 0} \\
(0.00)\end{array}$ & $\begin{array}{r}1.00 \\
(0.00)\end{array}$ \\
\hline Categorical Variabl & & & & \\
\hline Education Categories & 1,561 & $\begin{array}{r}1.97 \\
(0.83)\end{array}$ & $\begin{array}{r}1.97 \\
(0.85)\end{array}$ & $\begin{array}{r}1.96 \\
(0.80)\end{array}$ \\
\hline Continuous Variabl & & & & \\
\hline Age & 1,562 & $\begin{array}{r}32.27 \\
(10.69)\end{array}$ & $\begin{array}{r}\mathbf{3 1 . 8 0} \\
(10.82)\end{array}$ & $\begin{array}{r}32.91 \\
(10.49)\end{array}$ \\
\hline Children & 1,562 & $\begin{array}{r}0.89 \\
(0.75)\end{array}$ & $\begin{array}{r}\mathbf{0 . 8 4} \\
(0.71)\end{array}$ & $\begin{array}{r}\mathbf{0 . 9 5} \\
(0.80)\end{array}$ \\
\hline Firm Size & 1,562 & $\begin{array}{r}5.90 \\
(4.64)\end{array}$ & $\begin{array}{r}\mathbf{5 . 5 2} \\
(4.37)\end{array}$ & $\begin{array}{r}\mathbf{6 . 4 3} \\
(4.92)\end{array}$ \\
\hline Household Size & 1,562 & $\begin{array}{r}4.80 \\
(2.11)\end{array}$ & $\begin{array}{r}4.69 \\
(2.13)\end{array}$ & $\begin{array}{r}4.94 \\
(2.07)\end{array}$ \\
\hline Wage & 1,447 & $\begin{array}{r}178.17 \\
(135.65)\end{array}$ & $\begin{array}{r}\mathbf{1 6 9 . 8 8} \\
(138.33)\end{array}$ & $\begin{array}{r}\mathbf{1 8 8 . 4 1} \\
(131.65)\end{array}$ \\
\hline Risk Aversion & 1,544 & $\begin{array}{r}5.73 \\
(3.10)\end{array}$ & $\begin{array}{r}5.70 \\
(3.06)\end{array}$ & $\begin{array}{r}5.77 \\
(3.15)\end{array}$ \\
\hline
\end{tabular}

Note $(s)$ : Standard deviation in row below the mean. Coefficients in bold indicate differences between workers before and after UISA introduction that are significant at the 5 percent level. Wages and firm size are winsorized at 1 percent. 
Table B.3: Summary Statistics - Post-Unemployment

\begin{tabular}{lrrrr}
\hline VARIABLE & $\begin{array}{r}\text { Number of } \\
\text { observations }\end{array}$ & $\begin{array}{r}\text { Mean } \\
\text { overall }\end{array}$ & $\begin{array}{r}\text { Mean } \\
\text { before UISA }\end{array}$ & $\begin{array}{r}\text { Mean } \\
\text { after UISA }\end{array}$ \\
\hline Binary Variables & & & & \\
Female & 1,281 & 0.38 & $\mathbf{0 . 3 3}$ & $\mathbf{0 . 4 3}$ \\
& & $(0.48)$ & $(0.47)$ & $(0.49)$ \\
Knowledge of UISA & 1,281 & 0.21 & 0.21 & 0.20 \\
Married & & $(0.40)$ & $(0.41)$ & $(0.40)$ \\
Metropolitan Region & 1,233 & 0.52 & $\mathbf{0 . 5 5}$ & $\mathbf{0 . 4 9}$ \\
Permanent Contract & & $(0.50)$ & $(0.50)$ & $(0.50)$ \\
UISA & 1,281 & 0.34 & $\mathbf{0 . 3 7}$ & $\mathbf{0 . 3 0}$ \\
& & $(0.47)$ & $(0.48)$ & $(0.46)$ \\
Categorical Variables & 1,281 & 0.33 & $\mathbf{0 . 4 0}$ & $\mathbf{0 . 2 4}$ \\
Education Categories & & $(0.47)$ & $(0.49)$ & $(0.43)$ \\
& 1,281 & 0.47 & $\mathbf{0 . 0 0}$ & $\mathbf{1 . 0 0}$ \\
Continuous Variables & & $(0.50)$ & $(0.00)$ & $(0.00)$ \\
Age & 1,276 & & & \\
& & 1.73 & 1.76 & 1.69 \\
Children & & $(0.73)$ & $(0.73)$ & $(0.74)$ \\
Firm Size & 1,281 & 32.31 & $\mathbf{3 1 . 4 6}$ & $\mathbf{3 3 . 2 7}$ \\
Household Size & & $(10.65)$ & $(10.50)$ & $(10.73)$ \\
Wage & 1,281 & 0.86 & 0.86 & 0.86 \\
Risk Aversion & & $(0.71)$ & $(0.68)$ & $(0.74)$ \\
& 1,569 & 6.16 & $\mathbf{5 . 5 9}$ & $\mathbf{6 . 8 2}$ \\
& & $(4.45)$ & $(3.49)$ & $(5.26)$ \\
& & 4.78 & $\mathbf{4 . 6 4}$ & $\mathbf{4 . 9 4}$ \\
& & $(2.05)$ & $(1.94)$ & $(2.15)$ \\
& & 149.11 & 148.83 & 149.32 \\
& & $(97.19)$ & $(93.23)$ & $(100.18)$ \\
& & 5.31 & 5.41 & 5.20 \\
& & & $(3.22)$ & $(3.30)$ \\
\hline & & & &
\end{tabular}

Note(s): Standard deviation in row below the mean. Coefficients in bold indicate differences between workers before and after UISA introduction that are significant at the 5 percent level. Wages and firm size are winsorized at 1 percent. 


\section{Definition of Variables}

Female Gender of the worker, female $(=1)$.

Knowledge of UISA Self-reported answer. Worker knows or has heard of the UISA scheme $(=1)$.

Married If married or cohabiting at the moment employment was started $(=1)$.

Metropolitan Region Residency in Santiago at the moment employment was started $(=1)$.

Permanent Contract Permanent contract $(=1)$. Temporary contracts include the following contract types: temporary, seasonal, occasional, probationary.

UISA

Start of employment in October 2002 or after that date $(=1)$. As affiliation to UISA is mandatory for employment relations that started in October 2002 or after that date, I allocate UISA $(=1)$ to all workers starting an employment in the corresponding time period.

Education Four categories in education are defined as follows: basic education $(=1)$ includes illiterate workers and workers with primary education, high school $(=2)$ includes workers who obtained a high school degree from two different tracks (scientific-humanist and technical), professional formation $(=3)$ includes workers who obtained a degree in a technical institute or an institute for professional formation, university and higher $(=4)$ includes workers with a university degree (bachelor, master, post-graduate).

Age Age of the worker in years at the moment employment was started. Only individuals 18 years and older.

Children Number of children living in the household (15 years or younger).

Firm Size

Hours Number of workers in the firm where the worker is employed.

Household Size Average number of hours worked per week.

Wage Number of household members.

Average monthly net wage (in 1,000s CLP). Exchange rate on 23 July 2015: 1 USD = 654 CLP [www.xe.com].

Risk Aversion Measured by asking survey participants about their individual risk assessment on a scale from 0 (for individuals considering themselves as highly risk averse) to 10 (for individuals stating they are highly disposed to take risk). 


\section{B.3 Test of PH Assumption}

Table B.4: Test of Proportional Hazards Assumption - Multiple Cox Regression

Time: $\log (\mathrm{t})$

\begin{tabular}{|c|c|c|c|}
\hline VARIABLE & Base Specification & Final Model & Interactions \\
\hline & \multicolumn{3}{|c|}{ Schoenfeld Residuals } \\
\hline UISA & 0.819 & 0.001 & 0.978 \\
\hline Female & 0.039 & 0.081 & 0.149 \\
\hline Age & 0.034 & 0.036 & 0.022 \\
\hline Temp. Contract & 0.000 & 0.000 & 0.000 \\
\hline $\begin{array}{l}\text { Education } \\
\text { - High School } \\
\text { - Prof. Formation } \\
\text { - Univ. and Higher }\end{array}$ & $\begin{array}{l}0.556 \\
0.833 \\
0.701\end{array}$ & $\begin{array}{r}0.759 \\
0.956 \\
0.159\end{array}$ & $\begin{array}{l}0.630 \\
0.476 \\
0.058\end{array}$ \\
\hline Hours & & 0.069 & 0.108 \\
\hline $\begin{array}{l}\text { Wage } \\
-100,000 \text { CLP } \\
-200,000 \text { CLP } \\
-300,000 \text { CLP } \\
>300,000 \text { CLP }\end{array}$ & & $\begin{array}{l}0.017 \\
0.002 \\
0.000 \\
0.001\end{array}$ & $\begin{array}{l}0.002 \\
0.000 \\
0.000 \\
0.000\end{array}$ \\
\hline Household Size & & 0.188 & 0.278 \\
\hline $\begin{array}{l}\text { UISA x Temp. Contract } \\
\text { UISA x High School } \\
\text { UISA x Prof. Formation } \\
\text { UISA x Univ. and Higher }\end{array}$ & & & $\begin{array}{l}0.413 \\
0.370 \\
0.970 \\
0.584\end{array}$ \\
\hline Global Test & 0.000 & 0.000 & 0.000 \\
\hline
\end{tabular}


Table B.5: Test of Proportional Hazards Assumption - Competing-Risk

Time: $\log (\mathrm{t})$

\begin{tabular}{lccc}
\hline VARIABLE & $T_{1}$ - Employment & $T_{2}$ - Unemployment & $T_{3}$ - Inactivity \\
\hline & \multicolumn{3}{c}{ Schoenfeld Residuals } \\
UISA & 0.694 & 0.018 & 0.016 \\
Female & 0.087 & 0.031 & 0.238 \\
Age & 0.581 & 0.309 & 0.000 \\
Temp. Contract & 0.000 & 0.000 & 0.005 \\
Education & & & \\
- High School & 0.117 & 0.446 & 0.101 \\
- Prof. Formation & 0.089 & 0.315 & 0.355 \\
- Univ. and Higher & 0.237 & 0.472 & 0.000 \\
Hours & 0.199 & 0.158 & 0.474 \\
Wage & & & \\
- 100,000 CLP & 0.182 & 0.753 & 0.594 \\
- 200,000 CLP & 0.032 & 0.876 & 0.458 \\
- 300,000 CLP & 0.024 & 0.616 & 0.332 \\
$>$ 300,000 CLP & 0.040 & 0.870 & 0.095 \\
Household Size & 0.327 & 0.186 & 0.123 \\
\hline Global Test & 0.000 & 0.000 & 0.000 \\
\hline
\end{tabular}

Note(s): The PH test is based on the final model. 


\section{B.4 Stratified Cox Model}

Table B.6: Stratified Cox Model

\begin{tabular}{|c|c|c|c|}
\hline VARIABLE & Base Specification & Final Model & Interactions \\
\hline & \multicolumn{3}{|c|}{ Coefficients } \\
\hline $\begin{array}{l}\text { UISA } \\
\text { - UISA Marg. Effect }\end{array}$ & $0.255^{* * *}$ & $0.541^{* * *}$ & $\begin{array}{l}0.589^{* * *} \\
0.518^{* * *}\end{array}$ \\
\hline Female & $0.265^{* * *}$ & $0.2160^{* *}$ & $0.196^{* * *}$ \\
\hline Age & $-0.005^{* * *}$ & - & - \\
\hline Temp. Contract & - & - & - \\
\hline $\begin{array}{l}\text { Education } \\
\text { - High School } \\
\text { - Prof. Formation } \\
\text { - Univ. and Higher }\end{array}$ & $\begin{array}{r}-0.180^{* * *} \\
-0.227^{* *} \\
-0.442^{* * *}\end{array}$ & $\begin{array}{r}-0.144^{* *} \\
0.013 \\
-0.151\end{array}$ & $\begin{array}{r}-0.037 \\
0.120 \\
-0.001\end{array}$ \\
\hline Hours & & - & 0.012 \\
\hline $\begin{array}{l}\text { Wage } \\
-100,000 \text { CLP } \\
-200,000 \text { CLP } \\
-300,000 \text { CLP } \\
>300,000 \text { CLP }\end{array}$ & & $\begin{array}{r}-0.017 \\
-0.274 \\
-0.540^{* *} \\
-0.561^{* *}\end{array}$ & $\begin{array}{r}-0.020 \\
-0.284 \\
-0.539^{* *} \\
-0.582^{* *}\end{array}$ \\
\hline Household Size & & -0.016 & -0.014 \\
\hline $\begin{array}{l}\text { UISA x Temp. Contract } \\
\text { UISA x High School } \\
\text { UISA x Prof. Formation } \\
\text { UISA x Univ. and Higher }\end{array}$ & & & $\begin{array}{r}0.246^{*} \\
-0.260^{* *} \\
-0.262 \\
-0.385 \\
\end{array}$ \\
\hline Strata & & & \\
\hline Age & - & Yes & Yes \\
\hline Contract Type & Yes & Yes & Yes \\
\hline Hours & - & Yes & Yes \\
\hline Global PH Test & 0.1822 & 0.8125 & 0.7166 \\
\hline Log Likelihood & $-12,546$ & $-2,417$ & $-2,413$ \\
\hline AIC & 25,103 & 4,854 & 4,854 \\
\hline Pseudo $R^{2}$ & 0.003 & 0.020 & 0.021 \\
\hline Wald Test Education & 0.000 & 0.107 & 0.059 \\
\hline Wald Test Wage & & 0.000 & 0.000 \\
\hline Employment Exit & 1,976 & 1,691 & 1,691 \\
\hline At Risk & 66,484 & 63,986 & 63,986 \\
\hline $\mathrm{N}$ & 2,319 & 2,028 & 2,028 \\
\hline
\end{tabular}

Note(s): ${ }^{*} p<0.1,{ }^{* *} p<0.05,{ }^{* * *} p<0.01$. 
Table B.7: Stratified Cox Model - Competing Risk

\begin{tabular}{|c|c|c|c|}
\hline VARIABLE & $T_{1}$ - Employment & $T_{2}$ - Unemployment & $T_{3}$ - Inactivity \\
\hline & \multicolumn{3}{|c|}{ Coefficients } \\
\hline UISA & $0.355^{* * *}$ & $0.563^{* * *}$ & $0.605^{* * *}$ \\
\hline Female & $-0.345^{* * *}$ & $0.368^{* * * *}$ & $1.251^{* * *}$ \\
\hline Age & - & - & - \\
\hline Temp. Contract & - & - & - \\
\hline \multicolumn{4}{|l|}{ Education } \\
\hline - High School & 0.113 & $-0.230 * *$ & $-0.426 * *$ \\
\hline - Prof. Formation & $0.277^{*}$ & $-0.472^{* *}$ & 0.238 \\
\hline - Univ. and Higher & 0.128 & $-0.740^{* * *}$ & 0.338 \\
\hline Hours & -0.002 & $0.017^{* * *}$ & 0.007 \\
\hline \multicolumn{4}{|l|}{ Wage } \\
\hline - 100,000 CLP & $-0.591^{* *}$ & 0.484 & 0.773 \\
\hline - 200,000 CLP & $-0.784^{* * *}$ & 0.198 & 0.143 \\
\hline - 300,000 CLP & $-0.979 * * *$ & -0.114 & -0.553 \\
\hline$>300,000$ CLP & $-0.915^{* * *}$ & -0.429 & -0.769 \\
\hline Household Size & 0.000 & -0.015 & -0.055 \\
\hline \multicolumn{4}{|l|}{ Strata } \\
\hline Age & Yes & Yes & Yes \\
\hline Temp. Contract & Yes & Yes & Yes \\
\hline Global PH Test & 0.4307 & 0.2553 & 0.4192 \\
\hline Log Likelihood & $-1,941$ & $-1,745$ & -553 \\
\hline AIC & 3,904 & 3,512 & 1,128 \\
\hline Pseudo $R^{2}$ & 0.011 & 0.035 & 0.110 \\
\hline Wald Test Education & 0.319 & 0.001 & 0.002 \\
\hline Wald Test Wage & 0.002 & 0.000 & 0.000 \\
\hline Employment Exit & 741 & 689 & 240 \\
\hline At Risk & 63,427 & 63,427 & 63,427 \\
\hline $\mathrm{N}$ & 2,006 & 2,006 & 2,006 \\
\hline
\end{tabular}

Note(s): ${ }^{*} p<0.1,{ }^{* *} p<0.05,{ }^{* * *} p<0.01$. 


\section{B.5 Robustness}

\section{B.5.1 Extended Sample}

The extended sample includes workers starting a new employment during the two years before or during the two years after UISA introduction, in contrast to the sample of the main analysis that included workers starting a new employment during the year before or the year after UISA introduction. 2,473 workers started their employment during the two years before, and 1,814 workers during the two years after UISA introduction, containing 2,770 single individuals.

Using the extended sample, the analysis (using the semi-parametric Cox model) is replicated in Table B.8, including the simple model (1), the base specification (2), the final regression (3) and the regression with interactions (4). The coefficients report qualitatively the same results as the one-year analysis: UISA affiliation is statistically significant at the 1 percent level throughout the regressions and increases the hazard of leaving employment. Quantitatively, hazard rates are lower compared to the one-year sample, the differences however moderate: in the final model, for example, the one-year analysis reports an elevated hazard of 67.7 percent, while in the two-year analysis the hazard is increased by 54.2 percent.

In the regressions (5) to (8) I additionally include year dummies for workers starting one or two years before the introduction of UISA, and one or two years after the introduction. Year dummies for year one or two after UISA introduction are not statistically different from each other and are combined in the UISA variable. The dummy variable "Year Dummy" in the regression output contains workers who started two years before the UISA introduction, with the reference category referring to all workers who started in the year before. Interpreting these regression results, workers who started a new employment two years before the UISA introduction show an elevated hazard rate compared to workers who started a new employment in the year before. UISA affiliates of year one and two equally show an elevated hazard rate compared to the reference category. 


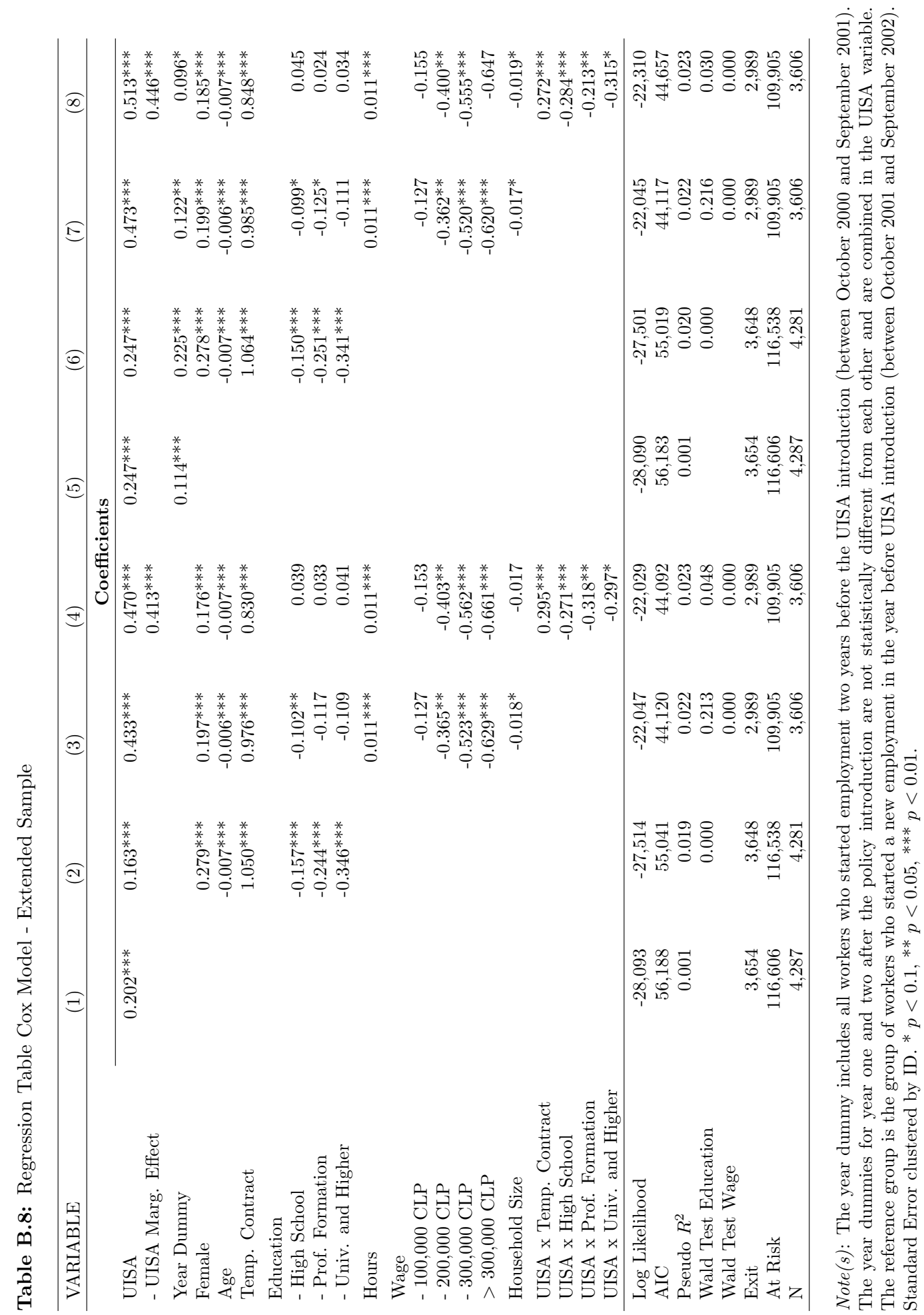




\section{B.5.2 Control Group - Public Sector Employees}

As control group I take a sample of public sector employees, since these workers were not affected by the policy introduction and can serve as a control group for this analysis. I equally separate them by the starting date of their employment "as if" they had experienced the policy introduction in October 2002.

In Table B.9 the variable UISA is used to indicate if the public sector employees started their employment during the year before or after October 2002 "as if" they had experienced the policy introduction. 107 employment relations were started during the year before October 2002, 78 during the year after that date, containing overall 172 individuals. Regressions (1) to (4) replicate the analysis using the semi-parametric Cox model including the simple model, the base specification, the final regression and the regression with interactions. In all regressions the UISA variable is not statistically significant, resulting in no significant difference in employment duration between both groups. Regressions (5) to (7) replicate the parametric models, using the generalized gamma distribution, as the AIC reported the lowest value for this shape. I take the same regressions as before, except of the interaction model: due to the relatively low number of observations, a discontinuous region was encountered and the regression could not be computed. In the parametric models, the UISA variable is equally not significant, resulting in no significant difference in employment duration between both groups.

The result of this section, however, must be interpreted with care: due to a considerably lower number of observations in the sample, the regression results are imprecisely estimated. The coefficients are still smaller compared to the private sector employees. 
Table B.9: Regression Table Cox Model - Control Group

\begin{tabular}{|c|c|c|c|c|c|c|c|}
\hline VARIABLE & (1) & $(2)$ & (3) & (4) & $(5)$ & $(6)$ & (7) \\
\hline & \multicolumn{4}{|c|}{ Coefficients } & \multicolumn{3}{|c|}{ Acceleration Parameters } \\
\hline $\begin{array}{l}\text { UISA } \\
\text { - UISA Marg. Effect }\end{array}$ & 0.126 & 0.109 & 0.274 & $\begin{array}{r}-0.438 \\
0.150\end{array}$ & -0.151 & -0.066 & -0.347 \\
\hline $\begin{array}{l}\text { Female } \\
\text { Age } \\
\text { Temp. Contract }\end{array}$ & & $\begin{array}{r}0.150 \\
-0.015^{*} \\
1.368^{* * *}\end{array}$ & $\begin{array}{r}0.172 \\
-0.015 \\
1.150^{* * *}\end{array}$ & $\begin{array}{r}0.156 \\
-0.022^{* *} \\
0.682^{* *}\end{array}$ & & $\begin{array}{r}-0.219 \\
0.022^{* *} \\
-1.795^{* * *}\end{array}$ & $\begin{array}{r}-0.109 \\
0.025^{* *} \\
-1.489^{* * *}\end{array}$ \\
\hline $\begin{array}{l}\text { Education } \\
\text { - High School } \\
\text { - Prof. Formation } \\
\text { - Univ. and Higher }\end{array}$ & & $\begin{array}{r}-0.307 \\
-0.678^{*} \\
0.108\end{array}$ & $\begin{array}{r}-0.545^{*} \\
-0.959^{* *} \\
-0.009\end{array}$ & $\begin{array}{r}-0.739^{*} \\
-0.439 \\
0.117\end{array}$ & & $\begin{array}{r}0.621^{* *} \\
0.909^{* *} \\
0.335\end{array}$ & $\begin{array}{r}0.785^{* *} \\
1.012^{* *} \\
0.534\end{array}$ \\
\hline Hours & & & -0.012 & -0.014 & & & $0.021^{*}$ \\
\hline $\begin{array}{l}\text { Wage } \\
\text { - 100,000 CLP } \\
\text { - 200,000 CLP } \\
\text { - 300,000 CLP } \\
>300,000 \text { CLP }\end{array}$ & & & $\begin{array}{l}-0.130 \\
-0.005 \\
-0.341 \\
-0.496\end{array}$ & $\begin{array}{l}-0.342 \\
-0.281 \\
-0.766 \\
-0.861\end{array}$ & & & $\begin{array}{r}-0.019 \\
-0.080 \\
0.185 \\
0.359\end{array}$ \\
\hline Household Size & & & $-0.136^{* *}$ & $-0.140 * *$ & & & $0.178^{* * *}$ \\
\hline $\begin{array}{l}\text { UISA x Temp. } \\
\text { Contract } \\
\text { UISA x High School } \\
\text { UISA x Prof. } \\
\text { Formation } \\
\text { UISA x Univ. and } \\
\text { Higher }\end{array}$ & & & & $\begin{array}{r}1.207^{* * *} \\
0.489 \\
-1.238 \\
-0.151\end{array}$ & & & \\
\hline Constant & & & & & $2.072^{* * *}$ & $2.642^{* * *}$ & 0.631 \\
\hline $\begin{array}{l}\ln s i g \\
\kappa\end{array}$ & & & & & $\begin{array}{r}0.457^{* * *} \\
-1.568^{* * *} \\
\end{array}$ & $\begin{array}{l}0.357^{* * *} \\
-0.668^{* *} \\
\end{array}$ & $\begin{array}{l}0.322^{* * *} \\
-0.718^{* *} \\
\end{array}$ \\
\hline$\sigma$ & & & & & 1.579 & 1.429 & 1.381 \\
\hline Log Likelihood & -624 & -592 & -521 & -514 & -308 & -275 & -245 \\
\hline $\begin{array}{l}\text { AIC } \\
\text { Pseudo } R^{2}\end{array}$ & 1,250 & 1,199 & 1,067 & 1,062 & 625 & 571 & 521 \\
\hline $\begin{array}{l}\text { Pseudo } R^{2} \\
\text { Wald Test Education }\end{array}$ & 0.000 & $\begin{array}{l}0.051 \\
0.044\end{array}$ & $\begin{array}{l}0.058 \\
0.053\end{array}$ & $\begin{array}{l}0.071 \\
0.114\end{array}$ & & 0.055 & 0.060 \\
\hline Wald Test Wage & & & 0.794 & 0.386 & & & 0.882 \\
\hline Exit & 132 & 132 & 119 & 119 & 132 & 132 & 119 \\
\hline At Risk & 6,887 & 6,887 & 6,506 & 6,506 & 6,887 & 6,887 & 6,506 \\
\hline $\mathrm{N}$ & 185 & 185 & 169 & 169 & 185 & 185 & 169 \\
\hline
\end{tabular}

Note(s): Public sector employees are divided by the start day of their employment (one year before or after October 2002) "as if" they had experienced the UISA introduction. For them, however, unemployment protection did not change and they were not affected by UISA introduction. Standard Error clustered by ID. ${ }^{*} p<0.1,{ }^{* *} p<0.05,{ }^{* * *} p<0.01$. 


\section{B.6 Ordered Probit Model}

Table B.10: Marginal Effects

\begin{tabular}{lcccccc}
\hline & \multicolumn{3}{c}{ Post-Employment } & \multicolumn{3}{c}{ Post-Unemployment } \\
$\Delta$ contract type & $(-1)$ & $(0)$ & $(+1)$ & $(-1)$ & $(0)$ & $(+1)$ \\
\hline UISA & -0.021 & 0.002 & 0.019 & -0.024 & 0.001 & 0.023 \\
& $(0.01)$ & $(0.00)$ & $(0.01)$ & $(0.01)$ & $(0.00)$ & $(0.01)$ \\
D2 & $-0.073^{* * *}$ & 0.007 & $0.065^{* * *}$ & $-0.066^{* *}$ & 0.002 & $0.064^{* *}$ \\
& $(0.03)$ & $(0.01)$ & $(0.02)$ & $(0.03)$ & $(0.00)$ & $(0.03)$ \\
Emp. Duration & $0.006^{* * *}$ & $-0.001^{*}$ & $-0.005^{* * *}$ & $0.005^{* * *}$ & -0.000 & $-0.005^{* * *}$ \\
& $(0.00)$ & $(0.00)$ & $(0.00)$ & $(0.00)$ & $(0.00)$ & $(0.00)$ \\
Same Sector & $-0.057^{* * *}$ & 0.006 & $0.051^{* * *}$ & -0.010 & -0.000 & 0.010 \\
\multirow{2}{*}{ Unemp. Duration } & $(0.02)$ & $(0.00)$ & $(0.02)$ & $(0.03)$ & $(0.00)$ & $(0.03)$ \\
& & & & 0.002 & -0.000 & -0.002 \\
& & & & $(0.00)$ & $(0.00)$ & $(0.00)$ \\
\hline $\mathrm{N}$ & 1,562 & 1,562 & 1,562 & 1,281 & 1,281 & 1,281 \\
\hline
\end{tabular}

Note(s): Marginal Effects are calculated for the models (3) and (6) of Table 7.3 and report the marginal effects for the three possible scenarios of contract type differences. Standard errors in parentheses and clustered at the individual level. $* p<0.1$, ** $p<0.05$, *** $p<0.01$. 


\section{B.7 Economic Cycle Chile}

During the time frame studied in Chapter 7, approximately the period from 2000 to 2009, Chile showed a stable economic performance. ${ }^{1}$ The country achieved macroeconomic stability and its per-capita income tripled by the end of the decade compared to 1990 . Furthermore the poverty-rate was cut by two-thirds through a reduction in economic vulnerabilities due to pro-poor policies (Simanovska and Söderling, 2008). After a cyclical slowdown from 1998 to 2003, growth has reinitialized since 2003 due to strong policy settings (OECD, 2007). The unemployment rate was approximately stable in the time period from which the sample is drawn, and only decreased in the years 2006 to 2008, before it increased again due to the world economic crisis. The business cycle was more volatile in 2000 and 2001, but has shown a reduced volatility since 2002, with a small peak in 2005 .

Even though the overall performance was rather stable in the decade from 2000 to 2010, the increased economic growth after 2003 could still affect wages and contract types due to the importance of the macroeconomic environment on labor market outcomes. However, during the time the sample is selected, the unemployment rate was stable. During the two years before UISA introduction, the unemployment rate ranged from 9.5 to 10.2 percent (average: 9.9 percent) and during the two years after from 9.2 to 10.5 percent (average: 9.8 percent).

Table B.11 provides a detailed overview of basic macroeconomic indicators describing the Chilean economic cycle, Figure B.3 shows the volatility of the business cycle from 2000 to 2007, and Figure B.4 the unemployment rate from 2000 to 2010.

Table B.11: Basic Macroeconomic Indicators - Overview

\begin{tabular}{lrrrrrr}
\hline & 2001 & 2002 & 2003 & 2004 & 2005 & 2006 \\
\hline GDP Growth Rate (real, in \%) & 3.4 & 2.2 & 4.0 & 6.0 & 5.7 & 4.0 \\
Nom. Budget Balance (in \% of GDP) & -0.5 & -1.2 & -0.4 & 2.1 & 4.7 & 7.9 \\
Current Account Balance (in \% of GDP) & -1.6 & -0.9 & -1.1 & 2.2 & 1.1 & 3.6 \\
Exchange Rate (CLP per USD, period avg) & 634.9 & 688.9 & 691.4 & 609.5 & 559.8 & 530.3 \\
CPI Inflation (IPC, in \%, end of period) & 2.6 & 2.8 & 1.1 & 2.4 & 3.7 & 2.6 \\
Unemployment Rate (in \%) & 9.9 & 9.8 & 9.5 & 10.0 & 9.2 & 7.8 \\
\hline
\end{tabular}

Note(s): OECD (2007), OECD Economic Surveys Chile (based on: Central Bank of Chile, Instituto Nacional de Estadísticas and Ministry of Finance).

1 Time period studied: two years before UISA introduction in October 2002 until the last survey round was conducted in 2009 . 
Figure B.3: Business Cycle Volatility

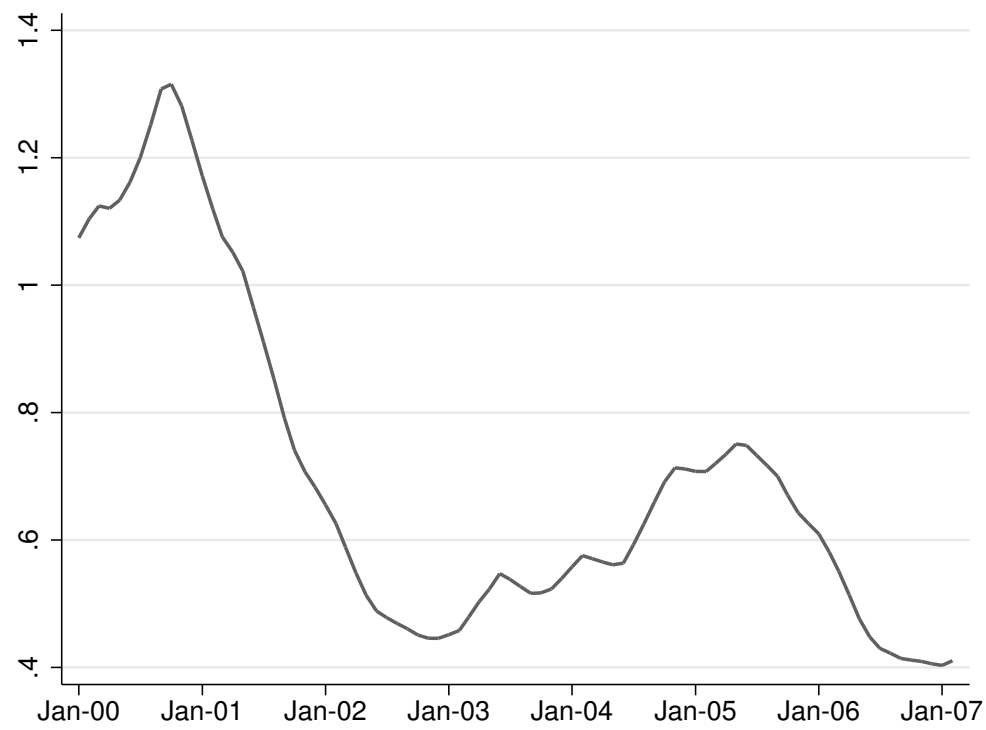

Note(s): OECD (2007), OECD Economic Surveys Chile (based on: Ministry of Finance, Central Bank of Chile and OECD calculations). Business cycle volatility is defined as the 12-months moving average of the standard deviation (calculated over 12 months) of the output gap, defined as the percentage difference between the seasonally adjusted IMACEC index (monthly indicator of economic activity) and its trend. 
Figure B.4: Unemployment Rate

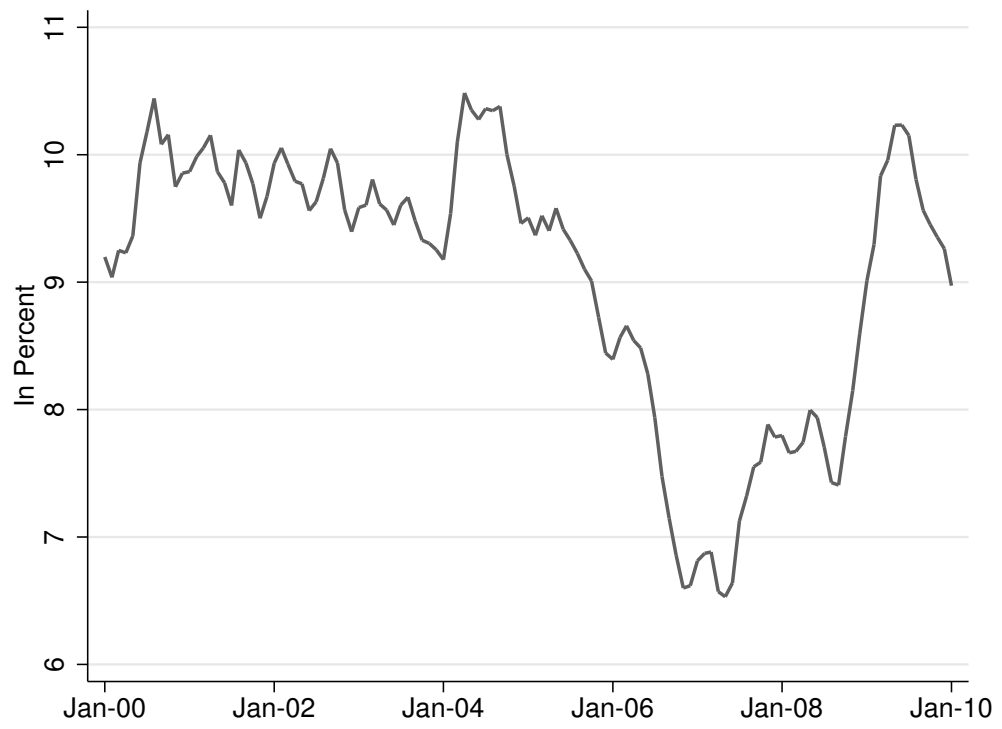

Note(s): OECD (2013), Unemployment rates (indicator). doi: 10.1787/997c8750-en (Accessed on 13 November 2014). 



\section{Valorization}

This thesis analyzes and discusses two examples of occupational choice within the labor market framework of developing economies. How can the results of this research effort be used as a helpful component in shaping future research and policies?

Labor provides the main and often only source of household income around the world. As a consequence, the occupational choices of household members determine their labor allocation and income, and thus their livelihoods. This thesis provides new insights for researchers, as well as for policy makers, to understand and shape labor market conditions that facilitate a more favorable framework and that allow workers to generate sufficient income under good working conditions in emerging and developing economies.

For the first theme, entrepreneurship in Sub-Saharan Africa, the thesis provides new insights in two areas where limited knowledge has so far existed. First, on the patterns and determinants of enterprise operation: I describe the nature of rural entrepreneurship in six African countries, and identify which individual, household and location characteristics are significant to enter the sector and to operate an enterprise. Second, on the performance of these enterprises: I identify the individual, household and location characteristics that have an impact on the success of business operation, measured as labor productivity. The thesis also shows that enterprises are ubiquitous and contribute with a significant share to household income, underlining their importance in the rural economy.

Governmental policies shape the conditions in which the economy operates. Having knowledge about the relevant factors that motivate households to become entrepreneurial, presents a critical step in formulating policies that have the potential to support this process. My findings provide a number of insights, suggesting entrepreneurship policies that can support the rural population from two angles. On the one hand, by supporting 
aspiring entrepreneurs who plan to set up businesses, for example through the access to credit or through the improvement of local infrastructure. On the other hand, by helping poor households in times of economic constraints, and therefore limiting the number of low-productive and necessity-driven enterprises, or by preventing existing businesses to stop operations. The measures suggested in the following list can be applied for individuals and households that face the decision to enter entrepreneurship, as well as for existing enterprises, where the owner or manager intends to enhance labor productivity.

\section{Supporting aspiring entrepreneurs}

- Training and education matter. Investing in overall better education while providing specific training for entrepreneurs, can significantly enhance the entrance of opportunity-motivated businesses and increase labor productivity.

- Access to information, e.g. via ICT, plays a decisive role, for example through information on supply chains, the client base, or the possibility to buy and sell products and services online.

- Provision and access to credit are crucial in offering financial support, especially in poor rural areas where financial institutions are scarce, and where people possess limited wealth that can serve as collateral.

- Improving the local infrastructure, for example by connecting rural areas to electricity or by providing space to establish businesses, can offer new opportunities that will create both higher supply and demand of products and services.

- Providing roads and public transportation in rural areas to regional towns or major cities that connect businesses with the client base, and where products and services can be offered and sold, has the potential to significantly increase and diversify the sales.

- Generating a positive business climate, including simple access to public services and the possibility to formalize businesses in an uncomplicated and inexpensive procedure, can decisively increase the number of entrants and increase the productivity of businesses. 


\section{Shielding households from negative external events}

- Establishing social protection schemes, for example conditional or unconditional cash transfers that provide poor households with sufficient means to overcome periods of extreme hardship, can limit the creation of businesses that are born out of necessity. This type of business is often small, low-productive and exits the market once the household overcomes the negative shock, providing little valueadded to the labor market and the economic development.

- Providing (micro)-insurance schemes that can shield aspiring entrepreneurs from harsh negative consequences if their businesses fail will motive more people to become entrepreneurial. (Micro)-insurance schemes can also operate in other areas, for example agriculture, where a failed harvest might lead to the necessity type of entrepreneurship.

These suggestions have the potential to generate new and effective policy measures based on empirical evidence that will allow people to enter entrepreneurship when they perceive opportunities, while shielding them from necessity motivated entrepreneurship or adverse events. However, it remains important to take the specific socio-economic context of each country into account when designing policies to support entrepreneurship. In this thesis I analyze six countries in Sub-Saharan Africa and show that individual, household and location characteristics vary from one country to the other. It is therefore also a call for more country specific research of African, or more general, developing countries, to study labor market conditions in which businesses are established and operate.

The thesis also made use of the recently available LSMS-ISA data set, initiated and executed by the World Bank in close collaboration with national statistics offices, where the learning process of representative surveys is part of the data collection effort. The data collection is taking place over several years with the intention to create panel data (the data collection process is still ongoing). Working closely on the entrepreneurship section and in collaboration with the World Bank's LSMS-ISA team also gave me the possibility to identify shortcomings and to suggest improvements of the questionnaires for further data collection rounds.

Finally, the research so far conducted has been widely disseminated, in working papers, conferences, seminars, public events and blogs. It has also been taken up by nongovernmental organizations for their work and discussed by a broad audience, clearly 
indicating interest in and relevance of the topic.

For the second theme, unemployment insurance savings accounts, the thesis studies two aspects of this type of unemployment protection scheme and the impact on labor market outcomes. First, whether the introduction of UISA had an effect on employment duration. And second, whether it had an effect on subsequent employment quality measured by the difference in wages and contract types.

The results show that the introduction of UISA led to shorter employment duration, which can be interpreted as a reduction in labor market rigidities, but might also imply more unstable labor relations. With regard to subsequent employment quality, the results support the finding of increased labor market flexibility. While the scheme did not have an effect on the difference in contract types, the results are significant for the difference in wage growth, suggesting that workers put less emphasis on higher wages when changing employment. However, wage growth is marginally higher and significant once the UISA amount is added to net wages. The difference-in-differences analysis is positive for workers who experienced a period of unemployment compared to the control group, suggesting that workers could search for a subsequent job with higher employment quality if measured in wage growth.

These findings are useful information for Chile, as well as for other countries that plan to introduce this type of unemployment protection or to modify existing schemes. Different outcomes can be deducted from the results, and are summarized as follows.

\section{Findings for Chile}

- Higher labor market flexibility, described by shorter employment duration. However, more unstable labor relations might equally apply.

- No impact on the subsequent contract type.

- The difference in the growth of net wages is lower among workers with UISA affiliation. However, it is marginally higher once the UISA amount is added to net wages.

- The difference-in-differences for wage growth is positive for workers experiencing a period of unemployment compared to the control group, suggesting that these workers had a financial cushion while searching for a new employment. 


\section{Findings for other countries}

- The implementation of this type of unemployment protection scheme is possible while keeping a severance pay scheme. It might therefore also be possible to introduce UISA alongside unemployment insurance, in a similar procedure.

- The UISA scheme is affordable, as shown by Chile, when certain aspects are taken into account, for example embedding the scheme into existing institutions.

- UISA have the potential to reduce moral hazard, as shown by Reyes et al. (2011). For countries that struggle with the high cost of unemployment insurance, this type of unemployment protection therefore presents a viable alternative, replacing the existing unemployment insurance or introducing it as an additional component.

While these outcomes are important points to note, further research is recommended. I suggest to conduct follow-up studies for the Chilean UISA scheme based on the current findings, for example to study the consequences of shorter employment duration for workers affiliated to UISA and to identify if increased labor market flexibility or more unstable work relation dominate the overall effect. I also want to make the research community aware that the data set used, the Chilean Social Protection Survey, is a rich and freely available data set that can be employed for further research to study the Chilean labor market.

If other countries are interested in the UISA scheme, either to replace or to implement it alongside existing schemes, it is necessary to account for the specific socio-economic context of each country, as previously also mentioned for the research on entrepreneurship in rural Sub-Saharan Africa.

Overall, the research of this thesis is innovative and fills a research gap, since labor markets in developing economies have not been studied to the same extent as labor markets in more advanced economies. Adding more insights into the area of entrepreneurship in rural Sub-Saharan Africa using a comparative cross-country data set has been lacking so far. Also, studying unemployment insurance savings accounts has the potential to disseminate information on this type of unemployment protection, raising awareness of this alternative scheme, as well as providing information of the impact on labor market outcomes.

Finally, I would like to outline which persons could benefit from the results of this thesis. 
First, the research community of labor economists who work on emerging and developing countries, and who are interested in the determinants of enterprise operation and labor productivity, or in the effects of introducing social protection schemes to improve rigid labor markets. Second, government officials that are involved in formulating, designing and implementing new policies that have an effect on the labor market, for example in facilitating more favorable labor market conditions, such as improvements in the local infrastructure, implementation of changes in the national education system or the provision of training. Third, anyone involved in the analysis, evaluation and implementation of policies, who is not necessarily part of the research community nor the government, for example aid workers, or more broadly the development community. 


\section{About the Author}

Paula holds a Master Degree in Economics and Latin American Studies from the University of Cologne and a Post-Graduate Degree in International Economic Policy Research from the Kiel Institute for the World Economy. During her studies she interned at the United Nation's Economic Commission for Latin America and the Caribbean in Santiago de Chile (with a DAAD scholarship) and at the Inter-American Development Bank in Washington DC (with a Carlo-Schmid scholarship). Before joining the PhD program, she worked at the International Policy Centre for Inclusive Growth in Brasília and was a Policy Analyst at the OECD Development Centre in Paris. Paula joined the PhD program at UNU-MERIT/Maastricht Graduate School of Governance in 2010, and spent four months at the Universidad de Chile as a visiting $\mathrm{PhD}$ in 2012. At the graduate school, Paula taught several courses in public economics and econometrics, as well as further economic courses at the Faculty of Arts and Social Sciences and at the School of Business and Economics of Maastricht University. She also participated in the World Bank project "Agriculture in Africa - Telling Facts from Myths" as a Research Fellow, where she conducted research on non-farm entrepreneurship in rural Africa. Since September 2015 she is an Assistant Professor at the School of Business and Economics at Maastricht University. 



\section{MGSoG Dissertation Series}

Jasmin Kientzel

Determinants of Professional Commitment to Environmental Sustainability

MGSoG Dissertation Series, Nr. 62 (2015)

Mehmet Güney Celbiş

Regional Policies: Convergence, Trade, and the Allocation of Public Capital

MGSoG Dissertation Series, Nr. 61 (2015)

Florian Henning

Living Up to Standards: Interoperability Governance and Standards Adoption in Government Information Networks

MGSoG Dissertation Series, Nr. 60 (2015)

Niels P. Groen

The Never-ending Project: Understanding E-Government Project Escalation

MGSoG Dissertation Series, Nr. 59 (2015)

Derek Copp

Teacher-based Reactivity to Provincial Large-scale Assessment in Canada

MGSoG Dissertation Series, Nr. 58 (2015)

Michaella Vanore

Family-Member Migration and the Psychosocial Health Outcomes of Children in Moldova and Georgia

MGSoG Dissertation Series, Nr. 57 (2015)

Sonja Fransen

The Economic and Social Effects of Remittances and Return Migration in ConflictAffected Areas: The Case of Burundi

MGSoG Dissertation Series, Nr. 56 (2015)

Ibrahim Khalil Conteh

The Impact of Floods on Primary School Education in Zambia

MGSoG Dissertation Series, Nr. 55 (2015)

Richard Bluhm

Growth Dynamics and Development: Essays in Applied Econometrics and Political Economy

MGSoG Dissertation Series, Nr. 54 (2015) 
Nevena P. Zhelyazkova

Work-Family Reconciliation and Use of Parental Leave in Luxembourg: Empirical Analysis of Administrative Records

MGSoG Dissertation Series, Nr. 53 (2015)

Sachin Kumar Badkas

Metachoice and Metadata: Innovating with Environmental Policy Analysis in Europe

MGSoG Dissertation Series, Nr. 52 (2014)

Irina S. Burlacu

An Evaluation of Tax-Benefit Systems Impact on the Welfare of Frontier Workers: The Case of Luxembourg and Belgium

MGSoG Dissertation Series, Nr. 51 (2014)

Özge Bilgili

Simultaneity in Transnational Migration Research: Links Between Migrants' Host and Home Country Orientation

MGSoG Dissertation Series, Nr. 50 (2014)

Yulia Privalova Krieger

Reshaping the Big Agenda: Transnational Politics and Domestic Resistance - Financial crisis and social protection reform in Bosnia and Herzegovina

MGSoG Dissertation Series, Nr. 49 (2014)

Marieke van Houte

Moving Back or Moving Forward? Return migration after conflict

MGSoG Dissertation Series, Nr. 48 (2014)

Oxana Slobozhan

Global Governance in the Management of Natural Resources: The Case of the Extractive Industries Transparency Initiative (EITI)

MGSoG Dissertation Series, Nr. 47 (2014)

Luis Bernardo Mejia Guinand

The Changing Role of the Central Planning Offices in Latin America: A Comparative Historical Analysis Perspective (1950-2013)

MGSoG Dissertation Series, Nr. 46 (2014)

Cheng Boon Ong

Ethnic Segregation in Housing, Schools and Neighbourhoods in the Netherlands

MGSoG Dissertation Series, Nr. 45 (2014)

Luciana V. Cingolani

Bureaucracies for Development: Oxymoron or Reality? Studies on State Capacity in Challenging Governance Contexts

MGSoG Dissertation Series, Nr. 44 (2014)

Carlos Cadena Gaitán

Green Politics in Latin American Cities: Sustainable Transport Agendas

MGSoG Dissertation Series, Nr. 43 (2014) 
Katie Kuschminder

Female Return Migration and Reintegration Strategies in Ethiopia

MGSoG Dissertation Series, Nr. 42 (2014)

Metka Hercog

Highly-Skilled Migration and New Destination Countries

MGSoG Dissertation Series, Nr. 41 (2014)

Margaret Agaba Rugadya

Can Remittances Influence the Tenure and Quality of Housing in Uganda?

MGSoG Dissertation Series, Nr. 40 (2014)

Ilire Agimi

New Governance Under Limited Statehood

The Case of Local Government Reform in Kosovo

MGSoG Dissertation Series, Nr. 39 (2014)

Kristine Farla

Empirical Studies on Institutions, Policies and Economic Development

MGSoG Dissertation Series, Nr. 38 (2013)

Marina Petrovic

Social Assistance and Activation in the Pursuit of Happiness: Shedding New Light on Old Policy Solutions to Social Exclusion

MGSoG Dissertation Series, Nr. 37 (2013)

Laura Torvinen

Assessing Governance Assessments: The Case of Mozambique - Governance Assessments in the Context of Aid Effectiveness Discourse

MGSoG Dissertation Series, Nr. 36 (2013)

Biniam Egu Bedasso

Institutional Change in the Long Shadow of Elite: Essays on Institutions, Human Capital and Ethnicity in Developing Countries

MGSoG Dissertation Series, Nr. 35 (2013)

Sepideh Yousefzadeh Faal Deghati

Childhoods Embargoed: Constructing and Reconstructing Multidimensional Child Poverty in Iran 1984-2009

MGSoG Dissertation Series, Nr. 34 (2013)

Robert Bauchmüller

Investing in Early Childhood Care and Education: The Impact of Quality on Inequality

MGSoG Dissertation Series, Nr. 33 (2013)

Martin Rehm

Unified Yet Separated: Empirical Study on the Impact of Hierarchical Positions within Communities of Learning

MGSoG Dissertation Series, Nr. 32 (2013) 
Dorcas Mbuvi

Utility Reforms and Performance of the Urban Water Sector in Africa

MGSoG Dissertation Series, Nr. 31 (2012)

Lina Salanauskaite

Distributional Impacts of Public Policies: Essays in Ex-Ante and Ex-Post Evaluation

MGSoG Dissertation Series, Nr. 30 (2012)

Esther Schüring

To Condition or not - is that the Question? An Analysis of the Effectiveness of Ex-Ante and Ex-Post Conditionality in Social Cash Transfer Programs

MGSoG Dissertation Series, Nr. 29 (2012)

Joe Abah

Strong Organisations in Weak States: Atypical Public Sector Performance in Dysfunctional Environments

MGSoG Dissertation Series, Nr. 28 (2012)

Zina Samih Nimeh

Social Citizenship Rights: Inequality and Exclusion

MGSoG Dissertation Series, Nr. 27 (2012)

Lenka Eisenhamerová

Legitimacy of 'Humanitarian Military Intervention'

MGSoG Dissertation Series, Nr. 26 (2011)

Sonila Tomini

Informal Payments for Health Care Services in Albania

MGSoG Dissertation Series, Nr. 25 (2011)

Jinjing Li

Dynamic Microsimulation in Public Policy Evaluation

MGSoG Dissertation Series, Nr. 24 (2011)

Aziz Atamanov

Rural Nonfarm Employment and International Migration as Alternatives to Agricultural Employment: The Case of Kyrgyzstan

MGSoG Dissertation Series, Nr. 23 (2011)

Frieda Vandeninden

Poverty Alleviation: Aid and Social Pensions

MGSoG Dissertation Series, Nr. 22 (2011)

Juliana Nyasha Tirivayi

The Welfare Effects of Integrating AIDS Treatment with Food Transfers: Evidence from Zambia

MGSoG Dissertation Series, Nr. 21 (2011)

Agnieska Ewa Sowa

Who's Left Behind? Social Dimensions of Health Transition and Utilization of Medical Care in Poland

MGSoG Dissertation Series, Nr. 20 (2011) 
Emmanaouil Sfakianakis

The Role of Private Actors in the Provision of Public Goods with Applications to Infrastructure and Financial Stability

MGSoG Dissertation Series, Nr. 19 (2011)

Siu Hing Lo

White Collars Green Sleeves: An Interonganizational Comparison of Determinants of Energy-Related Behaviors among Office Workers

MGSoG Dissertation Series, Nr. 18 (2011)

Treena $\mathrm{Wu}$

Constraints to Human Capital Investment in Developing Countries: Using the Asian Financial Crisis in Indonesia as a Natural Experiment

MGSoG Dissertation Series, Nr. 17 (2011)

Henry Espinoza Peña

Impact Evaluation of a Job-Training Programme for Disadvantaged Youths: The Case of Projoven

MGSoG Dissertation Series, Nr. 16 (2011)

Florian Tomini

Between Family and Friends: Understanding the Interdependency of Private Transfers

MGSoG Dissertation Series, Nr. 15 (2010)

Michał Polalowski

The Institutional Transformation of Social Policy in East Central Europe: Poland and Hungary in comparative and historical perspective

MGSoG Dissertation Series, Nr. 14 (2010)

Maha Ahmed

Defining, Measuring and Addressing Vulnerability: The Case of Post Conflict Environments

MGSoG Dissertation Series, Nr. 13 (2010)

Pascal Beckers

Local Space and Economic Success: The role of spatial segregation of migrants in the Netherlands

MGSoG Dissertation Series, Nr. 12 (2010)

Victor Cebotari

Conflicting Demands in Ethnically Diverse Societies: Ethnopolitical Contention and Identity Values in Europe

MGSoG Dissertation Series, Nr. 11 (2010)

Dennis Gyllensporre

Competing and Complementary Perspectives on the EU as a Crisis Management Actor: An Examination of the Common Security and Defence Policy through the Lenses of Idealism and Realism

MGSoG Dissertation Series, Nr. 10 (2010) 
Judit Vall Castello

Business Cycle and Policy Effects on Labour Market Transitions of Older and Disabled Workers in Spain

MGSoG Dissertation Series, Nr. 9 (2010)

Keetie Roelen

False Positives or Hidden Dimensions: The definition and measurement of child poverty MGSoG Dissertation Series, Nr. 8 (2010)

Denisa Maria Sologon

Earning Dynamics in Europe

MGSoG Dissertation Series, Nr. 7 (2010)

Melissa Siegel

Money and Mobility: Migration and Remittances

MGSoG Dissertation Series, Nr. 6 (2010)

Jessica S. Hagen-Zanker

Modest Expectations: Causes and effects of migration on migrant households in source countries

MGSoG Dissertation Series, Nr. 5 (2010)

Mirtha R. Muñiz Castillo

Human Development and Autonomy in Project Aid: Experiences from four bilateral projects in Nicaragua and El Salvador

MGSoG Dissertation Series, Nr. 4 (2009)

Christiane Arndt

Governance Indicators

MGSoG Dissertation Series, Nr. 3 (2009)

Britta Augsburg

Microfinance: Greater Good or Lesser Evil?

MGSoG Dissertation Series, Nr. 2 (2009)

Geranda Notten

Measuring and Managing Poverty Risks

MGSoG Dissertation Series, Nr. 1 (2008) 